\title{
BACK ANALYSIS OF AN ANCIENT ROCKSLIDE AT LAKE FUNDUDZI, LIMPOPO PROVINCE, SOUTH AFRICA
}

\section{Sibonakaliso Goodman Chiliza}

A dissertation submitted in fulfilment of the requirements for the degree of Master of Science (MSc) in Environmental and Engineering Geology

In the

School of Agricultural, Earth and Environmental Sciences

College of Agriculture, Engineering and Science

University of KwaZulu-Natal

Durban, 4000

South Africa

Supervisor: Dr E.D.C. Hingston

February 2015 


\section{DECLARATION}

I declare that this is my own unaided work except where referenced or suitably acknowledge. It is being submitted for the Degree of Master of Science in the University of KwaZulu-Natal. It has not been submitted before for any degree or any examination in any other University. The information used in the dissertation has been obtained while also employed by the Council for Geoscience. 


\begin{abstract}
A massive rockslide event occurred in the Soutpansberg Mountains of the Limpopo province approximately twenty thousand years ago that blocked the course of the eastern flowing Mutale River forming Lake Fundudzi, which is the only known true inland lake in South Africa. The landslide occurred in the northward dipping and highly jointed Fundudzi Formation of the Soutpansberg Group. The failed slope was observed to be a homogenous jointed sandstone rock slope which is quartzitic in places. The techniques of back analysis have been employed in establishing the conditions that may have caused the landslide.

Kinematic analysis using Rocscience Inc. Dips revealed three major joint sets (JS1, JS2 and JS3) in the rock mass which are oriented northeast-southwest, north west-south east, and north-south respectively. The main failure plane best correlated with JS2, which dips towards the lake. The kinematic analysis also revealed that the mechanism of failure was planar which is in agreement with site observations.

The strong rock material classification of sandstone from laboratory index and mechanical tests was one of the indicators that failure could have been mostly structurally controlled than rock material degradation. Rock mass classification using Rock Mass Rating (RMR) and Slope Mass Rating (SMR) showed that prior to the inclusion of discontinuity adjustment in the ratings, which reflects the relationship between the slope face and joint dip, the rock slope classified as Class II for 'good rock mass'. However, upon incorporating rating adjustment in RMR and SMR for discontinuity orientation, the rock mass quality of the slope dropped to 'poor' and 'bad' respectively.

The techniques of back analysis were employed using Slide and RocPlane in Rocscience Inc. suite in order to investigate the geotechnical conditions that may have resulted in failure. Prior to conducting the back analysis, sensitivity analysis was carried out for a realistic range in values of the shear strength parameters, in both Slide and RocPlane in order to investigate the parameter which has the most impact on the factor of safety $(\mathrm{F})$. The results obtained from the sensitivity analysis in both Slide and RocPlane showed that the joint roughness coefficient (JRC) followed by the residual basic friction angle $\left(\phi_{\mathrm{r}}\right)$ were the main influential shear strength parameters on $\mathrm{F}$ as opposed to the joint wall compressive strength (JCS) which has very little impact on F for the range of values considered. The shear strength parameters derived from Slide by back analysis were found to be notably higher than the parameters obtained in RocPlane under various groundwater and seismic ground acceleration scenarios considered in the back analysis. This showed that different methods of stability analysis can give different results. Using RocPlane seems more plausible than Slide as the rockslide could have failed as a single unit. Results also showed that seismic ground acceleration has more impact on the back analysed $\phi_{\mathrm{r}}$ and JRC values from a pseudostatic analysis in Slide and RocPlane than
\end{abstract}


groundwater. This suggests that ground acceleration due to seismicity was more likely the trigger for the Lake Fundudzi rockslope failure than groundwater.

This study shows the usefulness of back analysis techniques in assessing various conditions of failure that may have resulted in ancient landslides and avoids many of the problems associated with laboratory tests. Although it may not result in a unique set of geotechnical parameters that may have resulted in failure, it however gives an insight into probable causes of failure and thus can be useful in mitigation of future failures. Results obtained from back analysis must be treated with caution as many uncertainties exist which can be reduced by making sensible, careful and realistic assumptions. 


\section{Table of Contents}

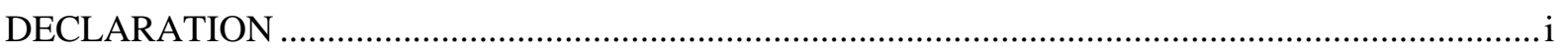

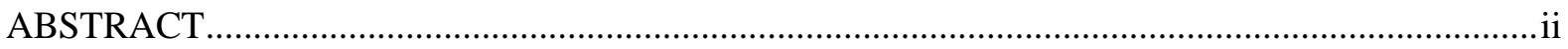

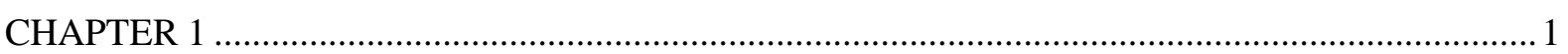

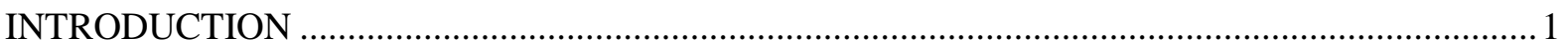

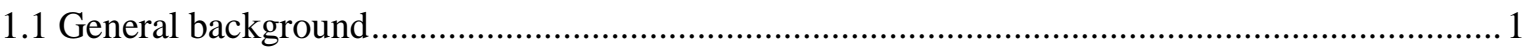

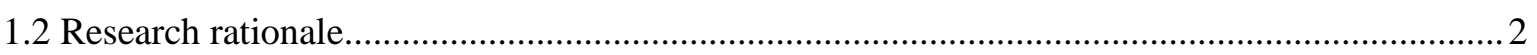

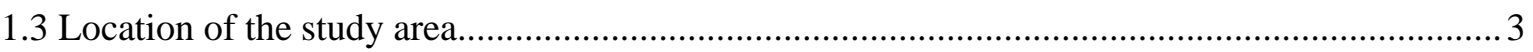

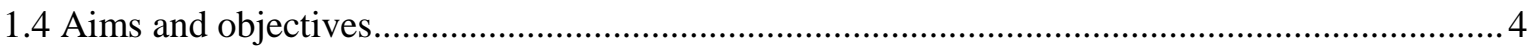

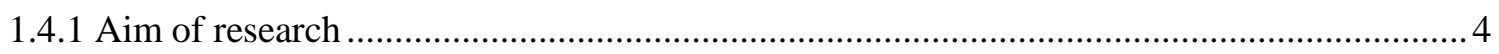

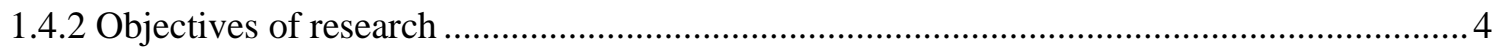

1.5 Methodology

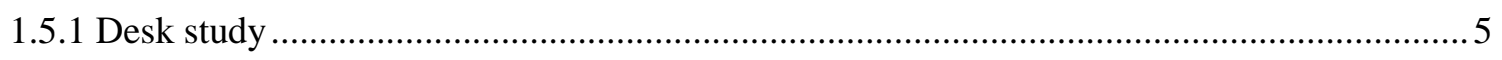

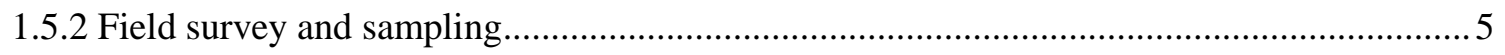

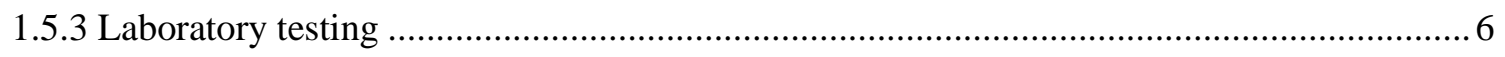

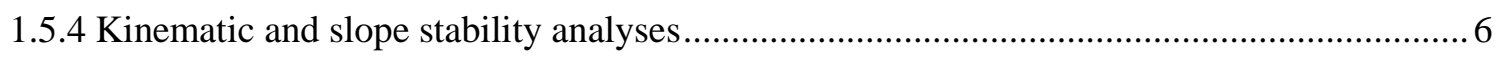

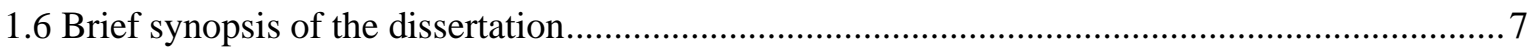

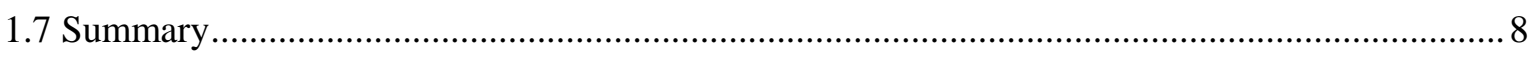

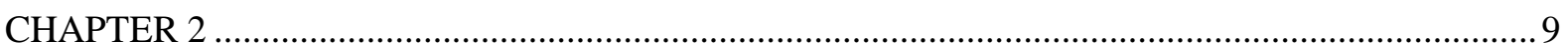

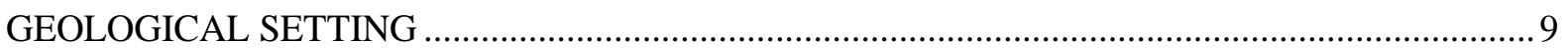

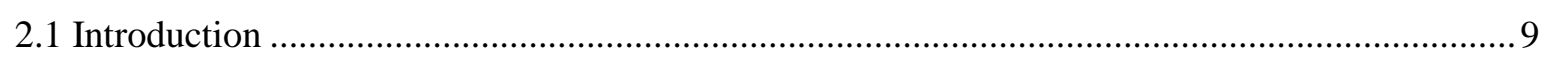

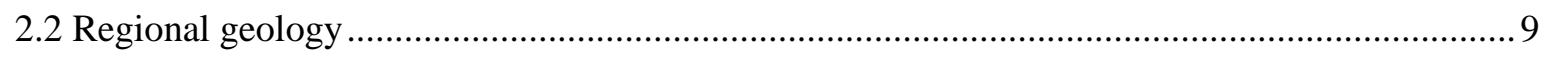

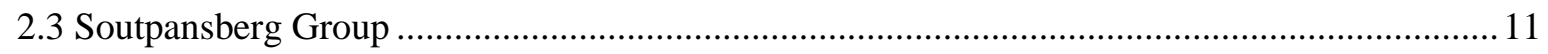

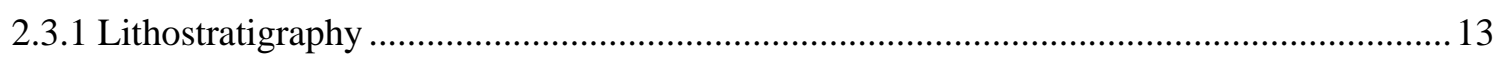

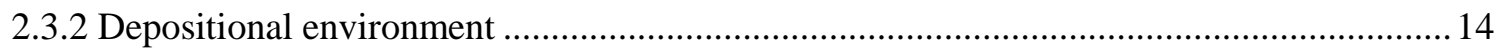

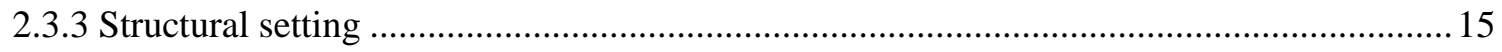

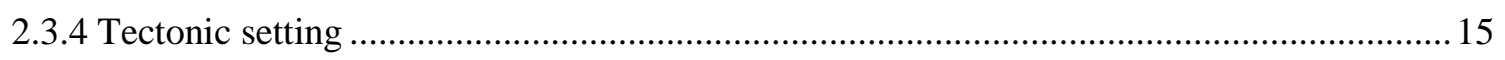

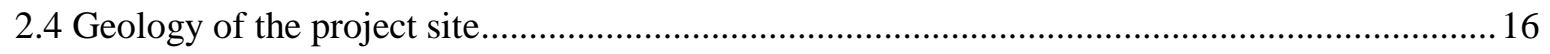

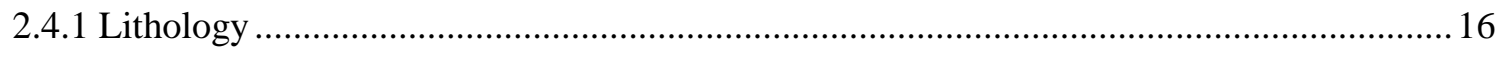




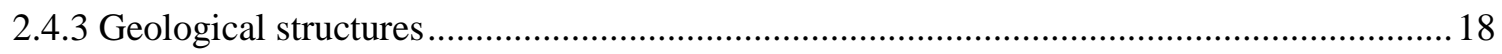

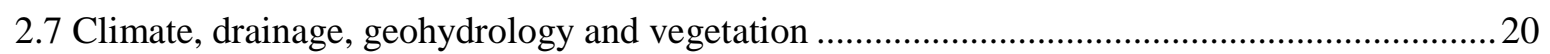

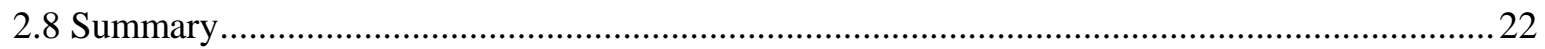

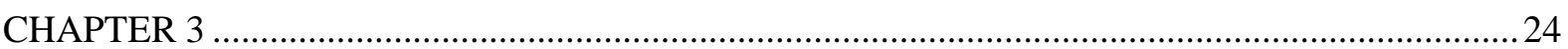

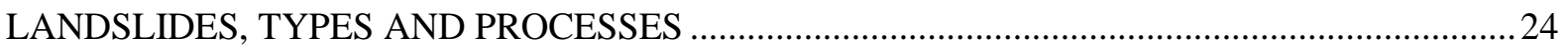

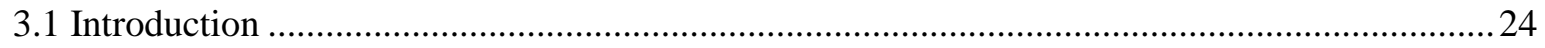

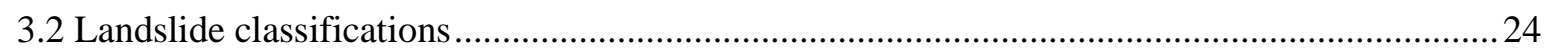

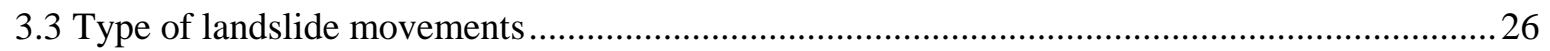

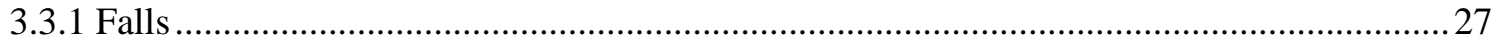

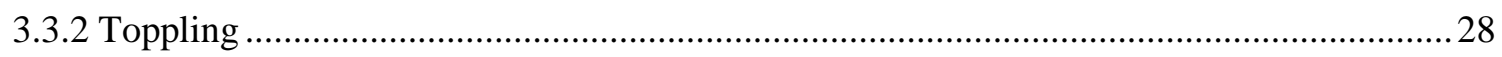

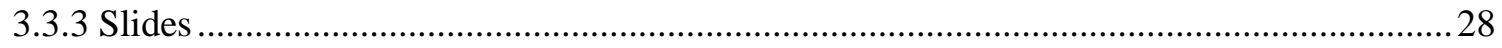

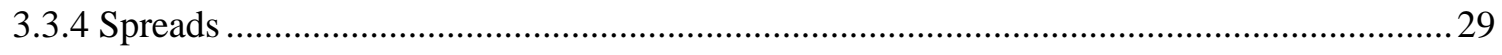

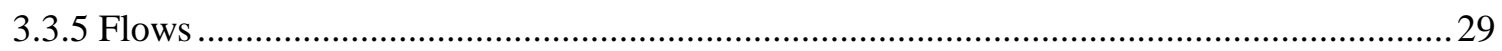

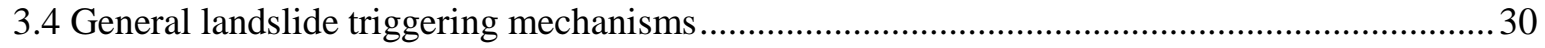

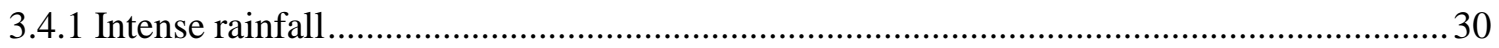

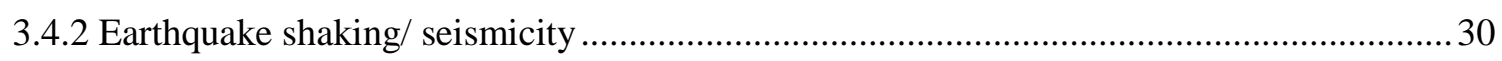

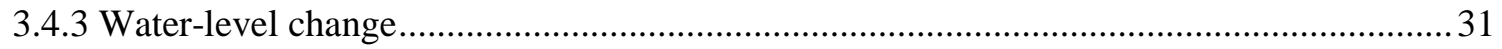

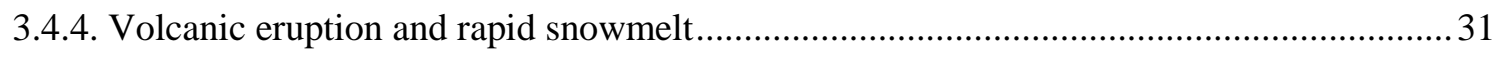

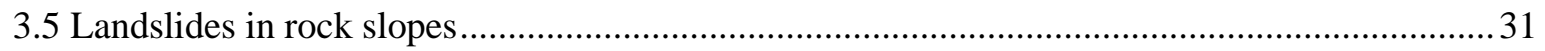

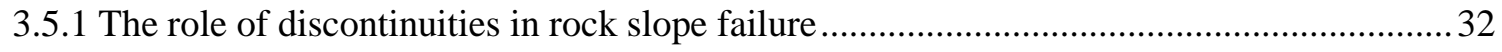

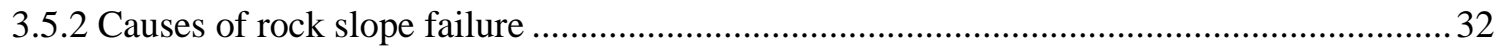

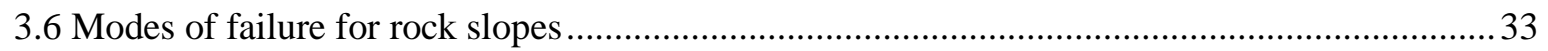

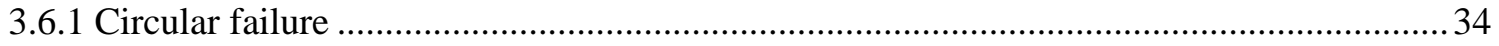

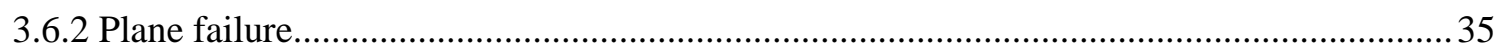

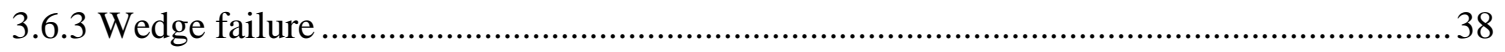

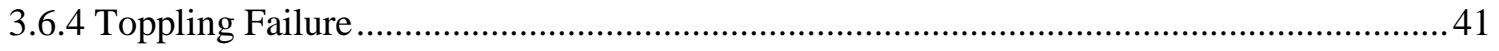

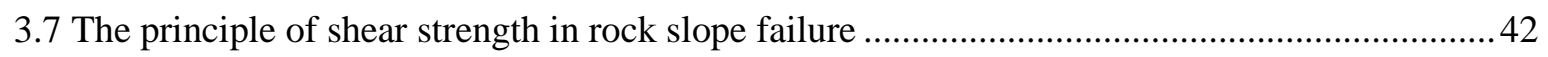

3.7.1 Criterion (models) for shear strength of discontinuities .................................................... 43 


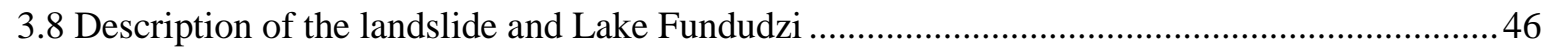

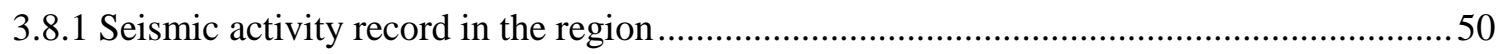

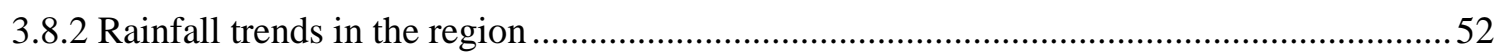

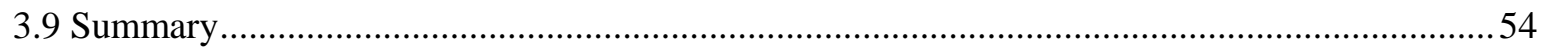

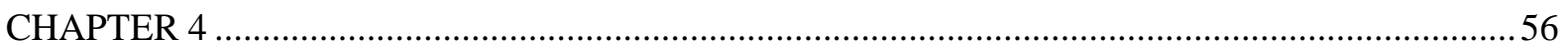

METHODS OF LANDSLIDE HAZARD ASSESSMENT AND SLOPE STABILITY ANALYSES 56

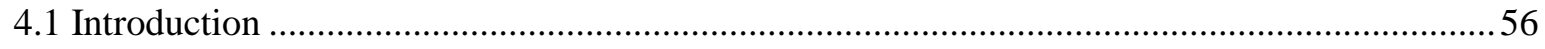

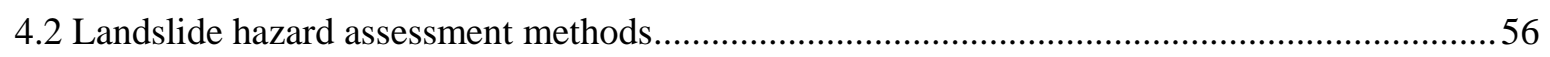

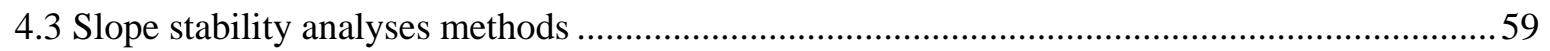

4.3.1 Kinematic analysis (using stereographic interpretation) ..................................................5

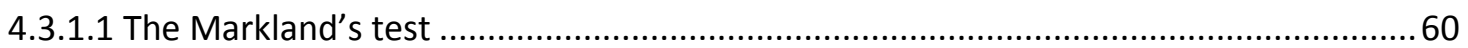

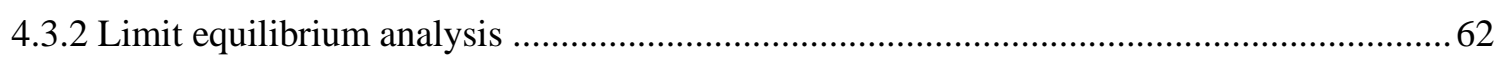

4.3.2.1 Types of limit equilibrium (LE) methods of slices ........................................................63

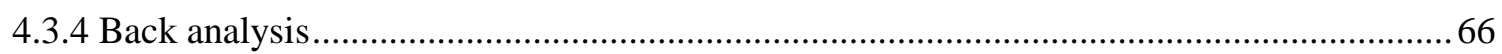

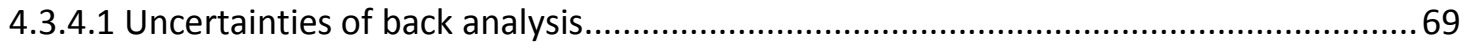

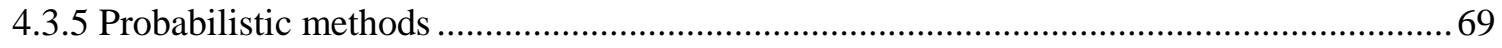

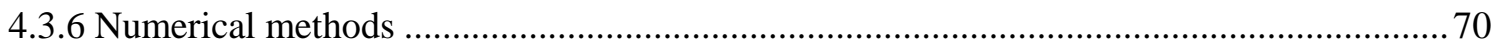

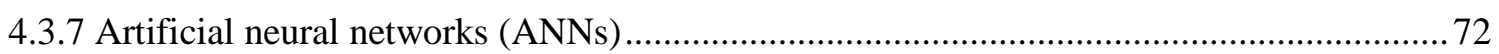

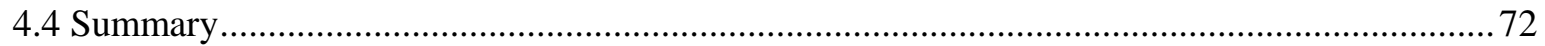

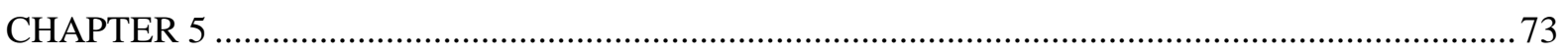

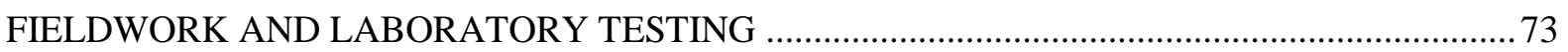

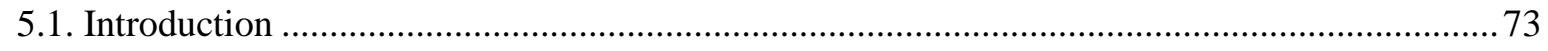

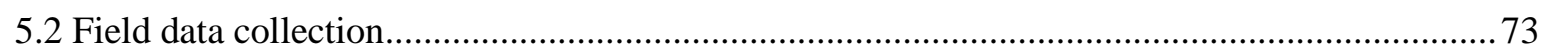

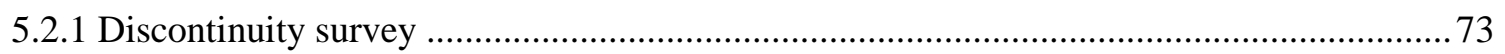

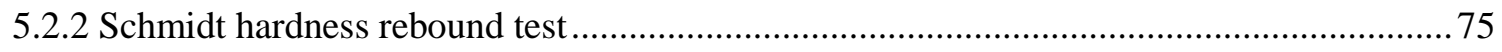

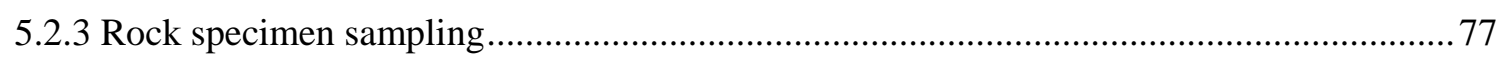

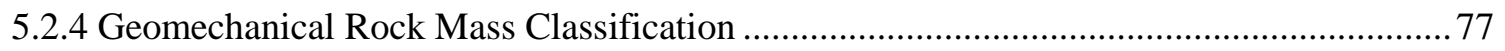

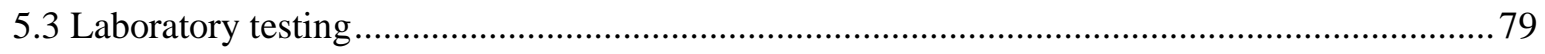

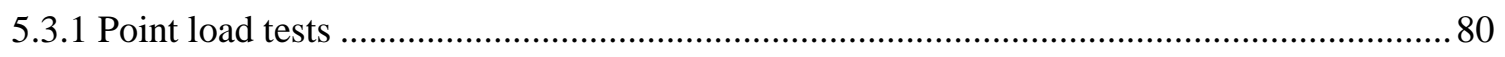

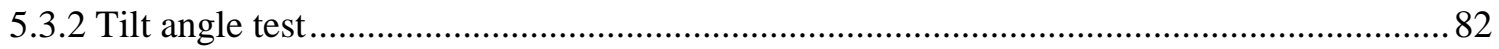




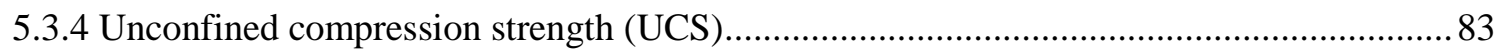

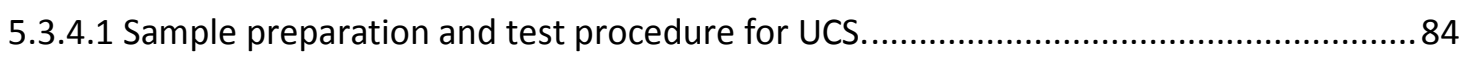

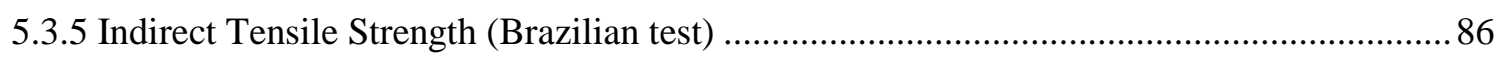

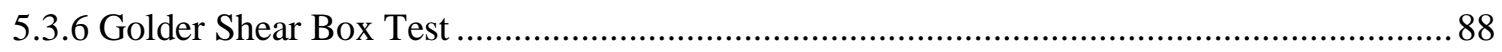

5.3.6.1 Specimen Preparation and Testing Procedure …......................................................... 88

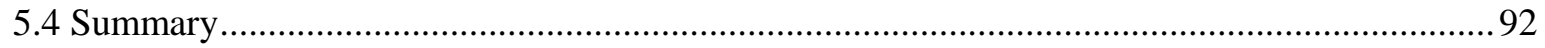

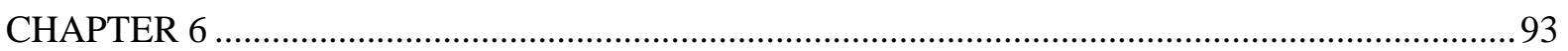

RESULTS AND GEOTECHNICAL CHARACTERISTICS OF THE PROJECT SITE …................93

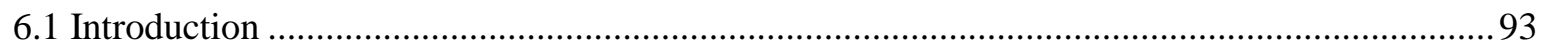

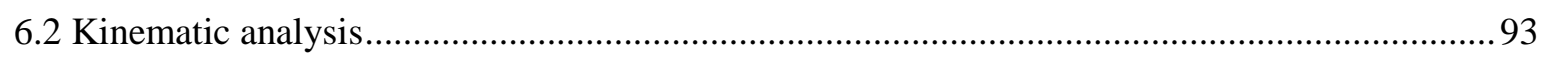

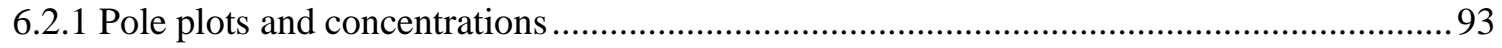

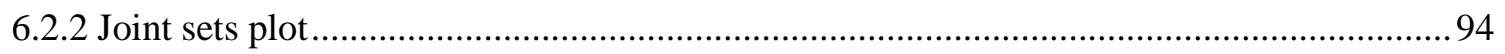

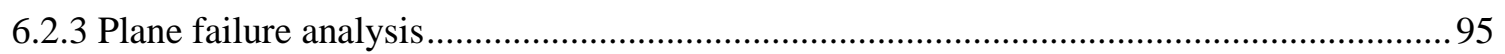

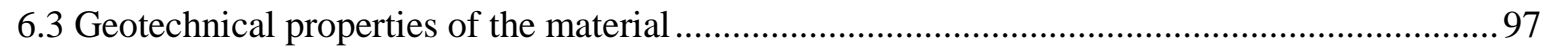

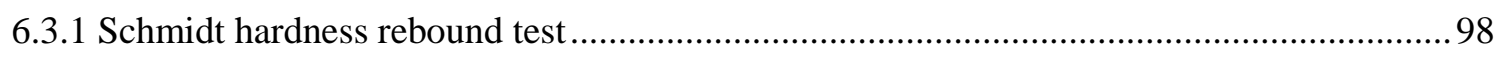

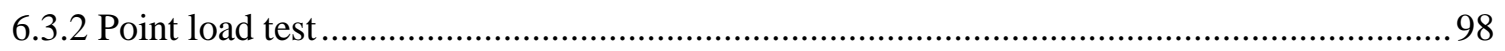

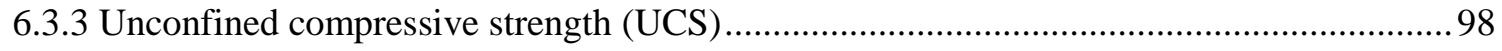

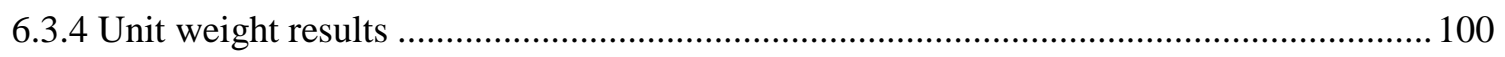

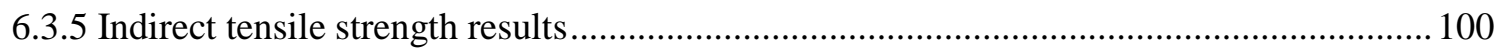

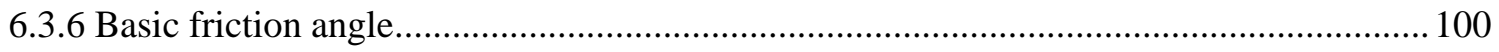

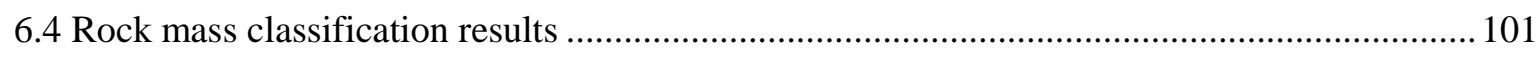

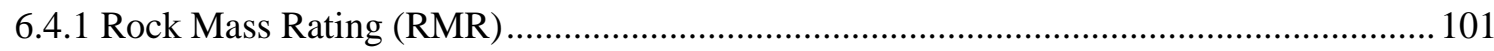

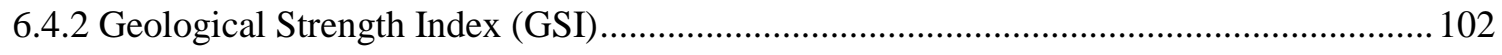

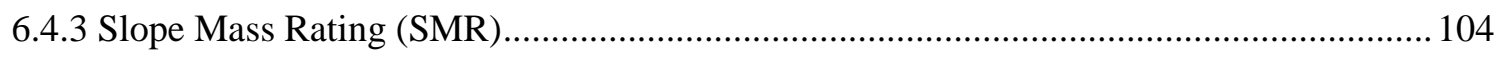

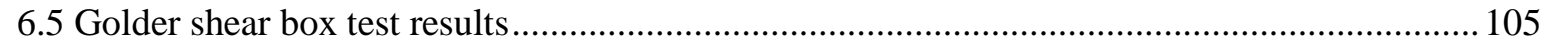

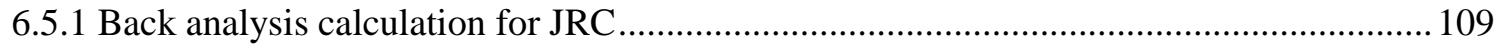

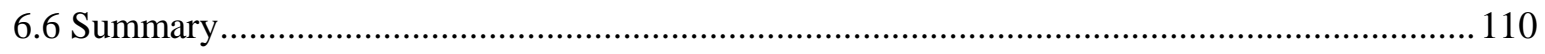

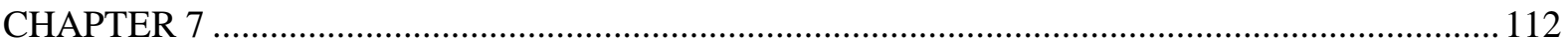


7.1 Introduction

7.2 Selection of method of analyses

7.2.1 Selection of cross section and geometry of slope.

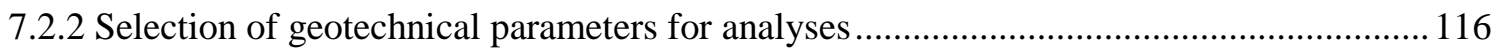

7.2.3 Groundwater conditions for analyses

7.2.4 Seismic ground acceleration condition for analyses

7.3 Back analyses of the planar rockslide using Slide and RocPlane under dry and static conditions

7.3.1 Sensitivity analysis using Slide

7.3.2 Back analysis using Slide

7.3.3 Sensitivity analysis using RocPlane.

7.3.4 Back analysis using RocPlane.

7.4 Back analyses of $\phi_{\mathrm{r}}$ under different JRC values and groundwater conditions using Slide and RocPlane.

7.4.1 Groundwater analysis in Slide.

7.4.2 Groundwater analysis in RocPlane

7.5 Back analyses of $\phi_{\mathrm{r}}$ under different JRC values and seismic coefficient scenarios using Slide and RocPlane

7.5.1 Pseudostatic analysis in Slide......

7.5.2 Pseudostatic analysis in RocPlane

7.6 Back analysis of JRC under typical $\phi_{\mathrm{r}}$ values and groundwater conditions using Slide and RocPlane.

7.6.1 Groundwater analysis in Slide.

7.6.2 Groundwater analysis in RocPlane

7.7 Back analysis of JRC under typical assumed $\phi_{\mathrm{r}}$ values and seismic coefficient scenarios using Slide and RocPlane

7.7.1 Pseudostatic analysis in Slide

7.8 Back analysis of the required seismic coefficient for $\mathrm{F}=1.00$. 
7.8.1 Back analysis of the required seismic coefficient in Slide...... 146

7.8.2 Back analysis of the required seismic coefficient in RocPlane ......................................... 147

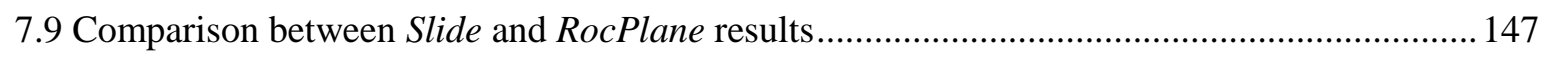

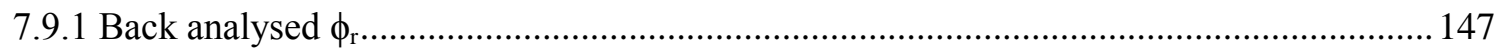

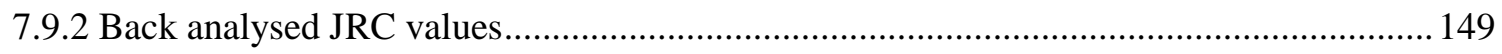

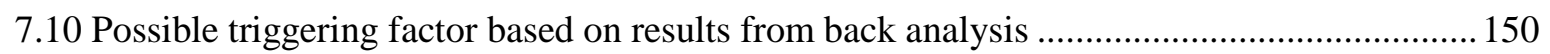

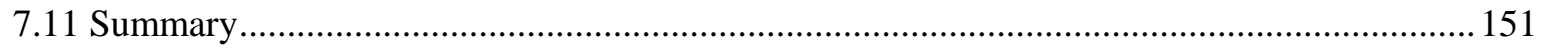

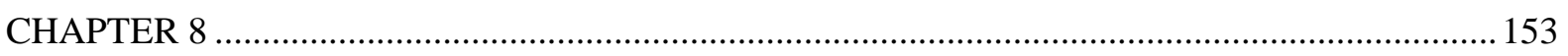

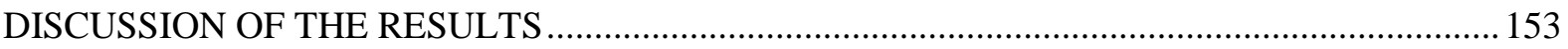

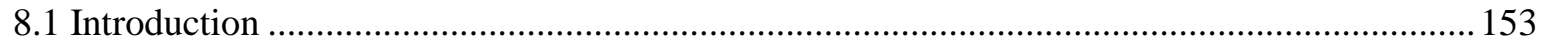

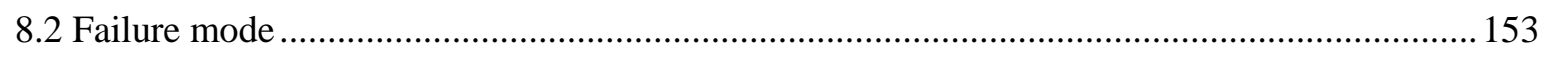

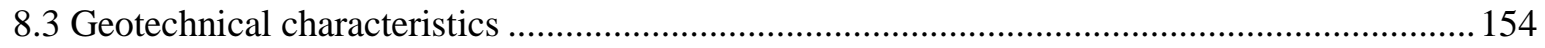

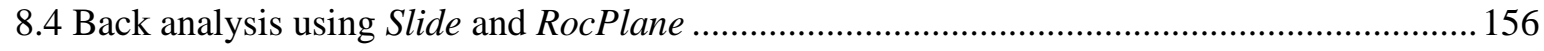

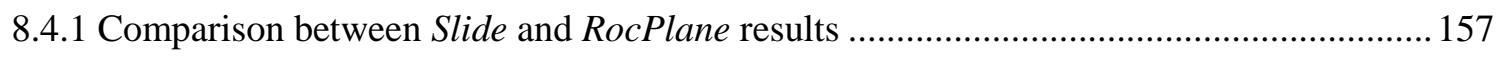

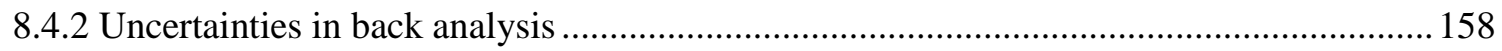

8.5 The relevance or importance of back analysis in landslide studies. ....................................... 159

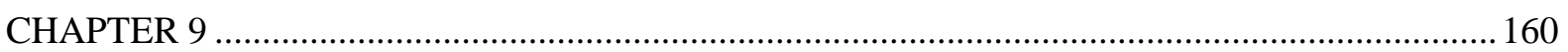

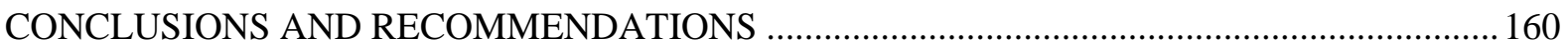

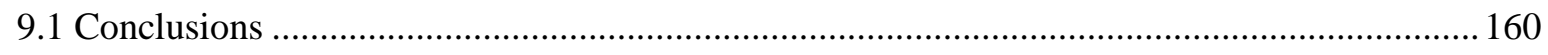

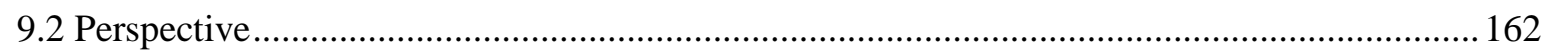

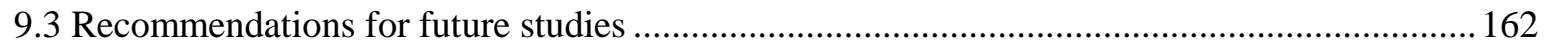

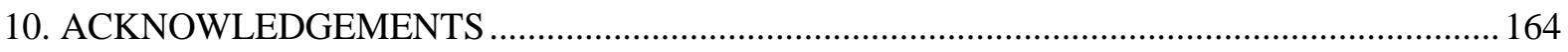

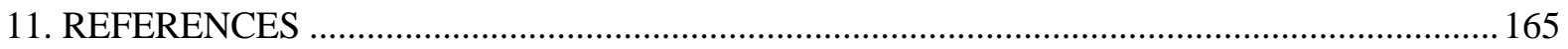

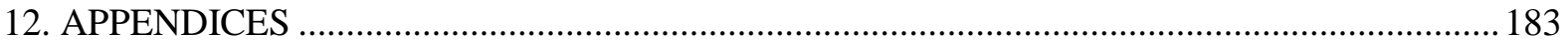




\section{LIST OF FIGURES}

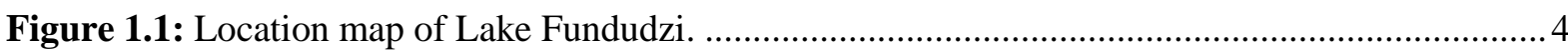

Figure 1.2: A diagonally aerial view of the Lake Fundudzi landslide situated in the Soutpansberg mountains.

Figure 2.1: Regional geological map of the Soutpansberg Group, the Waterberg Groups, and the Blouberg Formation (after Barker et al., 2006).

Figure 2.2: Local geological map of the Lake Fundudzi landslide area. 16

Figure 2.3: Photomicrograph of sandstone under plane polarized light.

Figure 2.4: Photomicrograph of sandstone under crossed-polarized light.

Figure 2.5: A Google Earth ${ }^{\circledR}$ satellite imagery showing major structural features in the vicinity of the site.

Figure 2.6: A view of the landslide failure surface from the southern shore of the lake showing northward dipping beds of the rock mass.

Figure 2.7: A map showing catchment areas of Lake Fundudzi (after van der Waal, 1997). 21

Figure 2.8: A view of a mass of rock debris blocking the Mutale River. .22

Figure 3.1: Types of landslide movements (after Varnes, 1978 and Cornforth, 2005). .27

Figure 3.2: Modes of rock slope failure (after Hoek and Bray, 1981). 34

Figure 3.3: Geometries of plane slope failure: (a) tension crack in the upper slope; (b) tension crack in the face (after Willie and Mah, 2005). 36

Figure 3.4: Wedge failure geometry (after Willie and Mah, 2005). 39

Figure 3.5: Resolution of forces to calculate factor of safety for wedge: (a) view of wedge looking at face showing definition of angles $\beta$ and $\xi$, and reactions on sliding planes RA and RB; (b) stereonet showing measurement of angles $\beta$ and $\xi$; (c) cross-section of wedge showing resolution of wedge weight W (after Willie and Mah, 2005).

Figure 3.6: Definition of shear strength of discontinuity surface; (a) shear test of discontinuity; (b) plot of shear displacement vs shear stress; (c) Mohr plot of peak strength; (d) Mohr plot of peak and residual strength (after Willie and Mah, 2005).

Figure 3.7: Patton's experiment on the shear strength of saw-tooth specimens (after Hoek, 2007).... 44

Figure 3.8: The ten joint roughness profiles showing the typical range of JRC (after Barton and Choubey, 1977). .. 46 
Figure 3.9: An illustration of a failure surface which extends back for about $230 \mathrm{~m}$ from the face of very steep eastern buttress or release surface (Dongwe). This photo was taken halfway between the shown buttress and the western buttress (Chitanda) not shown here which is at the back of the photographer.

Figure 3.10: An illustration of a failure surface and the distance between the two buttresses. This photo was taken from Dongwe buttress facing in the direction of the western buttress (Chitanda).....48

Figure 3.11: Extent of landslide deposit across the valley floor. 49

Figure 3.12: Seismic events record in the project site region on Richter scale magnitudes from 1908 to 2003 (Source: CGS South African National Seismic Database).

Figure 3.12a: Spatial distribution of historical earthquake magnitudes (Ml) within $150 \mathrm{~km}$ of Lake Fundudzi rockslide.

Figure 3.13: Regional annual rainfall data from 1960 up to 2007 (Source: WeatherSA). 52

Figure 3.14: Forestry plantation land removed by an earth flow landslide triggered by the 2000 heavy rainfall in the region. .53

Figure 4.1: Modes of rock slope failure and stereo plots of structural conditions (after Hoek and Bray, 1981).

Figure 5.1: A Clar type geological compass used for the discontinuity survey conducted. .74

Figure 5.2: Schmidt Hammer Rebound tests as carried out on site. 77

Figure 5.3: General chart for GSI estimates from the geological observations (after Hoek and Brown, 1998).

Figure 5.4: An illustration of the point load testing apparatus 81

Figure 5.5: Tilting devise for the determination of $\phi_{\mathrm{b}}$. .82

Figure 5.6: The UCS testing machine used at the University of KwaZulu-Natal .84

Figure 5.7: A Rothenberger ${ }^{\circledR}$ rodiadrill 1800 machine used to core rock blocks to NX-size diameter.

Figure 5.8: Principle of the Brazilian testing arrangement and apparatus and nature of failure (after Wittke, 1990). .86

Figure 5.9: Laboratory set up for the Brazilian indirect tensile strength test. .87

Figure 5.10: Casting position with clamp holding the joint sample. .89

Figure 5.11: Preparation of quick setting gypsum plaster to cast half of one mould pair..... .90

Figure 5.12: A Golder shear box machine set up. 91 
Figure 6.1: Dips pole plots of 6\% or greater Fischer concentrations. .94

Figure 6.2: Stereoplot showing the contoured plot of the poles and the three joint sets. .95

Figure 6.3: Stereonet plot showing analysis of plane failure using daylight envelope and friction cone. .96

Figure 6.4: Conical and axial splitting failure patterns ( $a$, and $b$ respectively) from UCS testing. ..... 99

Figure 6.5: GSI values selection on RocLab program and resultant rock mass properties. 103

Figure 6.6: Shear displacement versus horizontal displacement graph for Golder shear box sample GSB-5b. 106

Figure 6.7: Shear displacement versus vertical displacement graph for Golder shear box sample GSB 5 b.

Figure 6.8: Shearing contact showing actual contact surface area for Sample GSB 4 . 109

Figure 7.1: Line of cross section (A-A') for the analyses. 114

Figure 7.2: Re-constructed slope of the Lake Fundudzi rockslide cross section A-A' shown in Figure 7.1 .

Figure 7.3: Sensitivity analysis plot for JRC (Slide).

Figure 7.4: Sensitivity analysis plot for the residual friction angle (Slide).

Figure 7.5: Sensitivity analysis plot for JCS (Slide).

Figure 7.6: Sensitivity analysis of back calculated shear strength parameters (Slide)...

Figure 7.7: Input parameters for back analysis of residual friction angle along the failure surface.. 125 Figure 7.8: Back analysis of the shear strength parameters based on the Barton-Bandis shear strength criterion (Slide). 126

Figure 7.9: Geometric slope parameters captured on RocPlane. 127

Figure 7.10: Shear strength input data used for back analysis in RocPlane and the slope's 3-D perspective view

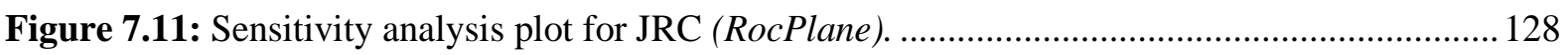

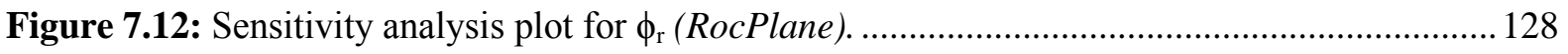

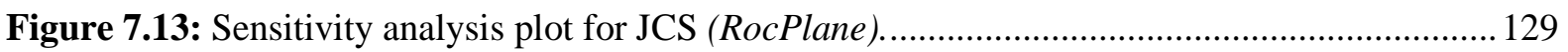

Figure 7.14: Sensitivity analysis of back calculated shear strength parameters (RocPlane)............. 130

Figure 7.15: Planar failure stability back analysis using RocPlane.

Figure 7.16: Graph of back calculated JRC values versus residual friction angle obtained from different groundwater conditions (Slide). 
Figure 7.17: Graph of assumed JRC values versus residual friction angle obtained from different groundwater conditions (RocPlane).

Figure 7.18: Graph of assumed JRC values versus residual friction angle obtained from different seismic ground acceleration scenarios (Slide)

Figure 7.19: Graph of assumed JRC values versus residual friction angle obtained from different seismic ground acceleration scenarios (RocPlane).

Figure 7.20: Back analysed JRC values for an assumed range of $\phi_{\mathrm{r}}$ values angle under different groundwater levels in the tension crack (Slide).

Figure 7.21: Back analysed JRC values for an assumed range of $\phi_{\mathrm{r}}$ values under different groundwater levels in the tension crack (RocPlane).

Figure 7.22: Back analysed JRC values versus assumed $\phi_{\mathrm{r}}$ under different seismic ground acceleration coefficient (Slide).

Figure 7.23: Back analysed JRC values versus assumed $\phi_{\mathrm{r}}$ under different seismic ground acceleration coefficient (RocPlane). 146

\section{LIST OF TABLES}

Table 2.1: Stratigraphic subdivision of the Soutpansberg Group (after Barker et al., 2006) 11

Table 2.2: Stratigraphy of the Soutpansberg Group with summary of the typical lithology (after Brandl, 1999). .12

Table 3.1: Classification of slope movements (after Cruden and Varnes, 1996).

Table 3.2: Landslide classification based on velocity scale and probable destructive significance (after Cruden and Varnes, 1996). .26

Table 3.3: Typical shear strength and unit weight rock values (after Hoek and Bray, 1981).

Table 4.1: Recommended scales and categories for landslide susceptibility classification (modified from Soeters and van Westen, 1996). .57

Table 4.2: Characteristics of kinematic method of analysis (after Coggan et al., 1998). 60

Table 4.3: Characteristics of limit equilibrium method of analysis (after Coggan et al., 1998).

Table 4.4: Summary of limit equilibrium methods used their use and assumptions made (modified after Abramson et al., 2002; Duncan and Wright, 2005).....

Table 5.1: An example of a discontinuity survey sheet. .75

Table 6.1: Average discontinuity set data obtained from Dips. .95 
Table 6.2a: Results of index and mechanical properties of the rock material obtained from laboratory testing.

Table 6.2b: Results of index and mechanical properties of the rock material obtained from laboratory testing.

Table 6.3: Determination of the RMR for the rock slope under consideration 102

Table 6.4: Results of the direct shear strength tests on natural joints under constant normal stress... 108

Table 6.5: Back calculated JRC and peak shear strength results.

Table 7.1: Geometrical parameters of the reconstructed landslide features used in Slide and RocPlane limit equilibrium analyses.

Table 7.2: Summary of results for JRC values, average JRC and peak shear strength.....

Table 7.3: Recommended horizontal seismic coefficients for design (adapted after Melo and Sharma, 2004).

Table 7.4: Seismic coefficient $(\alpha)$ values calculated from the available peak ground acceleration values.

Table 7.5: Back analysed $\phi_{\mathrm{r}}$ values under different groundwater levels in the tension crack (Slide). 132

Table 7.6: Back analysed $\phi_{r}$ values under different groundwater levels in the tension crack (RocPlane).

Table 7.7: Back analysed $\phi_{\mathrm{r}}$ values under different seismic coefficient scenarios (Slide).

Table 7.8: Back analysed $\phi_{\mathrm{r}}$ values under different seismic coefficient scenarios (RocPlane).

Table 7.9: Back analysed JRC values given assumed $\phi_{\mathrm{r}}$ values under different groundwater levels in the tension crack (Slide)

Table 7.10: Back analysed JRC given $\phi_{\mathrm{r}}$ under different groundwater levels in the tension crack (RocPlane).

Table 7.11: Back analysed JRC given assumed typical $\phi_{\mathrm{r}}$ values for sandstone under different seismic coefficient scenarios (Slide)

Table 7.12: Back analysed JRC values given $\phi_{\mathrm{r}}$ under different seismic coefficient scenarios (RocPlane)

Table 7.13: Comparison between Slide and RocPlane back analysed $\phi_{\mathrm{r}}$ values under different groundwater scenarios. 148

Table 7.14: Comparison between Slide and RocPlane back analysed $\phi_{\mathrm{r}}$ results under different seismic ground acceleration conditions. 148 
Table 7.15: Comparison between Slide and RocPlane back analysed JRC results under different seismic ground acceleration conditions.

Table 7.16: Comparison between Slide and RocPlane back analysed JRC results under different seismic ground acceleration conditions. 


\section{CHAPTER 1}

\section{INTRODUCTION}

\subsection{General background}

The term landslide is defined as 'any gravitational movement of earth materials' (Cruden and Varnes, 1996). Globally, landslides cause approximately 1000 deaths per year with property damage of about US\$4 billion (Alexander, 1995). Landslides pose serious threats to settlements and to structures that support transportation, natural resource management and tourism, and also cause considerable damage to highways, railways, waterways and pipelines. Damage from landslides and other ground failures has sometimes exceeded damage directly related to earthquakes (Singhroy, 2004).

In the United States of America (USA) for example, landslides occur in every one of the states. Deaths resulting from landslide in the USA have been estimated at twenty five to fifty per year, and total annual economic losses due to landslides estimated to range from US $\$ 1.6$ billion to US\$3.2 billion (Schuster, 1996; Schuster and Highland, 2001).

According to Paige Green (1989), the annual costs of landslide associated expenses in Southern Africa were estimated at approximately US $\$ 20$ million. Based on annual standard inflation rate of $6 \%$, the current associated expenses would be US $\$ 90$ million. Death causalities associated with landslides have also been reported. These took place in Stanger, Chapmans Peak Drive and Merriespruit where six, five and seventeen deaths respectively, were reported (Paige Green, 1989). A recent fatal landslide event occurred in November 2011 at Quarry Heights in Durban, KwaZulu-Natal (KZN) that led to the loss of a life.

Two major landslide events that have been reported in South Africa are Mount Currie, which was a translational debris avalanche, near Kokstad in the Eastern Cape Province as reported by Singh (2009), and the Agulhas submarine landslide off the coast of South Africa. The Agulhas submarine landslide is the largest slope failure ever documented worldwide, involving a volume as large as $20,000 \mathrm{~km}^{3}$ and a run-out distance of greater than $140 \mathrm{~km}$ (Dingle, 1977).

Lake Fundudzi is a particular landslide site of great interest situated in the heart of the Soutpansberg Mountains in the Limpopo Province of South Africa. It is a $3 \mathrm{~km}$ long and $1 \mathrm{~km}$ wide inland freshwater body formed by a landslide event that blocked the course of the 
eastward flowing Mutale River. The landslide occurred approximately 20000 years ago in the northward dipping quartzitic sandstone of the Fundudzi Formation of the Soutpansberg Group (van der Waal, 1997).

\subsection{Research rationale}

No single comprehensive publication deals with past and present sub-aerial landslides and their distribution in South Africa. However, there are limited number of papers from local and international conferences and journals on the subject (Diop et al., 2010). Very few research monographs on local landslides and slope-instability problems exists. Notable amongst published journal material are those dealing with (i) the inherently unstable seaward dipping Ecca Group strata of the Greater Durban area mudslides developed in the Berea Red Sand, and the Table Mountain colluvial deposits in KwaZulu-Natal Province (e.g. Knight et al., 1977; Bell and Maud 1996; Singh et al., 2008), (ii) circular and earth-flow failures within the Ecca Group shales near Pietermaritzburg in the KwaZulu-Natal province (e.g. Maurenbrecher and Booth, 1975), (iii) the numerous debris flows of the Du Toits Kloof area, and the fatal rockfalls and remediation measures undertaken along the Chapmans Peak Drive near Cape Town (e.g. Boelhouwers et al., 1998; Gupta 2001), and (iv) slope failures in flat bedded Cretaceous shales at Amsterdamhoek, flanking the Swartkops River estuary near Port Elizabeth, Eastern Cape Province (Blight, 1981).

Part of the main requirements for most planning and feasibility studies in geological engineering is for the potential of landslides occurring to be established and the scale of the hazard to be defined (Griffiths et al., 2002).

In an attempt to assess landslide hazard, risk, and indicate the spatial distribution of previous events, the Council for Geoscience (CGS) identified the Limpopo Province for landslide inventory and susceptibility assessment mapping. Landslides were identified to be a major geohazard in that province and rural communities are becoming increasingly vulnerable as it was seen recently in the year 2000 after intense rainfall that triggered landslides and floods. It was during this CGS landslide inventory and susceptibility mapping programme that a unique landslide was discovered at Lake Fundudzi. It was discovered that the landslide resulted in the damming of the eastward flowing Mutale River to form the only known true inland lake in South Africa (Van der Waal, 1997). 
It was reported back in 2008 by South African Heritage Resource Agency (SAHRA) that the sacred Lake Fundudzi situated in the mountainous area of Tshiavha village, north of South Africa, will soon be declared a national heritage site.

A detailed search of the literature revealed that there is no comprehensive publication or unpublished report that has investigated the cause of the landslide that formed the lake. One of the possible reasons could be attributed to the difficulty of access to the site. The current study was triggered by the need to determine the geotechnical conditions that prevailed at the time of the landslide occurrence. A better understanding of these large scale slope failure is important in order to detect future rockslides or to mitigate against such failures.

Selby (1982) highlighted that stability analyses are usually more difficult to carry out, and the results are less reliable for rock than for soil slopes. He further suggested that, complex geological conditions are the cause of this situation in rock slopes as discontinuities largely control the stability and features such as water pressures, are difficult to measure. As a result, it is common practice to undertake a back analysis (i.e. post-mortem) in which the factor of safety, $\mathrm{F}=1.00$ (Selby, 1982). The back analysis technique is basically used to assess reasonable shear strength parameters for the soil/ rock, possibly with the view of recommending remedial measures (Sauer and Fredlund, 1988). In this study, the techniques of back analysis were used to determine the geotechnical conditions that could have led to a factor of safety equal to 1.00 at the time of failure of the landslide at Lake Fundudzi given that the failure surface is well defined. In most cases though, the information regarding the conditions under which a slide occurred is incomplete to some degree and this lack of complete information reduces the reliability (which is commonly referred to as uncertainty) of the back calculated shear strengths (Duncan and Stark, 1992).

\subsection{Location of the study area}

Lake Fundudzi is located in the Mutale River valley of the eastern Soutpansberg Mountains in the Limpopo Province (22 $50^{\prime} 22.08^{\prime \prime} S$ and $30^{\circ} 18^{\prime} 36^{\prime \prime}$ E) near the Kruger National Park. The Limpopo province is the northern-most province in South Africa and borders Mozambique, Zimbabwe and Botswana. The study area lies approximately $57 \mathrm{~km}$ north east of Louis Trichardt and $21 \mathrm{~km}$ north-west of Thohoyandou as shown in Figure 1.1. 


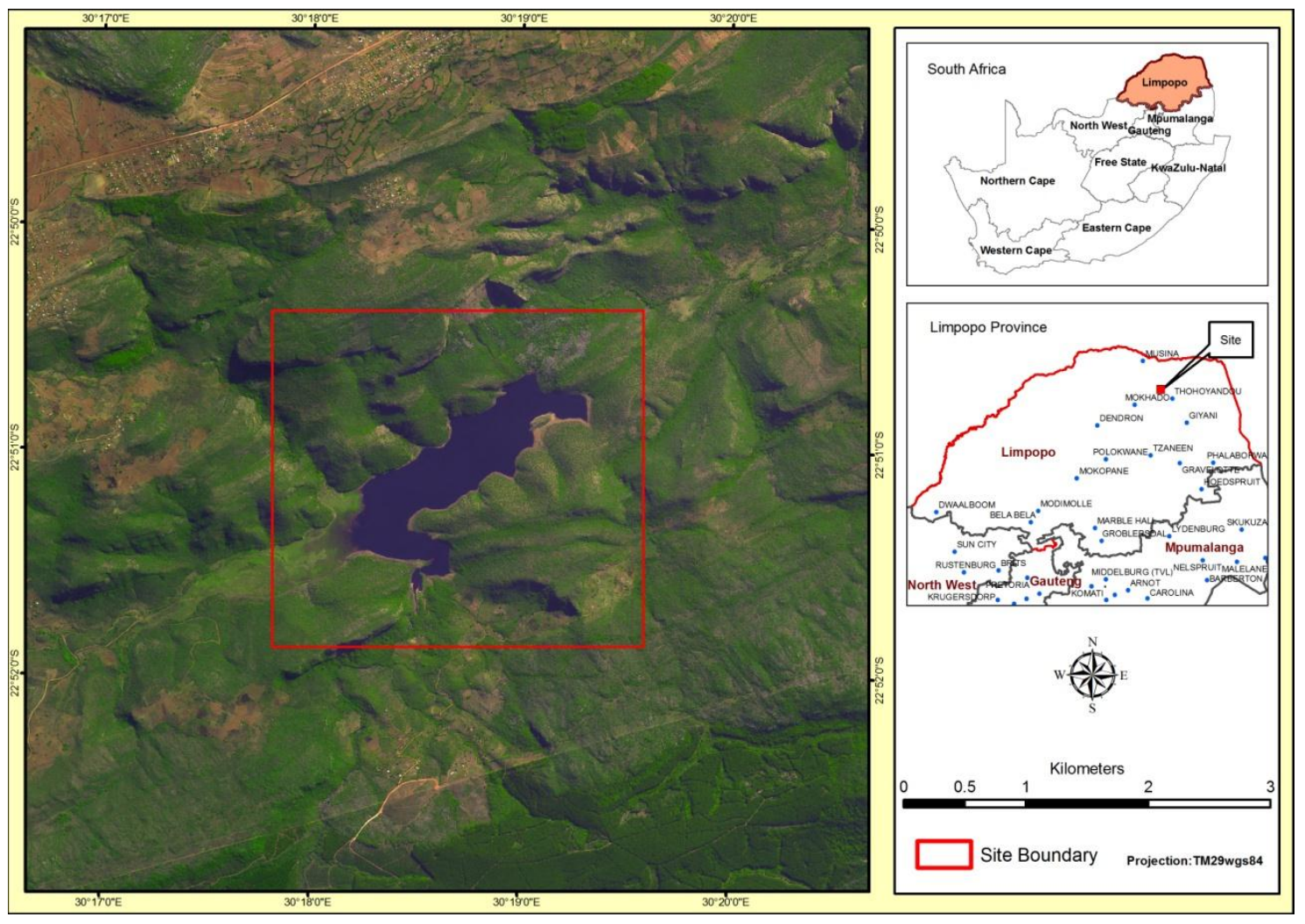

Figure 1.1: Location map of Lake Fundudzi.

\subsection{Aims and objectives}

\subsubsection{Aim of research}

The main aim of this research was to investigate the geotechnical conditions that could have led to the landslide that formed Lake Fundudzi by back analyses techniques.

\subsubsection{Objectives of research}

The objectives of this research were:

1) to determine the type of failure mechanisms that may have led to the landslide;

2) to geotechnically characterize the site in order to obtain the relevant input parameters such as unit weight $(\gamma)$, joint wall compressive strength (JCS) and joint roughness coefficient (JRC) for slope stability analysis; 
3) to undertake back analyses based on the limit equilibrium procedures using RocPlane and Slide in Rocscience ${ }^{\circledR}$ Inc. software of the landslide that formed Lake Fundudzi in order to investigate the geotechnical conditions that may have led to failure; and

4) to investigate the importance of back analysis techniques in landslide studies.

\subsection{Methodology}

\subsubsection{Desk study}

The desk study comprised literature review of published and unpublished information on the regional and local geology of the area, landslides, causes of rock slope failure and slope stability analyses techniques. Information studied included previous regional geological reports on Soutpansberg Group, 1:250 000 geological maps, 1:50 000 scale topographical maps and journal articles. The assessment of landslide morphology was conducted using stereoscopic examination, interpretation and data compilation of chromatic aerial photo pairs and digitally enhanced aerial images. The colour 3D space imagery of Google Earth ${ }^{\circledR}$ was also perused for aerial view perspective assessment. Throughout the study, journal articles, textbooks and other sources of information on landslides with specific emphasis on rockslides, kinematic analyses, back analysis studies, rock slope stability analysis were reviewed.

\subsubsection{Field survey and sampling}

For the purpose of this study, a field trip to the site took place on the first week of July 2012. It was undertaken by the author and Supervisor, Dr E. Hingston. Field work primarily included, natural joints sampling for laboratory testing, discontinuity survey and conducting the Schmidt hammer tests.

Additional data obtained from previous investigations collected by the author, Dr S. Diop, and Ms S. Richardson was also used in this study. The initial field work was undertaken in February 2008 where a top wing micro light aircraft was employed for an airborne survey to have a good inspection of the Lake Fundudzi site and capture aerial photographs (Figure 1.2). The field work also included discontinuity survey, point load and Schmidt hammer tests. 


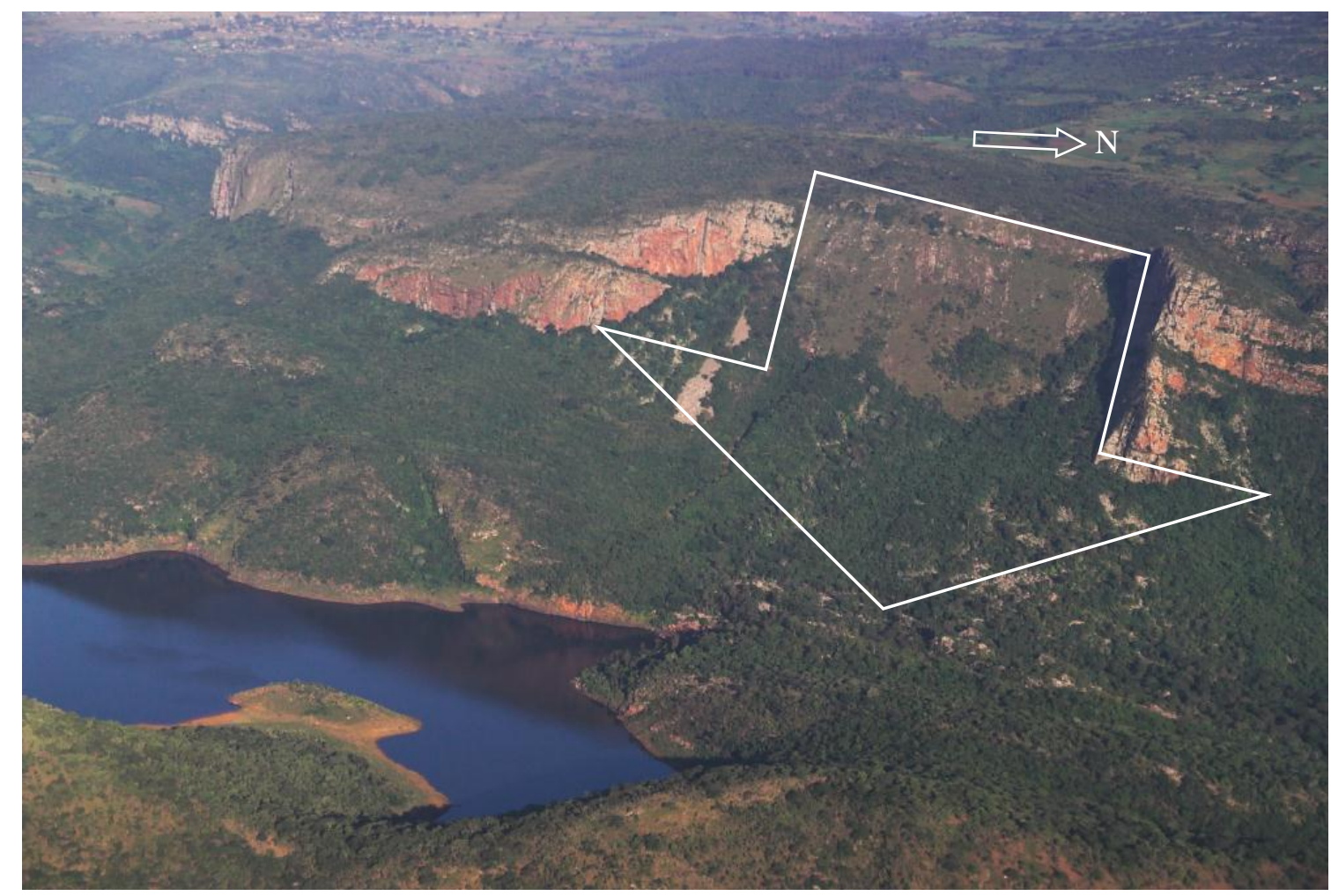

Figure 1.2: A diagonally aerial view of the Lake Fundudzi landslide situated in the Soutpansberg mountains.

\subsubsection{Laboratory testing}

Laboratory testing was conducted at intervals from January 2013 to the end of October 2013. The main purpose for laboratory testing was to aid in the geotechnical characterization of the rock material and to obtain parameters necessary for the slope stability analyses. This commenced with the sample preparation by coring of rock blocks and cutting of joint samples for Golder box shear strength testing.

\subsubsection{Kinematic and slope stability analyses}

The analyses consisted of a two-step process. The first involved kinematic analysis which was to determine whether the orientation of the discontinuities could have resulted in instability for a rock slope defined by those discontinuities and also the possible failure mechanism (Piteau and Peckover, 1978). This was accomplished by means of stereographic analysis using the Dips software by Rocscience ${ }^{\circledR}$ Inc. This was followed by back analysis using the limit equilibrium method of analysis; this constituted the second step and the Rocscience ${ }^{\circledR}$ Slide and RocPlane software were employed. 


\subsection{Brief synopsis of the dissertation}

The dissertation has been organised in chapters and appendices. There are eight chapters that present the research. A synopsis of each chapter is presented below.

\section{Chapter 1: Introduction}

Chapter 1 presents a general background on landslides and that of South Africa in particular. The aims and objectives of the study are stated. A brief methodology outline is given as well as the organisation of the dissertation.

\section{Chapter 2: Geological setting}

This chapter gives an account on the regional geology, structural setting and hydrology based on theoretical literature background and aerial photography survey and mapping of project site geology. The local geology as well as the petrographic analysis of the main rock type in the area are also presented in this chapter.

\section{Chapter 3: Landslide, types and processes}

This chapter provides a literature review on landslides, definition, types of movement and classification systems. The general causes and triggers of landslides are also discussed.

\section{Chapter 4: Methods of hazard assessment and stability analysis}

The methods of landslide risk and hazard assessments are discussed followed by methods of slope stability analyses. The slope stability analysis methods described include kinematic analysis, limit equilibrium procedures, numerical methods and back analyses techniques and their pros and cons. The features and dimensions of the Lake Fundudzi landslides are also presented.

\section{Chapter 5: Methodology and laboratory testing}

This chapter summarises the rock mechanics principles behind each step of data collection for the determination of rock characterization parameters. The chapter also describes how data collection was collected from literature review, fieldwork, and laboratory testing to equilibrium analysis using Slide software.

\section{Chapter 6: Results and geotechnical characteristics}

This chapter discusses the results of fieldwork i.e. joints survey results and laboratory testing (UCS, shear strength testing, frictional angle, JRC) for the determination of input parameters for the analyses. Laboratory direct shear tests results that were carried out on natural 
discontinuities to measure the shear strength parameters are presented. The results/interpretation of stereographic analysis of joint survey using Dips by Rocscience ${ }^{\circledR}$ Inc. is presented. The failure mechanism for the landslide (type of failure) is characterized from these results.

\section{Chapter 7: Back analyses of Lake Fundudzi landslide}

Back analyses to determine the conditions that could have led to failure using sensitivity analysis via Slide and RocPlane of Rocscience ${ }^{\circledR}$ Inc. geotechnical software that is limit equilibrium based is presented. In the back analyses process $F=1.00$ was assumed which is a point of imminent failure.

\section{Chapter 8: Discussion of the results}

This chapter closes the loop of the main research questions or aim which was to "investigate the geotechnical conditions that led to the landslide that formed Lake Fundudzi by back analyses techniques".

\section{Chapter 9: Conclusions}

The findings of the study are summarised and recommendations are put forward for further studies that may employ different techniques in the determination of material strength properties of the current project site.

\subsection{Summary}

The background, rationale behind the study, aims and objectives, methodology outline and synopsis of the dissertation have been given.

The next chapter discusses the regional geology followed by the local geology of the site. These include structural geology and hydrogeological accounts. 


\section{CHAPTER 2}

\section{GEOLOGICAL SETTING}

\subsection{Introduction}

Slope failures in rock slopes are often associated with regional geological evolution, structural setting and other geological triggering factors such as seismic events. Hence they need to be taken into account in slope stability studies (Sancio, 1981). It is for this reason that the regional and local geological settings have to be understood. This chapter presents an overview of the regional geology and as well as the geology of the project area.

\subsection{Regional geology}

The regional geology described here falls in an area within 100 to $200 \mathrm{~km}$ radius from the landslide. The main sources of information that were reviewed for the regional geology are those of Visser (1998) and Barker et al. (2006).

The regional geological setting consists of the Soutpansberg Group, the Waterberg Group, and the Blouberg Formation which lie within the Limpopo, Mpumalanga and Gauteng Provinces of South Africa, with the Waterberg Group also extending westwards into Botswana (Figure 2.1) (Barker et al., 2006).

The Soutpansberg Group is partially buried beneath younger Karoo Supergroup sedimentary and volcanic rocks of varying thicknesses (Barker et al., 2006). It occupies a wedge-shaped mountainous area stretching from the Kruger National Park in the east up to Blouberg in the west, where the rock wedge out against the northeastern extension of the Melinda Fault (indicated by $f$----- $f$ ) on the northern side of Figure 2.1 (Visser, 1998).

The Waterberg Group extends southwards from the Melinda Fault towards Bela-Bela (Warmbaths) and also into southeastern Botswana. The Wilge River Formation in the Middelburg Basin east of Pretoria is also included in the group (Figure 2.1) (Barker et al., 2006). 


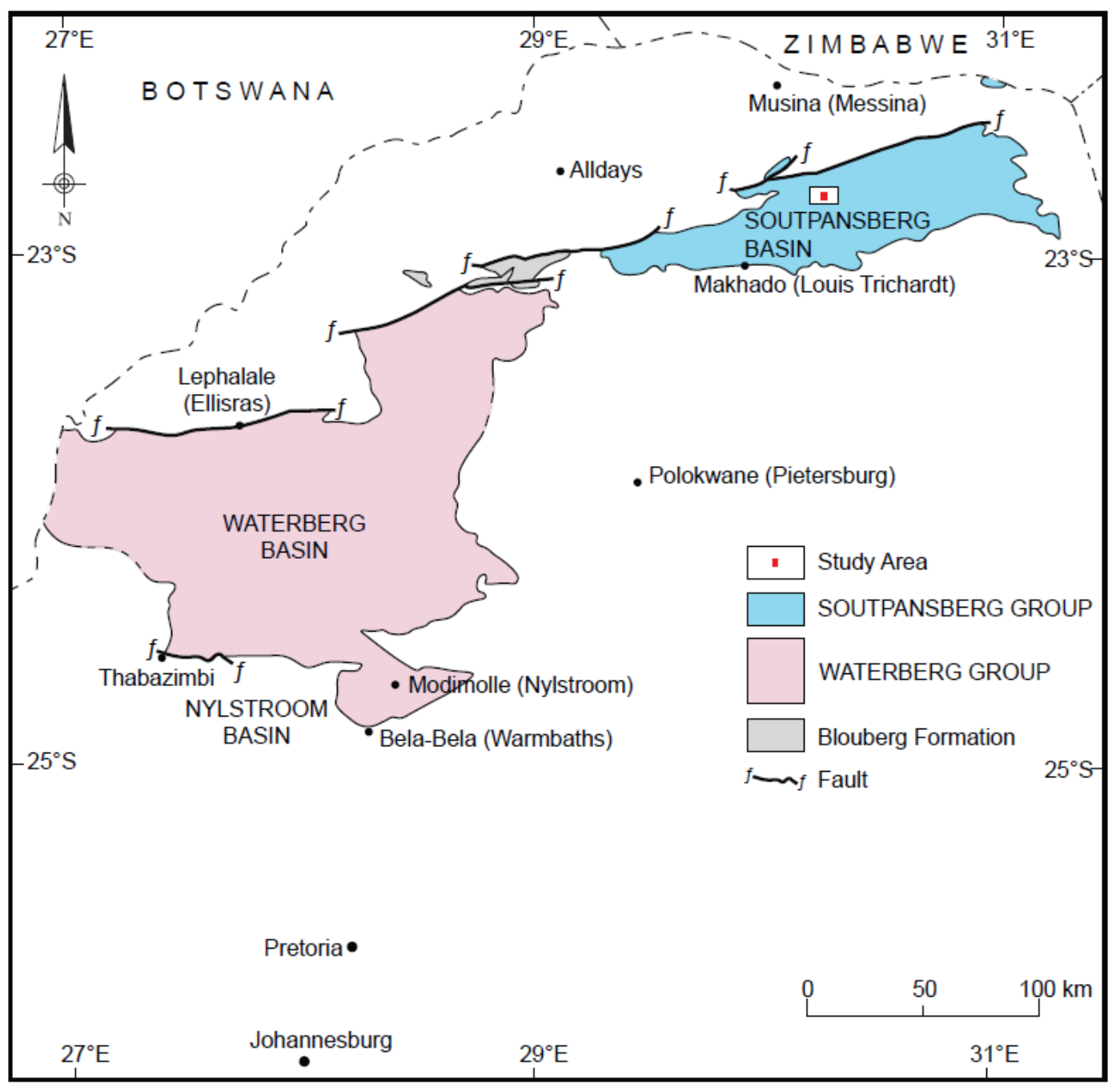

Figure 2.1: Regional geological map of the Soutpansberg Group, the Waterberg Groups, and the Blouberg Formation (after Barker et al., 2006).

The Blouberg Formation occurs mainly to the north of the Melinda Fault, and predates the Soutpansberg Group (Barker et al., 2006).

The Soutpansberg, Waterberg and Blouberg successions have in the past been considered to be between 1700 and $2000 \mathrm{Ma}$ old and are thus of Kheisian (Palaeoproterozoic) age (Barker et al., 2006). According to Barker et al. (2006), they fall within that period of earth's evolution when free atmospheric oxygen was available for the first time in sufficient quantity to produce oxides of the ferruginous minerals, thus creating suitable conditions for the formation of "red beds". These Palaeoproterozoic-age "red beds" occur in an intracratonic to mobile belt or nearcratonic environment, in the case of the Blouberg Formation and the Soutpansberg Group, and a cratonic setting in the case of the Waterberg Group (Barker et al., 2006). 


\subsection{Soutpansberg Group}

The study area falls within the Soutpansberg Group and thus it has been described in great detail.

The Soutpansberg Group is a volcano-sedimentary succession which is subdivided into six Formations (Brandl, 1999) as shown in Table 2.1. This table shows the lithostratigraphy of the Soutpansberg Group as approved and proposed by the South African Committee for Stratigraphy SACS (1980) and Brandl (1999) respectively. Differences exist between the stratigraphic classification proposed by Barker (1979) and that accepted by SACS (1980). For example, the number and names of Formations are not the same as shown in Table 2.1.

Table 2.1: Stratigraphic subdivision of the Soutpansberg Group (after Barker et al., 2006).

\begin{tabular}{|c|c|c|c|}
\hline \multicolumn{2}{|c|}{ Barker (1979) } & \multicolumn{2}{|c|}{ SACS (1980), Brandl (1999) } \\
\hline Formation & Member & Formation & Member \\
\hline Nzhelele & Mutale, Mphephu & Nzhelele & $\begin{array}{l}\text { Lukin Quartzite } \\
\text { Mutale Tuff }\end{array}$ \\
\hline Ngwanedzi & & Musekwa & \\
\hline \multirow[t]{2}{*}{ Musekwa } & & Wyllies Poort & \\
\hline & $\begin{array}{l}\text { Fundudzi, Mountain } \\
\text { Inn }\end{array}$ & Fundudzi & \\
\hline \multirow[t]{2}{*}{ Sibasa } & $\begin{array}{ll}\text { Natal } & \text { House, } \\
\text { Mutshindudi } & \end{array}$ & Sibasa & \\
\hline & & Tshifhefhe & \\
\hline
\end{tabular}

Barker (1979) had earlier subdivided the Soutpansberg Group into Five formations. A summary of the typical lithology is summarized in Table 2.2. The rocks strike east - west and dip at $20^{\circ}-$ $30^{\circ}$ to the north. The rocks of the Soutpansberg Group are severely faulted by faults of various geological ages (Visser, 1989). The group consists essentially of reddish, arenaceous and minor argillaceous deposits, and reaches a thickness of around $12000 \mathrm{~m}$. Basic lava, tuff and pyroclasts occur as layers and lenses of variable thickness throughout the succession (Visser, 1998). According to Brandl (1999), the rocks of the Soutpansberg Group did not attract much scientific attention in the past, since they are almost devoid of any economic mineralization. 
Table 2.2: Stratigraphy of the Soutpansberg Group with summary of the typical lithology (after Brandl, 1999).

\begin{tabular}{|c|c|c|c|c|c|c|}
\hline Ma & Epoch & Period & Formation & Member & $\begin{array}{c}\text { Thickness } \\
\text { (m) }\end{array}$ & Typical lithology and rock type \\
\hline \multirow[t]{5}{*}{1600} & \multirow{6}{*}{ 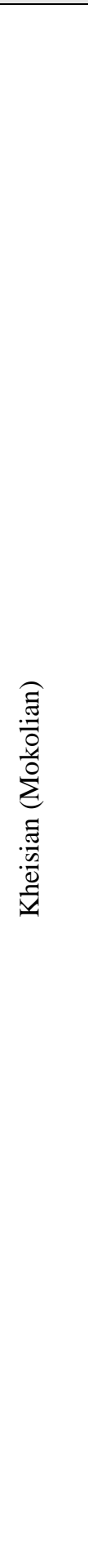 } & \multirow{6}{*}{ 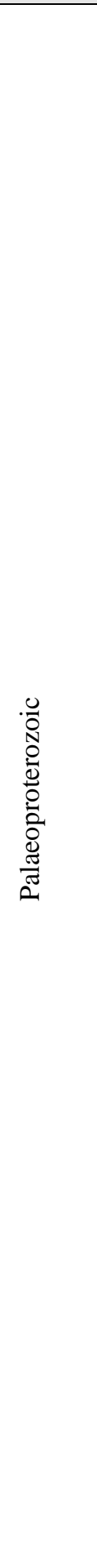 } & Nzhelele & $\begin{array}{l}\text { Lukin } \\
\text { Quartzite } \\
\text { Mutale } \\
\text { Tuff }\end{array}$ & 600 & $\begin{array}{l}\text { Red argillaceous and arenaceous } \\
\text { sediments with fairly consistent layers } \\
\text { of pyroclastic rocks. } \\
\text { Purple Tuff constitutes an important } \\
\text { marker horizon with an ENE-WSW } \\
\text { strike continuity of more than } 60 \mathrm{~km}\end{array}$ \\
\hline & & & Musekwa & & 400 & $\begin{array}{l}\text { Similar to those in the Sibasa } \\
\text { Formation. }\end{array}$ \\
\hline & & & $\begin{array}{l}\text { Wyllies } \\
\text { Poort }\end{array}$ & & 1500 & $\begin{array}{l}\text { Resistant pink quartzite and sandstone } \\
\text { with minor pebble washes, and } \\
\text { prominent agate conglomerate at the } \\
\text { base. }\end{array}$ \\
\hline & & & Fundudzi & & 1900 & $\begin{array}{l}\text { Arenaceous and argillaceous } \\
\text { sediments with a few thin pyroclastic } \\
\text { horizons. Near the top of the } \\
\text { succession up to four }+/-50 \mathrm{~m} \text { thick } \\
\text { layers of epidotised basaltic lava are } \\
\text { intercalated with the sediments. }\end{array}$ \\
\hline & & & Sibasa & & 3000 & $\begin{array}{l}\text { Volcanic succession with clastic } \\
\text { sediments. The basalts are generally } \\
\text { dark green, massive speckled white in } \\
\text { frequently developed amygdaloidal } \\
\text { zones. } \\
\text { The clastic sediments include } \\
\text { quartzite, shale and minor } \\
\text { conglomerate. }\end{array}$ \\
\hline 2050 & & & Tshifhefhe & & $\sim 10$ & $\begin{array}{l}\text { Strongly epidotised clastic sediments, } \\
\text { including shale, greywacke and } \\
\text { conglomerate. }\end{array}$ \\
\hline
\end{tabular}


The Soutpansberg rocks rest uncomfortably on the gneisses of the Limpopo Belt and Bandelierkop Complex (Barker et al., 2006). Along the eastern and most of the northern margin, the outcrops are unconformably overlain or tectonically juxtaposed against rocks of the Karoo Supergroup. The contact relationship between the rocks of the Soutpansberg Group and Waterberg Group is a tectonic one, though the latter rocks are believed to be younger. The Group is best developed in the eastern part where the maximum preserved thickness is about $500 \mathrm{~m}$ (Barker et al., 2006).

\subsubsection{Lithostratigraphy}

The basal, discontinuous Tshifhefhe Formation is only a $\sim 10$ metres thick and comprises strongly epidotised clastic sediments, including shale, greywacke and conglomerate. The clasts generally indicate local derivation (Brandl, 1999). Barker (1979) included this unit in his Sibasa Formation and is best developed in the Kruger National Park.

The Sibasa Formation is a dominantly volcanic succession, with several lenticular, but laterally persistent, intercalations of clastic sediments. The Formation is estimated to reach a thickness of about $3000 \mathrm{~m}$ (Barker, 1979). The volcanic rocks comprise a repetitive sequence of cyclically erupted basalts (Barker et al., 2006). The basalts are generally dark green, massive and epidotised, but are speckled white in frequently developed amygdaloidal zone. The occasional presence of prehnite-pumpellyite suggests that at least the basal volcanic rocks were subjected to very low-grade metamorphism (Barker et al., 2006). The pyroclastic rocks of the Sibasa Formation are typically lenticular and can be up to $200 \mathrm{~m}$ thick (Barker, 1979). The occurrence of peperite is considered to have been formed by the interaction of hot lava with wet sediments. Interbedded clastic sediments include quartzite, shale and minor conglomerate, and locally may reach a maximum thickness of $400 \mathrm{~m}$ (Barker et al., 2006).

The Fundudzi Formation attains a thickness of up to $1900 \mathrm{~m}$ and consists mainly of arenaceous and argillaceous rocks with few thin pyroclastic beds (Barker et al., 2006). At the top of the succession is a $50 \mathrm{~m}$ thick layer of epidotised basaltic lava which is intercalated with sediments (Barker, 1979; Brandl, 1981).

The Wyllies Poort Formation is a clastic succession and reached a maximum thickness of 1500 m (Barker et al., 2006). Pink quartzitic sandstones with minor pebble washes dominate the succession (van Eeden et al., 1955; Barker et al., 1979). A prominent agate conglomerate is developed at the base in some areas (Barker et al., 2006). 
The Musekwa Formation is a volcanic succession that attains a thickness of $400 \mathrm{~m}$ (Brandl, 1999). According to Van Eeden et al. (1955), the basalts are very similar to those in the Sibasa Formation, with the exception that individual flow units locally exhibit a very coarse "gabbroic" texture.

The Nzhelele Formation constitutes the uppermost unit and attains a maximum preserved thickness of $600 \mathrm{~m}$. The Formation comprises red argillaceous and arenaceous sediments at the top, together with several thin but fairly consistent, layers of pyroclastic rocks of which one is copper bearing (Barker et al., 2006). The tuffaceous Mutale Member, capped by the $1.2 \mathrm{~m}$ thick "Purple Tuff", constitute an important marker horizon with an ENE-WSW strike continuity of more than $60 \mathrm{~km}$ (Barker, 1979).

\subsubsection{Depositional environment}

The Soutpansberg Group sediments are generally believed to have been deposited in a continental environment under fluvial conditions (Barker, 1979, 1983). Mud cracks in the argillaceous Fundudzi Formation top set beds indicate cycles of flooding and sub aerial exposure. The existence of trough cross-bedding in sand bodies and horizontal lamination in muddy layers is also compatible with alluvial flood plain depositional environment (Barker, 1979). Arenaceous rocks of the Wyllie's Poort Formation tend to exhibit planar and trough cross-bedding and thin pebble washed. The depositional environment was possibly a braided, mid-alluvial plain, or a proximal fluvial flood-plain system (Barker, 1979), with the pebble washes representing channel lag deposits.

The lower argillaceous rocks and higher sandy unit of the Nzhelele Formation display convolute bedding, desiccation cracks, raindrop imprints and trough cross bedding, ripple crosslamination respectively (Barker, 1979). Higher up, the unit gradually becomes more sandy and the rocks are laminated to thinly bedded, with mud-clast conglomerate being present. Towards the top of the succession, upward-fining sequences, trough cross-bedding and ripple crosslamination are developed (Barker, 1979). The Nzhelele sediments probably mirror change in the environmental setting, from a distal to a mid-alluvial flood plain (Barker, 1979). Palaeocurrent measurements of the Soutpansberg sediments indicate source regions generally in the north and northwest (Barker, 1979), and Brandl (1981) suggested that only in the uppermost sediments is derivation of some units from a southerly source.

Cheney et al. (1990) concluded that the Soutpansberg Group, or at least its lower part, was deposited sometime between $1974 \mathrm{Ma}$ and about $1800 \mathrm{Ma}$. 


\subsubsection{Structural setting}

The strike of the beds is east - west and the dip is moderate to steep towards the north (Visser, 1998). The Soutpansberg strata generally dip at less than $30^{\circ}$ in a north-northwest direction (Brandl, 1999). Three main fault and joint orientations are recognized (Barker, 1979; Brandl, 1981). The most dominant and continuous are the E-NE to W-SW trending extensional faults. These resulted in the truncation and duplication of at least four times by these continuous structures forming discrete, fault-bounded elongated blocks. A conjugate fault and joint set, oriented NW-SE and NE-SW is similarly widely developed. Events suggest that both shear and extensional movements may have occurred and the shear movement is thought to be pre-Karoo in age (Barker, 1979).

There are numerous diabase intrusions which occur as dykes and sills within the Soutpansberg rocks. The dykes tend to intrude along fault planes, whereas the sills were commonly emplaced along the interface between shale and competent quartzite (Barker et al., 2006).

\subsubsection{Tectonic setting}

The Soutpansberg Group rocks were interpreted by Jensen (1975) to have been laid down in a trough or aulacogen which developed progressively from the edge of the Kaapvaal Craton into the interior. The view was disputed by Barker (1976) who drew attention inter alia to the absence of marine sediments, and to the fact that transported direction as measured in the Soutpansberg sediments are not unidirectional. He proposed that during regional uplift, a number of localized fault-bounded basins developed, which coalesced with time to form the large Soutpansberg basin. Barker (1979 and 1983) suggested that the Soutpansberg sediments were deposited in a continental environment under fluvial conditions. The evidence lies in the Fundudzi Formation mud cracks and argillaceous topset beds which indicate cycles of flooding and sub aerial exposures. Trough cross-bedding in sands and horizontal lamination in muddy layers is also evident (Barker et al., 2006).

Cheney et al. (1990) suggested that the Soutpansberg rocks represent a cratonic sequence, which is separated into two major units by a prominent regional unconformity.

The proposal by Barker (1979 and 1983) of a continental environment under fluvial condition sediments deposition is generally widely accepted. 


\subsection{Geology of the project site}

The geology in the vicinity of the site is characterised by sandstone which is quartzitic in places. The rock strata were named the Fundudzi Formation after the landslide lake. The 1:250 000 geological map describes the lithology of the Fundudzi Formation as sandstone and quartzitic in places, locally gritty or conglomerate with interbedded basaltic lava, tuff, shale, agglomerate and siltstone as shown in Figure 2.2 (Barker, 1976).

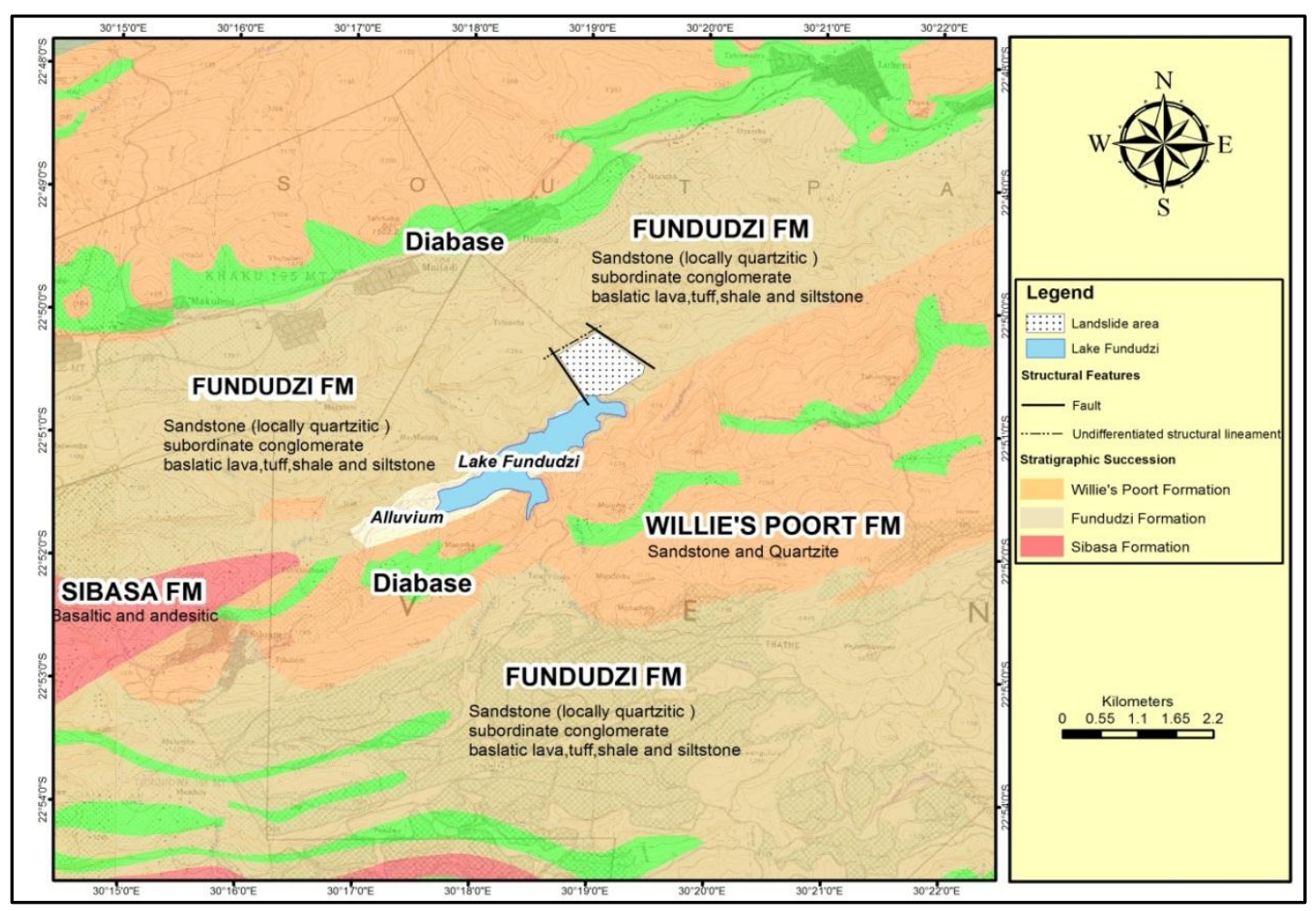

Figure 2.2: Local geological map of the Lake Fundudzi landslide area.

\subsubsection{Lithology}

The landslide slope was observed to be a homogenous rock slope. The sandstone which is quartzitic in places was the only rock type mapped during fieldwork. This homogenous slope rock mass attains a maximum height of $320 \mathrm{~m}$ in the project area from the lake's water level to the crest of the landslide. The sandstone is pinkish to reddish brown in colour, and medium to fine grained. The bedding is preserved and multi jointing of the rock mass is evident. 


\subsubsection{Petrography}

The thin section was prepared accordingly by the Laboratory and Geochemistry section at the Council for Geoscience in Pretoria.

Evident from thin section (Figure 2.3) microscope analysis is that the sandstone is composed predominantly of quartz (+95\%) and minor amounts of secondary carbonate minerals. Distinctly visibly also on stage rotation under crossed polarized light (Figure 2.4) is an undulatory extinction of quartz grains which indicates quartz minerals had undergone deformation. Grain to grain contact was evident and almost interlocking indicating recrystallization. The majority of these sediments also reflected in the increased sphericity $(0.7$ $-0.9)$ and roundness $(0.5-0.9)$ of the mineral grain and in general the sorting is good. Quartz veins are also present. Silica cements around quartz grains forming very hard rock sandstone. The original shape of many of the quartz grains may have been reworked because they are well sorted and are basically of equal size.

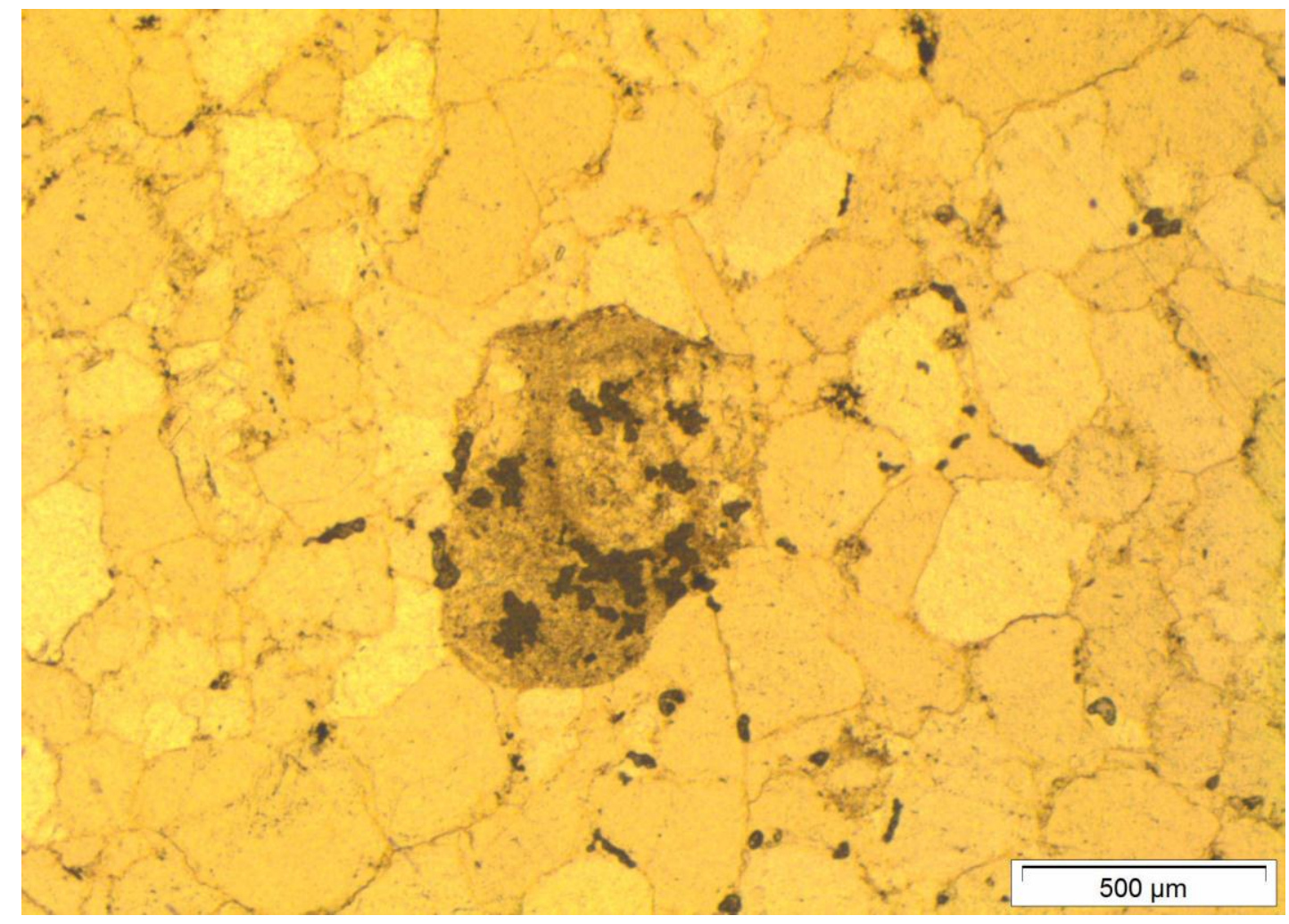

Figure 2.3: Photomicrograph of sandstone under plane polarized light. 


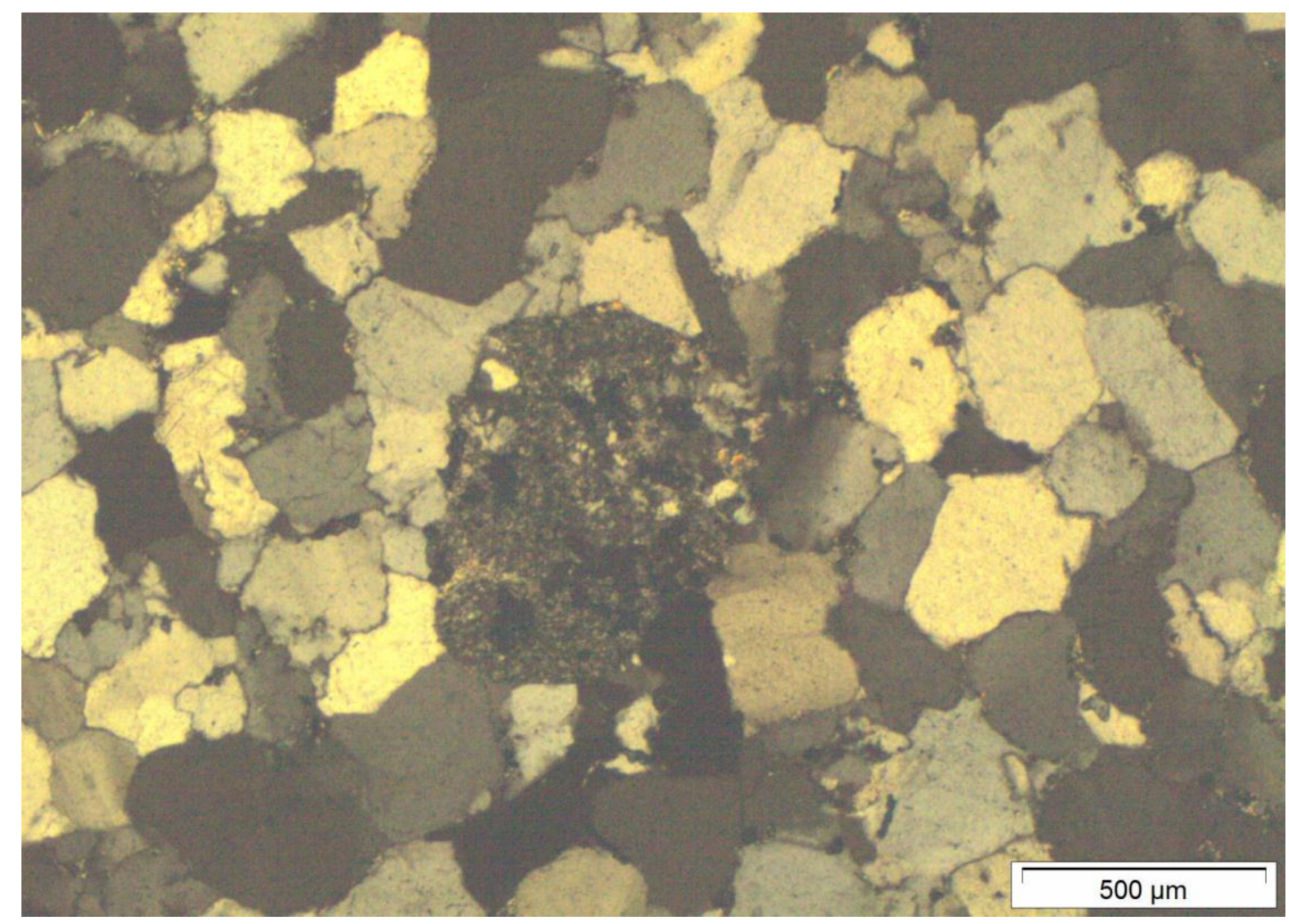

Figure 2.4: Photomicrograph of sandstone under crossed-polarized light.

\subsubsection{Geological structures}

According to Van Eeden et al. (1955), the Fundudzi fault running longitudinally through the lake has no relation to the formation of the landslide (Figure 2.5). Faults in the rocks of the highlands of the Soutpansberg are usually indicated by a line of dense bush.

Barker (1979) mapped two NW-SE and SW-NE intersecting faults which form the failure release surfaces (or buttresses) also as shown in Figure 2.5. A lineament that was identified in this study from satellite imagery perusal is the one that coincides with the tension crack at the scarp of the landslide. This lineament extends far beyond either of the release surfaces for over $500 \mathrm{~m}$ from each release surface side. Several minor rock slides and falls are still active and noticeable on each of the release surfaces, and were also noted by Janisch (1931). A $23 \mathrm{~m}$ deep vertical tension crack was also observed at the crest of the failure plane. 


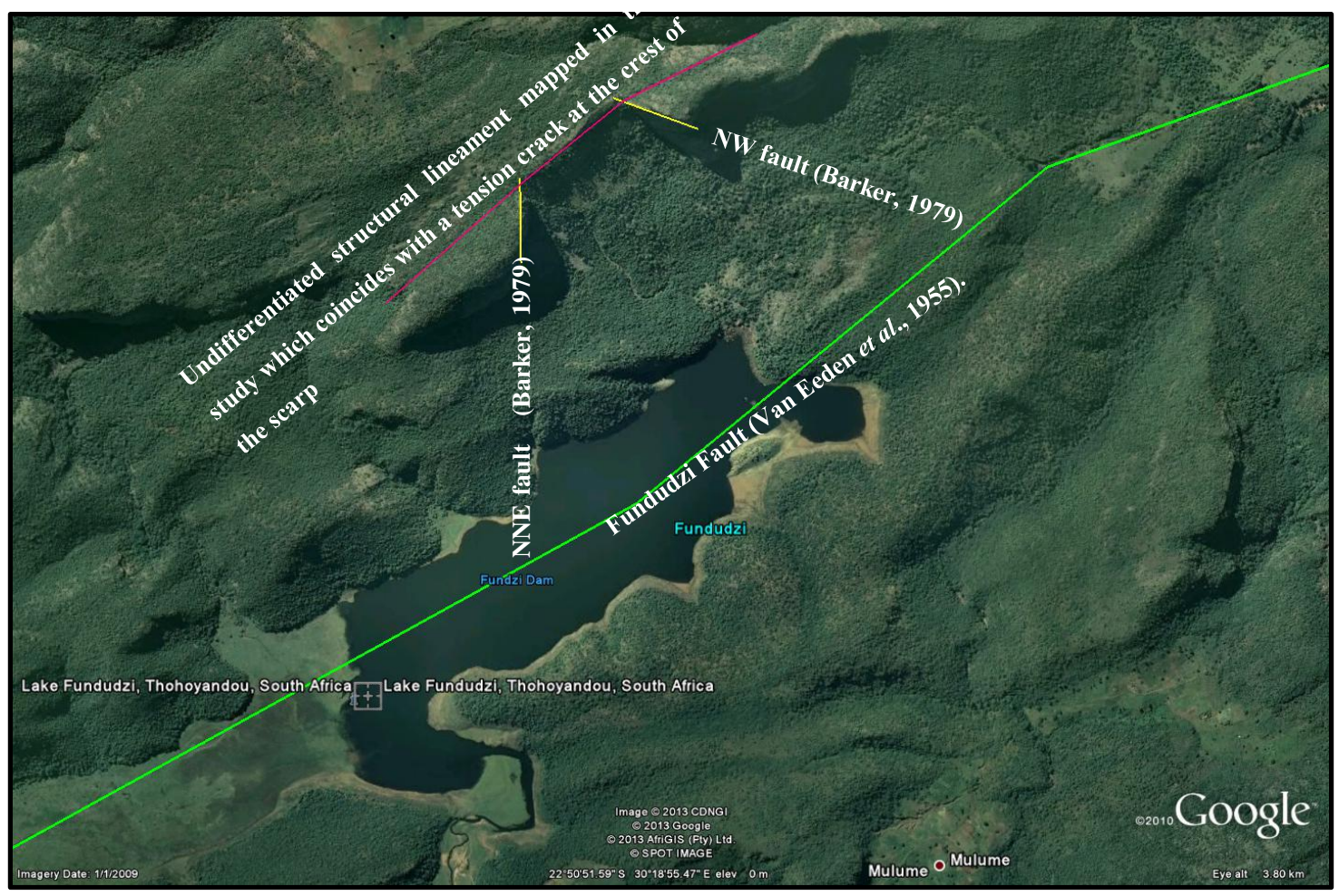

Figure 2.5: A Google Earth $^{\circledR}$ satellite imagery showing major structural features in the vicinity of the site.

The dips of the beds, as it can be seen in Figure 2.6, on the fractured sides of the release surfaces are $30^{\circ}$ north on Dongwe and $45^{\circ}$ north on Chitanda. Several minor rockfalls have taken place recently, notably on the eastern side of each releasing surfaces.

The rock mass itself is heavily jointed with three prominent joint sets; two discontinuity sets and one bedding set. Discontinuity survey methodology and analysis of these joints is presented later in Chapters 5 and 6 respectively. 


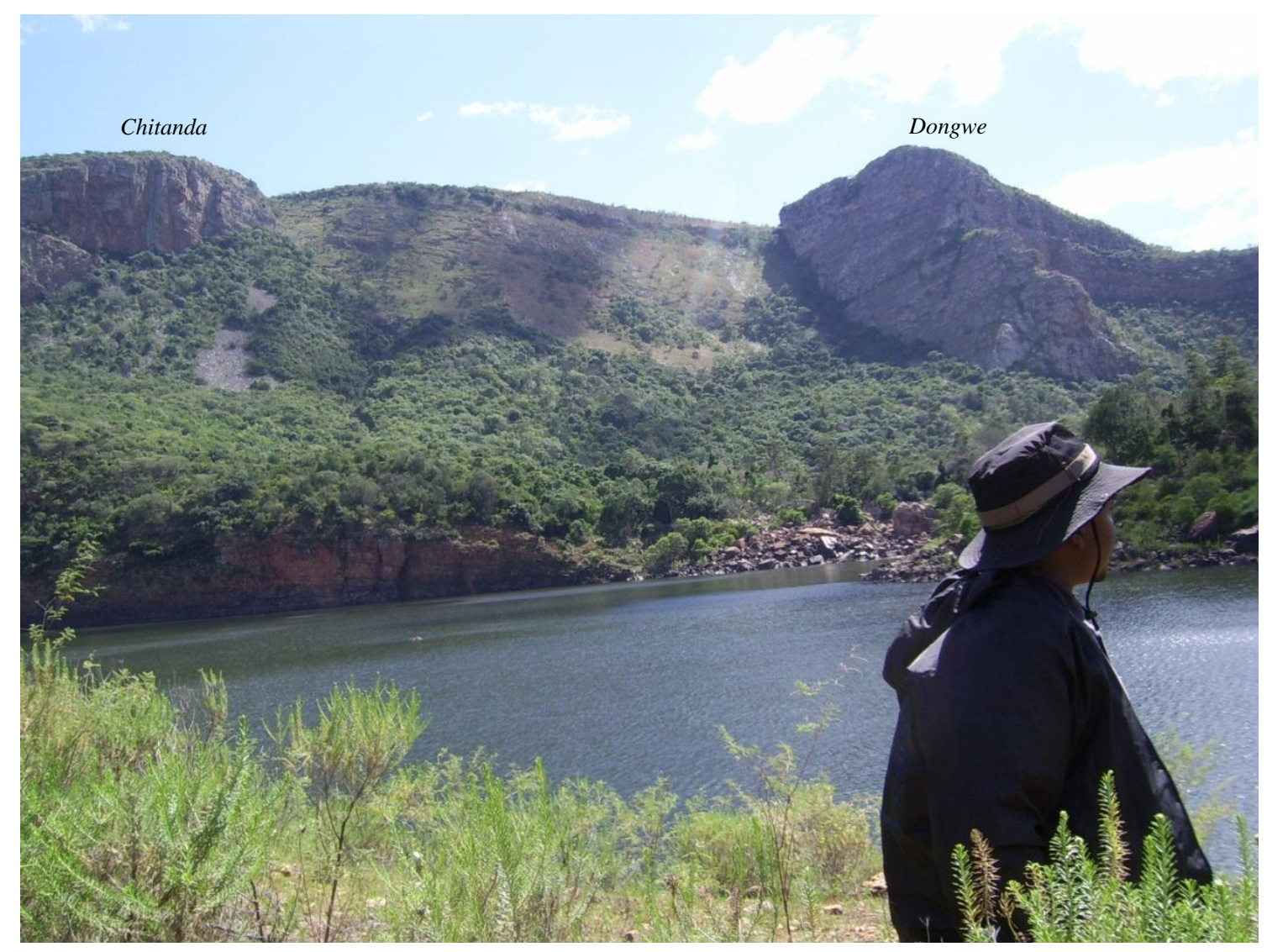

Figure 2.6: A view of the landslide failure surface from the southern shore of the lake showing northward dipping beds of the rock mass.

\subsection{Climate, drainage, geohydrology and vegetation}

The climatic conditions of the study area are characterised by summer rainfall, with an average annual precipitation of $1280 \mathrm{~mm}$.

The area has a subtropical climate which is hot and dry. Extreme cold and sharp frosts are exceptional and during June and July the climate is very pleasant. Thunder showers occur during summer months (October to March) only (Van Eeden et al., 1955).

The lake is fed by three streams, draining a catchment of more than 600 ha i.e. Mutale 2480 ha, Godoni 2270 ha and Muiladi 1270 ha as shown in Figure 2.7. The Mutale catchment is higher (up to $1438 \mathrm{~m}$ ) and receives a higher rainfall (> $1200 \mathrm{~mm}$ per annum) and accordingly has the greatest influence on the lake (van der Waal, 1997). 


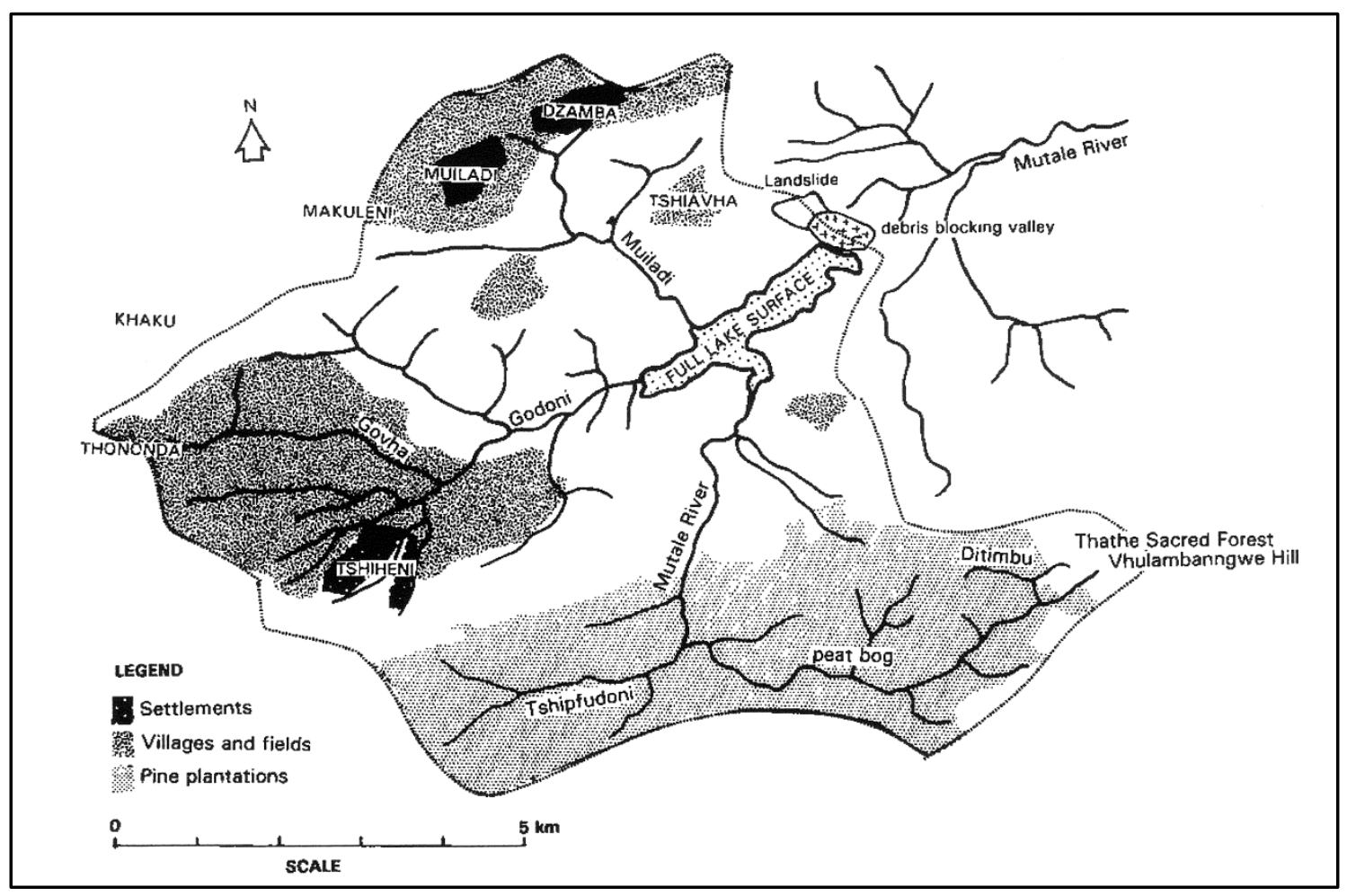

Figure 2.7: A map showing catchment areas of Lake Fundudzi (after van der Waal, 1997).

As it has been already mentioned, the Mutale River is important because Lake Fundudzi was formed in it as a result of a large landslide which is a subject of this study. At the lower end of Lake Fundudzi, the water flows out through a mass of loose rock blocks as shown in Figure 2.8 (Van Eeden et al., 1955).

At the time of this study there was no detailed literature material on local geohydrological conditions. However, no springs or any form of water drainage features were observed through the landslide from the scarp down to the lake. Dry and worst case groundwater scenarios were both used for determining the probable significant landslide trigger.

The Characteristic vegetation of the rocky country of the Soutpansberg is the "Massembier" (Androstachys johnsonii). It varies from a shrub to a tree with a height of $3.66 \mathrm{~m}$. According to the rainfall and nature of the soil it can grow to impenetrable thickets on the mountain slopes (Van Eeden et al., 1955). 


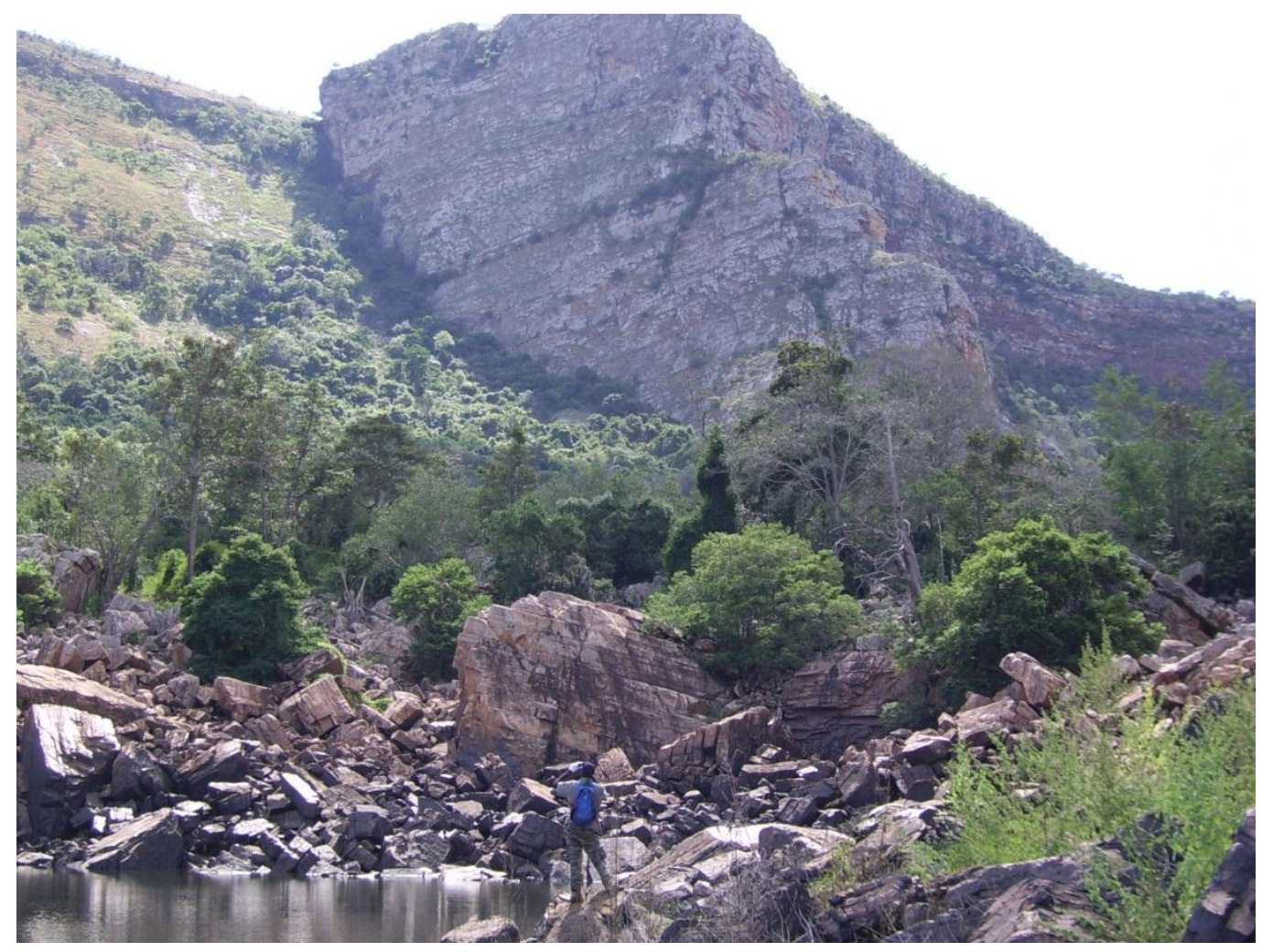

Figure 2.8: A view of a mass of rock debris blocking the Mutale River.

\subsection{Summary}

The regional geology comprises the Waterberg Group, Soutpansberg Group and Blouberg Formation with age bracketed between $1700-2000$ Ma. The landslide occurred in the Fundudzi Formation of the Soutpansberg Group which consists of arenaceous and argillaceous rocks. Faulting is prominent in the vicinity of the site and includes the Melinda Fault at a regional scale and the Fundudzi Fault traversing the floor of the Lake. Three main fault and joint orientations were recognized with the most dominant being the $\mathrm{E}-\mathrm{NE}$ to $\mathrm{W}-\mathrm{SW}$, trending faults, NW -SE and NE-SW trending fault and joint sets widely developed. Diabase dykes and sills intruded fault planes and bedding interfaces respectively. Local geological mapping and petrographic investigation indicated that:

- the failed rock slope is homogeneous sandstone which is quartzitic in places;

- the rock slope mass is evidently jointed;

- the Fundudzi Fault strikes on the lake floor,

- additionally, two faults coincide with the release surfaces of the landslide, and

- another undifferentiated lineament or joint coincides with the presumed tension crack at the scarp of the landslide. 
The study area receives an average annual rainfall of $1280 \mathrm{~mm}$. The site falls in an area with subtropical climate. At the time of this study there was no detailed literature material on local geohydrological conditions.

The next chapter focuses on landslide classification particularly the most recent classification by Cruden and Varnes (1996). General causes and triggers are also stated. Furthermore, the features and dimensions of the Lake Fundudzi landslide are also presented. Emphasis on rock slope failure is also made. 


\section{CHAPTER 3}

\section{LANDSLIDES, TYPES AND PROCESSES}

\subsection{Introduction}

The term landslide denotes the movement of mass of rock, debris or earth down a slope (Cruden, 1991). Cruden and Varnes (1996) noted that the term describes all kinds of mass movements and is not limited to granular soil (as the term "land" might suggest) or a sliding movement process. This chapter presents the classification of landslides based on Cruden and Varnes (1996) and also discussed the triggering mechanisms of landslides with emphasis on rock slope failure. The chapter further discusses the different types of landslide analyses techniques. The description of the Lake Fundudzi landslide and the possible triggering mechanisms is also presented.

\subsection{Landslide classifications}

The two generalized landslide classifications most likely to be encountered in the English speaking world are by Hutchinson (1968) and Varnes (1958). Both authors use type of movement to establish the principal groups. The major distinction between the two classifications is the difference accorded to the status of flow movements; slope movements which are initiated by shear failure on distinct boundary shear surfaces but which subsequently achieve most of their translational movement by flowage. According to Varnes (1996), this dilemma depends on whether the principal interest rests with analyzing the conditions of failure or with treating the results of movement. Hutchison's (1968) classification appears to be related more closely to this first purpose. However, both Hutchinson's and Varnes' classifications have tended to converge over recent years, particularly in terminology. Varnes' scheme is perhaps easier to apply and requires less expertise to use than Hutchinson's classification which has a particular appeal to the engineer contemplating stability analysis (Crozier, 1986). The synthesis of these two classifications has continued.

Cruden and Varnes (1996) proposed modifications to the Varnes (1978) classification, which introduced a multi-dimensional taxonomic framework. The modified classification by Cruden and Varnes (1996) has been adopted in this study. It is based on the type of movement and the type of material (Table 3.1). A landslide is described by two nouns: the first describes the 
material and the second describes the type of movement (e.g. rock fall, debris flow). The names for the types of materials (rock, debris and earth) are unchanged from Varnes's (1978) classification. The movements have again been divided into five types: falls, topples, slides, spreads, and flows. The sixth type earlier proposed by Varnes (1978), complex landslides, has been dropped from the formal classification, although the term complex has been retained as a description of the style of activity of a landslide (Cruden and Varnes, 1996).

Table 3.1: Classification of slope movements (after Cruden and Varnes, 1996).

\begin{tabular}{|c|c|c|c|}
\hline \multirow{3}{*}{$\begin{array}{l}\text { Type of } \\
\text { Movement }\end{array}$} & \multicolumn{3}{|c|}{ Type of material } \\
\hline & \multirow[b]{2}{*}{$\begin{array}{l}\text { Bedrock } \\
\text { Rock }\end{array}$} & \multicolumn{2}{|c|}{ Engineering Soils } \\
\hline & & $\begin{array}{l}\text { Predominantly Coarse } \\
\text { Debris }\end{array}$ & $\begin{array}{l}\text { Predominantly Fine } \\
\text { Earth }\end{array}$ \\
\hline Fall & Rock fall & Debris fall & Earth fall \\
\hline Topple & Rock topple & Debris topple & Earth topple \\
\hline Slide & Rock slide & Debris slide & Earth slide \\
\hline Spread & Rock spread & Debris spread & Earth spread \\
\hline Flow & Rock flow & Debris flow & Earth flow \\
\hline Complex ${ }^{l}$ & $\begin{array}{l}\text { e.g., rock } \\
\text { avalanche }\end{array}$ & e.g. flow slide & e.g. slump-earthflow \\
\hline
\end{tabular}

${ }^{1}$ Dropped from the formal classification but the term has been retained as a description.

The name landslide can be more elaborate as more information about the movement becomes available (Cruden and Varnes, 1996). Hence, to build up the complete identification of the movement, descriptors are added in front of the two-noun classification using a preferred sequence of terms. Landslide can be classified based on the movement velocity as shown in Table 3.2 (Cruden and Varnes, 1996). Thiebes (2012) regarded this classification to be a second widely acknowledged classification of landslides. It ranges from extremely fast to extremely slow and expected damages and public (population) reactions are given.

Moreover, landslides can be distinguished regarding their state of activity. Cruden and Varnes (1996) established eight groups namely active, suspended, reactivated, inactive, dormant, abandoned, stabilized and relict mass movements. Furthermore, single, multiple and successive movements are distinguished. Other differentiations can be based on, for example, the water content of involved materials (Cruden and Varnes, 1996). 
Table 3.2: Landslide classification based on velocity scale and probable destructive significance (after Cruden and Varnes, 1996).

\begin{tabular}{|l|l|l|l|}
\hline Class & Description & Typical velocity & $\begin{array}{l}\text { Expected damages and population } \\
\text { reaction }\end{array}$ \\
\hline 1 & Extremely rapid & $>5 \mathrm{~m} / \mathrm{sec}$ & $\begin{array}{l}\text { Catastrophe of major violence; } \\
\text { buildings destroyed by impact of } \\
\text { displaced material; many deaths; } \\
\text { escape unlikely. }\end{array}$ \\
\hline 2 & Very rapid & $>3 \mathrm{~m} / \mathrm{min}$ & $\begin{array}{l}\text { Some lives lost; velocity too great to } \\
\text { permit all persons to escape }\end{array}$ \\
\hline 3 & Rapid & $>1.8 \mathrm{~m} / \mathrm{h}$ & $\begin{array}{l}\text { Escape evacuation possible; structures, } \\
\text { possessions, and equipment destroyed. }\end{array}$ \\
\hline 4 & Moderate & $>13 \mathrm{~m} / \mathrm{month}$ & $\begin{array}{l}\text { Some temporary and insensitive } \\
\text { structures can be temporarily } \\
\text { maintained be }\end{array}$ \\
\hline 5 & Slow & $>1.6 \mathrm{~m} /$ year & $\begin{array}{l}\text { Remedial construction can be } \\
\text { undertaken during movement; } \\
\text { insensitive structures can be } \\
\text { maintained with frequent maintenance } \\
\text { work if total movement is not large } \\
\text { during a particular acceleration phase }\end{array}$ \\
\hline 6 & Very slow & $>16 \mathrm{~mm} /$ year & $\begin{array}{l}\text { Some permanent structures } \\
\text { undamaged by movement instruments; }\end{array}$ \\
\hline 7 & Extremely slow & $<16 \mathrm{~mm} /$ year & $\begin{array}{l}\text { Imperceptible without instecautions } \\
\text { construction possible with precan }\end{array}$ \\
\hline
\end{tabular}

The term creep by Terzaghi (1950), which was used to describe continuous and imperceptible slow movements of the ground (Cruden and Varnes, 1996) was omitted due to various definition and interpretations. Cruden and Varnes (1996) proposed not to use the term creep and to replace it with the appropriate descriptors of their classification. However, the term creep may still be applied in a simple mechanical way to describe deformation that continues under constant stress (Cruden and Varnes, 1996).

\subsection{Type of landslide movements}

The kinematics of a landslide is how movement is distributed through the displaced mass and is one of the principal criteria for classifying landslides (Cruden and Varnes, 1996). In this subsection, five kinematically distinct types of landslide movements are described in the sequence falls, toppling, slides, spreads, and flows as shown in Figure 3.1 according to the classification of Cruden and Varnes (1996). 


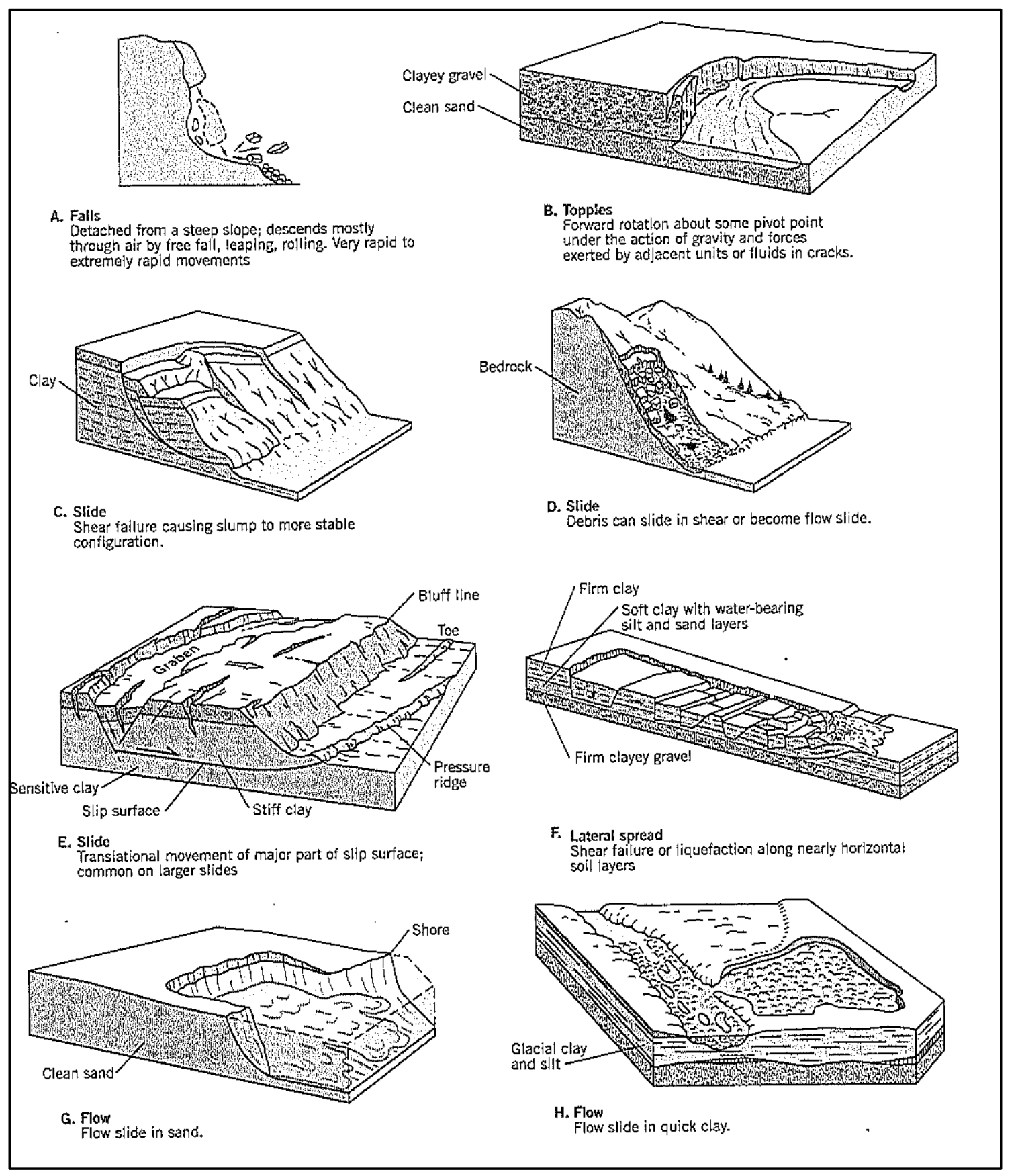

Figure 3.1: Types of landslide movements (after Varnes, 1978 and Cornforth, 2005).

\subsubsection{Falls}

Falls begin with the separation of earth material from a steep slope along a surface on which little or no shear displacement takes place. The material moves down mainly by bouncing, rolling and sliding and is also extremely rapid. Except when the displaced mass has been undercut, falling will be preceded by small sliding or toppling movements (Cruden and Varnes, 1996). 


\subsubsection{Toppling}

According to Cruden and Varnes (1996) "a topple is the forward rotation out of the slope of a mass of soil or rock about a point or axis below the centre of gravity of the displaced mass". This type of movement may result to falls or slides of the detached material, but depends on the geometry of the surface of separation, and the orientation and extent of the kinematically active discontinuities. Their rate of movement ranges from extremely slow to extremely rapid, and sometimes accelerating throughout the movement (Crude and Varnes, 1996).

\subsubsection{Slides}

Cruden and Varnes (1996) described slides as "a downslope movement of a soil or rock mass occurring dominantly on surfaces of rupture or on relatively thin zones of intense shear strain". The volume of displaced rock and/or soil enlarges from an area of local failure. Usually the initial signs of mass movement are crack in the original ground surface along which the main scarp of the slide form. The material may move beyond the toe of the surface of rupture covering the original ground surface of the slope (Cruden and Varnes, 1996).

Two following modes of sliding described below that are significant for stability analyses are namely rotational and translational slides (Cruden and Varnes, 1996):

i. Rotational slides move along a curved or concave surface of rapture. The dominant characteristic of the failed mass is a backward rotation. The common rotational sliding phenomenon involves a sliding surface with a spoon shape or a convex cylindrical shape. Rotational slides mainly occur in slopes made up of relatively homogeneous clays and shale deposits and also occur in slopes of granular material or closely jointed rocks, where pore water pressures are sufficiently high to cause a rotational rather than a shallow translational failure. Rotational failures also occur in slopes of highly altered and weathered rocks (Cruden and Varnes, 1996).

ii. Translational slides move along a planar or undulating surface of rupture and are generally shallower (Cruden and Varnes, 1996). As the detached mass continues to travel it may begin to disintegrate. The mass could then start to flow and become a debris flow rather than a slide. Translational sliding tends to follow structural discontinuities such as fault, joints and bedding surfaces (Cruden and Varnes, 1996). Translation slides on single planar discontinuities in rock slopes are called planar slides (Hoek and Bray, 1981). 
iii. Wedges slides result when a surface of rapture is formed by two discontinuities that cause the bounded rock mass to displace down the line of intersection of the discontinuities (Cruden and Varnes, 1996).

iv. Compound slides are defined as an intermediate between rotational and translational slides (Cruden and Varnes, 1996). These are characterized by markedly non-circular slip surfaces formed by a combination of a steep, curved or planar rear part and flatter sole. The shear surfaces have steep main scarps that may flatten with depth. Displacement along complexly curved surfaces of rupture usually requires internal deformation and shear along surfaces within the displaced material. Compound slides often point toward the presence of weak layer or the boundary between weathered and unweathered material (Cruden and Varnes, 1996).

\subsubsection{Spreads}

The term spread describes sudden movements on water bearing layers of sands or silt overlain by homogeneous clays (Terzaghi and Peck, 1948). According to Cruden and Varnes (1996), spread is defined as an "extension of cohesionless soil or rock mass combined with a general subsidence of the fractured mass of cohesive material into softer underlying material". The surface of rupture is not necessarily a surface of intense shearing. Two modes of spreading are distinguished by Cruden and Varnes (1996):

i. Block spreads which occur where a thick layer of rock overlies softer material; the rock layer may fracture and separate into strips. The underlying soft material is forced up the cracks and rates of movement are extremely slow.

ii. Liquefaction spreads which are formed in sensitive clays and silts that have lost their strength and have damage structures. Their movement is translational and often retrogressive, starting at a stream bank or a shoreline and extending away from these points.

\subsubsection{Flows}

Cruden and Varnes (1996) described a flow as a spatially continuous movement in which surfaces of shear are short-lived, closely spaced, and usually not preserved. This type of movement generally has a flow aspect or fluidity and occurs in unconsolidated materials. The flow rate can be low or high and the material can be saturated or drained. 


\subsection{General landslide triggering mechanisms}

Even though landslides can occur without the impact of external factors, their occurrence is generally linked to a triggering event (Thiebes, 2012). There are many factors that can act as triggers for landslides. The most common natural triggers are either related to geological events, such as seismic shaking due to volcanic eruptions or earthquakes, or hydrological events such as intense rainfall, rapid snow melt or water level changes in rivers or lakes at the foot of slopes (Wieczorek, 1996). In addition, human interaction in the form of loading or slope cutting can trigger landslide events. However, the most important trigger, in both shallow and deep-seated landslides is intense rainfall (Crosta and Frattini, 2008).

\subsubsection{Intense rainfall}

Storms that produce intense rainfall for periods as short as several hours or have a more moderate intensity lasting several days have triggered landslides (Cruden and Varnes, 1996). According to Wieczorek (1996), well documented studies have revealed a close relationship between rainfall intensity and activation of landslides. These studies show that shallow landslides in soils and weathered rock often are generated on steep slopes during the more intense parts of a storm, and thresholds of combined intensity and duration may be necessary to trigger them. However, such thresholds are regional, depending on local geologic, geomorphologic, and climatologic conditions. The rapid infiltration of rainfall, causing soil saturation and a temporary rise in pore-water pressures, is generally believed to be the mechanism by which most shallow landslides are generated during storms (Iverson, 2000). The Afghanistan landslide that occurred in the last week of April 2014 was the most recent example of a rainfall triggered landslide at the time of writing this dissertation. News bulletins e.g. www.cnn.com/2014/05/04/world/europe/afghanistan-landslide/ reported that over 2000 people died, and over 200 homes where buried by this landslide. The landslide literally turned the village into a mass grave.

\subsubsection{Earthquake shaking/ seismicity}

Strong ground shaking during earthquakes has triggered landslides in many different topographic and geological settings. Rock falls, soil slides, and rock slides from steep slopes, involving relatively thin or shallow disaggregated soils or rock, or both, have been the most 
abundant types of landslides triggered by historical earthquakes (Schuster and Kockelman, 1996).

The amount of landslide displacement during an earthquake is a critical factor in hazard assessment. A seismic analysis of earth dams was modified to calculate the displacement of individual landslides on the basis of records of strong ground shaking (Newmark 1965; Wilson and Keefer, 1983).

\subsubsection{Water-level change}

The sudden lowering of the water level (rapid drawdown) against a slope can trigger landslides in earth dams, along coastlines, and on the banks of lakes, reservoirs, canals, and rivers (Wieczorek, 1996). Rapid drawdown can occur when a river drops following a flood stage, the water level in a reservoir or canal is dropped suddenly, or the sea level drops following storm tide. Unless pore pressures within the slope adjacent to the falling water level can dissipate quickly, the slope is subjected to higher shear stresses and potential instability (Terzaghi, 1943).

Increases in groundwater levels on hill slopes following periods of prolonged above-normal precipitation or during the raising of water levels in rivers, lakes, reservoirs, and canals build up pore water pressure and reduce effective strength of saturated slope material and can trigger landslides. Rising groundwater levels can also accelerate landslide movement, as was observed at the Vajont (or Vaiont) Dam in Italy, where a slow moving landslide rapidly accelerated during the weeks following the initial filling of the reservoir (Lane, 1967)

\subsubsection{Volcanic eruption and rapid snowmelt}

Volcanic eruption and rapid snowmelt process may also trigger or cause landslides (Cruden and Varnes, 1996). However these processes are not relevant in the Southern Africa region of the study, hence they are not discussed further.

\subsection{Landslides in rock slopes}

The landslide that formed Lake Fundudzi occurred on a rock slope and this section and subsequent subsections present the mechanisms of rock slope failure and landslides in rock 
slopes. The basic mechanics of rock slope failure, the shear strength of discontinuities and the types of rock slope failures are explained.

\subsubsection{The role of discontinuities in rock slope failure}

Hard rock is generally too strong that failure can occur under gravity alone. Failure is possible if discontinuities permit for easy movement of discrete blocks (Goodman, 1980). Hoek and Bray (1981) concurred and stated that the stability of rock slope varies with inclination of discontinuity surfaces, such as faults, joints and bedding planes, within the rock mass. When these discontinuities are vertical or horizontal, simple sliding cannot take place and the slope failure will involve fracture of intact rock blocks as well as movement along some of the discontinuities. However, when the slope face at angles of between $30^{\circ}$ and $70^{\circ}$, simple sliding can occur than those with only horizontal and vertical discontinuities. Clearly, the presence or absence of discontinuities has a very important influence upon the stability of rock slopes and the detection of these geological features is one of the most critical parts of a rock slope stability investigation (Hoek and Bray, 1981).

\subsubsection{Causes of rock slope failure}

According to Giani (1992), the causes which determine sliding movement in a slope depend on phenomena which contribute to an increase in shear stress and/or a reduction of shear strength. These phenomena which contribute to a shear stress increase involve the toe, or the slope face weakening or the slope surcharging. The weakening of the toe or the slope could be due to undercutting by streams, waves, wetting and drying, frost action, natural subsidence and human activity such as civil excavations.

Hoek and Bray (1981) stated that several causes and conditions have an effect on the limit equilibrium state of a rock slope. These maybe be summarized as follows:

\section{a) Sliding due to gravitational loading}

Bell (1993) stated that the common force that tends to generate movements on slope is gravity. If the weight of the slope material increases, this results in an increase in the shearing stress leading to a decrease in the stability of a slope.

\section{b) The influence of pore water pressure}

Water pressure reduces the available shear resistance or effective shear strength on discontinuities. It is generally agreed that groundwater or pore water pressure 
constitutes the most important single cause. Also, water increase means an increase in the weight of the slope material or its bulk density, which can induce slope failure (Hoek and Bray, 1981). Giani (1992) stated that water filling discontinuities involves a lowering of stability conditions for natural or artificial slopes.

\section{c) The effective stress law}

The normal stress $\sigma$ acting across the failure surface is reduced to the effective stress ( $\sigma$ - u) by the water pressure $u$. The relationship between shear strength and normal strength is defined by equation 3.1 :

$$
\tau=\mathbf{c}+(\boldsymbol{\sigma}-\mathbf{u}) \tan \phi
$$

Where $\tau$ is shear strength, $\mathrm{c}$ is cohesion, $\sigma$ is normal stress, $\mathrm{u}$ is pore water pressure and $\phi$ is angle of internal friction.

In most hard rocks, the cohesive and frictional properties (i.e. $\mathrm{c}$ and $\phi$ respectively) of the materials are not significantly altered by the presence of water and hence, reduction in shear strength of these materials is due, almost entirely to the reduction of normal stress across failure surface. Consequently, it is water pressure rather than moisture content which is important in defining the strength characteristics of hard rocks (Hoek and Bray, 1981).

\section{d) The effect of water pressure in a tension crack}

The water pressure in the tension crack increases linearly with depth and a total force $\mathrm{V}$, due to this water pressure acting on the rear face of the block, acts down the inclined plane. This water pressure distribution results in an uplift force, $\mathrm{U}$, which reduces the normal force acting across this surface (Hoek and Bray, 1981).

The shear strength characteristics and unit weight of intact rock determine the stability conditions of a homogeneous slope. As the intact rock shear failure envelope is nonlinear, the strength features depend on the applied normal stress level (Hoek and Bray, 1981).

\subsection{Modes of failure for rock slopes}

Goodman (1980) stated that failure involving movement of rock block on discontinuities combines one or more of the three basic modes of failure plane failure, wedge failure and toppling failure as shown in Figure 3.2. Hoek and Bray (1981) also stated these three modes of failure for rock slope stability problems as primary failure mechanisms, including circular failure as failure in soil or fragmented rock. They further stated that these primary failure mechanisms are the three modes of failure in which the "Factor of Safety" of a slope can be 
calculated. The three modes of failure are described below in the context of rock slope failure mechanisms and not intended at repeating definitions or descriptions of general landslide types of movement given in Section 3.3 of this chapter.

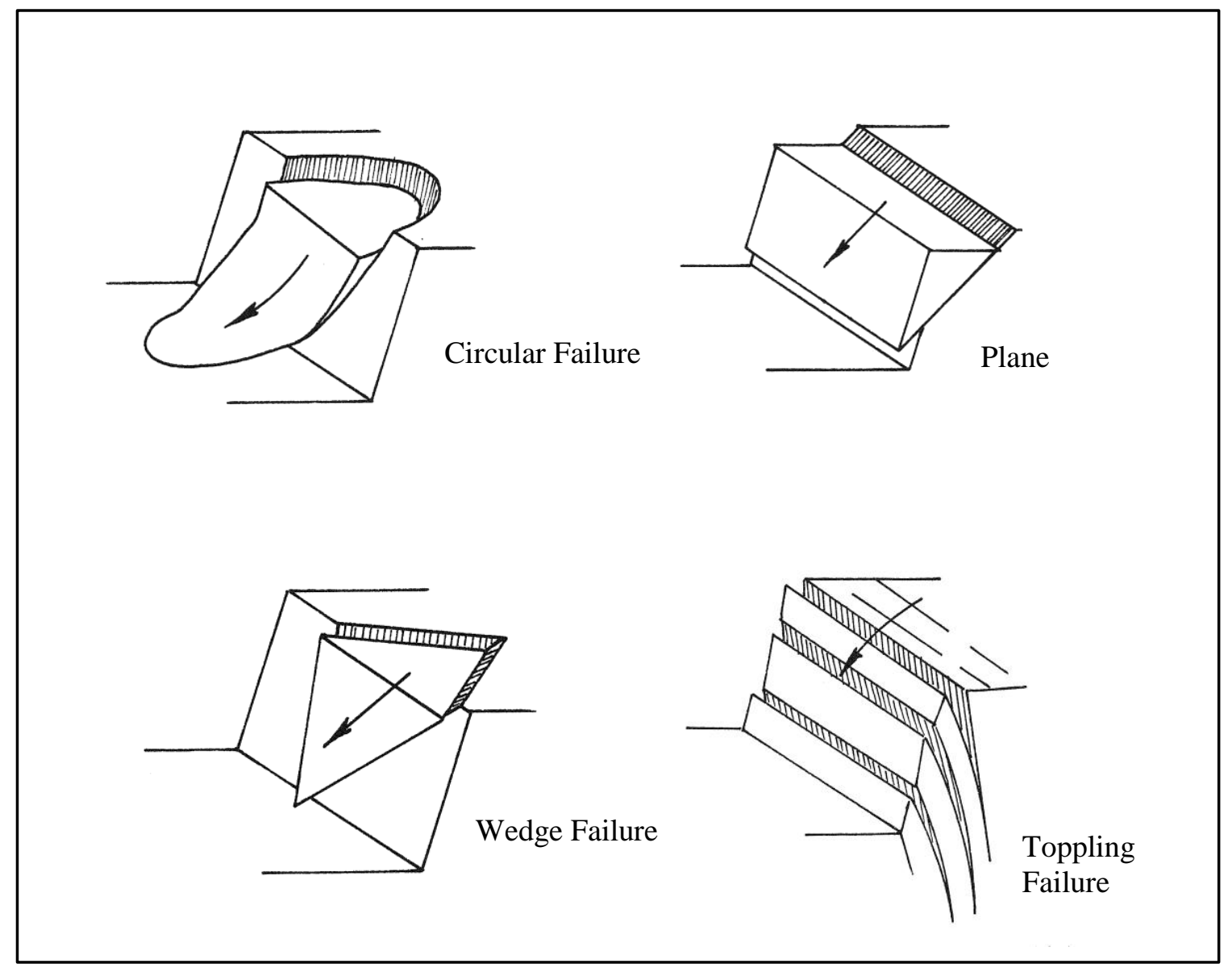

Figure 3.2: Modes of rock slope failure (after Hoek and Bray, 1981).

\subsubsection{Circular failure}

According to Hoek and Bray (1981), circular failure surface is often related to soft material like soils, highly altered, weathered and closely jointed rock mass. This is where strongly defined structural pattern e.g. bedding and joints no longer exists and the failure surface is free to find the line of least resistance through the slope. The slope stability theories for circular failure are based on this failure surface shape.

Occurrence of this type of failure arises when the individual particles in a soil or rock mass are very small as compared with the size of the slope and when the particles are not interlocked as a result of their shape. The mass behave as a "soil" and large waste dump will occur in a circular mode (Hoek and Bray, 1981). 
For the analysis and deriving the stability charts the following assumptions are made:

a) The material forming the slope is assumed to be homogenous, i.e. its mechanical properties do not vary with direction of loading.

b) The shear strength of the material is characterized by a cohesion c, and a friction angle $\phi$, which are related by the equation:

$$
\tau=c+\sigma \cdot \operatorname{Tan} \phi .
$$

c) Failure is assumed to occur on a circular failure surface which passes through the toe of the slope.

d) A vertical tension crack is assumed to occur in the upper surface or in the face of the slope.

e) The locations of the tension crack and of the failure surface are such that the factor of safety, F of the slope is a minimum for the slope geometry and groundwater conditions considered.

f) A range of groundwater conditions, varying from a dry slope to fully saturated slope under heavy recharge, are considered in the analysis.

Calculation of the factor of safety $(\mathrm{F})$ is defined as

$$
\mathbf{F}=\frac{\text { Shear strength available to resist sliding }}{\text { Shear stress mobilised along failure surface }}
$$

And when rearranged:

$$
\tau_{m b}=\frac{\mathrm{C}}{\mathrm{F}}+\frac{\sigma \cdot \tan \phi}{\mathrm{F}}
$$

Where $\tau_{\mathrm{mb}}$ is the shear stress mobilized along the failure surface.

\subsubsection{Plane failure}

Plane failure is a rock slope failure resulting from sliding on a single planar surface dipping into the excavation (Hoek and Bray, 1981). Selby (1982) suggested that the movement is rapid and deformation of the rock mass occurs. According to Goodman (1980), a plane failure occurs under gravity alone when a rock block rests on an inclined weakness plane that "daylight" into free space.

Hoek and Bray (1981) stated that the general conditions for plane failure are as follows; 
1. The plane on which sliding occur must strike parallel or really parallel (i.e. within approximately $+/-20^{\circ}$ ) to the slope face.

2. The failure plane must "daylight" in the slope face. The meaning of this is that the dip of the failure plane must be smaller than the dip of the slope face, $\psi$.

3. The dip of the failure plane or discontinuity must be greater than the angle of friction, $\phi$, of this failure plane.

4. The release surfaces which give negligible resistance to sliding must be present in the rock mass to define the lateral boundaries of the slide.

Two slope geometry cases need to be considered in the analysis of plane failure. These are,

a) a slope having a tension crack in its upper surface (Figure 3.3a), and

b) a slope with a tension crack in its face (Figure 3.3b).

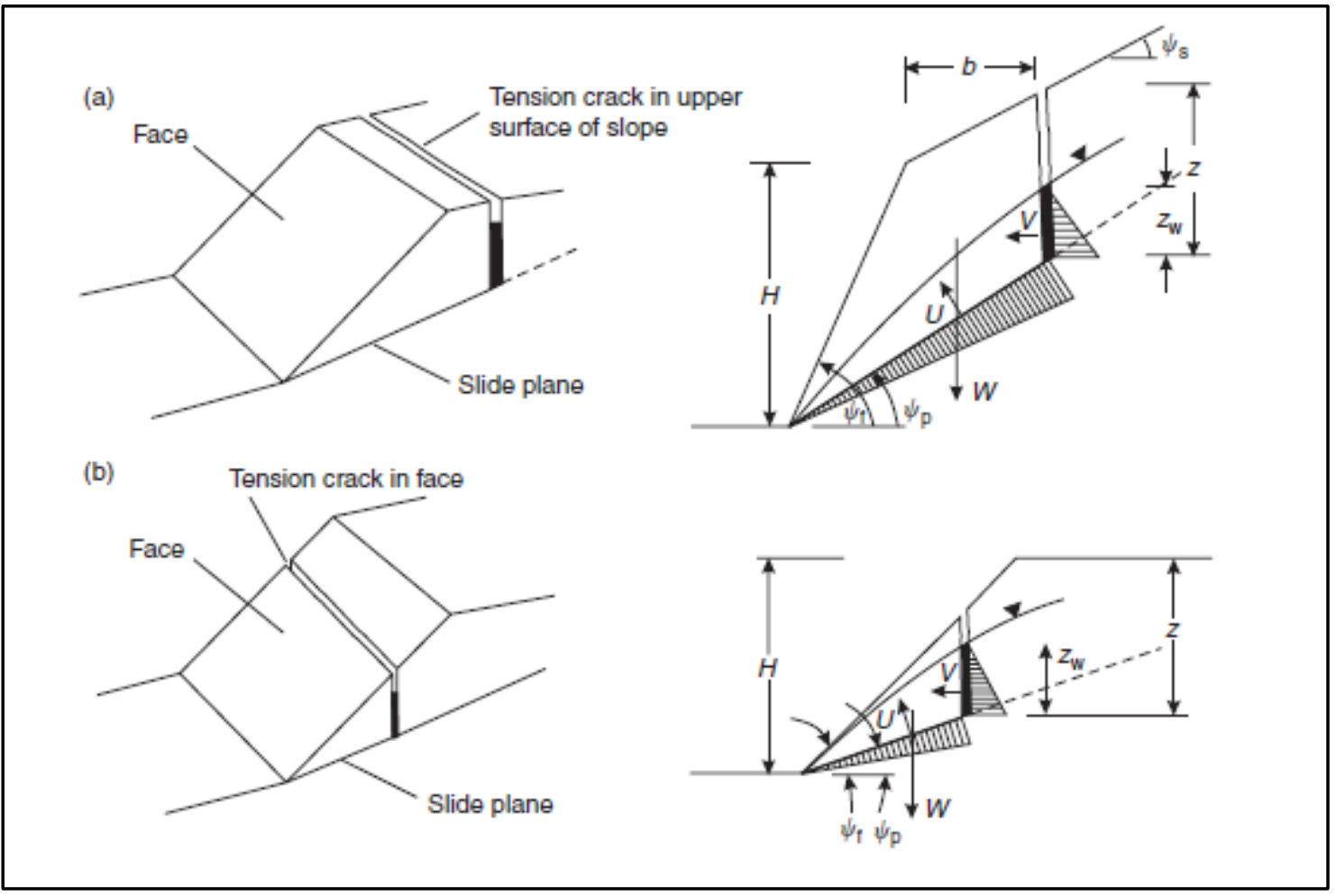

Figure 3.3: Geometries of plane slope failure: (a) tension crack in the upper slope; (b) tension crack in the face (after Willie and Mah, 2005). 
The transition from one case to another occurs when the tension crack coincides with the slopes crest, i.e. where,

$$
\mathrm{Z} / \mathrm{H}_{\mathrm{H}}=\left(1-\cot \psi_{f} \cdot \tan \psi_{p}\right)
$$

Where, $\mathrm{Z}=$ the depth of the tension crack, $\mathrm{H}=$ the slope height, $\boldsymbol{\psi}_{f}=$ the slope angle and $\boldsymbol{\psi}_{\boldsymbol{p}}=$ the dip of the sliding plane.

For the analysis, the following assumptions are made (Willie and Mah, 2005):

a) Both sliding surface and tension crack strike parallel to the slope surface.

b) The tension crack is vertical and is filled with water to a depth, $Z_{w}$.

c) Water enters the sliding surface along the base of the tension crack and seeps along the sliding surface, escaping at atmospheric pressure where the sliding surface daylights in the slope face.

d) The forces $\mathrm{W}$ (the weight of the skidding block), $\mathrm{U}$ (uplift force due to water pressure on the sliding surface) and $\mathrm{V}$ (force due to water pressure in the tension crack) all act through the centroid of the sliding mass.

e) The shear strength of the sliding surface is defined by cohesion $c$ and a friction angle $\phi$ which are related by the equation, $\boldsymbol{\tau}=\mathbf{c}+\boldsymbol{\sigma} \cdot \tan \phi$.

f) A slice of unit thickness is considered and it is assumed that release surfaces are present so that there is no resistance to sliding at the lateral boundaries of the failure.

The value of $\mathrm{F}$ is calculated in the same way as that of block on an inclined plane. It is given by the total force resisting sliding to the total force tending to induce sliding, as

$$
\mathrm{F}=\frac{\mathrm{cA}+\left(\mathrm{W} \cdot \operatorname{Cos} \Psi_{\mathrm{p}}-\mathrm{U}-\mathrm{V} \cdot \operatorname{Sin} \psi_{\mathrm{p}}\right) \operatorname{Tan} \phi}{\mathrm{W} \cdot \operatorname{Sin} \psi_{\mathrm{p}}+\mathrm{V} \cdot \operatorname{Cos} \Psi_{\mathrm{p}}}
$$

where,

$$
\begin{aligned}
A & =(H-z) \cdot \operatorname{Cosec} \Psi_{p} \\
U & =\frac{1}{2} \gamma_{w} \cdot Z w(H-z) \cdot \operatorname{Cosec} \psi_{p} \\
V & =\frac{1}{2} \gamma_{w} \cdot Z_{w}^{2}
\end{aligned}
$$

Where, $\boldsymbol{\gamma}_{\mathrm{w}}$ is the density of water.

For the tension crack in the upper slope surface,

$$
W=\frac{1}{2} \gamma H^{2}\left\{\left(1-(z / h)^{2}\right) \operatorname{Cot} \Psi_{p}-\operatorname{Cot} \Psi_{f}\right\}
$$


And for tension in the slope face,

$$
\mathrm{W}=\frac{1}{2} \gamma \mathrm{H}^{2}\left\{\left(1-(\mathrm{z} / \mathrm{h})^{2}\right)\left(\operatorname{Cot} \Psi_{\mathrm{p}} \cdot \operatorname{Tan} \Psi_{\mathrm{f}}-1\right)\right\}
$$

Where the geometry of the slope and the depth of water in the tension crack are known, the solution of the equation for $\mathrm{F}$ is relatively simple. However, if a variety of groundwater conditions have been considered then repeatedly solving the equation becomes tedious. Graphical plots, or stability charts in Hoek and Bray (1981), may then be used to solve components of these equations.

\subsubsection{Wedge failure}

Wedge failure is a failure resulting when two discontinuities strike obliquely across the slope face and their line of intersection daylights in the slope face. The wedge of rock resting on these discontinuities will slide down the line of intersection, provided that the inclination of this line is significantly greater than the angle of friction (Hoek and Bray, 1981). Goodman (1980) stated that wedge failure may occur when two planes of weakness intersect to define a tetrahedral block. Sliding can occur without any topographic or structural release features if the line of intersection of two discontinuities daylights into the excavation (Goodman, 1980).

For sliding to occur (Willie and Mah, 2005):

a) the plunge of the line of intersection of two discontinuities must exceed the angle of friction $\phi$, for the rock surface, and

b) the line of intersection of two discontinuities must daylight in the slope face.

Figure 3.4 depicts wedge failure geometry and the basic mechanics of sliding. The flatter of the two planes is called Plane A while the steeper plane is called Plane B. 


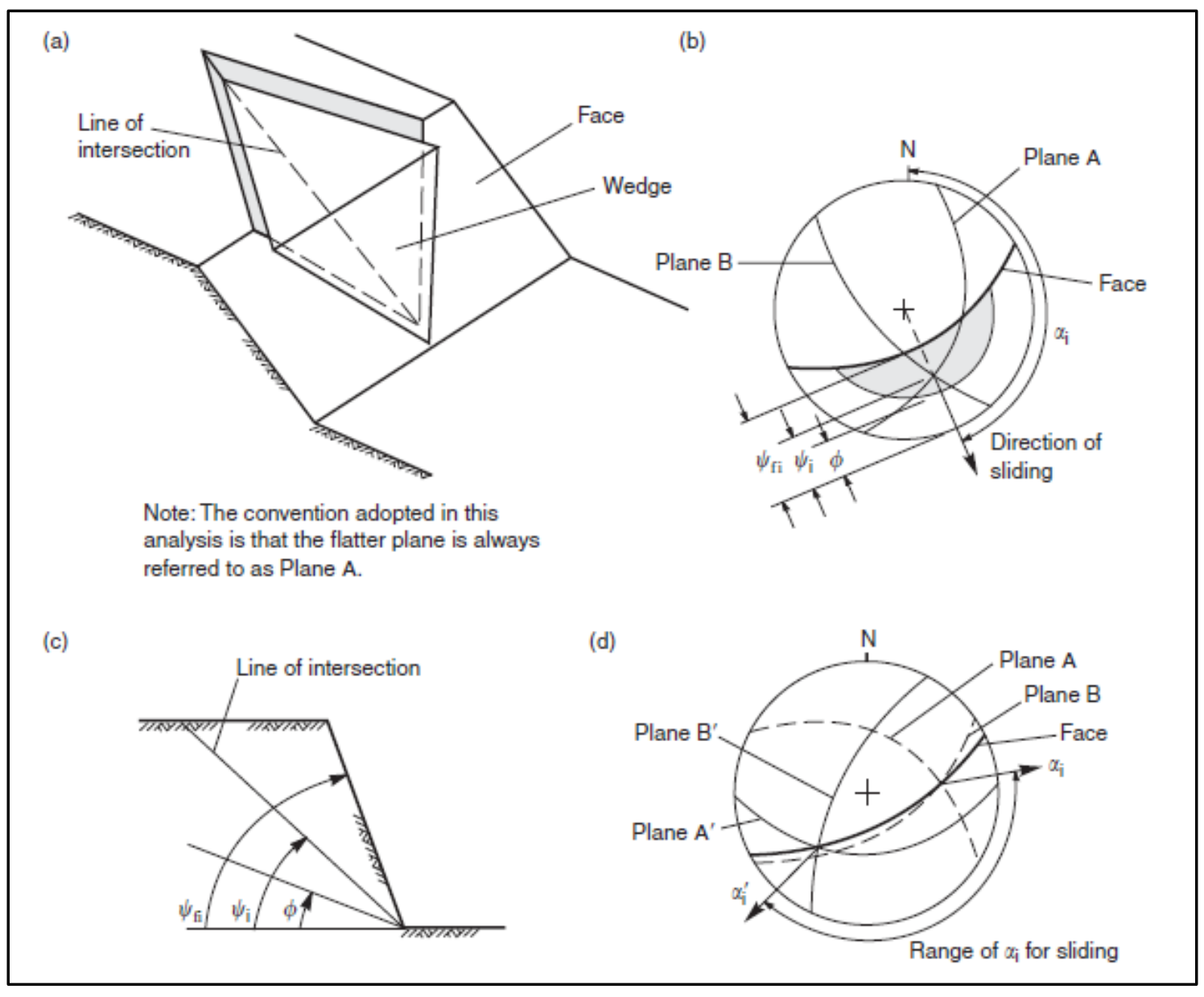

Figure 3.4: Wedge failure geometry (after Willie and Mah, 2005).

The value of $\mathrm{F}$ for wedge failure defined in Figure 3.5, assuming that sliding is resisted by friction only, and that the friction angle $\phi$ is the same for both planes, is given by:

$$
\mathbf{F}=\frac{\left(R_{A}+R_{B}\right) \operatorname{Tan}_{\phi}}{\operatorname{W.Sin} \Psi_{\mathrm{i}}}
$$

Where $R_{A}$ and $R_{B}$ are the normal reactions provided by planes $A$ and $B$ (Figure 3.5) and the component of the weight acting down the line of intersection is $\left(\mathbf{W} . \operatorname{Sin} \Psi_{\mathbf{i}}\right)$.

The forces $\mathrm{R}_{\mathrm{A}}$ and $\mathrm{R}_{\mathrm{B}}$ are found by resolving them into components normal and parallel to the direction along the line of intersection as follows: 


$$
\begin{aligned}
& \mathbf{R}_{\mathrm{A}} \operatorname{Sin}\left(\beta-\frac{1}{2} \xi\right)=\mathbf{R}_{\mathrm{B}} \sin \left(\beta-\frac{1}{2} \xi\right) \\
& \mathbf{R}_{\mathrm{A}} \cos \left(\beta-\frac{1}{2} \xi\right)-\mathbf{R}_{\mathrm{B}} \cos \left(\beta+\frac{1}{2} \xi\right)=\mathrm{W} \cos \psi_{\mathrm{i}}
\end{aligned}
$$

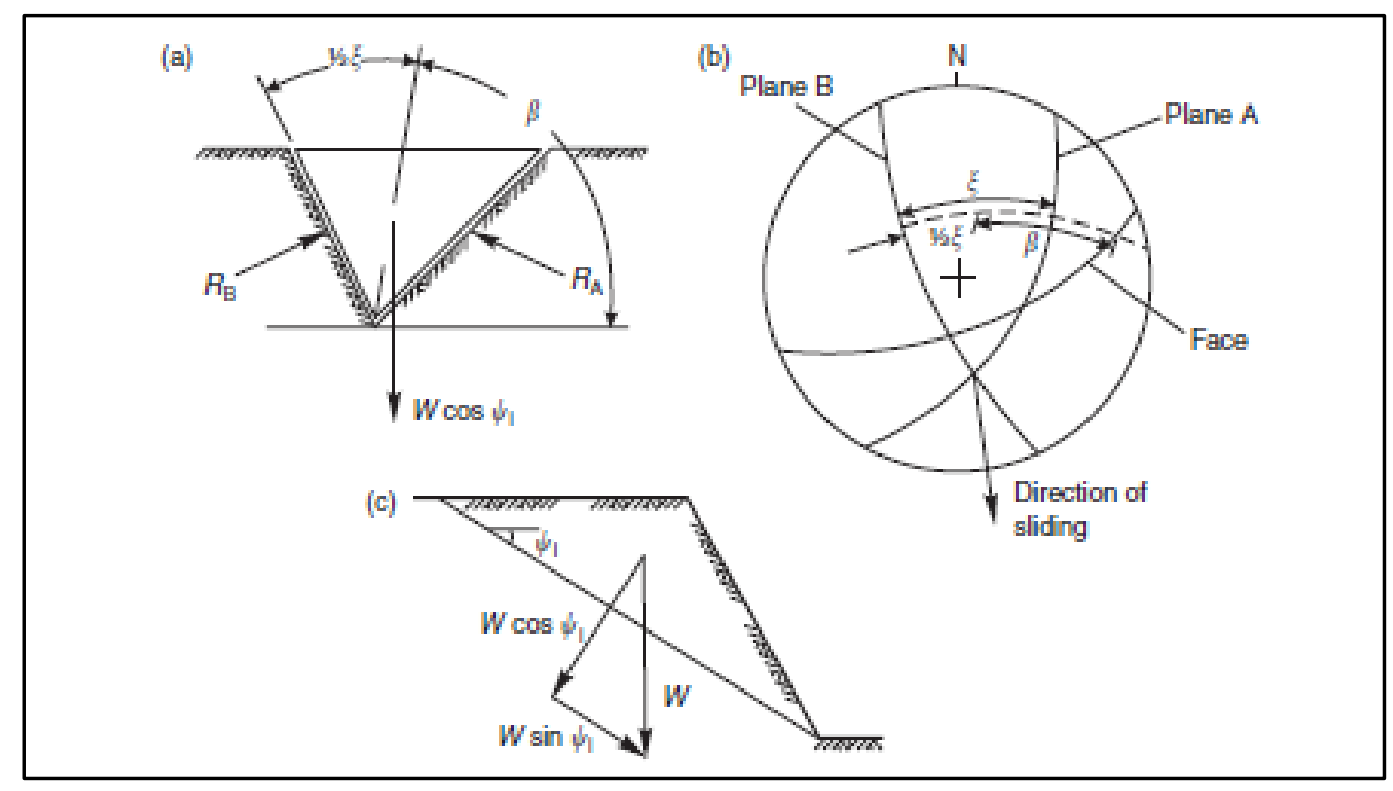

Figure 3.5: Resolution of forces to calculate factor of safety for wedge: (a) view of wedge looking at face showing definition of angles $\beta$ and $\xi$, and reactions on sliding planes RA and $\mathrm{RB}$; (b) stereonet showing measurement of angles $\beta$ and $\xi$; (c) cross-section of wedge showing resolution of wedge weight $\mathrm{W}$ (after Willie and Mah, 2005).

Where the angles $\xi$ and $\beta$ are defined in Figure 3.5 (a), Angles $\xi$ and $\beta$ are measured on the great circle containing the pole to the line of intersection and the poles of the two slide planes. In order to meet the conditions for equilibrium, the normal components of the reactions are equal (Equation 3.14), and the sum of parallel components aquals the components of the weight acting down the line of intersection (Equation 3.15).

The values of $R_{A}$ and $R_{B}$ are found from Equations (3.14 and 3.15) by solving and adding as follows:

$$
\begin{aligned}
& \mathbf{R}_{\mathrm{A}}+\mathbf{R}_{\mathrm{B}}=\frac{W \cos \psi_{i} \sin \beta}{\sin (\xi / 2)} \\
& \text { Hence } \mathbf{F}=\frac{\sin \beta}{\sin \left(\frac{\xi}{2}\right)} \cdot \frac{\tan \phi}{\tan \psi_{i}} \\
& \text { In other words, } \mathbf{F}_{\mathrm{w}}=\mathbf{K} \mathbf{F}_{\mathrm{p}}
\end{aligned}
$$

where, $F_{w}$ is $F$ of a wedge supported by friction only, $F_{p}$ is $F$ of safety of a plane failure in which the slope face is inclined at $\psi_{\mathrm{fi}}$ and the failure plane is inclined at $\psi_{\mathrm{i}}$, and $\mathrm{K}$ is the wedge 
factor which depends upon the included angle of the wedge and upon the angle of tilt of the wedge (Hoek and Bray, 1981).

\subsubsection{Toppling Failure}

Toppling failure involves rotation or overturning of columns or blocks of rock about some fixed base (Hoek and Bray, 1981). Goodman (1980) stated that, each layer tending to bend downhill under its own weight transfers force downslope. If the toe of the slope is allowed to slide or overturn, flexural cracks will form in the layers above, liberating a large mass of rock. If there are frequent cross joints, the layers can overturn as rigid columns rather than having to fail in flexure. According to Selby (1993), toppling is particularly common in slates and schists, but also occurs in thinly bedded sedimentary rock and in columnar jointed igneous rock such as basalts and dolomite.

There are three primary different types of toppling failures (Hoek and Bray, 1981):

a) Flexural toppling; continuous columns of the rock, which are separated by welldeveloped steeply dipping discontinuities, break in flexure as they bend forward. Undermining or erosion of the toe of the slope allows the toppling process to start and it retrogresses backwards into the rock mass with the formation of deep, wide tension crack.

b) Block toppling; occurs when individual columns of hard rock are divided by widely spaced orthogonal joints.

c) Block-flexure toppling; this type of failure is characterized by pseudo-continuous flexure along long columns which are divided by numerous cross joints.

The calculation of $\mathrm{F}$ for toppling failure is given by:

$$
\mathbf{F}=\frac{\operatorname{Tan} \phi_{\text {available }}}{\operatorname{Tan} \phi_{\text {required }}}
$$

where,

Tan $\phi_{\text {available }}$ is the tangent of the friction angle believed to apply to the rock layers and Tan $\phi_{\text {required }}$ is the tangent of the friction angle required for equilibrium with a given support force $\mathrm{T}$. 


\subsection{The principle of shear strength in rock slope failure}

Apart from the geometry of the rock mass, the next most important factor when analysing the stability of a rock slope, is the shear strength of the potential failure surfaces. In rock slope design, most often the rock is assumed to be a Coulomb material in which the shear strength of the sliding surface is expressed in terms of the cohesion $(c)$ and the friction angle $(\phi)$ (Hoek and Bray, 1981).

The friction angle and cohesion are best defined by the plot of shear stress versus normal stress as shown in Figure 3.6. The shear stress $\tau$ required to cause sliding increases with increasing normal stress $\sigma$. The slope of the line relating shear to normal stress defines the angle of friction, $\phi$ (Hoek and Bray, 1981).

If the peak shear strength values from tests carried out at different normal stress levels are plotted, a relationship shown in Figure 3.6(c) is obtained; this is termed a Mohr diagram (Mohr, 1900). When the residual shear stress values at each applied normal stress are plotted on the Mohr diagram, the residual shear strength line is obtained as shown on Figure 3.6(d) (Willie and Mah, 2005)

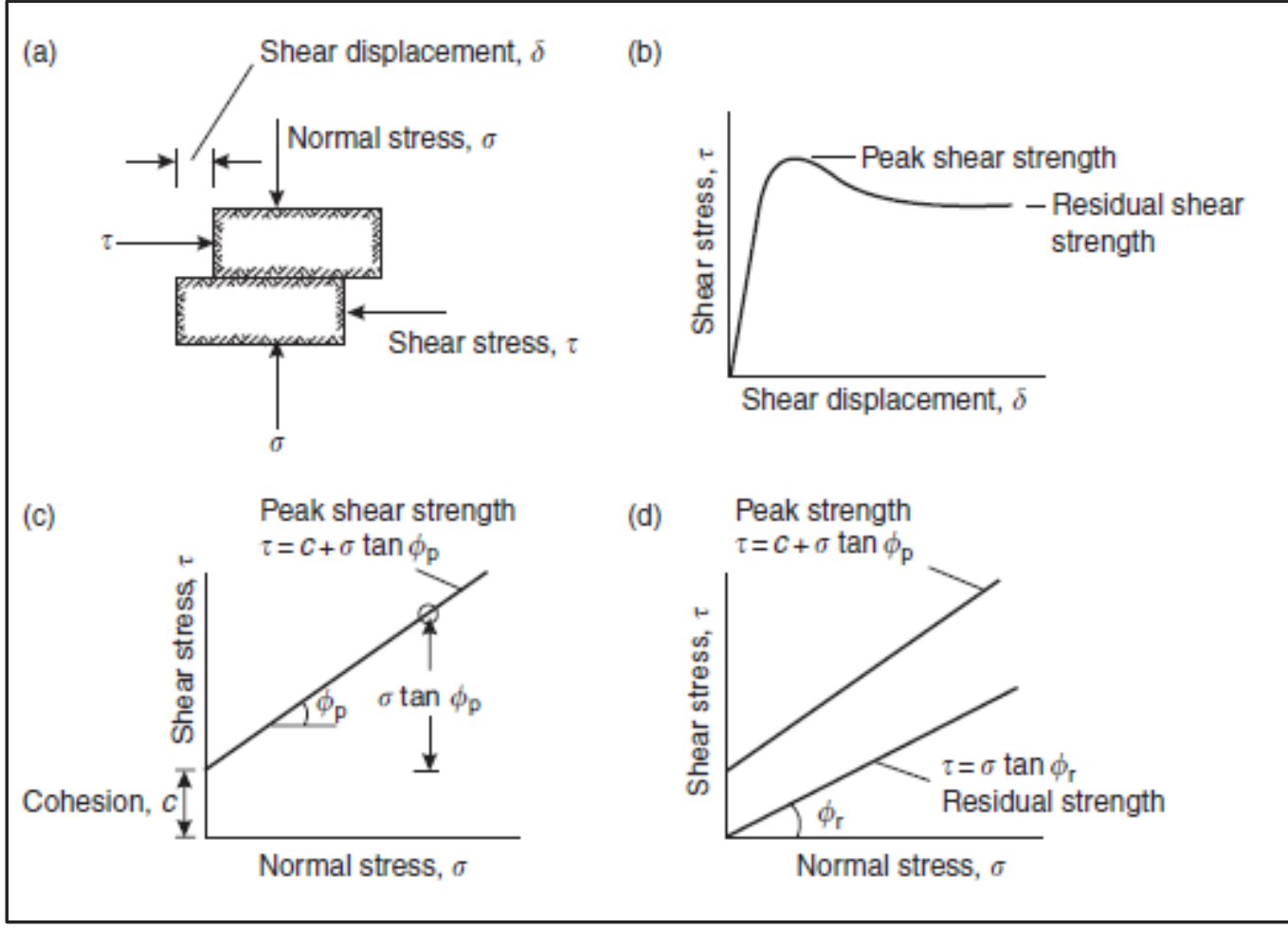

Figure 3.6: Definition of shear strength of discontinuity surface; (a) shear test of discontinuity; (b) plot of shear displacement vs shear stress; (c) Mohr plot of peak strength; (d) Mohr plot of peak and residual strength (after Willie and Mah, 2005). 
Typical values for the angle of friction and cohesion which are found in shear tests on a range of rocks are listed in Table 3.3 together with unit weights for these materials.

The published Hoek and Bray (1981) values for shear strength, reveal that there is a good relationship between the intact rock strength e.g. soft and hard sedimentary rock and shear strength parameters (Table 3.3).

Table 3.3: Typical shear strength and unit weight rock values (after Hoek and Bray, 1981).

\begin{tabular}{|l|c|c|c|}
\hline Rock type & $\begin{array}{c}\text { Dry unit weight } \\
\left(\mathbf{k N} / \mathbf{m}^{\mathbf{3}}\right)\end{array}$ & $\begin{array}{c}\text { Cohesion } \\
(\mathbf{M P a})\end{array}$ & $\begin{array}{c}\text { Friction angle } \\
\left({ }^{\circ}\right)\end{array}$ \\
\hline Hard igneous rocks: granite, basalt, porphyry & $25-30$ & $35-55$ & $35-45$ \\
\hline Metamorphic rocks: quartzite, gneiss, slate & $25-28$ & $20-40$ & $30-40$ \\
\hline $\begin{array}{l}\text { Hard sedimentary rocks: limestone, dolomite, } \\
\text { sandstone }\end{array}$ & $23-28$ & $10-30$ & $35-45$ \\
\hline Soft sedimentary rocks: sandstone, coal, chalk, shale & $17-23$ & $1-20$ & $25-35$ \\
\hline
\end{tabular}

\subsubsection{Criterion (models) for shear strength of discontinuities}

There are several criteria (models) that have been developed for determining the shear strength for rock discontinuities and they are based on using frictional angle. Those that were advocated by Hoek and Bray (1981) include, Mohr-Coulomb criterion (Mohr, 1900), Patton (1966) criterion, Barton-Bandis (1990) criterion and Ladanyi and Archambault (1970) criterion. The most commonly used failure criterion to date is the empirical Mohr-Coulomb liner law which postulates that the shear strength of discontinuities consist of a normal stress-independent component which is 'cohesion' and a normal stress-dependent frictional component. The MohrCoulomb criterion ignores the contribution of surface roughness to available shear. However, Paton (1966), Ladanyi and Archambault (1970), and Barton (1973) shear strength criterion takes into consideration the contribution of surface roughness (Hoek and Bray, 1981).

\section{i. Mohr-Coulomb Criterion}

The criterion assumed a bedding plane that is absolutely planar with no surface undulation or roughness (Goodman, 1980). According to the Mohr-Coulomb criterion the shear strength $(\tau)$ is given by:

$$
\tau=\mathbf{c}+\boldsymbol{\sigma} \operatorname{Tan} \phi
$$


Where $\mathrm{c}$ is cohesion, $\sigma$ is normal stress and $\phi$ is angle of friction.

When water is present, the shear strength is reduced due to the reduction of the effective normal stress as a result of water pressure. The equation 3.20 then becomes:

$$
\boldsymbol{\tau}=\mathbf{c}+(\boldsymbol{\sigma}-\boldsymbol{\mu}) \operatorname{Tan} \phi
$$

Hoek and Bray (1981) also stated that the presence of water would be more influential in clay filled discontinuities than discontinuities filled with sand and gravel because water reduces cohesion in clay soils.

\section{ii. Hoek-Brown Model, Empirical Failure Criterion}

Hoek and Brown criterion was introduced to provide input data for the analyses required for the design of underground excavation in hard rock (Hoek et al., 2002).

\section{iii. Patton Criterion}

Patton (1966) found that the inclination of the bedding plane trace was approximately equal to the sum of the average angle $\mathrm{i}$ and the basic friction angle $\phi$ found from laboratory tests on planar surfaces (i.e. saw cut sample tested using a tilt test) Figure 3.7.

$$
\boldsymbol{\tau}=\boldsymbol{\sigma} \operatorname{Tan}(\phi+\mathbf{i})
$$
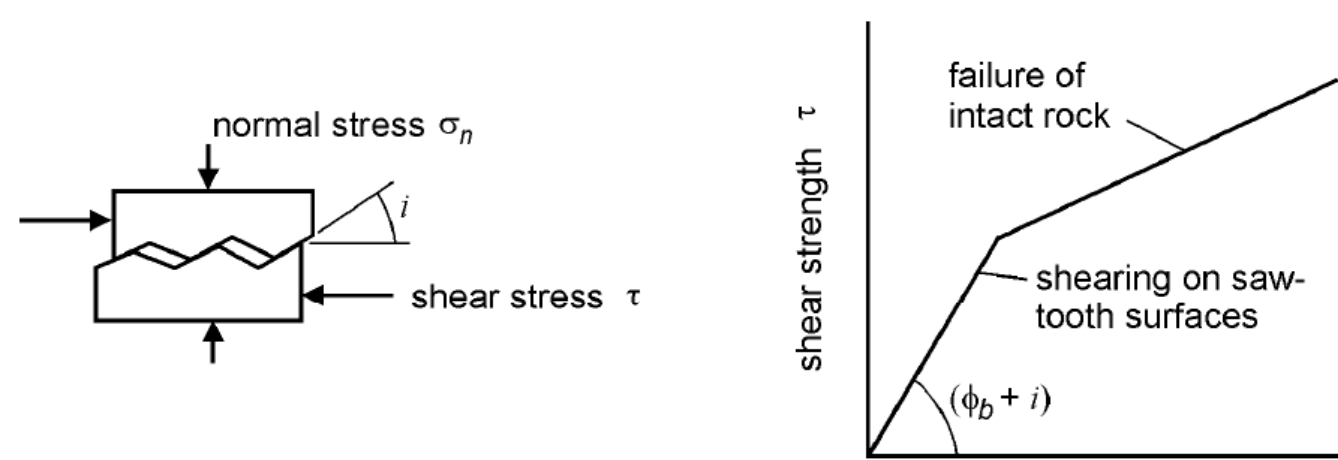

normal stress $\sigma_{n}$

Figure 3.7: Patton's experiment on the shear strength of saw-tooth specimens (after Hoek, 2007). 


\section{iv. Ladanyi and Archamault Criterion}

The criterion considered intact material strength, amount of intact shear, degree of interlocking, dilation and residual friction angle. Their proposed criterion demonstrated the curvilinear nature of shear strength envelopes for discontinuous material (Ladanyi and Archamault, 1970).

\section{v. Barton-Bandis Criterion}

Barton (1973) suggested a different approach to solve the problem of predicting the shear strength of rough joints. The approach was derived from finding after tests and observations on artificially produced rough "joints". Subsequently Barton and Choubey (1977) derived an empirical equation as follows:

$$
\tau=\sigma_{\mathrm{n}} \tan \left[\phi_{\mathrm{b}}+\mathrm{JRC} \cdot \log 10\left(\mathrm{JCS} / \sigma_{\mathrm{n}}\right)\right]
$$

Where, JRC $=$ joint roughness coefficient, JCS $=$ joint compressive strength, $\tau=$ shear strength along the rock joint, $\sigma_{\mathrm{n}}=$ normal stress acting on the surface of the rock joint, $\phi_{\mathrm{b}}=$ angle of frictional sliding of the planar surface (basic friction angle).

a) The joint roughness coefficient (JRC) can be empirically determined by comparing profiles of rock surface roughness with 10 standardized rock roughness profiles in Figure 3.8. According to Kliche (1999) this method has been supported by the International Society of Rock Mechanics (Brown 1981). Another way of calculating JRC is by back calculation (Equation 3.5) when all other parameters in the equation are known.

$$
J R C=\left[\left(\arctan \frac{\tau}{\sigma_{n}}\right) \div\left[\log \left(\frac{J C S}{\sigma_{n}}\right)\right]\right]
$$

b) The rock joint compressive strength (JCS) is the same as or equal to the uniaxial compressive strength of the rock if the joint is unweathered. The value of JCS can be obtained from the Deer-Miller (1966) graph showing its dependence on the rock strength found from the Schmidt hammer measurements.

c) The angle of frictional sliding of the planar surface (basic friction angle) i.e. $\phi_{b}$ : Barton and Choubey (1977) suggested that the tilt and push tests provided a more reliable means of estimating the joint roughness coefficient due to errors that tend to arise in the profile comparison method.

The Barton-Bandis criterion for rock joint strength and deformability (Barton and Bandis, 1990) which is based on Barton and Choubey (1977) equations was used in the slope stability back 
analyses of this study to determine the geotechnical conditions that could have led to a factor of safety equal to 1.00 at the time of failure of the landslide at Lake Fundudzi.

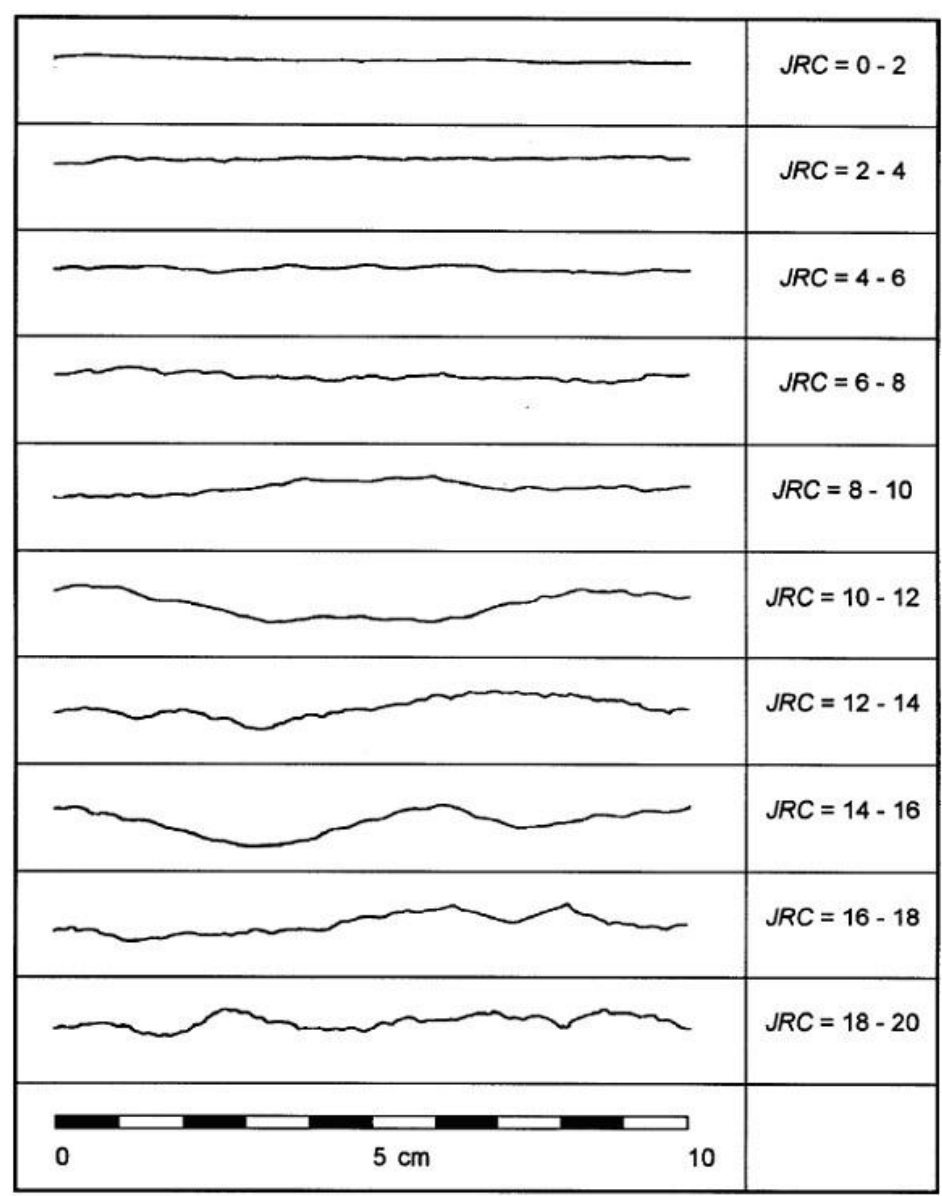

Figure 3.8: The ten joint roughness profiles showing the typical range of JRC (after Barton and Choubey, 1977).

\subsection{Description of the landslide and Lake Fundudzi}

The valley of Lake Fundudzi runs roughly NE- SW. It is long and narrow with high fringing mountains and on the northern side (slope failure plane) the valley walls are steeper i.e. greater than $60^{\circ}$. On the southern side, with the exception of the mountain on the west of the Mutale River, the outlines are softer. The eastern end is dammed by a landslide of immense proportions which has blocked the valley where a projecting spur (lateral ridge projecting from the mountain) from the south had narrowed it. Beyond this barricade the valley is broad and flat and extends as far as the eye can see (Janisch, 1931). 
The shore of the lake is steep and rocky, made of angular joint blocks and loose rubble lying at the angle of rest and marginally stable needing only a trigger to set into motion.

The landslide which piled up its largest blocks against the highest part of the spur consists of great angular blocks of sandstone, many of them exceeding $7 \mathrm{~m}$ in diameter, lying randomly and naturally with great spaces between them, so that climbing is extremely difficult. The landslide has obviously come from the northern mountain side where a great block of rock has slipped from between two high buttresses (release surfaces) which are about $500 \mathrm{~m}$ apart. The scar (failure surface) extends back for about $230 \mathrm{~m}$ from the faces of very steep buttresses, leaving a bare and steep rock slope above the accumulation of rock debris (Figure 3.9).

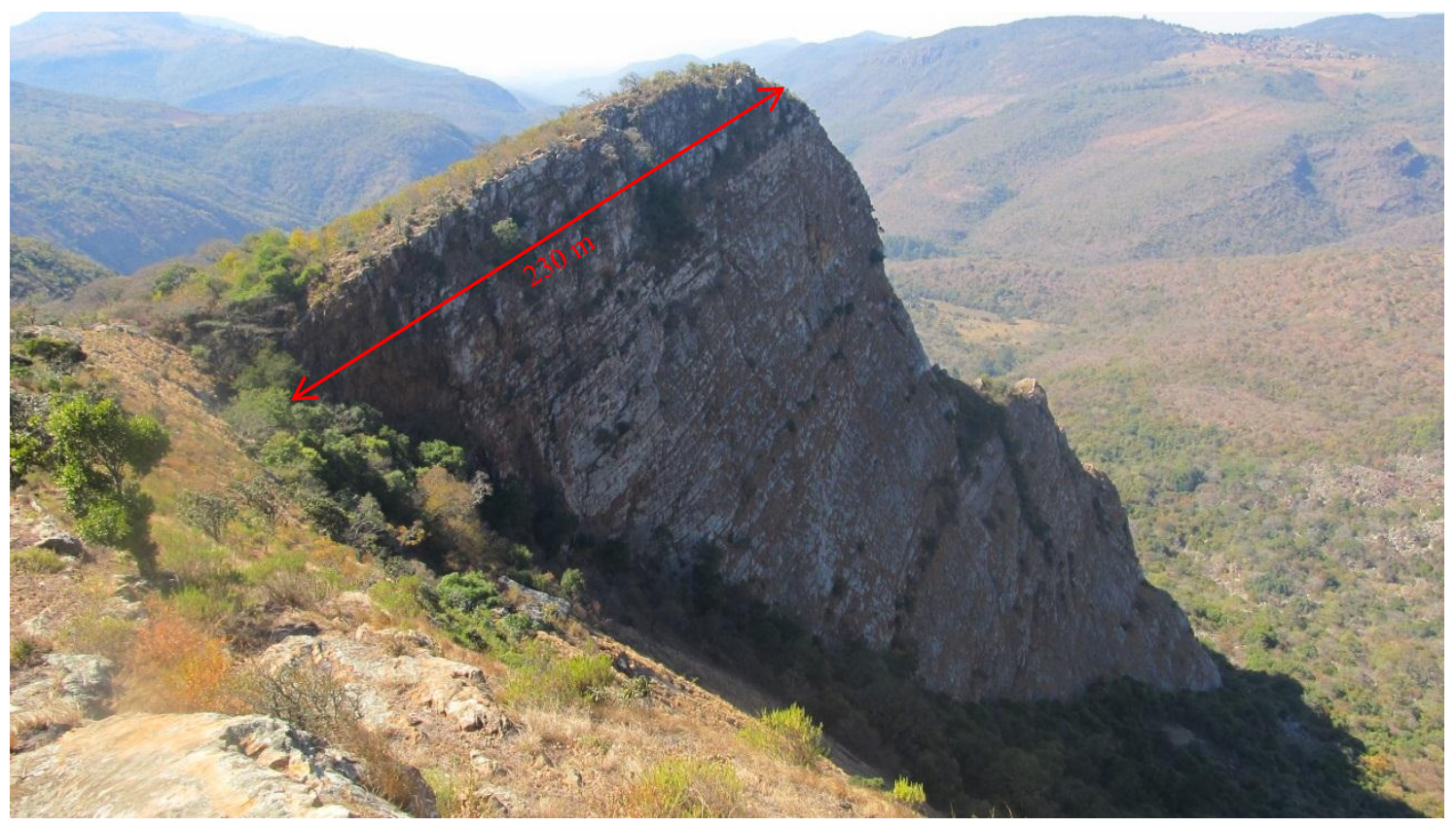

Figure 3.9: An illustration of a failure surface which extends back for about $230 \mathrm{~m}$ from the face of very steep eastern buttress or release surface (Dongwe). This photo was taken halfway between the shown buttress and the western buttress (Chitanda) not shown here which is at the back of the photographer.

The mountains on the northern shore of the lake are very high and steep. There is a dangerously high and steep escarpment which increases in height towards the east till it culminates in the two buttresses Chitanda and Dongwe, both at more than $300 \mathrm{~m}$ above the lake (Janisch, 1931). Beyond them, the escarpment continues eastwards, but becomes lower, and ultimately disappears. The buttresses are clearly visible from a distance despite being the highest part, just forward from the rest of the escarpment. The portion between the two buttresses which had slid down (collapsed) formed the central focus of this study (Figure 3.10). The near vertical rock surfaces of these release surfaces, Chitanda and Dongwe, are over $120 \mathrm{~m}$ high in places from the failure surface. This bare slip surface that forms a smooth rock slope between the buttresses 
above the landslide debris and lake is at an angle of at least $60^{\circ}$ with grass and some patches of shrubs growing on it. The rock face of Chitanda and Dongwe appear very unstable too, probably due to near vertical joints and possibly steady undercutting. Great views of the landslide and the lake were obtained from light aircraft fly overs, and on ground inspections from the landslide crest and bottom of the lake shores.

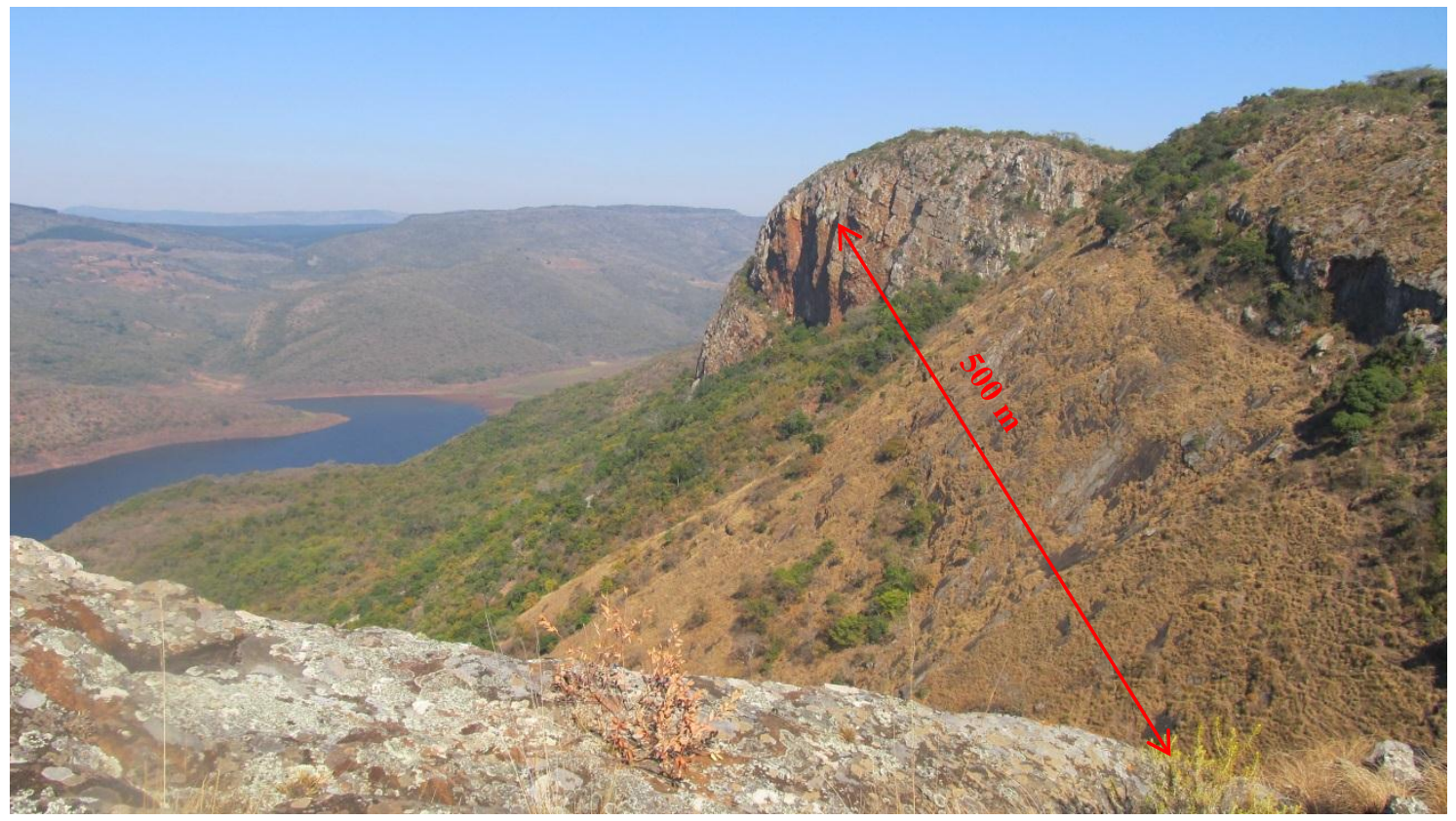

Figure 3.10: An illustration of a failure surface and the distance between the two buttresses. This photo was taken from Dongwe buttress facing in the direction of the western buttress (Chitanda).

Several minor rock falls and debris flows appear to have taken place recently, on the eastern end portion side of each buttress. The minor slide scars are characterised by the fresh pink colouration of the sandstone to that of the main slide which is greyish when viewed from the top (crest). Janisch (1931) suggested that the valley in which Lake Fundudzi lies has not been formed by erosion only, but has been controlled by faulting.

Chiliza and Richardson (2008) also stated that the landslide is approximately $500 \mathrm{~m}$ in length, $350 \mathrm{~m}$ high above the lake, and has a slope failure surface area of approximately $22 \mathrm{ha}$. The calculated volume of rock that slid down the failure surface is $(7-9)$ million $\mathrm{m}^{3}$. This was estimated thus:

$$
\text { Volume }_{\text {triangular prism }}=[(\mathbf{h} * \mathbf{b} * \mathbf{l}) / 2]
$$

Where $\mathrm{h}$ is the height, $\mathrm{b}$ is the breadth and $\mathrm{l}$ is the length: $\left[\left(245^{*} 500^{*} 115\right) / 2\right]=\mathbf{+ 7} \mathbf{0 0 0} \mathbf{0 0 0} \mathbf{~ m}^{\mathbf{3}}$ 
As Selby (1982) pointed out, rockslides may be very large and catastrophic in mountainous regions where large available relief permits acceleration of rock debris to great velocities. In the case of the Lake Fundudzi landslide the farthest blocks which are the largest travelled a distance up to $700 \mathrm{~m}$ across the valley as shown in Figure 3.11 (Chiliza and Richardson, 2008). The largest blocks have a diameter between $7-10 \mathrm{~m}$. The tributary valleys are also narrow and steep. Where bedrock protrudes through the landslide rock avalanche, it is seen to be dipping away from the lake with a dip angle averaging $20^{\circ}$ as on the scarp area.

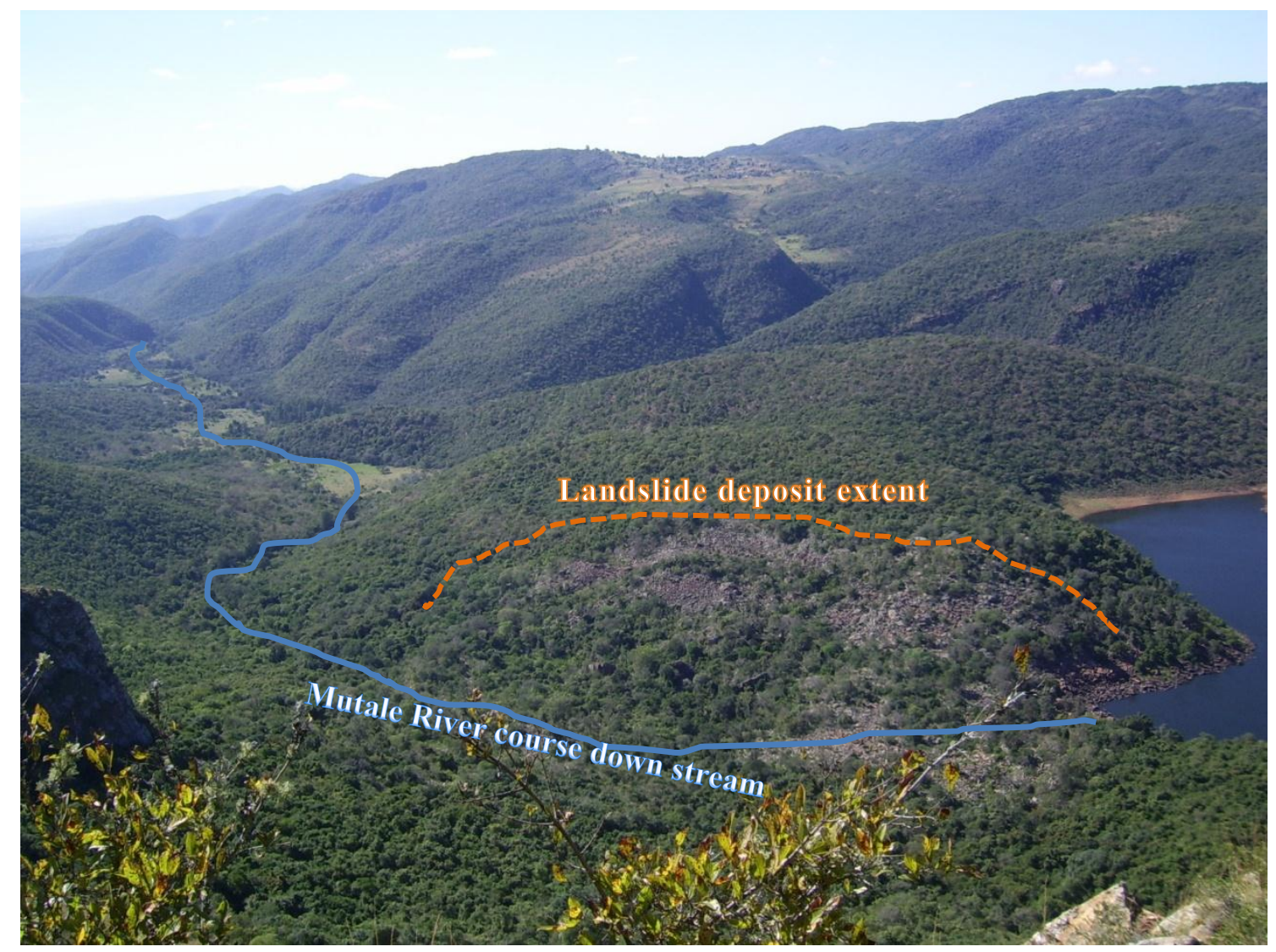

Figure 3.11: Extent of landslide deposit across the valley floor.

The great powers of Lake Fundudzi have been kept a closely guarded secret by the Venda people, who have preserved it for generations. The lake is often associated with myth and legends of the Venda people and is believed to be protected by a python god, who has to be pacified annually with gifts of traditionally brewed beer (Khorombi, 2000).

Special permission must be granted by the Netshiava royal family, to visit the lake.

In Venda culture, the python is the god of fertility and maidens still perform the famous Dombapython dance in the sacred lake to honour this god. The young women form a line in which they 
hold on to the elbows of the maiden in front of them, and using their joint arms, make snake-like movements next to the lake to honour the god (Stayt, 1968).

Other myths around the lake include a story of mysterious "zombies" which live near the lake and play the traditional Venda music known as Tshikona. The lake is surrounded by the Thathe Vondo forest, deemed to be so mystical and filled with spirits that few Venda people venture into it for fear of alleged hauntings and a lightning bird called "Ndadzi". It is believed that on the rare occasion that a visit to the lake is granted, visitors must turn their backs on the lake and view the water from between their legs. This ritual is called "Fundudzi" after which the lake is named (Stayt, 1968).

\subsubsection{Seismic activity record in the region}

Earthquakes have long been recognized as a major cause of landslides (Keefer, 1984). The smallest earthquake that can cause rock falls, rockslides, soil falls and disrupted soil slides is of a 4.00 magnitude on the Richter scale. However, the possibility of smaller events occasionally causing landslides cannot be discounted. Maximum distance of landslide from epicentre or fault rapture for a magnitude of 1.00 earthquakes can range from $0.5 \mathrm{~km}$ to $50 \mathrm{~km}$ (Keefer, 1984).

Although Southern Africa is basically a very low seismicity region, seismic activity records covering a 1908 to 2003 period were obtained for the study area since numerous landslides have been triggered by seismic activity throughout the world. Although there were no certain examples of seismic activity that triggered landslide in Southern Africa at the time of this study, seismicity was considered for stability analysis as a possible triggering factor.

Figures 3.12 and 3.12A give an overview and spatial distribution of historical seismic events within a $150 \mathrm{~km}$ radius of the project site recorded between 1908 and 2003 by the Council for Geoscience's (Seismic data records). The mean magnitude recorded over the region is 2.50 while two major events recorded in the years 1940 and 1970 were 5.00 Richter scale magnitude. In rock slope stability analysis, the so-called pseudo-statical principle is commonly used, i.e., to consider the maximum earthquake load as an equivalent horizontal load $\left(\mathrm{F}_{\mathrm{s}}\right)$, as the direction is generally most unfavourable (Pathak and Nilsen, 2004). Seismic coefficient $(\alpha)$ is a dimensionless number which represent the (maximum) earthquake acceleration as a fraction of the acceleration due to gravity. Typically the seismic coefficient might be around 0.10 to 0.30 . Hynes-Griffin and Franklin (1984) recommends that a seismic coefficient equal to $0.5 *$ PGA (peak ground acceleration). Keefer (1984) stated that, deeper-seated landslides require stronger 
shaking; lateral spreads and flows require shaking that is stronger still; and the strongest shaking is probably required for very highly disrupted rock avalanches and soil avalanches.

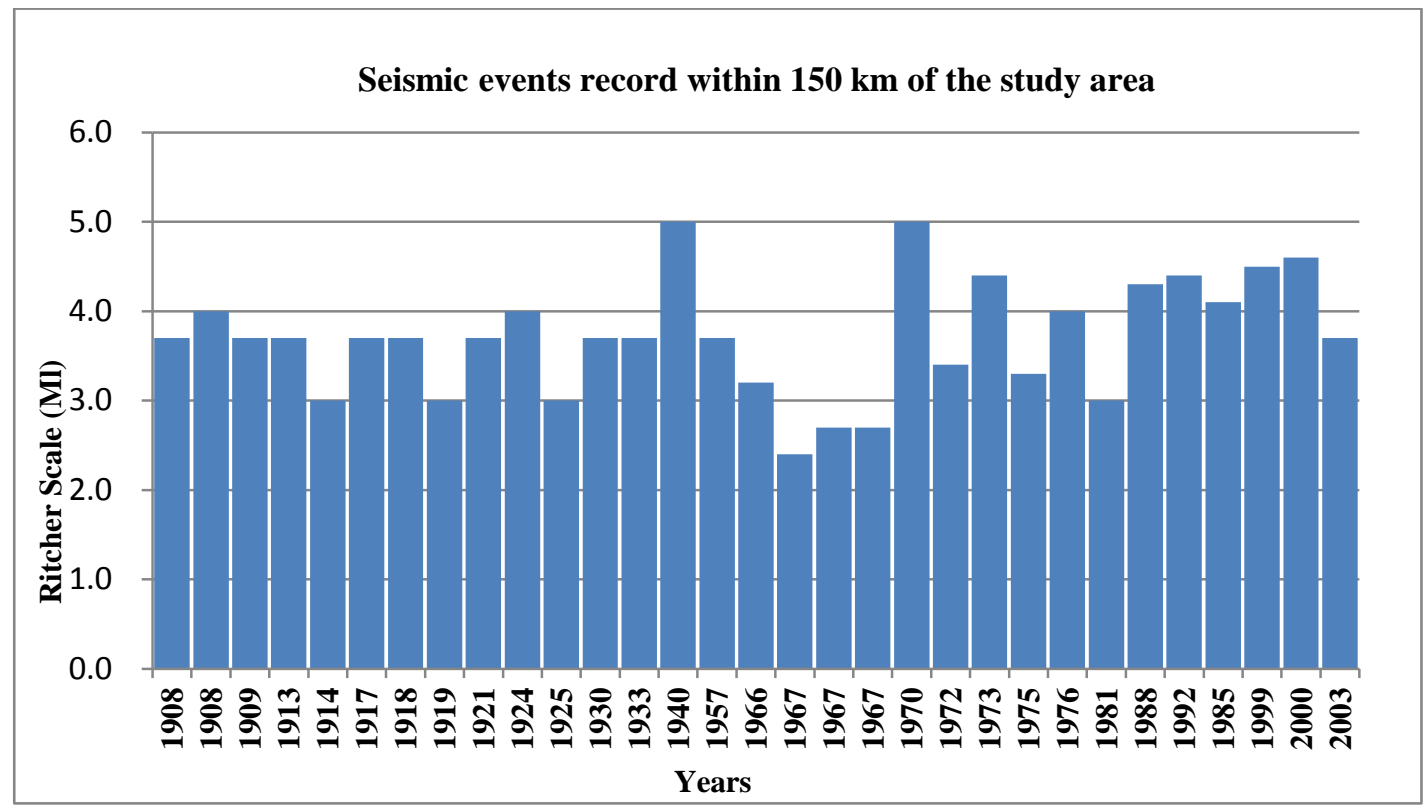

Figure 3.12: Seismic events record in the project site region on Richter scale magnitudes from 1908 to 2003 (Source: CGS South African National Seismic Database).

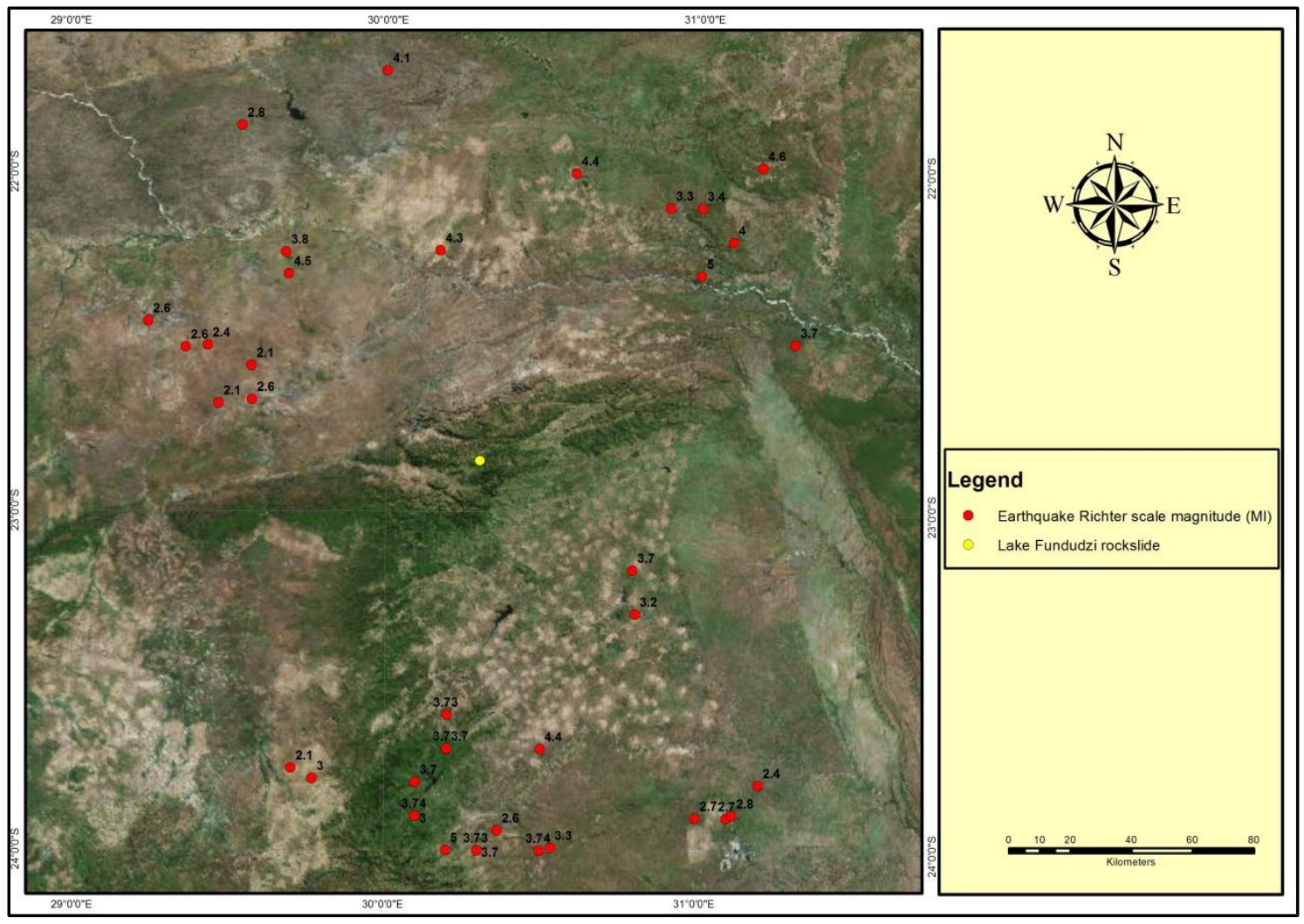

Figure 3.12a: Spatial distribution of historical earthquake magnitudes (Ml) within $150 \mathrm{~km}$ of Lake Fundudzi rockslide. 
Sepulveda et al. (2002) suggested that topographic amplification has effect on the generation of earthquake induced rockslides. It is characterised by increased amplitudes of the ground motion towards the crest of a ridge or slope and some de-amplifications at the base (Geli et al., 1988). Sepulveda et al. (2002) also found out that failures were triggered by seismic activity on steep slopes and in dry conditions. This suggests that seismic activity can solely trigger slope instability. A stability analysis of this scenario i.e. whereby seismic activity and dry slope conditions are assumed was evaluated for the project site case.

The table of historical earthquake data within $150 \mathrm{~km}$ of Lake Fundudzi rockslide is included in Appendix A1.

\subsubsection{Rainfall trends in the region}

The study area experiences relatively moderate rainfall with an average annual precipitation of $1280 \mathrm{~mm}$ (South Africa Weather Service records). The data presented in Figure 3.13 was made available by the South Africa Weather Service. The data was recorded from the nearest weather station located in the town of Thohoyandou which is about $29 \mathrm{~km}$ from the project site. Figure 3.13 gives an overview of the annual precipitation or rainfall (total $\mathrm{mm}$ ) from the year 1972 to 2013.

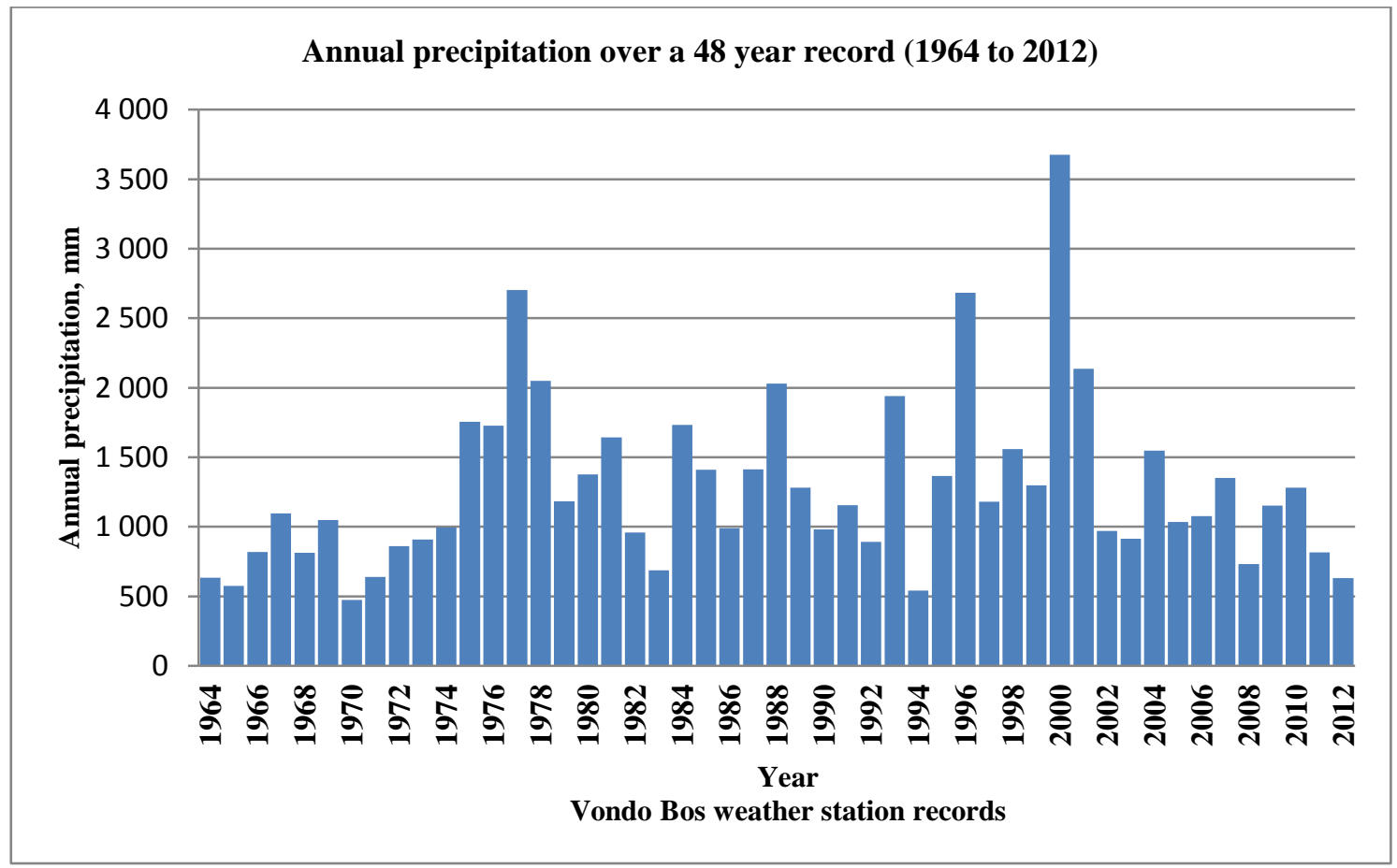

Figure 3.13: Regional annual rainfall data from 1960 up to 2007 (Source: WeatherSA). 
Many previous slope instability events tend to occur along road cuttings in the province: poorly constructed mitigation measures have done little to prevent these events (Chiliza and Richardson, 2008). Figure 3.14 shows what is seen to be an earth flow in the region of the project site after a heavy rainfall event in February of the year 2000.

Eye-witness accounts from locals during field investigations in the province indicate that the majority of recent landslide events had occurred in February 2000 after particularly heavy and intensive rainfall i.e. over $500 \mathrm{~mm}$ in one week (Chiliza and Richardson, 2008). The province experienced its worst floods in living memory in February 2000 owing to cyclone Eline. As a result, flooding and rainfall induced landslides on man-made as well as natural slopes caused loss of life (101), damaged to houses, infrastructure (\$166 million) and livestock losses (Limpopo Provincial Disaster Management, 2000).

Rainfall (water pressure) could also be a probable further destabilizing factor for the occurrence of the lake Fundudzi landslide. It significance versus other factors such as ground shaking or seismicity are evaluated in the stability analyses (Chapter 7).

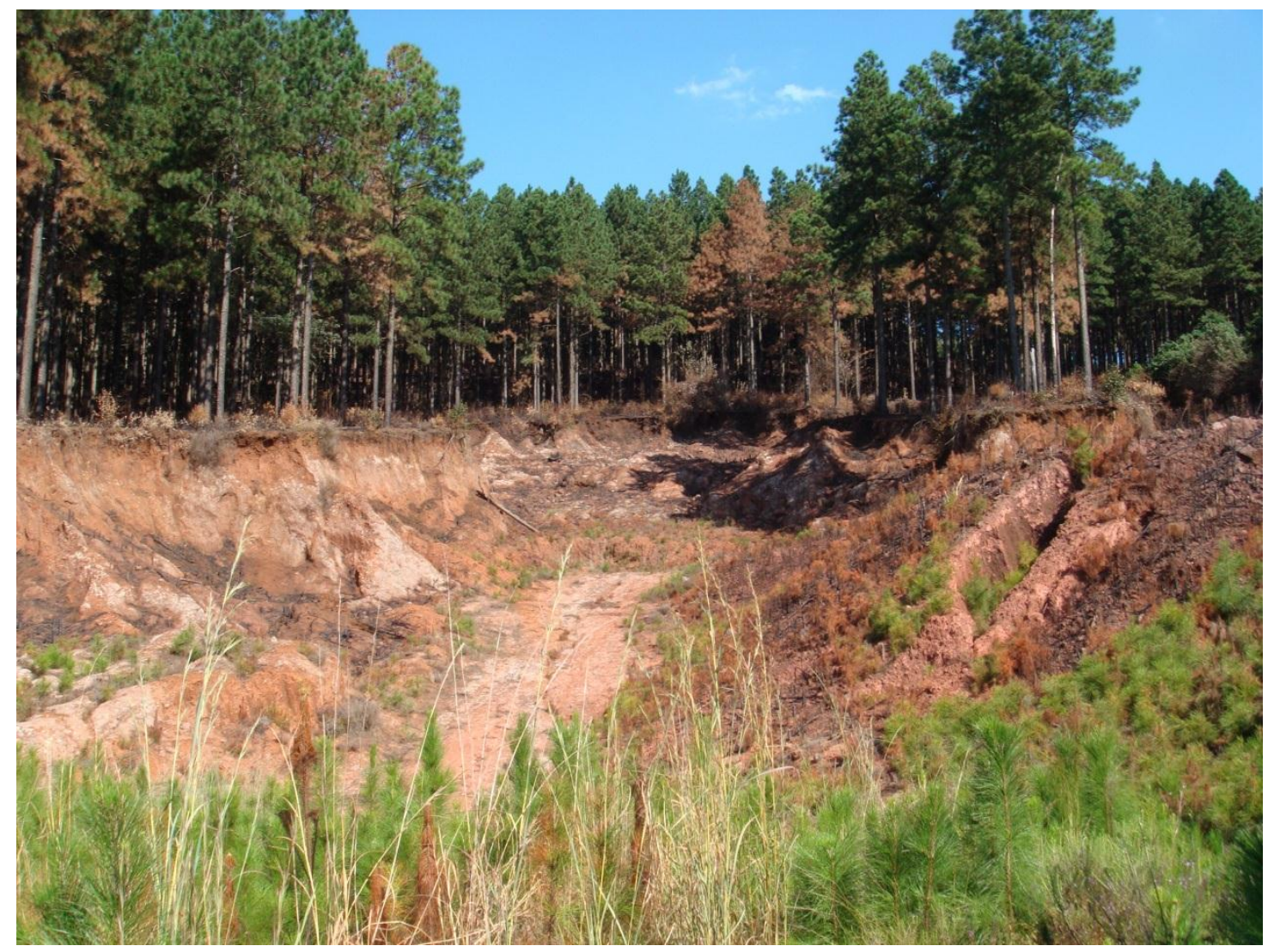

Figure 3.14: Forestry plantation land removed by an earth flow landslide triggered by the 2000 heavy rainfall in the region. 
Based on available literature, and preliminary site visits observations at the beginning of the study the landslide that formed the Lake Fundudzi was thought to have been caused by preexisting conditions such as joints, fractures and faults, which made the rock mass vulnerable to instability. The stream erosion by the Mutale River might have also led to over steepening of the foot slopes thus reducing its overall stability, and accelerating tension crack formation at the crest of the slope resulting in the failure (van der Waal, 1997).

Landslides have several causes, including geological, morphological, physical and human, but only one trigger (Varnes, 1978). Triggering factors might be rainfall, earthquakes, and individual human activities such as loading through construction on slope. Though it was obviously structural setting and their orientation played a role in the formation of a landslide; the stability analysis in Chapter 7 also seeks to determine the most critical triggering mechanism factor between those speculated here i.e. ground shaking or seismic activity and rainfall (increases water pressure) in the formation of this large rockslide.

\subsection{Summary}

The chapter has presented the definition of the term "landslide". The widely used and adopted classification system by Cruden and Varnes (1996) was described. The five general types of movement were discussed as per this classification. These five kinematically distinct types of landslides include falls, toppling, slides, spreads and flows. Another second widely acknowledged classification which is based on the rate of movement was also defined. Triggering mechanisms were discussed with intense rainfall and seismic activity believed to be the most important factors.

Lake Fundudzi landslide occurred on a rock slope and literature review of the geology and structural setting revealed that failure is primarily controlled by discontinuities, their orientation and shear strength parameters prevailing on them. Therefore the role of discontinuities, the mechanics of rock slope failure, the shear strength of discontinuities, the type of rock slope failure and their causes were also accordingly discussed.

The shear strength criterion upon which shear strength for rock discontinuities can be determined based on using frictional angle were also discussed. The criterion included the Mohr-Coulomb criterion, Hoek-Brown Empirical Failure criterion, Ladanyi and Archamault criterion and Barton-Bandis criterion.

The modes of rock slope failures which include circular, plane, wedge and toppling and equations for calculation of $\mathrm{F}$ were discussed and presented in this Chapter. 
The geomorphological setting of the Lake Fundudzi landslide and the surrounding including the cultural aspects associated with the Lake were also described.

The chapter also presented the characteristics/features of the lake Fundudzi landslide such as, the $500 \mathrm{~m}$ landslide length, the slope failure surface area of approximately $22 \mathrm{Ha}$ and the calculated volume of rock that slid down the failure surface which is about 7-9 million $\mathrm{m}^{3}$.

And lastly, a speculative discussion of possible triggering factors and their available data for the regions of the project site was also given.

The next chapter firstly gives an overview of landslide hazard assessment and methods of slope stability analysis. 


\section{CHAPTER 4}

\section{METHODS OF LANDSLIDE HAZARD ASSESSMENT AND SLOPE STABILITY ANALYSES}

\subsection{Introduction}

This chapter presents a review of landslide hazard assessment and methods of slope stability analysis. A particular emphasis is made on kinematic analysis, limit equilibrium analysis, back analysis and probabilistic techniques in slope stability studies.

Several methods have been developed to reveal the occurrence of landslides in space and time, to investigate processes acting within mass movements and to monitor ground displacements (Thiebes, 2012). The wide range of methodological approaches for landslide research stretch from field or desk based mapping, to measuring of surface and subsurface movement in the field or by remotely acquired data sources, recordings of triggering factors like rainfall or hydrological parameters, and the use of simulation models. Landslide assessments can be made at various spatial scales such as mapping and inventory approaches for regional approaches, field investigations of boreholes to define the slip surface and geotechnical investigations for displacement monitoring and modelling techniques at local scale (Wieczorek et al., 2005).

As a result, the theoretical background of each of these methods should be reviewed in order to properly analyse the problem at hand.

\subsection{Landslide hazard assessment methods}

Investigations of numerous landslides extending over larger regions have been conducted for years. These regional assessments were carried out based on mapping techniques as part of extensive field surveys (Brabb and Pampeyan, 1972). However, new computer technologies, particularly Geographical Information System (GIS) techniques, are becoming popular. These modern techniques are commonly based on remote sensing data and use either aerial photography or satellite images to obtain spatial information on landslide occurrence and movement (Hervas et al., 2003). Soeters and van Western (1996) recommended the following for slope instability hazard methods: 
- Landslide inventory mapping, heuristic qualitative approach particularly suited for small-scale regional surveys, statistical quantitative approaches for medium scale surveys (1:25000 - 1:500 000),

- Deterministic approach for detail studies at large scale as shown in Table 4.1. The Soeters and van Westen (1996) recommended scales for different spatial landslide analysis are based on the IAEG (1976) scale classification for engineering geology maps with slight modifications. The classification is summarized in Table 4.1.

Table 4.1: Recommended scales and categories for landslide susceptibility classification (modified from Soeters and van Westen, 1996).

\begin{tabular}{|c|c|c|c|c|c|}
\hline \multirow{2}{*}{$\begin{array}{c}\text { Scale or } \\
\text { other } \\
\text { information }\end{array}$} & \multicolumn{2}{|c|}{ Qualitative methods } & \multicolumn{3}{|c|}{ Quantitative methods } \\
\hline & Inventory & Heuristic analysis & $\begin{array}{c}\text { Statistical } \\
\text { analysis }\end{array}$ & $\begin{array}{c}\text { Probabilistic } \\
\text { analysis }\end{array}$ & $\begin{array}{c}\text { Process } \\
\text { based and } \\
\text { numerical } \\
\text { analysis }\end{array}$ \\
\hline$<1: 10000$ & Yes & Yes & Yes & Yes & Yes \\
\hline $\begin{array}{l}1: 15000- \\
1: 1000000\end{array}$ & Yes & Yes & Yes & Yes & Probable \\
\hline $\begin{array}{l}1: 125000- \\
1: 500000\end{array}$ & Yes & Yes & Probable & Probable & No \\
\hline$>1: 750000$ & Yes & Yes & No & No & No \\
\hline Technique & $\begin{array}{c}\text { Landslide } \\
\text { distribution } \\
\text { analysis }\end{array}$ & $\begin{array}{l}\text { Geomorphological } \\
\text { analysis and } \\
\text { qualitative map } \\
\text { combination }\end{array}$ & $\begin{array}{c}\text { Use expert- } \\
\text { based weight } \\
\text { values of } \\
\text { parameter } \\
\text { maps }\end{array}$ & - & $\begin{array}{l}\text { Factor of } \\
\text { safety } \\
\text { analysis }\end{array}$ \\
\hline Characteristics & $\begin{array}{l}\text { Hazard map is } \\
\text { derived } \\
\text { directly from } \\
\text { the landslide } \\
\text { inventory map }\end{array}$ & $\begin{array}{l}\text { Use in-field expert } \\
\text { opinion in zonation } \\
\text { and Use expert- } \\
\text { based weight values } \\
\text { of parameter maps }\end{array}$ & $\begin{array}{c}\text { Calculate } \\
\text { importance of } \\
\text { contributing } \\
\text { factor } \\
\text { combinations } \\
\text { and prediction } \\
\text { formula from } \\
\text { data matrix }\end{array}$ & - & $\begin{array}{c}\text { Apply } \\
\text { hydrologic } \\
\text { al and } \\
\text { slope } \\
\text { stability } \\
\text { models }\end{array}$ \\
\hline
\end{tabular}

The main type of investigation can broadly be differentiated on the basis of methodology which can be qualitative or quantitative. In nearly all spatial investigations, landslide inventories are the basis for developing and/or verifying the method. Even if the chosen methods do not require these (such as numerical methods), information on location is still needed for verification and validation of results (Santacana et al., 2003). They are important even for potential future developments in spatial analysis (Guzzetti et al., 1999).

The heuristic approach is based on prior knowledge, local experiences, as well as expert judgement. It also uses spatial information in explaining landslide occurrence. This information includes factors such as topography, hydrology, geotechnical, and other geomorphic factors. 
Experts weight the importance of different environmental factors based on personal knowledge and experience and hence providing the initial landslide susceptibility assessment (Glade and Crozier, 2005a).

In contrast, quantitative methods are generally based on objective criteria and are thus repeatable, producing identical results for similar data sets. The quantitative approaches include statistical, probabilistic prediction, process-based, or numerical approaches. According to Glade and Crozier (2005a), statistical methods are the most popular one. Factor maps such as geology, soils, or topographic conditions (e.g. slope angle, horizontal or vertical curvature, aspect, distance to divide) are compared with landslide distribution from inventory maps and landslide density is calculated (Soeters and van Westen, 1996).

Firstly, a bivariate statistical analysis can be used to compare each factor separately with landslide location, and weighting factors are computed on this basis for each factor. However, using multivariate statistics, any combination of factor maps can be related to landslide locations and the resulting matrix is then analysed using statistical tests, such as multiple regression or discriminant analysis (e.g. Chung et al., 1995). The statistical tests would then provide information on the factor or combination of factors that best explains landslide occurrence. The resultant maps give only spatial landslide susceptibility, because they do not contain any direct information of the hazard (i.e. temporal variation of magnitude and frequency of landslides) (Soeters and van Westen, 1996).

The second group of quantitative methods includes the empirical and deterministic process based methods. In this set of methods, topographic attributes (e.g. slope angle, vertical and horizontal curvatures, slope aspect, distance to divide or channel, contributing area) are joined with hydrological conditions (e.g. soil saturation, permeability, hydraulic conductivity) and generalized geotechnical information on soil properties (e.g. cohesion, angle of internal friction, specific weight) in order to perform stability analysis (Glade and Crozier, 2005b). The study presented here falls within this group of quantitative methods. The following sub section gives a brief account of slope stability analyses methods and in greater detail those approaches adopted in this study. 


\subsection{Slope stability analyses methods}

Slope stability analyses are performed in order to assess the safe and functional design of an excavated slope such as road cuts, open-pit mining and open excavations and the equilibrium conditions of natural slopes (Abramson et al., 2002). Several types of slope stability analysis methods are available and they range from the conventional methods to sophisticated numerical methods (Eberhardt, 2003). The traditional approach is the limit equilibrium methods that evaluate F against failure (Duncan, 1996; Krahn, 2003) and it remains the most common adopted solution. The factor of safety $(\mathrm{F})$ is an index used to compare the stability of slopes under conditions other than those of limiting equilibrium (Hoek and Bray, 1981). The resisting and driving forces are calculated by solving equilibrium equations in order to determine $\mathrm{F}$ defined as:

$$
\mathbf{F}=\frac{\text { Resising Force }}{\text { Driving Force }}
$$

Rock masses are formed under wide-ranging complex physical conditions (Hammah and Yacoub, 2009). As a result, probabilistic analysis has been used as a tool to analyse and model variability and uncertainty for rock slope stability analysis. The probabilistic approach calculates the probability of failure instead of $\mathrm{F}$ against failure. It has become more common practice as reflected by the many international conferences over the last few years focussing on this issue (Nilsen, 2000).

\subsubsection{Kinematic analysis (using stereographic interpretation)}

Kinematic methods concentrate on the feasibility of translational failures due to the formation of "daylighting" wedges or planes. As a result, these methods rely on the detailed evaluation of rock mass structure and the geometry of existing discontinuity sets that may contribute to block instability (Eberhardt, 2003). The stereographic projection provides a useful form of display of the orientation of rock slopes in relation to sets of discontinuities present, with the aid of density contours and their modal orientation. This relationship makes it possible to assess the type of failure most likely to occur. This assessment may be carried out by means of stereographic projection techniques based on specialized computer codes which focus on planar and wedge formation, for example, the program Dips in the software suite Rocscience ${ }^{\circledR}$ Inc. (Rocscience, 2012). The program allows for the visualization and determination of the kinematic feasibility of rock slopes using friction cone, daylight and toppling envelopes, in addition to graphical statistical analysis of the discontinuity properties. This approach only recognizes potential sliding failures involving single discontinuities or discontinuity intersection and do not cater for 
failure involving multiple joints/joint sets or internal deformation and fracture (Eberhardt, 2003).

Tables 4.2 gives account on critical input parameters, advantages and limitations of conventional methods of kinematic analysis using stereographic technique which was used in this study.

Table 4.2: Characteristics of kinematic method of analysis (after Coggan et al., 1998).

\begin{tabular}{|c|c|c|c|}
\hline $\begin{array}{l}\text { Analysis } \\
\text { method }\end{array}$ & $\begin{array}{l}\text { Critical input } \\
\text { parameters }\end{array}$ & Advantages & Limitations \\
\hline $\begin{array}{l}\text { Kinematic methods } \\
\text { using stereographic } \\
\text { projections }\end{array}$ & $\begin{array}{ll}\text { Critical slope and } \\
\text { discontinuity } \\
\text { geometry; } \\
\text { representative shear } \\
\text { strength } \\
\text { characteristics }\end{array}$ & 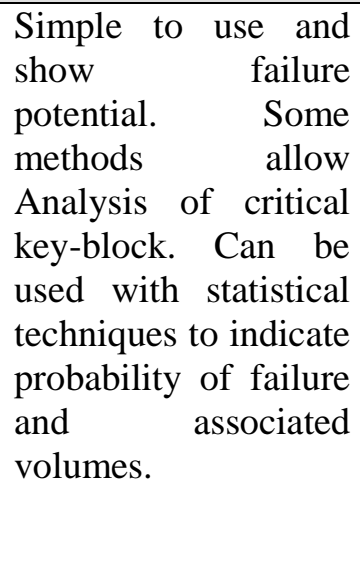 & $\begin{array}{l}\text { Suitable for } \\
\text { preliminary design or } \\
\text { for non-critical slopes, } \\
\text { using mainly joint } \\
\text { orientations. } \\
\text { Identification } \\
\text { critical joints requires } \\
\text { engineering } \\
\text { judgement which must } \\
\text { be used with } \\
\text { representative } \\
\text { joint/discontinuity } \\
\text { strength data. }\end{array}$ \\
\hline
\end{tabular}

\subsubsection{The Markland's test}

Different types of slope failure are associated with different geological structures and it is important that the slope designer should be able to recognise the potential stability problems during the early stages of a project (Hoek and Bray, 1981).

Figure 4.1 shows the four main types of failure considered by Hoek and Bray (1981) and gives the appearance of typical plots of geological conditions likely to lead to such failures. Hoek and Bray (1981) further suggested that the cut face of the slope must be included in the stereo plot since sliding can only occur as a result of movement towards the free face by the cut.

In a typical field study in which structural data has been plotted on stereonet, a number of significant pole concentrations may be present. It is necessary to be able to identify those which represent potential failure planes. The widely used and common method for identifying important pole concentrations is that developed by Markland (1972).

Kinematic analysis for the four modes of rock slope failures is based on Markland's test which is described in Hoek and Bray (1981). These are summarized in Figure 4.1. 


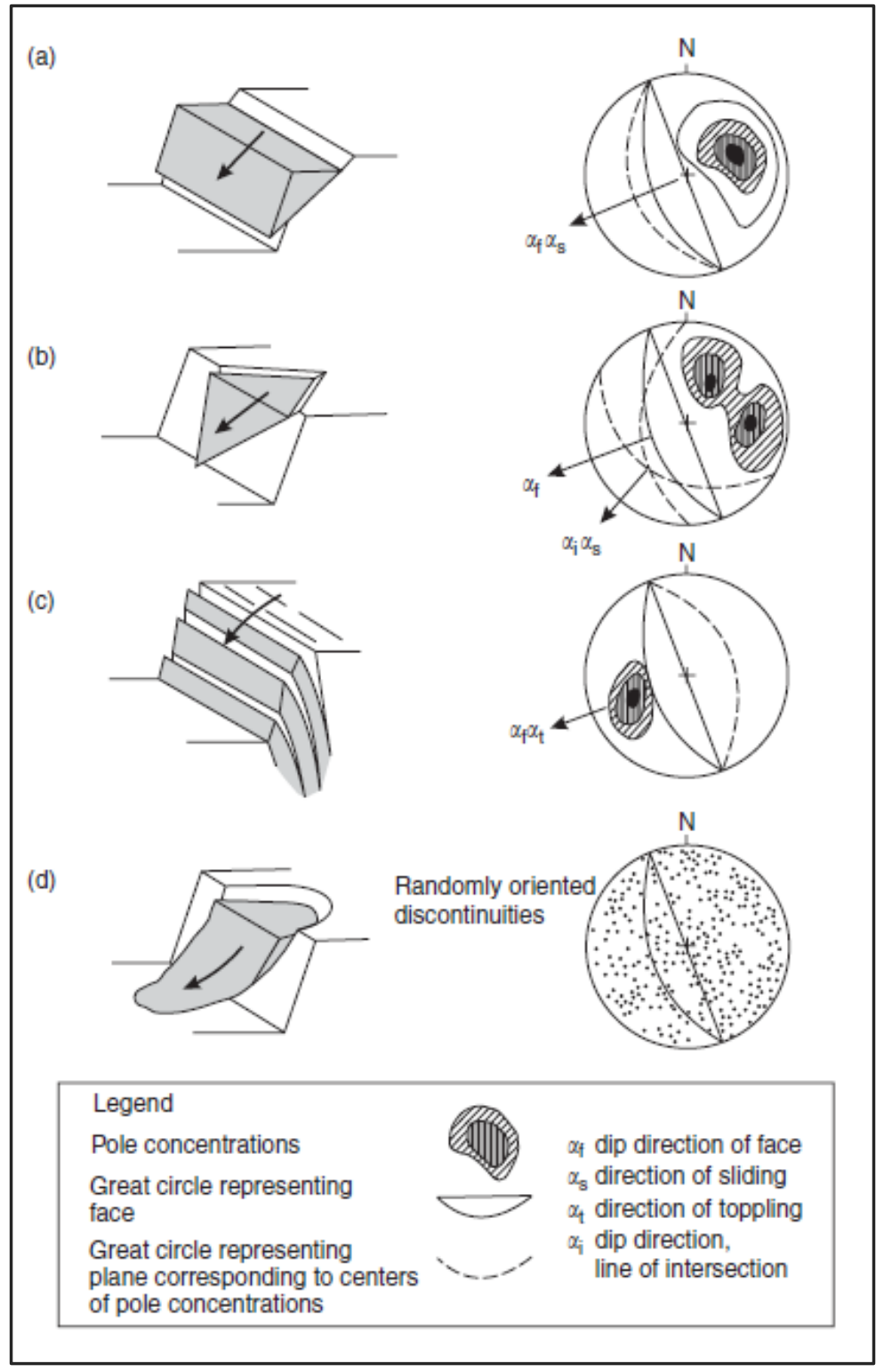

Figure 4.1: Modes of rock slope failure and stereo plots of structural conditions (after Hoek and Bray, 1981).

The Markland's test was designed to establish the possibility of a wedge failure. However, plane failure is also covered by this test since it is a special case of wedge failure. If contact is maintained on both planes, sliding can only occur along the line of intersection and hence this line of intersection must "daylight" in the slope face. This implies that, the plunge of the line of intersection must be greater than the dip of the slope face, measured in the direction of the line of intersection (Hoek and Bray, 1981).

Kinematic analysis is purely geometric and is used to examine which modes of slope failure are possible in a slope rock mass. In a kinematic analysis, it is the orientation of the combination of discontinuities that the slope face, the upper slope face, and any other slope surface of interest- 
together with friction that is examined to determine if certain modes of failure can possibly occur (Kliche, 1999).

The Markland's test for plane shear failure (i.e. plane failure or wedge failure) utilizes stereographic projection of the great circle representing the slope face together with a circle representing the friction angle, $\phi$, of the discontinuity (Kliche, 1999).

The zone between the great circle representing the slope face and the friction circle represents a critical zone within which plane shear failure is kinematically possible if additional conditions expressed by the following relationship are met:

$$
\boldsymbol{\psi}>\boldsymbol{\beta}>\phi
$$

Where, $\psi$ is the dip of the slope face, $\beta$ is the dip of the discontinuity or plunge of the line of intersection and $\phi$ is the angle of friction for the rock surface.

For toppling failure to be kinematically possible, the discontinuity set must dip steeply back into the slope face (undercutting condition) and the strike of the discontinuity set must be approximately parallel to the strike of the slope face (Willie and Mah, 2005).

\subsubsection{Limit equilibrium analysis}

The limit equilibrium (LE) analysis is the most widely applied analytical technique used in geotechnical analysis, whereby force or/and moment equilibrium conditions are examined on the basis of statics. These analyses require information about material strength, but not stressstrain behaviour (Wright, 1969).

The typical output from limit equilibrium analysis is the "Factor of Safety", F, where:

$$
F=\frac{\text { resisting forces }}{\text { driving forces }}=\frac{\text { shear strength }}{\text { shear stress }}
$$

Where $\mathrm{F}>1.00$ represents a stable situation, $\mathrm{F}<1.00$ denotes failure and $\mathrm{F}=1.00$ means failure is imminent.

Limit equilibrium analyses can be undertaken to provide a value for $\mathrm{F}$ of a potential surface, or through back-analysis a range of shear strength parameters at failure (Eberhardt, 2003).

Tables 4.3 shows the critical input parameters and advantages and limitations of limit equilibrium method of analysis. 
Table 4.3: Characteristics of limit equilibrium method of analysis (after Coggan et al., 1998).

\begin{tabular}{|c|c|c|c|}
\hline $\begin{array}{l}\text { Analysis } \\
\text { Method }\end{array}$ & $\begin{array}{l}\text { Critical input } \\
\text { parameters }\end{array}$ & Advantages & Limitations \\
\hline $\begin{array}{l}\text { Limit } \\
\text { equilibrium }\end{array}$ & $\begin{array}{l}\text { Representative } \\
\text { geometry, } \\
\text { material/joint shear } \\
\text { strength, material unit } \\
\text { weights, groundwater } \\
\text { and external loading/ } \\
\text { support conditions }\end{array}$ & $\begin{array}{lr}\text { Much } & \text { software } \\
\text { available for different } \\
\text { failure } \\
\text { (planar, modes } \\
\text { wedge, circular, } \\
\text { etc.). toppling, } \\
\text { deterministic } r \text { bostly } \\
\text { some probabilistic } \\
\text { analyses in } \\
\text { 3-D with multiple } \\
\text { materials, } \\
\text { reinforcement and } \\
\text { groundwater profiles. } \\
\text { Suitable } \\
\text { sensitivity analysis of } \\
\text { F to most inputs }\end{array}$ & $\begin{array}{l}\text { F calculations must } \\
\text { assume instability } \\
\text { mechanisms and } \\
\text { associated } \\
\text { determinacy } \\
\text { requirements. In situ } \\
\text { stress, strain and intact } \\
\text { material failure not } \\
\text { considered. Simple } \\
\text { Probabilistic analyses } \\
\text { may not allow for } \\
\text { sample/data } \\
\text { covariance. }\end{array}$ \\
\hline
\end{tabular}

Slope stability analysis can be carried out by the limit equilibrium (LE) method and by far most engineers still use this method. There are several methods that have been proposed for performing the two-dimensional limit equilibrium method of slices (Wright, 1969).

\subsubsection{Types of limit equilibrium (LE) methods of slices}

When a slope does not have uniform properties throughout the slope, and failure occurs along a circular slide path that does not pass through the toe of the slope, it becomes impossible to use circular failure charts. In such cases it is necessary to use one of the methods of slices (Yu et al., 2008). According to Fredlund et al. (1981), the methods that are most commonly used are;

a) The Ordinary method of slices. Other names given to this method are the Fellenius, Swedish Circle and Conventional method.

b) The Simplified Bishop method.

c) The Spencer method

d) The Janbu simplified and the Janbu generalized methods

e) Force equilibrium methods such as the Lowe and Karafiaths method, the Corps of Engineers method, and the Taylor modified Swedish method.

f) The Morgenstern-Price method.

The similarities and differences in these methods have been unclear. This is attributed to the lack of uniformity in formulating $\mathrm{F}$ equations, the ambiguity concerning interslice forces and unknown limitation is imposed by non-circular failure surface (Fredlund et al., 1981). The various methods of limit equilibrium used and their characteristics have been summarized by 
several researchers such as Fredlund et al., (1981), Nash (1987) and Duncan and Wright (2005) Table 4.4.

The common features of the methods of slices have been summarized by Zhu et al. (2003) as:

a) The sliding body over the failure surface is divided into a finite number of slices. The slices are usually cut vertically, but horizontal also for inclined cuts. In general, the differences between different methods of cutting are not major, and the vertical cut is preferred by most engineers currently.

b) The strength of the slip surface is mobilized to the same degree to bring the sliding body into a limit state. This implies there is only a single $\mathrm{F}$ which is applied through the whole failure mass.

c) Assumptions regarding inter-slice forces are employed to render the problem determinate

d) The factor of safety is computed from force and/ or moment equilibrium equations.

In general, the quantitative difference in factors of safety obtained by the various methods, are not substantial with the exception of the Ordinary method of slices which can differ by more than $60 \%$ from other methods (Fredlund et al., 1981).

Several computer software products based on these techniques have been developed since the early 1980's to modern times making it possible to handle ever-increasing complexity in the analysis such as Slide and Slope/W. These tools also make it possible to better understand the limit equilibrium method (Krahn, 2003).

Fundamental shortcomings of limit equilibrium methods have been highlighted by several researchers e.g. (Duncan, 1996 and Krahn, 2003) that they only satisfy equations of statics, but do not consider strain and displacement compatibility. These limitations fall outside the scope of this study and would not be discussed further.

These methods have been developed over the years in order to refine analysis of slopes using limit equilibrium methods by using vertical slices. The fundamental difference in these LE methods is the applied equilibrium conditions. Some methods consider only force equilibrium or moment equilibrium, while other methods consider both force and moment. Another difference that some methods only consider normal force and other consider both normal and tangential forces acting in a slice (Duncan, 1996).

A summary of LE methods, their use and characteristics are presented in Table 4.4. 
Table 4.4: Summary of limit equilibrium methods used their use and assumptions made (modified after Abramson et al., 2002; Duncan and Wright, 2005).

\begin{tabular}{|c|c|c|c|c|}
\hline \multirow[t]{2}{*}{ Method } & \multicolumn{2}{|c|}{ Type of failure use } & \multirow[t]{2}{*}{ Use } & \multirow[t]{2}{*}{ Assumptions } \\
\hline & circular & $\begin{array}{c}\text { non- } \\
\text { circular }\end{array}$ & & \\
\hline Fellenius & $\sqrt{ }$ & - & $\begin{array}{l}\text { Applicable to nonhomogeneous slopes } \\
\text { and c- } \phi \text { soils where slip surface can be } \\
\text { approximated by a circle. Very } \\
\text { convenient for hand calculations. } \\
\text { Inaccurate for effective stress analyses } \\
\text { with high pore water pressure. }\end{array}$ & $\begin{array}{l}\text { The slip surface is circular; the } \\
\text { forces on the sides of the slices } \\
\text { are neglected. }\end{array}$ \\
\hline Bishop & $\sqrt{ }$ & $(*)$ & $\begin{array}{l}\text { Applicable to nonhomogeneous slopes } \\
\text { and c- } \phi \text { soils where slip surface can be } \\
\text { approximated by a circle. More } \\
\text { accurate than Ordinary Method of } \\
\text { Slices, especially for analyses with high } \\
\text { pore water pressures. Calculations } \\
\text { feasible by hand or spreadsheet. }\end{array}$ & $\begin{array}{l}\text { The slip surface is circular; the } \\
\text { forces on the sides of the slices } \\
\text { are horizontal (i.e. there is no } \\
\text { shear force between slices). }\end{array}$ \\
\hline Janbu & $\sqrt{ }$ & $\sqrt{ }$ & $\begin{array}{l}\text { Applicable to virtually all slope } \\
\text { geometries and soil profiles. The only } \\
\text { procedures suitable for hand } \\
\text { calculations with non-circular slip } \\
\text { surface. Less accurate than complete } \\
\text { equilibrium procedures and results are } \\
\text { sensitive to assumed inclinations for } \\
\text { interslice forces. }\end{array}$ & $\begin{array}{l}\text { The inclinations of the interslice } \\
\text { forces are assumed; assumptions } \\
\text { vary with procedure. }\end{array}$ \\
\hline $\begin{array}{l}\text { GLE/ } \\
\text { Morgenstern- } \\
\text { price }\end{array}$ & $\sqrt{ }$ & $\sqrt{ }$ & $\begin{array}{l}\text { An accurate procedure applicable to } \\
\text { virtually all slope geometries and soil } \\
\text { profiles. Rigorous, well-established } \\
\text { complete equilibrium procedure. }\end{array}$ & $\begin{array}{l}\text { Interslice shear force is related to } \\
\text { interslice normal force by } X= \\
\lambda f(x) E \text {; the normal force }(\mathrm{N}) \text { acts } \\
\text { at the centre of the base of the } \\
\text { slice (typically) }\end{array}$ \\
\hline Spencer & $\sqrt{1}$ & $(*)$ & $\begin{array}{l}\text { An accurate procedure applicable to } \\
\text { virtually all slope geometries and soil } \\
\text { profiles. The simplest complete } \\
\text { equilibrium procedure for computing F. }\end{array}$ & $\begin{array}{l}\text { Interslice forces are parallel (i.e. } \\
\text { all have the same inclination). } \\
\text { The normal force }(\mathrm{N}) \text { acts at the } \\
\text { centre of the base of the slice } \\
\text { (typically). }\end{array}$ \\
\hline $\begin{array}{l}\text { Janbu } \\
\text { Simplified }\end{array}$ & $(*)$ & $\sqrt{ }$ & $\begin{array}{l}\text { Applicable to virtually all slope } \\
\text { geometries and soil profiles. The only } \\
\text { procedures suitable for hand } \\
\text { calculations with non-circular slip } \\
\text { surface. Less accurate than complete } \\
\text { equilibrium procedures and results are } \\
\text { sensitive to assumed inclinations for } \\
\text { interslice forces. }\end{array}$ & $\begin{array}{l}\text { The inclinations of the interslice } \\
\text { forces are assumed; assumptions } \\
\text { vary with procedure. }\end{array}$ \\
\hline $\begin{array}{l}\text { Lowe and } \\
\text { Karafiath's }\end{array}$ & - & $\sqrt{ }$ & $\begin{array}{l}\text { Applicable to virtually all slope } \\
\text { geometries and soil profiles. The only } \\
\text { procedures suitable for hand } \\
\text { calculations with non-circular slip } \\
\text { surface. Less accurate than complete } \\
\text { equilibrium procedures and results are } \\
\text { sensitive to assumed inclinations for } \\
\text { interslice forces. }\end{array}$ & $\begin{array}{l}\text { The inclinations of the interslice } \\
\text { forces are assumed; assumptions } \\
\text { vary with procedure. }\end{array}$ \\
\hline $\begin{array}{l}\text { Corps of } \\
\text { Engineers }\end{array}$ & - & $\sqrt{ }$ & $\begin{array}{l}\text { Applicable to virtually all slope } \\
\text { geometries and soil profiles. The only } \\
\text { procedures suitable for hand } \\
\text { calculations with non-circular slip } \\
\text { surface. Less accurate than complete } \\
\text { equilibrium procedures and results are } \\
\text { sensitive to assumed inclinations for } \\
\text { interslice forces. }\end{array}$ & $\begin{array}{l}\text { The inclinations of the interslice } \\
\text { forces are assumed; assumptions } \\
\text { vary with procedure. }\end{array}$ \\
\hline
\end{tabular}




\subsubsection{Back analysis}

One of the most difficult tasks in slope stability analysis is the determination of the shear strength parameters (c, $\phi)$ along the sliding surfaces (Sonmenz et al., 1998), that otherwise would not be obtained through conventional laboratory testing (Abrahmson et al., 2002). Due to the difficulties inherent in the classical design approach to slopes, back analysis of a slope failure often provides valuable information for future design purposes, remedial work and the redesign of failed slope (Sharifzadeh et al., 2009). However, this can only be meaningful in circumstances where the majority of factors that contributed to the failure can be evaluated. Back analysis calculation results should provide an unambiguous measure of the shear strength at failure. These back calculated shear strength parameters are applicable only to specific geological conditions and geographical location as they are results of the topography, geology and climate for that location (Abrahmson et al., 2002).

Sancio (1981) suggested that, back calculation of one of the strength parameters have been successfully performed for many years as early as 1916. There are recent examples where the techniques of back analysis have been successful particularly in rock slopes (Barton, 1971; Sharifzadeh et al. 2009). Barton (1971) estimated the in situ shear strength from back analysis of two slope failures which had occurred in one of the old open pits in the Rio Tinto district of southern Spain. Sharifzadeh et al. (2009) used both limit equilibrium and numerical back analysis methods to determine the shear strength parameters of a failed excavated slope in highly fractured rock mass. From both these studies, comparison with shear box tests results on representative joints suggested that the method is very useful.

Each failure process in soil and rock slopes can be reasonable explained as a large scale in situ shear test performed by nature. With the understanding of the failure mechanism and collecting the required data of the failed mass, its geomechanical properties can be acquired by a specific method which is called back analysis. It is generally accepted that shear strength parameters obtained by back analysis of slope failures ensure more reliability than those obtained by laboratory or in situ testing which is influenced by scale effect. Therefore, back analysis is a powerful method that can be used to determine the shear strength parameters of a failed material (Sharifzadeh et al., 2009).

In order for one to conduct a successful back analysis, it is essential to understand the process and mechanisms driving instability. Sonmez et al. (1998) pointed out that in general, there are three slope stability determination methods depending on the material involved: 
a) methods suitable for slopes in soils or soil like material where the strength of the material can be determined from testing small specimen of the material in the laboratory;

b) methods suitable for slopes in hard jointed rocks where slope stability is controlled by the discontinuities in the rock material. The potential for failure is dependent on the presence of/and orientation of discontinuities; and

c) methods suitable for closely jointed rock mass, as a result of a combination of macro and micro jointing, and through the rock substance.

The type of failure mechanism that was observed at the project site falls under category (b) whereby failure occurs along main discontinuity. Stead et al. (2006) suggested that, any conventional method of analyses which is based on limit equilibrium approach would be suitable for failure mechanism that falls under category (b). Hence the limit equilibrium approach is suitably and adequately applicable to the failed rock slope at Lake Fundudzi as it is characterised by planar failure along a persistent discontinuity.

In conventional back analysis, the internal friction angle or cohesion is assumed in order to calculate the other parameter, considering $\mathrm{F}=1.00$. However, in recent years, the geotechnical characterization of homogeneous and isotropic rock masses has mostly been performed using the geological strength index (GSI) system. According to Sharifzadeh et al. (2009), the conventional procedure obeys the linear Mohr-Coulomb failure criterion consisting of two unknowns (i.e. cohesion and friction angle) that are independent from normal stress given $\mathrm{F}=1$. Therefore such a back analysis approach may yield inaccurate results as it is satisfied by an infinite set of answers.

In order to overcome this problem, Sonmez et al. (1998) and Sonmez and Ulusay (1999) proposed a procedure which is practically applicable in closely fractured rock masses in which the non-linear Hoek-Brown (1997) failure criterion is used in conjunction with the rock mass classification system, Geological Strength Index (GSI) to satisfy the limit equilibrium condition. The GSI proposed in 2002 by Hoek and Brown allows the determination of rock mass strength and deformation parameters for both hard and weak rock mass (Hoek et al., 2002).

The back calculation of shear strength parameters of sliding surfaces using the linear-Coulomb criterion is independent from normal stress. However, the failure envelope of a closely jointed rock mass is non-linear and is sensitive to normal stresses (Sonmez et al., 1998). The HoekBrown non-linear failure criterion (Hoek et al., 2002) has been commonly employed for the back analysis of slope failure in heavily jointed rock mass (Sonmez et al., 1998; Sharifzadeh et al., 2009). 
The shear strength parameters of a failure surface in such rock masses can be determined for a specific normal stress using the material constants of Hoek-Brown failure criterion ( $\mathrm{m}$ and $\mathrm{s}$ ) as a function of the rock mass rating (RMR) system or the GSI system. The non-linear HoekBrown failure criterion for homogeneous and isotropic rock masses is defined by the equation below:

$$
\sigma_{1}^{\prime}=\sigma_{3}^{\prime}+\sigma_{\mathrm{ci}}^{\prime} \cdot\left[\mathrm{m}_{\mathrm{b}} \cdot\left(\sigma_{3 /}^{\prime} \sigma_{\mathrm{ci}}^{\prime}\right)+\mathrm{s}\right]^{0.5}
$$

where $\sigma_{1}{ }_{1}$ and $\sigma_{3}^{\prime}$ are the maximum and minimum principal effective stresses respectively acting upon the sliding surface, $\sigma_{c i}^{\prime}$ is the intact rock strength, and $m_{b}$ and $s$ are the material constants, which are determined by the following formulae in accordance with the GSI:

$$
\begin{aligned}
& m_{b}=m_{i} \cdot \exp [(G S I-100) /(28-14 D)] \\
& s=\exp [(G S I-100) /(9-3 D)]
\end{aligned}
$$

where $\mathrm{m}_{\mathrm{i}}$ is the intact material constant and $\mathrm{D}$ is the disturbance factor of rock mass due to blasting excavation. The GSI value can be directly determined in the field based on observation of rock mass structure and their condition. A computer program called RocLab (Rocscience, 2002) can also be used to assess GSI.

In addition, alternative procedures may be implemented in order not to overestimate the $\mathrm{m}_{\mathrm{b}}$ and $\mathrm{s}$ values, as overrated input parameters may lead to unrealistic results in the slope stability back analysis using the non-linear approach (Sonmez et al., 1998):

a) Firstly, the GSI value which is called GSI(s) is selected then the constant s is calculated by using Equation (4.6).

b) The material constant $m_{b}$ is calculated considering the existing slope geometry and slip surface in limit equilibrium software and applying the Hoek-Brown failure criterion defined in equation (4.4). The constant $\mathrm{m}_{\mathrm{b}}$ is determined by trial and error technique to lead to a value of $F$ equal to unity.

c) The calculated material constant $m_{b}$ in the previous step is employed in Equation (4.5) and new GSI value called GSI(m) is obtained. These steps will continue until the selected GSI(s) value became equal to the calculated GSI(m) which is the goal of the back analysis.

To incorporate these calculations into a computer program slope stability program such as Slide can be adopted. However, this method is applicable to heavily jointed rock mass where failure occurs as a result of a combination of macro and micro jointing, and through the rock substance. In the case of the project site, failure occurred as a result of the main discontinuity. Therefore, the method adopted was that of Barton and Bandis criterion (1990). 


\subsubsection{Uncertainties of back analysis}

Although back analysis usually yields better shear strength estimate than laboratory tests, there are uncertainties in this process. Some of these uncertainties have been discused by Leroueil and Tevenas (1981) and Duncan and Stark (1992). Hussain et al. (2010) mentioned that, some of the uncertainties that influence the back-caculated shear strength are engineering properties of the other materials in the cross-section, slope geometry at the time of failure, phreatic surface, and porewater pressures present at the time of failure, effect of rainfall, location of failure surface and existence of tension cracks.

According to Leroueil and Tavenas (1981), the back analysis of any case history involves a series of assumptions and procedures, each of which is a potential source of error. The first step in each analysis is usually to simplify the geometry of the problem. As a result, important features may be cancelled out. The second step is to assume an indealized material response, viz, drained or undrained, so as to select the type of analyitical method. The third step is to prostulate that the material behaviour corresponds to the analytical model at hand; linear or non linear elasticity, isotropy or anisotropy, Mohr Coulomb criterion or plastic flow rules and hence a large degree of idealization is unavoidable here. Laboratory tets are carried out to obtain orders of magnitude for the relevant input parameters. In most cases the first comparison is not too successful and some of the earlier assumptions on boundary conditions, model or input parameters are modified until a satisfactory fit is achieved between computation and observations (Leroueil and Tevenas, 1981).

The common practice in this process is to adjust only a few key input parameters and to try and obtain a good fit only for one or eventually two parameters of the field behaviors. Once a good fit is obtained for that particular apsect of the field behaviour which the back analysis had intended to investigate, the theory or model used or the techniques for determining the relevant material properties are declared valid. Nevertheless Leroueil and Tevenas (1981) stated that, major progress has been achieved on a variety of problems by using back analyses. Over the years several researchers (e.g. Sonmez et al., 1998; Hussain et al., 2010) have proposed guidelines for an appropriate use of back analyses.

\subsubsection{Probabilistic methods}

Due to rock masses being formed over large time periods under wide-ranging, complex physical conditions, their properties can vary significantly from place to place, even over short distances (Hammah and Yacoub, 2009). Several authors (e.g. Nilsen, 2000; Pathak and Nilsen, 2004) 
have published papers on the applicability of probability theory in underground mining and civil engineering. The uncertainties involved in slope design are made up of three categories: geological uncertainty; parameter uncertainty; and model uncertainty. Giani (1992) described two uncertainties as the first uncertainty being due to the spatial variability of the material properties and the uncertainty in their measurements. The second being due to the reliability of the hypothesis carried out to model rock mass mechanical behaviours. As a result, probabilistic approach which calculate the probability of failure instead of a single factor of saftey against failure, has become more common practice (Nilsen, 2000; Hammah and Yacoub, 2009 ). The step of the analysis that precede calculation, i.e. definition of potential stabilty problem and quantification of input parameters, are crucial for the final result (Nilsen, 2000).

The ultimate goal of a probabilistic slope stability analysis is to obtain the complete distribution of $F$ values given a set of random input variables with specified statistical properties. In this case, $\mathrm{F}$ is known as the response variable, the functional form that relates input $\mathrm{F}$ termed the response function (Hammah and Yacoub, 2009).

Various methods have been adopted in determining the probability of failure in geotechnical engineering. Some of the available methods are Monte Carlo Simulation, Point Estimate Methods and the First Order Second Moment Methods (FOSM). These methods can be considered generally well known (Christian, 2004). Probabilistic methods are capable of analysing multiple sets of slope stability paramters simultaneously. In this study Slide (Rocscience, 2012) version 6.0 software by Rocscience ${ }^{\circledR}$ was used for back analysis using a determinisitc approach. The probability approach was not used in the analysis for this study.

\subsubsection{Numerical methods}

In the current state of practice, there are several methods that are available such as numerical methods. These numerical methods include finite element methods (FEM) and the discrete element methods (DEM) and have been successfully applied in slope stability analysis since 1960s (Hammah and Yacoub, 2009).

Numerical modelling methods provide approximate solutions to problems incorporating intact rock deformation (strain) during rock slope failure (Stead et al., 2006). The first numerical analyses of rock slope were predominantly undertaken using continuum finite-element codes i.e. since 1960s (Hammah et al., 2008). The first joint or interface element for simulating the behaviour of discontinuities was proposed then (Goodman et al., 1968). Over the years however, discontinuum-based numerical approaches such as the Discrete Element Method 
(DEM) and Discontinuous Deformation Analysis (DDA) surpassed the FEM as the tool of choice for modelling block rock masses (Hammah et al., 2008). According to several researchers such as Eberhardt (2003); Stead et al. (2006) both finite element and finite difference models are most appropriate in the analysis of slopes involving weak rock/soils or rock masses where failure is controlled by the deformation of the intact material (i.e. continuum) or through a restricted number of discrete discontinuity such as bedding plane or fault.

Hammah et al. (2008) argue that the Shear Strength Reduction (SSR) method, combined with modern computing advances, has made it possible to apply the FEM to the practical and routine engineering of structures in discontinuous rock masses as originally envisaged. Through the development of special elements-joint elements (sometimes known as interface elements) Goodman (1968), Ghaboussi et al. (1973) and Beer (1985); the continuum-based FEM can also be applied to the modelling of discontinuous rock masses. These elements can have either zero thickness or thin, finite thickness. They can assume linear elastic behaviour or plastic response when stresses exceed the strengths of discontinuities (Hammah et al., 2008).

For the most part, earlier FEM studies were often limited to elastic analysis and as such limited in their application. Most continuum codes, however, now incorporate a facility for including discrete fractures such as faults and bedding planes. Numerous commercial codes are available, and offer a range of constitutive models including elasticity, elasto-plasticity, strain-softening and elasto viscoplasticity (allowing for modelling of time-dependent behaviour) (Eberhardt, 2003).

Based on the fundamental continuum analysis condition of displacement compatibility at element nodes, FEM programs do not allow the detachment of individual blocks. Nevertheless they are still useful for determining the onset of instability (collapse mechanisms) or large movements that cause block detachments (Hammah et al., 2008).

Hammah et al. (2008) highlighted two unique advantages of FEM over DEM and DDA but the one that stood out for the author of this dissertation is that "it can handle cases in which fractures intersect in a manner such that discrete blocks may not necessarily be formed, i.e. cases in which joints may terminate within intact rock and not only at intersection within intact rock and not only at intersections with other joints".

However these will not be discussed further as the scope of this study was limited to back analysis using a deterministic limit equilibrium approach of analysis. 


\subsubsection{Artificial neural networks (ANNs)}

In recent years there have been several attempts to use intelligent computational systems such as Artificial Neural Network in geotechnical engineering. Artificial neural networks (ANNs) are very sophisticated nonlinear modelling techniques, capable of modelling extremely complex functions (Erzin and Cetin, 2012). Sakellariou and Ferentinou (2005) stated that, there is growing interest among researchers which arises from the fact that these learning machines have an excellent performance in the issues of pattern recognition and the modelling of nonlinear relationships of multivariate dynamic systems. Several researchers had investigated the use of ANN in predicting the stability of slopes such as Sakellariou and Ferentinou (2005) and Lin et al. (2009). The paper by Sakellarious and Ferentinou (2005) is one of the most cited papers which deals with the use of neural networks in slope stability analysis on ResearchGate.net. They found favourably that the networks had successfully captured the relationship between input and output parameters. Also, the non-linear relationships that connect the parameters in multivariate problems are assessed in a very sophisticated manner through computational neural networks.

Artificial neural networks (ANNs) will not be discussed further as the scope of this study was limited to back analysis using a deterministic limit equilibrium approach of analysis.

\subsection{Summary}

In this chapter, a wide range of available and evolving landslide hazard assessment and slope stability analyses methods have been described. These include landslide inventory-heuristic qualitative methods and deterministic quantitative methods which comprise but not limited to the use of Markland's test for kinematic analysis, limit equilibrium methods of slices, back analysis techniques and its pros and cons, common probabilistic and numerical approaches.

In order to achieve aims and objectives of this study, several rock mechanics and geological parameters and principles had to be investigated. Hence the next chapter gives an account of the methodology which included fieldwork and laboratory testing. The scientific significance behind each of the activities undertaken is also discussed. 


\section{CHAPTER 5}

\section{FIELDWORK AND LABORATORY TESTING}

\subsection{Introduction}

This chapter presents a detailed account of the field work undertaken as well as the laboratory work done. The methodology is presented for most part in the sequence of execution during the course of this study.

Models in slope stability analyses require certain input parameters for the analyses to be undertaken. In the case of limit equilibrium analyses which are all based on Mohr-Coulomb failure criterion (Hoek and Bray, 1981) these shear strength parameters include the dry unit weight $(\gamma)$, cohesion $(c)$, and friction angle $(\phi)$. Also dealt in the stability analysis are physical external factors such as intense rainstorms and/or groundwater pressure, seismic shaking or slope undercutting which are common driving forces for the triggering of landslides (Glade and Crozier, 2005a).

Broadly data collection included discontinuity surveys and laboratory testing.

\subsection{Field data collection}

The corner-stone of any practical rock mechanics analysis is the geological model and the geological data based upon which the definition of rock types, structural discontinuities and material properties are based. Even the most sophisticated analysis can become a meaningless exercise if the geological model upon which it is based is inadequate or inaccurate (Hoek, 2007). Hence, several types of methods were used to collect data required for the successful analyses of the project.

\subsubsection{Discontinuity survey}

Discontinuity is a collective term that includes joints, fractures, bedding planes, shear zones, faults and other undifferentiated linear contacts (Wyllie and Mah, 2005). Goodman (1980) stated that, rock slopes may fail as rock blocks move on single or multiple weakness planes. The weakness or failure is brought about or introduced by joint planes which are strongly 
directional. Therefore, the most important attribute in the kinematic analysis can be considered to be orientation which can be reliably measured (Goodman, 1980).

The main objective for conducting a discontinuity survey was to determine the possible mode of failure. The procedure adopted followed the recommendations of the ISRM (1978). A Clar type geological compass manufactured by Beithaupts Kassel in Germany was used (Figure 5.1).

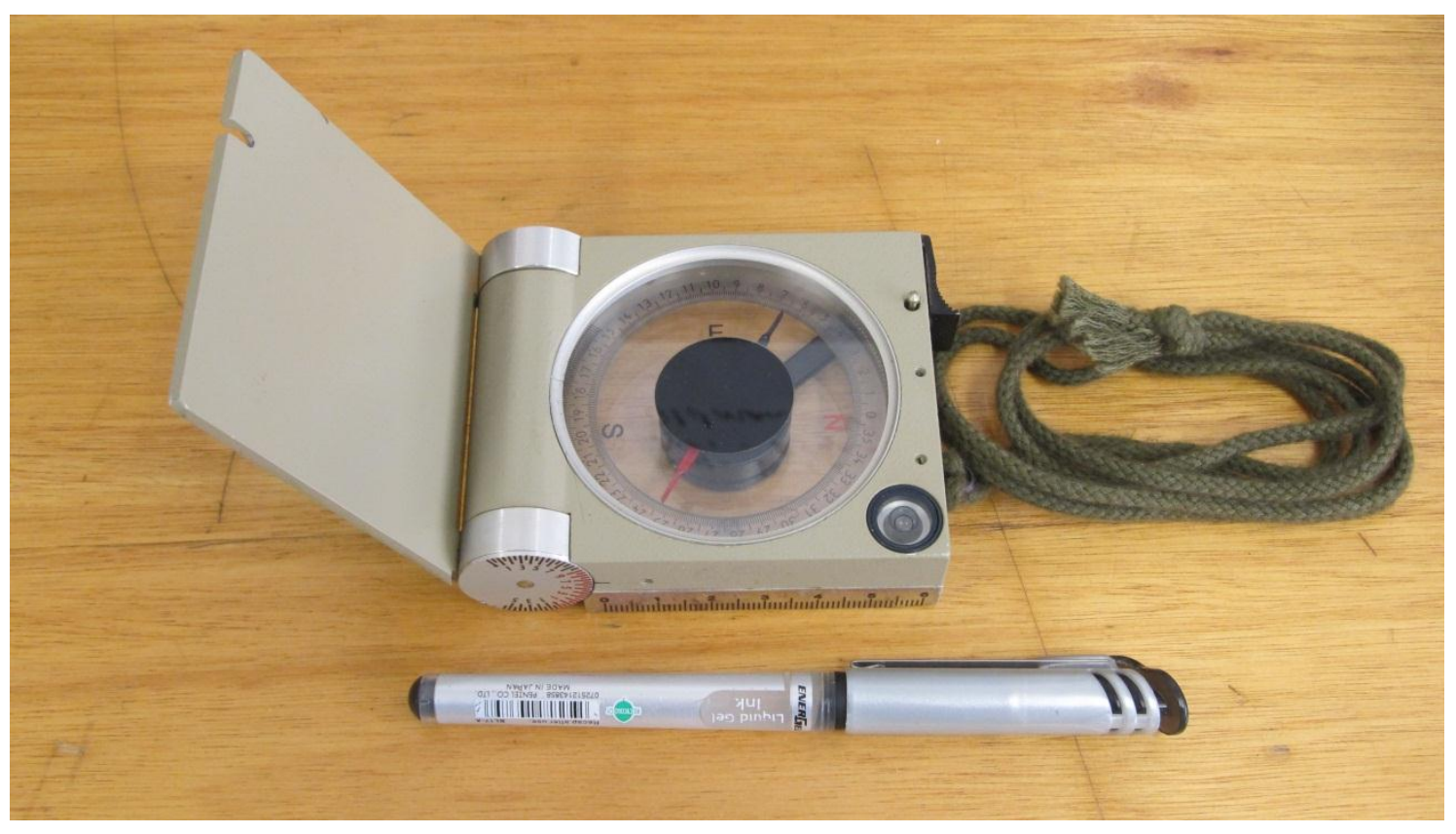

Figure 5.1: A Clar type geological compass used for the discontinuity survey conducted.

The basic technique used in mapping surface and underground exposures is the scanline survey (Brady and Brown, 2006). A scanline survey entails fixing a measuring tape to the rock face by means of masonry nails hammered into the rock. The tape is kept as straight as practically possible. Discontinuity features are then measured along the scanline. The distance of a line scan along which measurements are taken should ideally have been $30 \mathrm{~m}$ (Bell, 1992). However, due to the hazardous nature of the terrain coupled with the limited rock mass outcrops, it was impossible to carry out a full scale scanline survey. As a result, cell or window mapping of joints was used to collect the discontinuity data as shown in Table 5.1. Mathis (1987) suggested that, sparsely scattered joint sets are not readily detected with scan-line mapping, but are generally detected by cell mapping; hence local variations in properties are easily detected resulting in better knowledge of variability. Some of the discontinuity measurements were collected in 2008 before the author enrolled for part-time MSc studies presented by this dissertation in 2012.

Detailed visual observations and measurements of dip and dip direction by making use of geological compass were made at several locations where data was collected. Cell mapping 
involves systematically dividing the face to be mapped into zones of equal lengths called cells. Approximate areas of about $1 \mathrm{~m}^{2}$ were used as cell windows for joint data collection. At least 20 representative joints of the entire population were measured at each site or outcrop. Wherever possible, the discontinuity and rock mass parameters such as spacing, roughness, filling were measured. In total over 200 discontinuity datasets were recorded.

Table 5.1: An example of a discontinuity survey sheet.

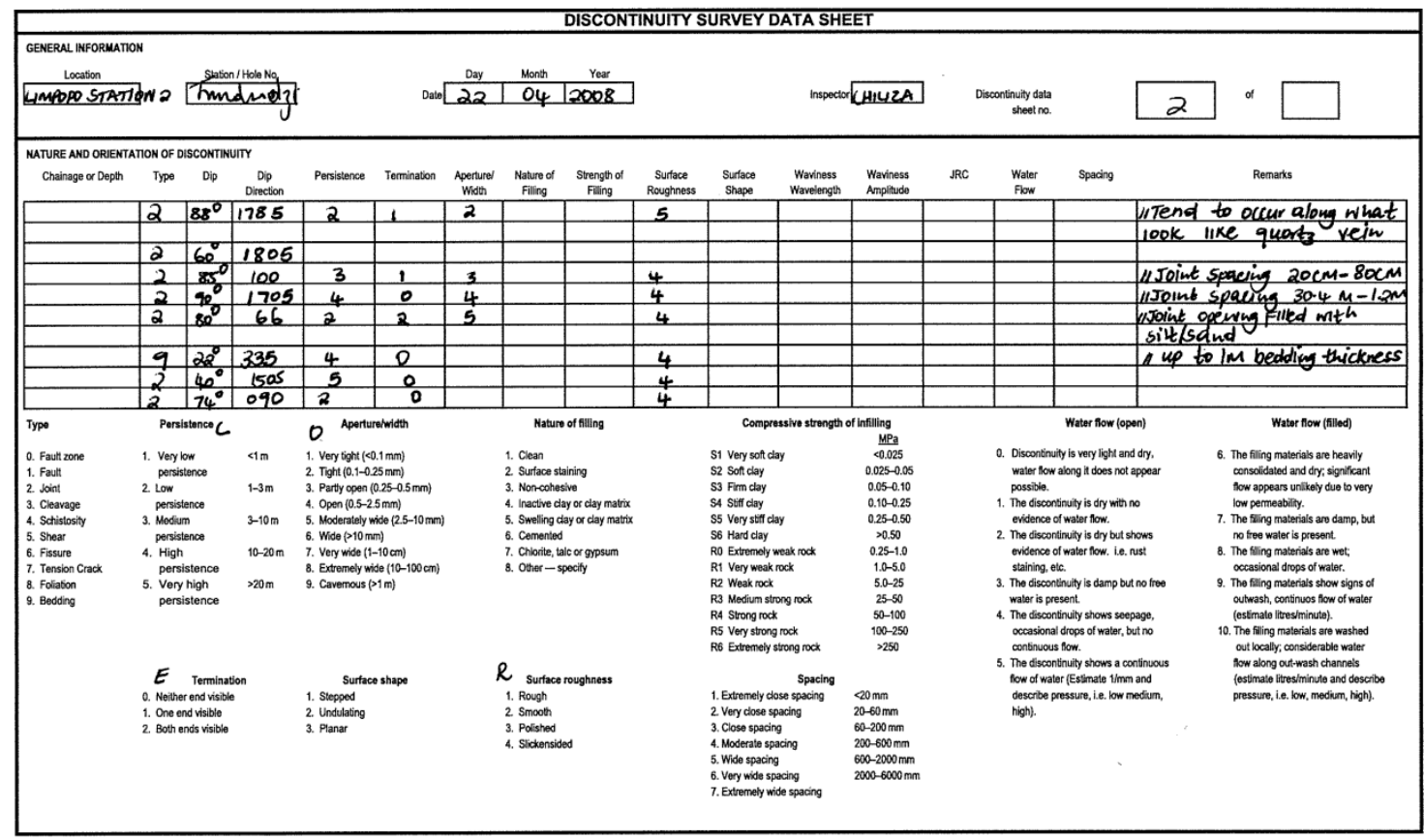

The discontinuity data recorded in the field was then transferred to Dips program for plotting, analysis and presentation of the data using spherical projection techniques. The structural setting or pattern of discontinuities in the rock mass was uniform hence all data set collected was plotted together. The bias angle used by Terzaghi (1965) correction was set at $15^{\circ}$ - which is a default setting. The Terzaghi weighting was not considered in this study as it is applied in contour plots, to correct for sampling bias introduced by data collection along traverses.

The results from the discontinuity survey are presented in the next chapter.

\subsubsection{Schmidt hardness rebound test}

The strength of the rock forming the walls of discontinuities will influence the strength of rough surfaces (Wyllie and Mah, 2005). Hoek and Bray (1981) suggested that it is adequate to estimate the uniaxial compressive strength (UCS) and quality of rock from the Schmidt Hammer field test (ISRM, 1981). 
The Schmidt Hammer was initially designed as a non-destructive test to measure concrete hardness (Schmidt, 1951). It is portable, simple, with affordable attributes and hence it is an ideal index apparatus for use in the field. The rebound hardness value is probably the most commonly used index in rock mechanics practice for estimating the UCS and the modulus of elasticity (Young's modulus) E of an intact rock both in the laboratory and in situ (Aydin, 2008).

The rebound hardness value $\mathrm{R}$ is used in the equation by Miller (1965) and was adopted later by Barton and Choubey (1977) and ISRM (1978) to correlate with the UCS as:

$$
\log _{10}(\mathrm{UCS})=0.0088 \gamma \mathrm{R}+1.01
$$

where UCS is unconfined compressive strength (MPa), $\gamma$ is the dry rock density $\left(\mathrm{kN} / \mathrm{m}^{3}\right)$ and $\mathrm{R}$ is rebound number.

Schimdt Hammer rebound tests were performed on representative joint surfaces measured for discontinuity survey. The International Society of Rock Mechanics (ISRM) (1978) recommended a total of twenty tests on each joint surface, which was not possible due to the minimal joint surface area exposed. An average of five readings was taken for each joint surface. An L type original Schmidt hammer was used in this study with an impact range of $0.735 \mathrm{Nm}$ (Figure 5.2). The recording of data suggested by Atkinson et al.(1978), is different to the revised version of ISRM by Aydin (2008). In the revised version no value is discarded whereas in the old suggestion only the mean of higher 50\% values was used. The justification by Aydin (2008) is that UCS and E values of material are strongly influenced by the density, distribution and connectivity of weak microstructural element meaning low and high rebound readings are equally necessary; therefore no readings should be discarded. In this study the procedure by Aydin's (2008) for recording data was used.

A total of 40 Schmidt hammer rebound tests were conducted. The tests procedure followed the recommendation of the International Society of Rock Mechanics (ISRM, 1981). For the purpose of this study, the tests were undertaken on the relatively fresh to slightly weathered surfaces of the in situ rock mass. The hammer is very sensitive to the effects of gravity, and corrections are necessary according to the angle at which the hammer is held during testing (Barton and Choubey, 1977). The tests were performed with the hammer held vertically downwards and horizontally i.e. at right angles to the vertical rock faces to assess effect of an angle at which the hammer was held. The rebound values were read from the dial. The Schmidt hammer conversion chart was used to determine the compressive strength. 


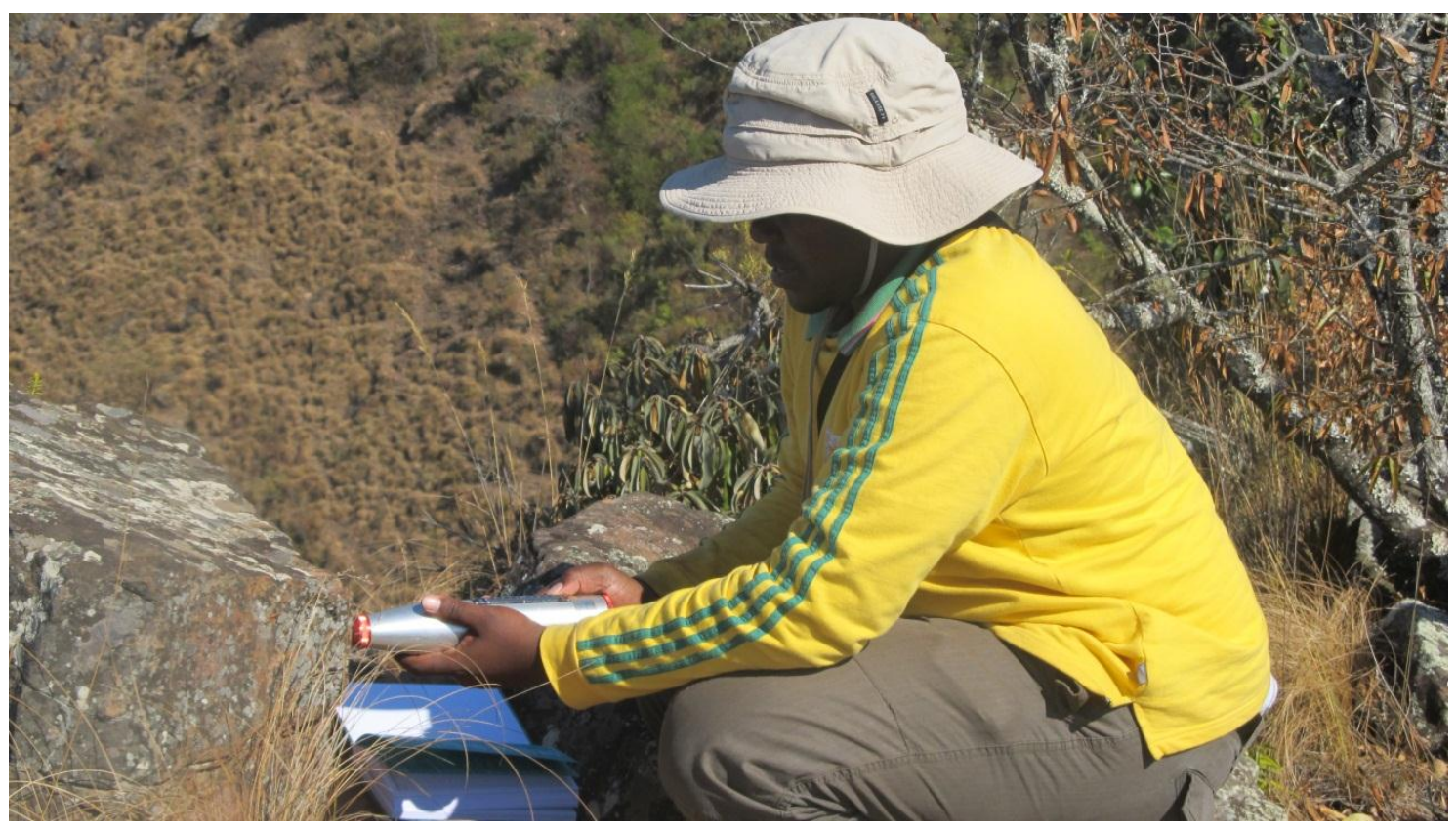

Figure 5.2: Schmidt Hammer Rebound tests as carried out on site.

\subsubsection{Rock specimen sampling}

Rock blocks of about $30 \mathrm{~kg}$ each were sampled with the help of locally sourced field assistants. These block samples were collected for coring to obtain core samples suitable for UCS testing. During sample collection, each block was inspected for macroscopic defects so that it would provide test specimen free from fractures and joints. These were wrapped in a rug to preserve the in situ moisture content state. Representative samples of the main joint sets were also taken for shear testing of discontinuities.

The natural joint samples were bonded together using a masking tape and wire to minimize breakage of asperities along the joint line area. They were transported from site to Pretoria and then to Durban with utmost care and caution where preparation and testing of these samples for tilt angle tests, unit weight measurements, UCS tests, indirect tensile strength tests and Golder shear box tests were conducted.

\subsubsection{Geomechanical Rock Mass Classification}

Determination of strength for an in situ rock mass by laboratory type testing is generally not practical. As a result the rock mass strength is estimated from geological observations and from test results on individual rock pieces or rock surfaces which have been taken from the rock mass (Hoek, 2007). 
The two of the more widely accepted classification systems for evaluating the rock mass are the Rock Mass Rating System (RMR) by Bieniawski (1989), and the Geological Strength Index (GSI) by Hoek and Brown (1998). The GSI system is more applicable than the RMR system when rating very weak rock masses where the stability of the rock mass is controlled by rock mass strength (i.e. where failure is not structurally controlled). The Geological Strength Index (GSI), introduced by Hoek (1994), Hoek et.al. (1995) and Hoek and Brown (1998), provides a system for estimating the reduction in rock mass strength for different geological conditions as identified by field observations.

The RMR engineering classification of rock mass was applied to characterize the slope rock mass. This classification incorporates six parameters which are, Uniaxial Compressive Strength of rock material (UCS), rock quality designation (RQD), spacing of joints, condition of joints, groundwater conditions and orientation of joints (Bieniawski and Orr, 1976). The RMR values are a result of the combination of these parameters. High values $(>81-100)$ indicate very good quality and very poor rock masses being RMR $<21$. Deere (1963) developed the rock quality designation (RQD) technique, which is simply estimated from percent of rock core recovery $\geq$ $10 \mathrm{~cm}$ (4 inches) compared to the total core run. However, in the field one may not have access to drill core. Therefore, Planström (1975) developed a technique to estimate RQD while evaluating the rock face, where:

$$
\text { RQD \% }=115-3.3 J_{\mathrm{v}} \text {. }
$$

Where, $J_{v}$ is the total number of discontinuities per cubic metre or volume of rock selected along the horizontal and vertical scanlines.

The RQD is a directionally dependent parameter and its value may change systematically depending upon borehole orientation. Therefore, using the volumetric joint count by Planström (1975) is useful in reducing this directional dependence. To evaluate $J_{v}$ in the field an open cleft in the rock which displays $\mathrm{x}, \mathrm{y}$ and $\mathrm{z}$ dimensions must be selected. The fractures along a $1 \mathrm{~m}$ length in 3-dimensions must be added to obtain a volumetric joint count.

At the core of the GSI classification is a careful engineering geology description of the rock mass which is essentially qualitative. The index is based on assessment of lithology, structure and condition of discontinuity surfaces in the rock mass. It is estimated from visual examination and observations of the rock mass exposed in outcrops. Once selected, a GSI "number" in Figure 5.3 is entered into a set of empirically developed equations to estimate the rock-mass properties which can be used as input into some form of numerical analysis. The index is used in conjunction with appropriate values for the unconfined compressive strength of the intact rock $\sigma_{\mathrm{ci}}$ and the petrographic constant $\mathrm{m}_{\mathrm{i}}$, to calculate the mechanical properties of a rock mass 
$\left(\sigma_{\mathrm{cm}}\right)$ and its deformation modulus (E) (Hoek et al., 2002). This is usually done by means of RocLab which determines rock mass strength parameters. The RocLab program can be freely downloaded from http://www.rocscience.com.

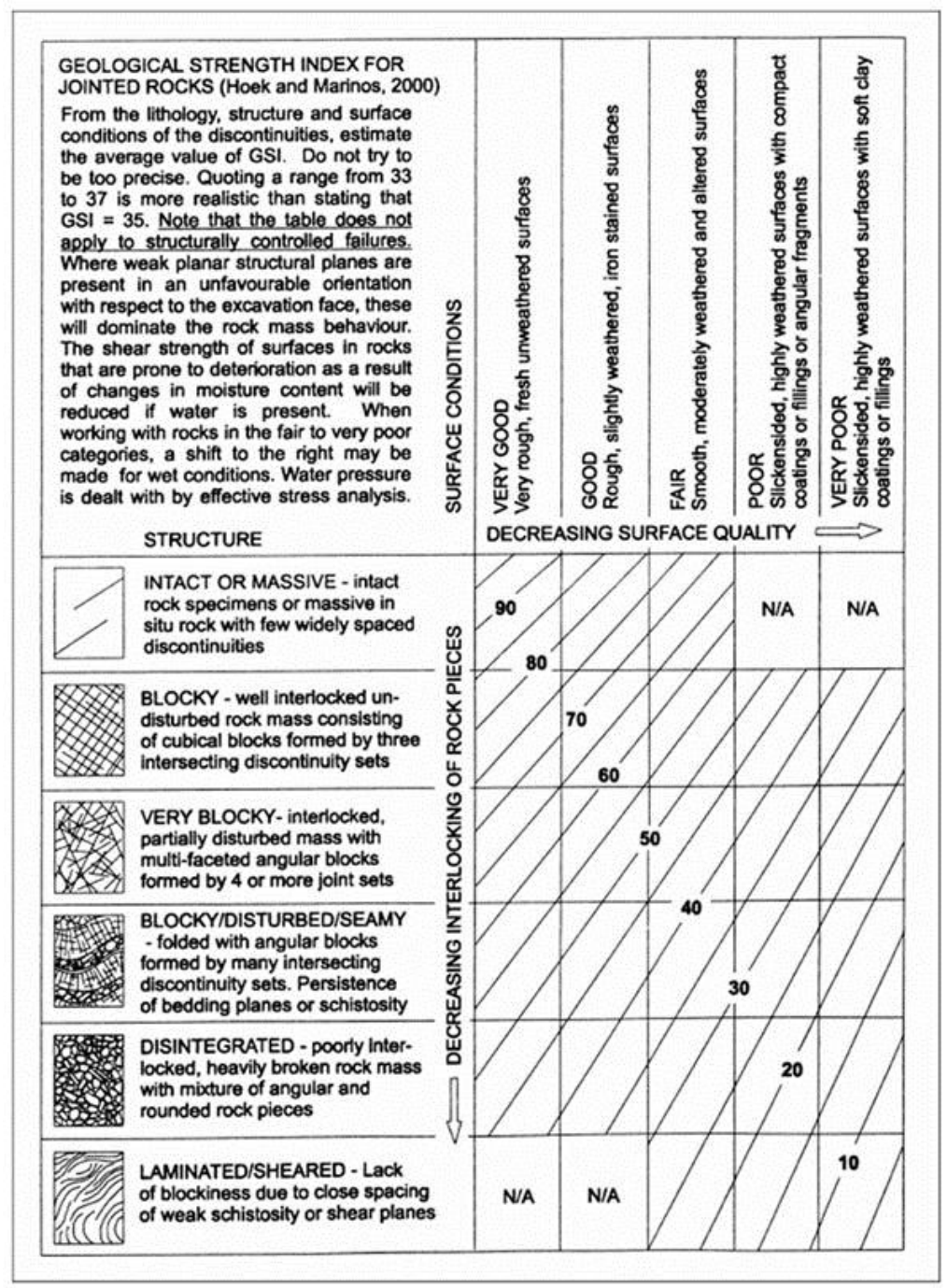

Figure 5.3: General chart for GSI estimates from the geological observations (after Hoek and Brown, 1998).

\subsection{Laboratory testing}

Hoek (2007) suggested that there has always been a tendency to equate rock mechanics with laboratory testing of rock specimen; as such laboratory testing has played an inappropriately large role in the subject. However, he further stated that this does not imply that laboratory testing is not important as $10 \%$ of a well-balanced rock mechanics program/ study should be allocated to laboratory testing. Laboratory tests commenced with the sample preparation work which is described below. 
Accordingly, a great effort was made into ensuring that the laboratory testing phase was wellorganized and relevant. The main purposes for laboratory testing was to geotechnically characterize the site in order to obtain the relevant input parameters such as unit weight $(\gamma)$, joint wall compressive strength (JCS) and joint roughness coefficient (JRC) for slope stability analysis.

\subsubsection{Point load tests}

The Point Load $\left(\mathrm{I}_{\mathrm{s}}\right)$ is a measure for the determination of rock strength and for estimating the UCS (ISRM, 1985). The test is quick and simple and can be done in the field because the testing machine is portable. A rock sample is loaded between hardened steel cones, causing failure by the development of tensile cracks parallel to the axis of the applied load. The point load strength is given by (Broch and Franklin, 1972):

$$
I_{s}=\frac{P}{D^{2}}
$$

Where $\mathrm{P}=$ failure load, and $\mathrm{D}=$ the distance between the point loads, $\mathrm{D}^{2}=\frac{4 \mathrm{~A}}{\pi}$, for axial, block and lump tests;

where $\mathrm{A}=\mathrm{WD}=$ minimum cross-sectional area of a plane through the platen contact points.

The strength/size effect exists and as such correction must be made to reduce results to a common size. The point load index is reported as the point load strength of a $50 \mathrm{~mm}$ core i.e. strength index $\mathrm{I}_{\mathrm{s}(50)}$ (Wittke, 1990):

$$
\mathbf{I}_{\mathbf{s}(\mathbf{5 0})=} \mathbf{F} . \mathbf{I}_{\mathrm{S}}
$$

Where F is "Size Correction Factor"; and F $=(\mathrm{D} / 50)^{0.45}$.

Broch and Franklin (1972) reported that estimation of compressive strength approximately equals to 24 times the point load index $\mathrm{Is}_{(50)}$. They also developed a size correction chart so that core of various diameters could be used for strength determination.

For these tests, saw cut block samples were tested for point load strength determination. The index-to-strength conversion (scale factor $\alpha$ ) of 24 was considered based on the $50 \mathrm{~mm}$ core size correction for block tests (Broch and Franklin, 1972). Equation 5.3 enables the order of magnitude of the specimen's UCS to be inferred from the determined strength index (Goodman, 1980 and Wittke, 1990). 
Where qu is the UCS of cylinders with a length to diameter ration of $2: 1$, and $I_{s(50)}$ is the point load strength corrected to a diameter of $50 \mathrm{~mm}$.

Point load testing was undertaken in accordance with the ISRM suggested methods (1985) as shown in Figure 5.4. Specimens in the form of rock cores, blocks, or irregular lumps can be tested. In this study blocks of measured dimensions were tested. A total of 29 block samples were tested for point load test under dry moisture condition state at the Council for Geoscience's now decommissioned Engineering Geology laboratory.

The 29 samples presented here only consist of samples with valid failure mode whereby failure fracture surface passes through both loading points (ISRM, 1985). Calculations for the analysis of test results were done using a spread sheet in accordance to procedures outlined in ASTM D5731 (1995) for uncorrected Point Load strength Index, size correction and estimation of uniaxial compressive strength (Appendix B).

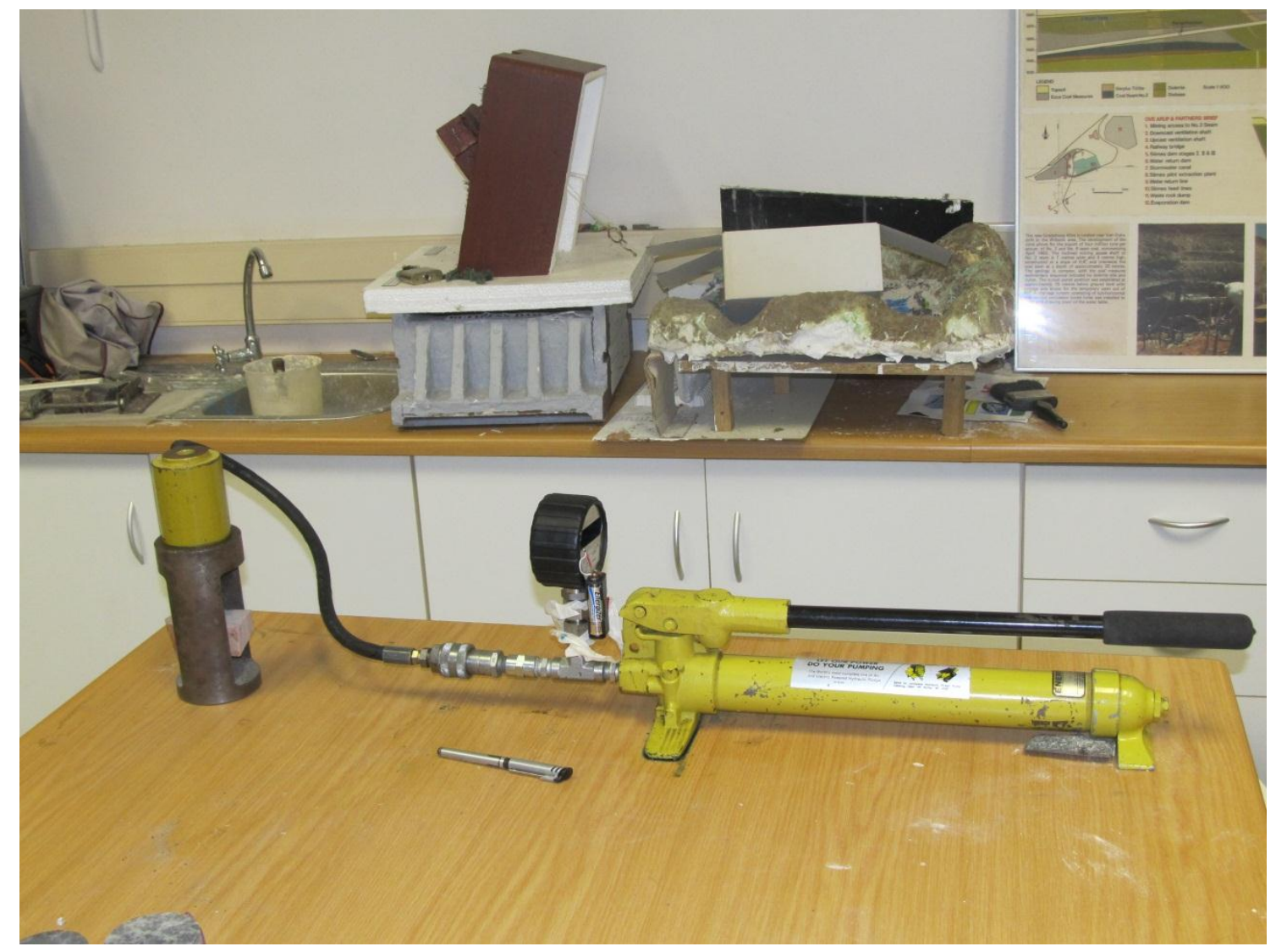

Figure 5.4: An illustration of the point load testing apparatus. 


\subsubsection{Tilt angle test}

The tilt test is a simple and relatively quick method to estimate the basic friction angle, $\phi_{\mathrm{b}}$ (Barton and Choubey, 1977). Stimpson (1981) described a method whereby three pieces of core of equal lengths are used. A third piece of core, which is free to slide, is placed on top. The table is then tilted until the sliding of the upper piece of core takes place. In this study, a modified version of the Stimpson's tilt test was adopted.

The basic friction angle can be estimated on smooth joint or clean surfaces that have been prepared by diamond saw cut as recommended by Hoek and Bray (1981). A core sample PB 01 was cut into two halves using a diamond saw. The halves were then placed together on a horizontal position of the tilting devise (Figure 5.5) which was designed by then visiting Prof. Colin Jermy in the Geological Science Discipline at the University of KwaZulu-Natal. The device was tilted from the horizontal position using a knob on the right which can tilt either forward or backwards until the top half of the core slides.

The point at which sliding took place was measured and taken as the tilt angle or basic friction angle, $\phi_{\mathrm{b}}$. Fifteen tests were performed and the average of these was taken as the basic friction angle.

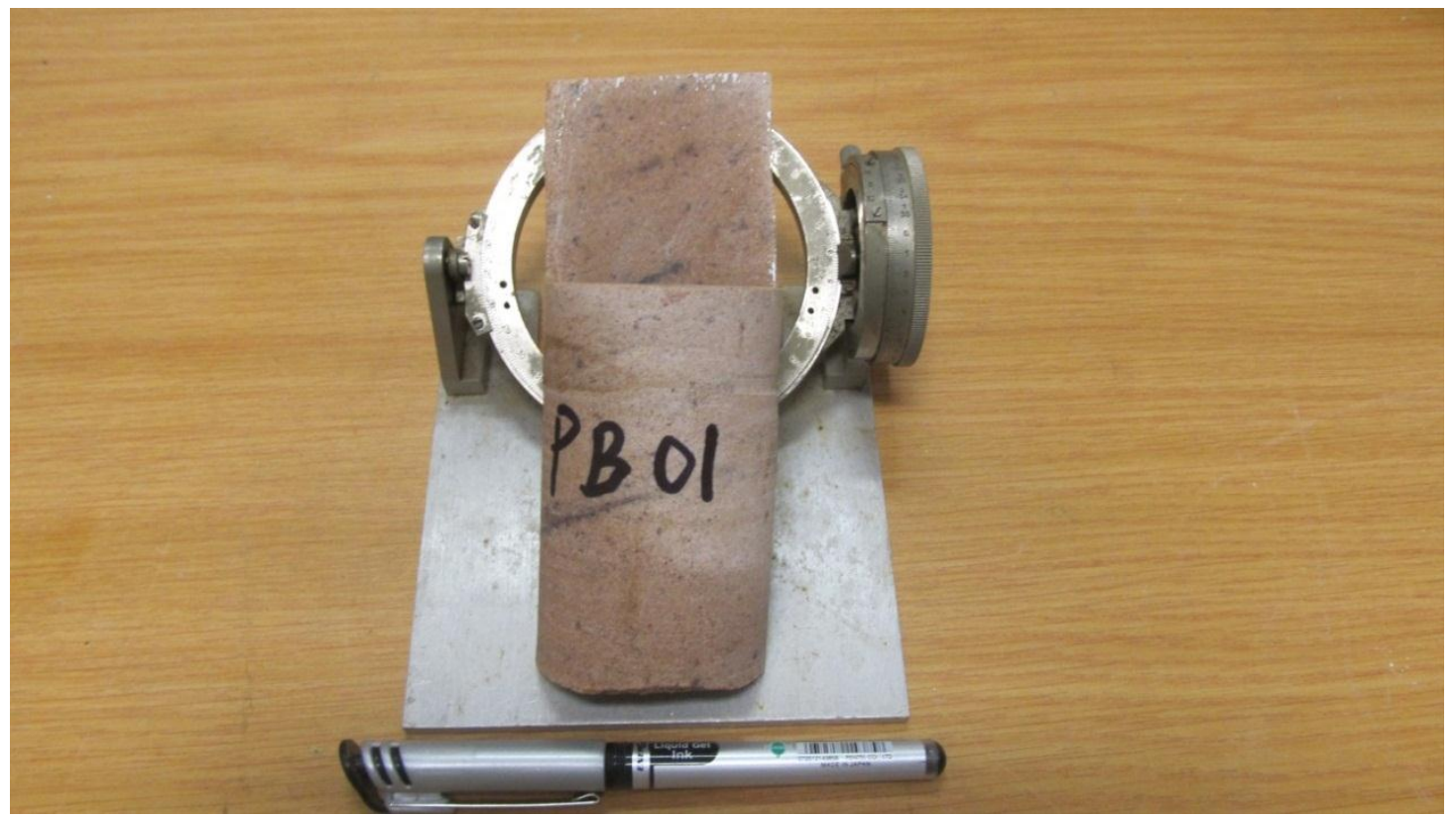

Figure 5.5: Tilting devise for the determination of $\phi_{\mathrm{b}}$. 


\subsubsection{Unit weight}

The unit weight of a rock $(\gamma)$ is the ratio of weight of rock mass (force) to its volume, and is generally expressed in $\mathrm{kN} / \mathrm{m}^{3}$ (Equation 5.5).

$$
\boldsymbol{\gamma}=\frac{\mathrm{w}}{\mathrm{v}}
$$

where $\mathrm{W}$ is the weight of rock material and $\mathrm{V}$ is the volume (volume is calculated by $\pi \mathrm{r}^{2} \mathrm{~h}$, where $\mathrm{r}$ is the radius and $\mathrm{h}$ is the height of core).

The knowledge of rock density is important in engineering and mining practice because it is used to calculate the overburden stress (Goodman, 1980). In order to determine the unit weight of the rock found on site the core samples were weighed using an electronic scale. The dimensions to calculate the volume of the core samples were measured using a caliper. Five core samples were used to determine the unit weight.

\subsubsection{Unconfined compression strength (UCS)}

The UCS test is the most commonly used strength test for characterising the strength of intact rock specimen (Goodman, 1980). It does not reflect large scale in situ properties. The UCS is expressed as the ratio of peak load (P) to initial cross-sectional area (A) of a core sample (Goodman, 1980):

$$
\mathrm{UCS}=\frac{\mathrm{P}}{\mathrm{A}}
$$

Where, UCS is unconfined compressive strength, $\mathrm{P}$ is maximum load, $\mathrm{A}$ is cross sectional area of a core sample.

The methods used for testing followed the recommendations of the ISRM (1978) and ASTM designation D2938 - 71a and subsequent revisions by ISRM (1981). The MTS systems UCS testing machine at the Rock Engineering laboratory in the Discipline of Geological Sciences at the University of KwaZulu-Natal was used to test the intact rock strength (Figure 5.6). The test and the results are controlled and managed by an intergraded data management software program SANZ. 


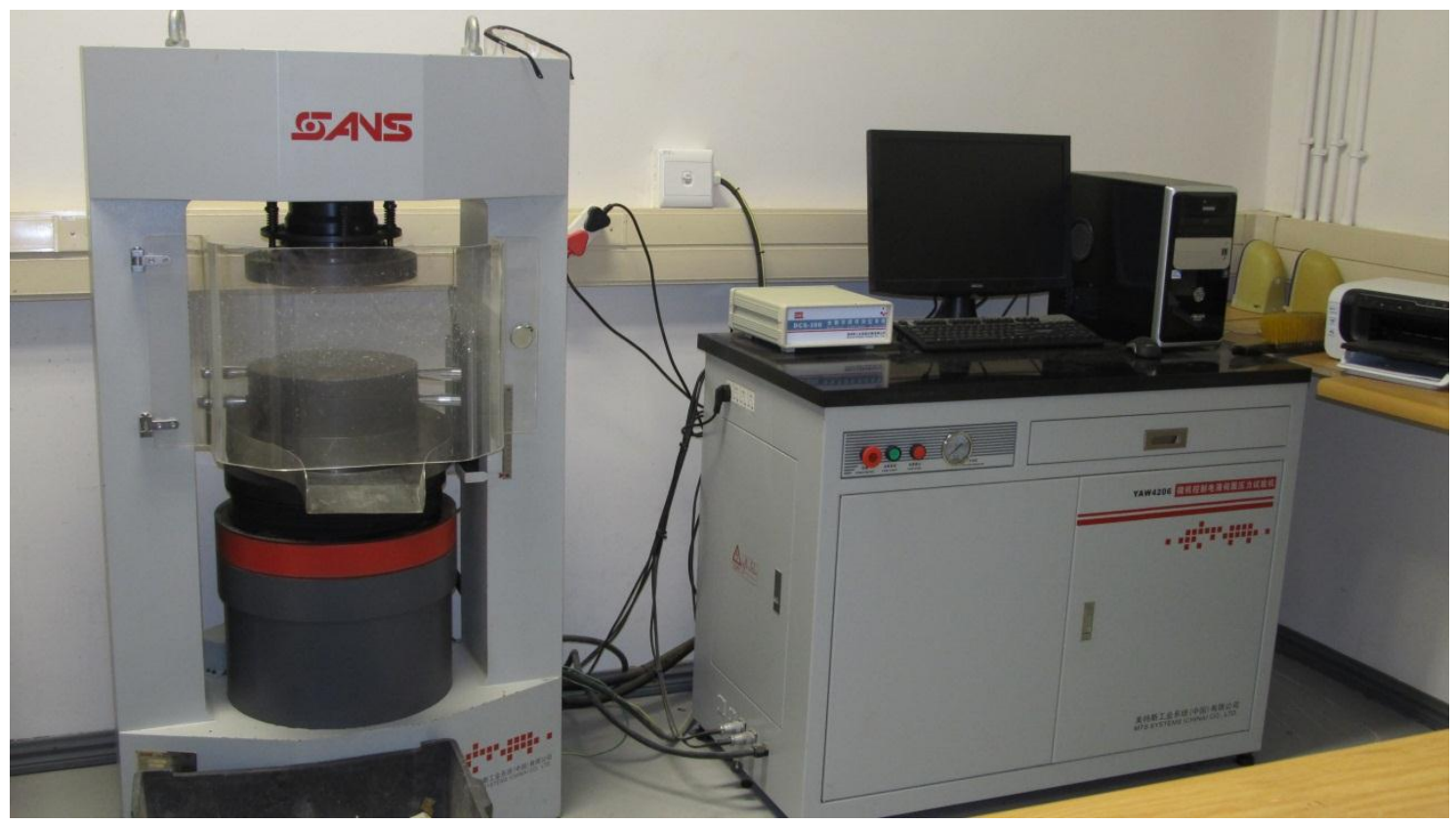

Figure 5.6: The UCS testing machine used at the University of KwaZulu-Natal.

Five (5) core samples were cut to length to diameter ratio of 2:1 and loading was carried out at $1 \mathrm{MPa}$ per second until failure occurred. Dry conditions were assumed for intact rock sample in this study.

\subsubsection{Sample preparation and test procedure for UCS.}

\section{i. $\quad$ Sample preparation}

The samples were of irregular shape, rock blocks of about $30 \mathrm{~kg}$ in mass. However, the "Suggested Methods for Determining the Uniaxial Compressive Strength and Deformability of Rock Materials" of the ISRM (1979) stipulates that the specimen should be circular cylinders and that the ratio of specimen height to diameter should be 2:1. The samples were trimmed using a cutting saw such that the blocks could be clamped properly in the cross vice of the coring machine as shown in Figure 5.7. The aim was to obtain core specimens of a $55 \mathrm{~mm}$ diameter with lengths greater than $110 \mathrm{~mm}$. The end surfaces of each specimen for UCS testing were sawed flat and parallel by cutting-off followed by grinding. This was done to avoid stress concentration on high points which could result in premature rock failure. 


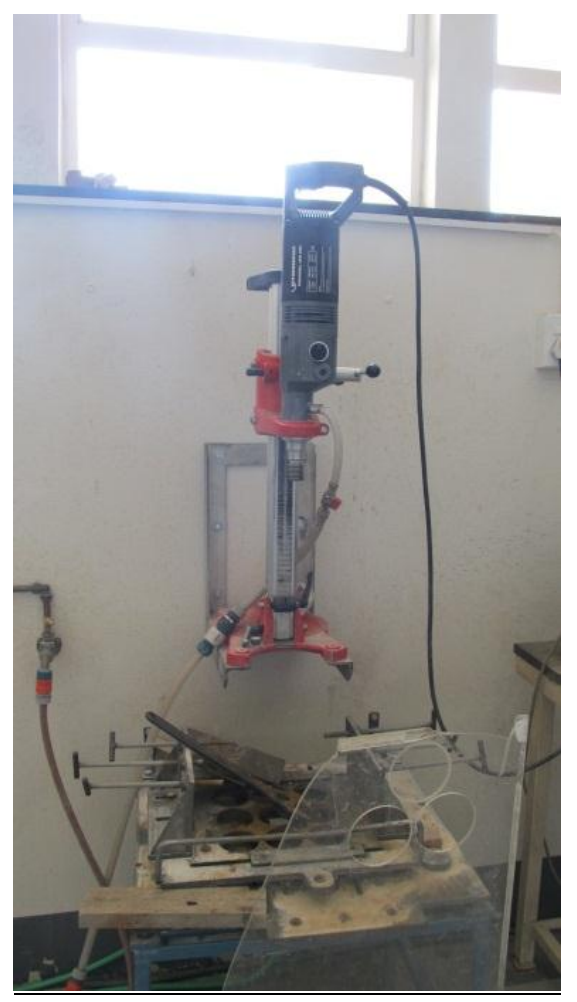

Figure 5.7: A Rothenberger ${ }^{\circledR}$ rodiadrill 1800 machine used to core rock blocks to NX-size diameter.

\section{ii. $\quad$ Test Procedure}

Five samples were tested in order to give representative values of the UCS. Preferably, the sample should be tested with its in situ moisture content. The ends of the sample were flattened and its sides straight because any irregularities on the sample can cause disturbances in the desired state of uniaxial stress. The platens must be at right angles with the specimen's axis. The ratio of the sample's height $H$ to diameter $D$ should be $2: 1$, since the introduction of the load at the specimen's ends does not take place free of shear stresses (Wittke, 1990).

After preparation, the diameter of the cores was $55 \mathrm{~mm}$ and the lengths were about $110 \mathrm{~mm}$.

The dimension of each sample prior to testing was entered into the computer. This was then followed by axial loading of the cylindrical specimen electronically using the MTS systems UCS testing machine until failure of the sample occurred. Once failure occurred, the machine was stopped and the results read off electronically. 


\subsubsection{Indirect Tensile Strength (Brazilian test)}

In this study, the Brazilian test has been employed for the purpose of determining the tensile strength of rocks. The test makes use of a circular solid disc which is compressed to failure across a diameter (Figure 5.8). The Brazilian test is assumed that failure results from the formation of a diametral tension crack and the stress distribution along that diameter is of greatest interest (Vutukuri et al., 1974). The approximation for the intact rock sample's tensile strength may be given by the following expression (ISRM, 1981):

$$
\sigma_{t}=0.636 \frac{P}{D . t}(\mathrm{MPa})
$$

where $\mathrm{P}$ is the ultimate load at failure $(\mathrm{N}), \mathrm{D}$ is the diameter of the test specimen $(\mathrm{mm}), \mathrm{t}$ is the thickness of the test specimen measured at the centre (mm).

The Brazilian test machine used at the University of KwaZulu-Natal was set in such a way that the Brazilian tensile strength is calculated by:

$$
\text { Brazilian disc strength }\left(\sigma_{t}\right)=\frac{0.636 \text {. Load }}{\text { Diameter. length }}
$$

where Load $=$ Pressure at failure $(\mathrm{MPa}) \times$ Ram Area $\left(\mathrm{m}^{2}\right)$, and Ram Area $=0.005027 \mathrm{~m}^{2}$.
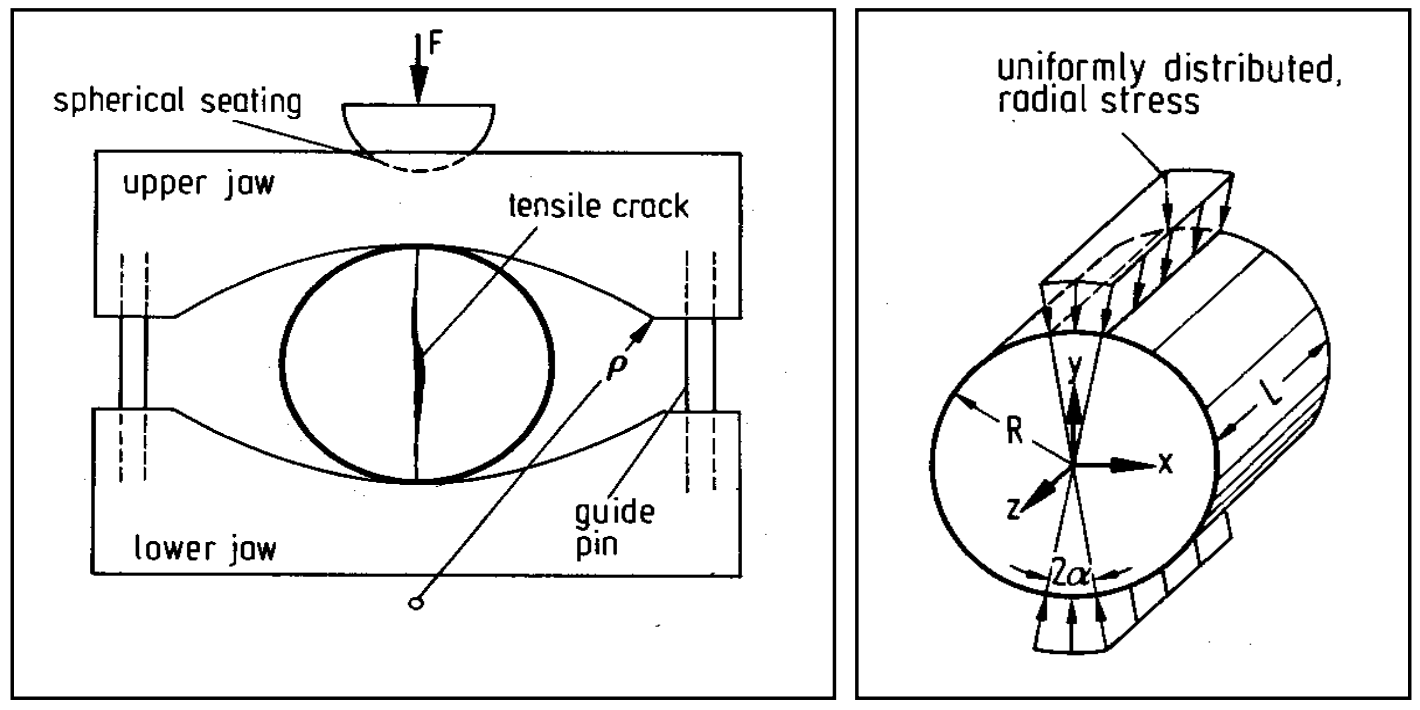

Figure 5.8: Principle of the Brazilian testing arrangement and apparatus and nature of failure (after Wittke, 1990). 
The load $(\mathrm{kN})$ is applied to the specimen by way of steel jaws with cylindrical loading surfaces, the radius of curvature of which is larger than the radius of the core sample. Elastic deformation of the specimen and loading jaws creates two surfaces of contact across which the load is applied. If the arc of contact illustrated in Figure 5.8, 2 $\alpha$, amounts to some 10\%, this manner of loading usually restrict the compressive stresses $\sigma_{\mathrm{x}}$ and $\sigma_{\mathrm{y}}$ in the area around the contact surfaces and largely prevents the intact rock's compressive strength from being exceeded (Wittke, 1990).

Samples were loaded manually with flat parallel platens, in order to achieve an almost uniformly distributed radial stress as shown in Figure 5.9. Prior to testing, a masking tape was wrapped around the cylindrical area of each sample surface to spread the load. Great care was taken during sample reparation to ensure an even cylindrical surface and parallel end surfaces. A total of six samples were tested.

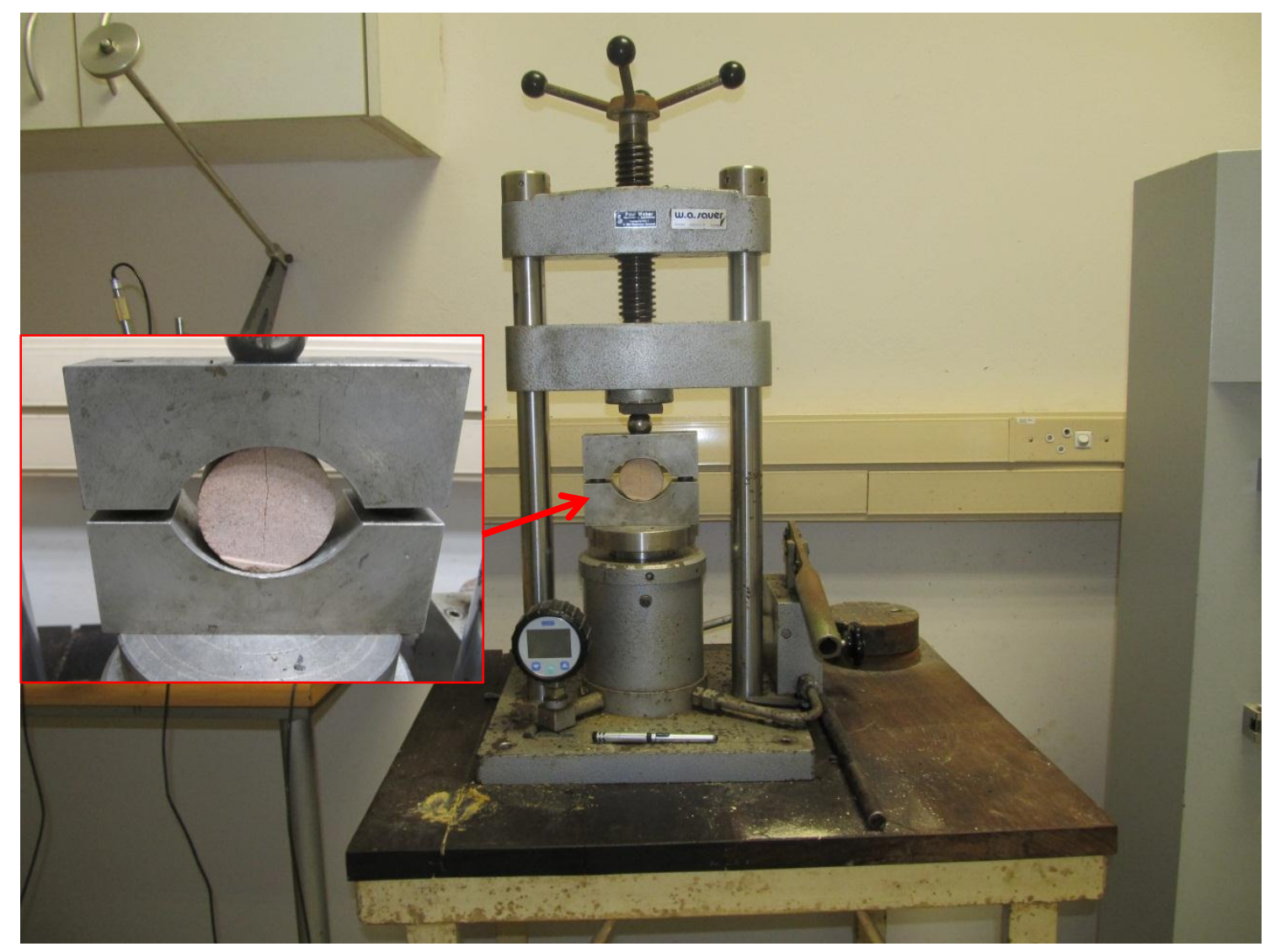

Figure 5.9: Laboratory set up for the Brazilian indirect tensile strength test. 


\subsubsection{Golder Shear Box Test}

The shear strength of joints is a key property in slope stability analysis and design of engineering structures. Determination of friction angles expressed as basic, residual or peak friction angle are fundamental to the understanding of the shear strength discontinuities in rock mass (Hoek, 2000). Determination of reliable shear strength values is a critical part of a slope stability analysis because relatively small changes in shear strength can result in significant changes in the safe height or angle of a slope (Bye and Bell, 2001). The shear strength of a rock mass and its deformability are greatly influenced by discontinuities and how they are developed. Failure of engineering structures on rock is largely controlled by the deformation of the joints and the surface roughness is a chief component of the factors contributing to the shear strength along these discontinuities (Bell, 1994).

The Golder shear box test is performed on specimens that are homogenous, or have planes of weakness, including natural or artificial discontinuities (ASTM: D 5607 - 95). The Golder associate shear box allows the shear strength of samples of rock discontinuities to be measured under normal stresses of up to $2 \mathrm{MPa}$ i.e. low normal stresses and the normal load is applied by means of a dead load system. It therefore remains constant throughout the test and is therefore more sensitive than the portable shear box (Hencher and Richards, 1989). It was developed in the early 1970's to provide a simple and adequately sensitive apparatus for testing discontinuities in most engineering situations. Moreover, the minimum effective normal stress acting across joints considered critical for stability lies in the range of 0.1 to $2.0 \mathrm{MPa}$ (Barton, 1976). Low normal stresses allow motion to take place by climbing up the ridges and asperities which make up the rough surface of the discontinuity in the direction of shearing (Hencher and Richards, 1989).

\subsubsection{Specimen Preparation and Testing Procedure}

\section{Specimen Preparation}

The specimens tested for shear strength determination were generally sampled on joints in the same set as the failure plane where exposures and recovery of these permitted.

The "shear box" mould can accommodate joint specimens with a side length and width of about $60 \mathrm{~mm}$, height of about $100 \mathrm{~mm}$ (Figure 5.10). Specimens were prepared from blocks with single natural discontinuities. 


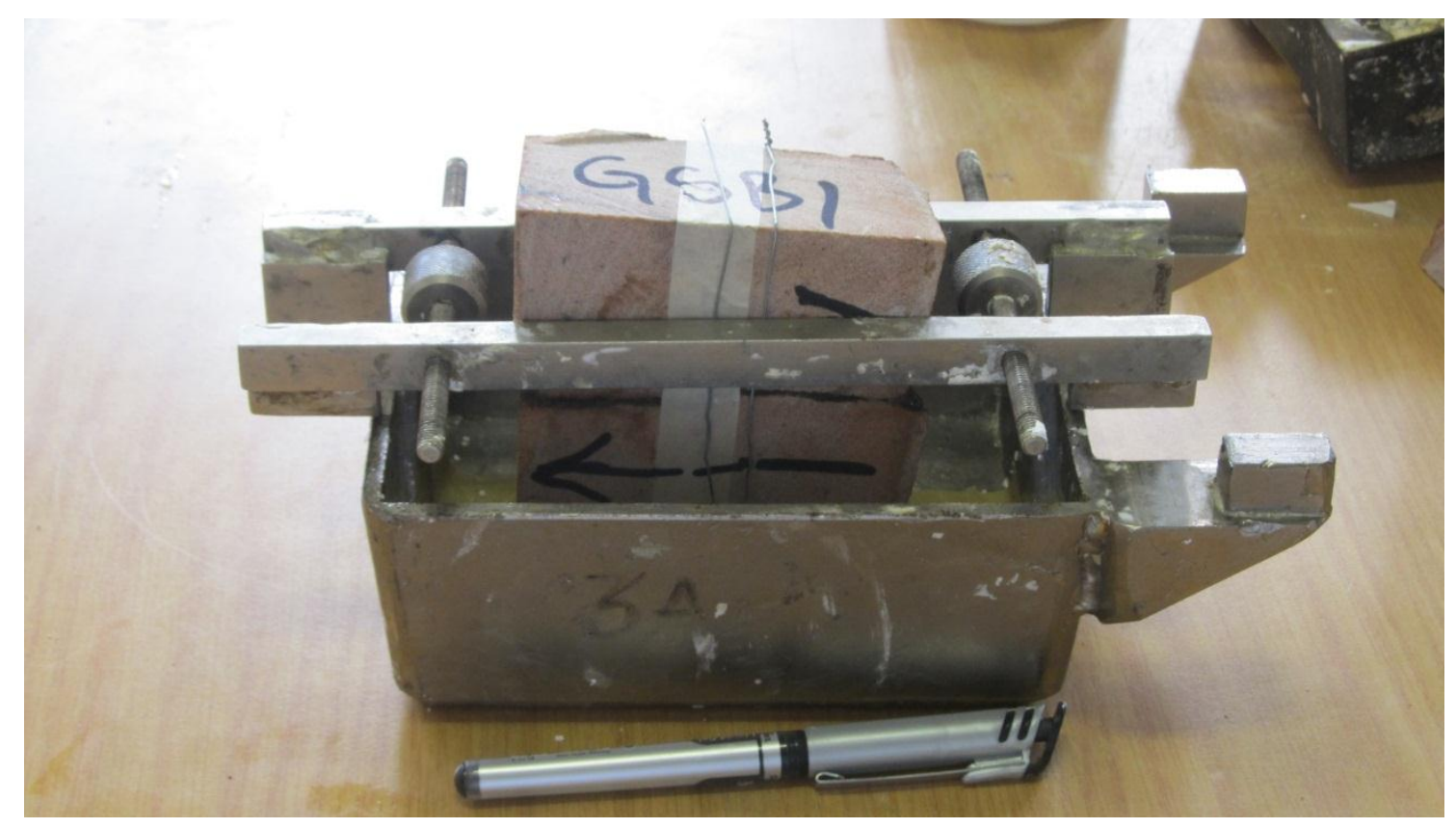

Figure 5.10: Casting position with clamp holding the joint sample.

The casting of a specimen was done in accordance with the Suggested Method for Laboratory Determination of Direct Shear Strength of the International Society for Rock Mechanics (ISRM 1974 and 2006). Before pouring in the gypsum plaster, the boxes were thoroughly greased with silicone lubricating paste. The casting of specimens into the upper and lower boxes involved the use of crystal base gypsum casting mix. Both halves of the specimen were fixed by wire in the casting moulds by gypsum plaster in a way that the discontinuity between them is in line with the direction of shearing.

The JRC value of the roughness profiles of each sample tested was estimated visually based on the standard joint profiles proposed by Barton and Choubey (1977) (Figure 4.3) prior to shear testing.

\section{The casting mix preparation}

The quick setting crystacal base gypsum plaster was used for casting the samples prior to testing. This gypsum plaster preparation has been used for many years in the rock engineering laboratory at the University of KwaZulu-Natal (Hingston, 1997). The preparation involves the use of $500 \mathrm{ml}$ of water to $1.25 \mathrm{~kg}$ of crystal base gypsum (Figure 5.11). This amount is sufficient for just half of one mould pair. The plaster required at least one hour to set before the clamp holding the sample in position could be removed. The samples were allowed to cure for at least 24 hours before testing. 


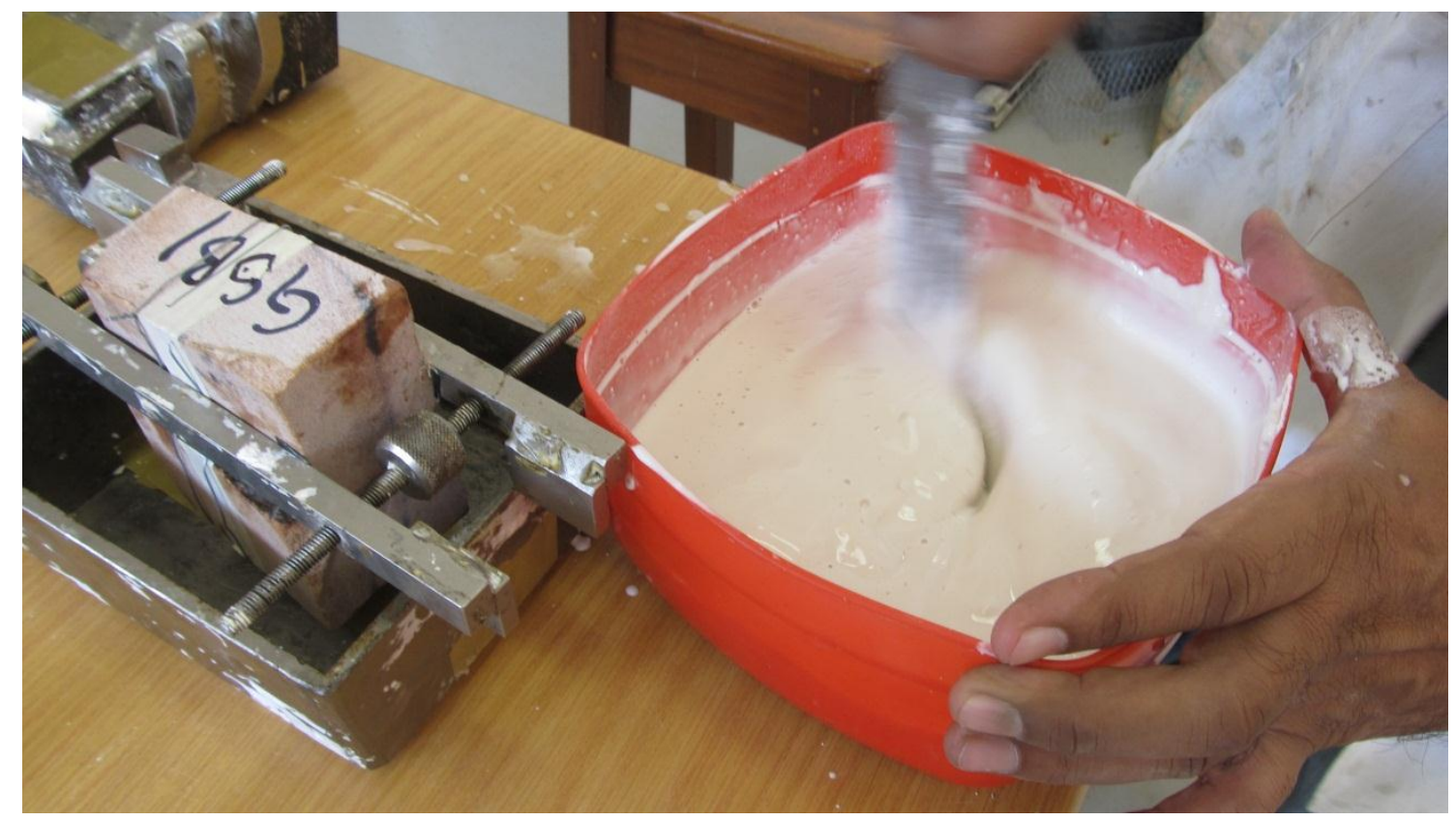

Figure 5.11: Preparation of quick setting gypsum plaster to cast half of one mould pair.

\section{The Golder Shear box apparatus and test procedure}

There are about ten main components in the Golder shear box test apparatus as shown in Figure 5.12. The Shear box is securely fastened to a bench so that application of the weights on the lever arm would not cause overturning. The lower box is able to move in horizontal direction and friction between the lower box and the bottom of the apparatus is minimized by the use of a low friction bearing plate. The upper box was fixed in place and connected to a force transducer that measures the shear force on the specimen's discontinuity. A ball bearing was placed on the upper mould before lowering the lever into position. The amount of weight required which ranged between 10 and $15 \mathrm{~kg}$ for the pre-determined normal stress was then added on the hanger system. The last step before shearing was the cutting of the wire binding the two halves using a long nose side cutting pliers.

The load cell and the vertical and horizontal displacement transducers were then installed and zeroed. The vertical displacement transducer was positioned on the loading arm in such a way that the measured displacement was amplified by a factor of 10 . This means that in the analysis of shear box test result, vertical displacement was divided by 10 . The shearing commenced by steadily pumping a hydraulic jack which then moved in relation to the upper box. 


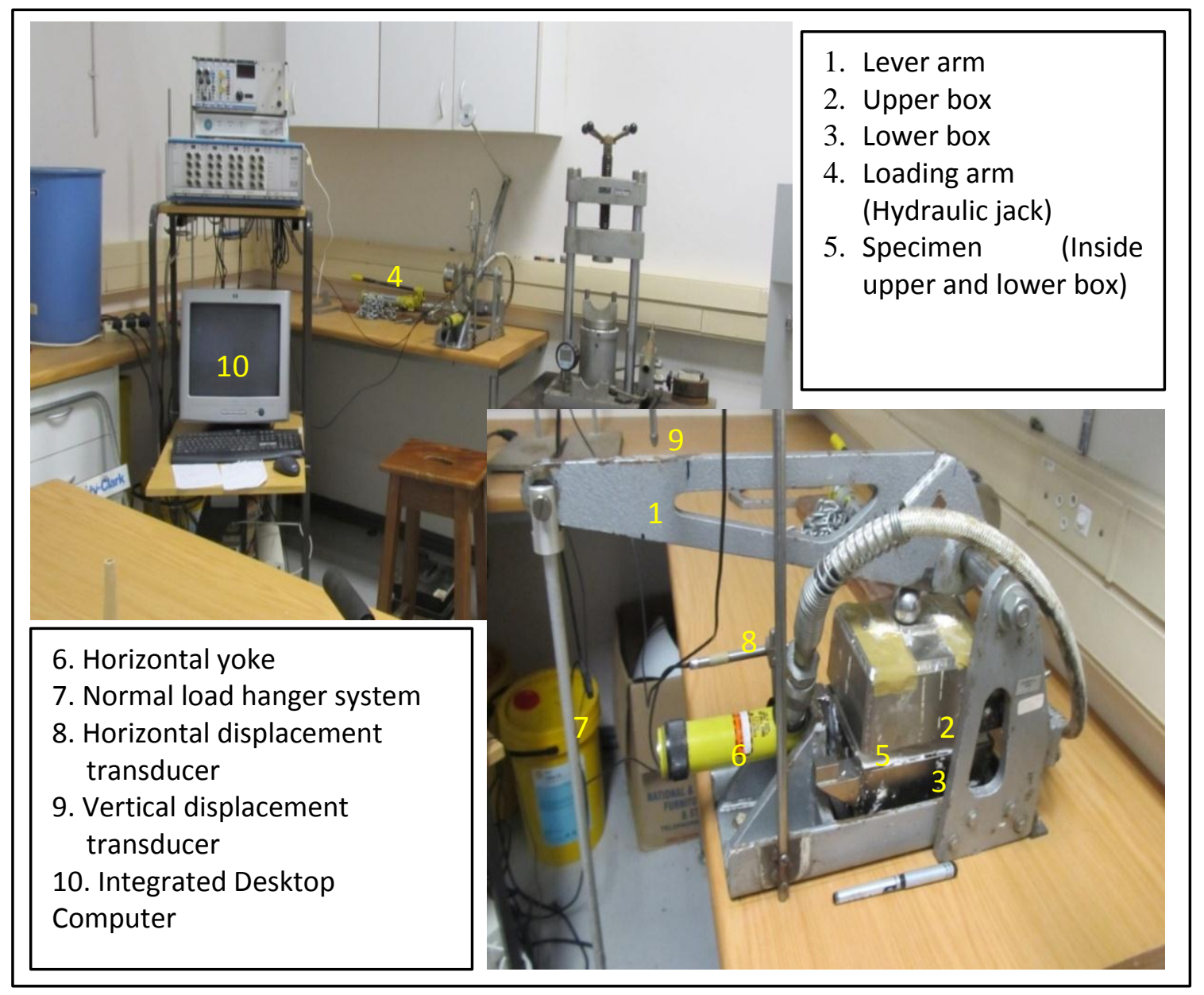

Figure 5.12: A Golder shear box machine set up.

Shearing was terminated after a point at which the load cell graph showed that peak shear strength has been reached and subsequently plateaued.

Readings from the transducers and the load cell were automatically recorded by a computer data logger program Catman Express. The recorded data was than exported to Microsoft Excel spreadsheet for further analysis.

Joint inspection after testing revealed that the sheared contact area was very small in relation to the entire sample surface area.

Six joint samples were tested and the results are presented in the next chapter.

\section{i. Loading calibration of the Golder shear box}

Hingston (1997) carried out loading calibration for the same Golder shear box at the University of KwaZulu Natal to achieve the required normal stress for each joint. This loading calibration 
was carried out to derive an equation to calculate the amount of dead load required for a particular normal stress. He derived the following equation by regression analysis:

$$
Y=0.112207 x+0.156859
$$

Where $\mathrm{Y}=$ normal load and $\mathrm{x}=$ weight on hanger.

Then, knowing the joint surface area, the quantity of weight required (x) for the normal load to achieve the required normal stress for each joint pair was calculated.

\subsection{Summary}

This chapter described broadly how the fieldwork and laboratory testing was undertaken. These consisted of discontinuity survey, sample collection and preparation, and laboratory testing.

The discontinuity survey was undertaken in order to carry out a kinematic analysis using the Markland's test for determining the possible mode of failure.

The RMR and GSI geomechanical rock mass classification systems which are influenced by field and laboratory data were also discussed.

The latter half of the chapter described how the laboratory tests (point load, tilt angle, UCS, indirect tensile strength and Golder shear box tests) were undertaken

The next chapter presents the results of relevant input parameters such as $(\gamma, \mathrm{JCS}, \mathrm{JRC})$ and geotechnical characteristics of the site. 


\section{CHAPTER 6}

\section{RESULTS AND GEOTECHNICAL CHARACTERISTICS OF THE PROJECT SITE}

\subsection{Introduction}

The kinematic analysis of discontinuity survey data is presented as well as the analyses of the failure mechanisms at the project site. Results of laboratory tests which consisted of UCS, Golder shear box, tilt angle, indirect tensile strength and point load tests are also presented.

\subsection{Kinematic analysis}

It was observed during field investigation, that the possible mode of failure of the landslide was planar. A kinematic analysis based on the dip and dip direction measurements obtained from the cell mapping was carried out in order to confirm this (Chiliza and Hingston, 2014).

The kinematic analysis was based on the Markland's (1972) test in conjunction with the Rocscience Inc. software Dips (2002) which was used to generate the stereonets from the discontinuity survey data collected. The software Dips, is a kinematic analysis toolkit for planar, wedge and toppling analysis which is continuously being upgraded. This program enables the relationships between discontinuities and the slope face to be established.

A total of 202 dip and dip direction measurements presented in Appendix A, were inputted into Dips in order to carry out the kinematic analysis. The data was inputed into Dips spreadsheet which contains the dip and dip direction columns.

\subsubsection{Pole plots and concentrations}

The data was plotted as poles and subsequently contoured into pole concentrations to be recognized from essentially random data as proposed by Hoek and Bray (1981). The stereographic projection used was the equal angle lower hemisphere projection which is a default projection for the Dips software. 
Figure 6.1 shows both pole scatter with contours that highlight the highly concentrated areas. The areas considered are those with Fisher concentration of $6 \%$ or greater for defining prominent joint sets.

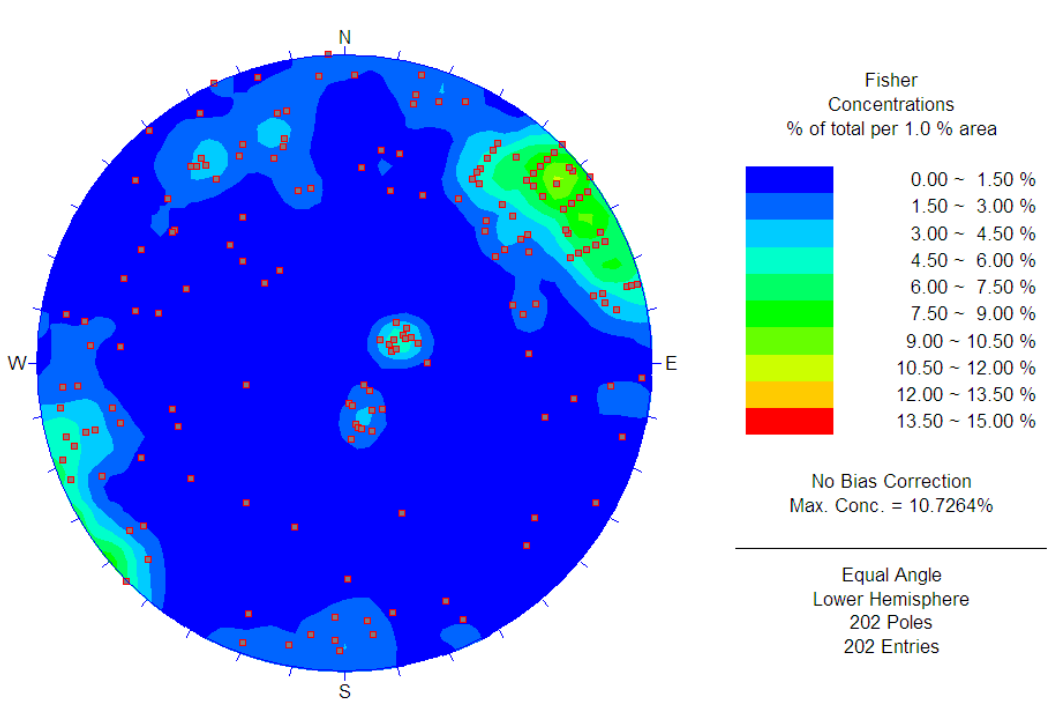

Figure 6.1: Dips pole plots of 6\% or greater Fischer concentrations.

\subsubsection{Joint sets plot}

The pole concentrations were then grouped to determine the major joint sets from which three sets of joints JS1 (bedding), JS2 and JS3 (discontinuities) were subsequently determined (Figure 6.2). The determination of these relationships is essential for further kinematic analysis of the major joint sets. Based on the results, bedding planes (JS1) are predominantly gently inclined towards the north east. The maximum concentration of poles for JS1 is approximated at $15^{\circ} / 283^{\circ}$. In the case of JS2 \& JS3, the maximum pole concentrations are approximated at $85^{\circ} / 237^{\circ}$ and $73^{\circ} / 157^{\circ}$ respectively as shown in Table 6.1 and Figure 6.2.

Table 6.1 shows a summary of the unweighted mean values for the three sets concentrations.

Joint set 2 (discontinuity) has the highest Fisher concentrations of poles followed by JS1 (bedding) then JS3 (discontinuity). 

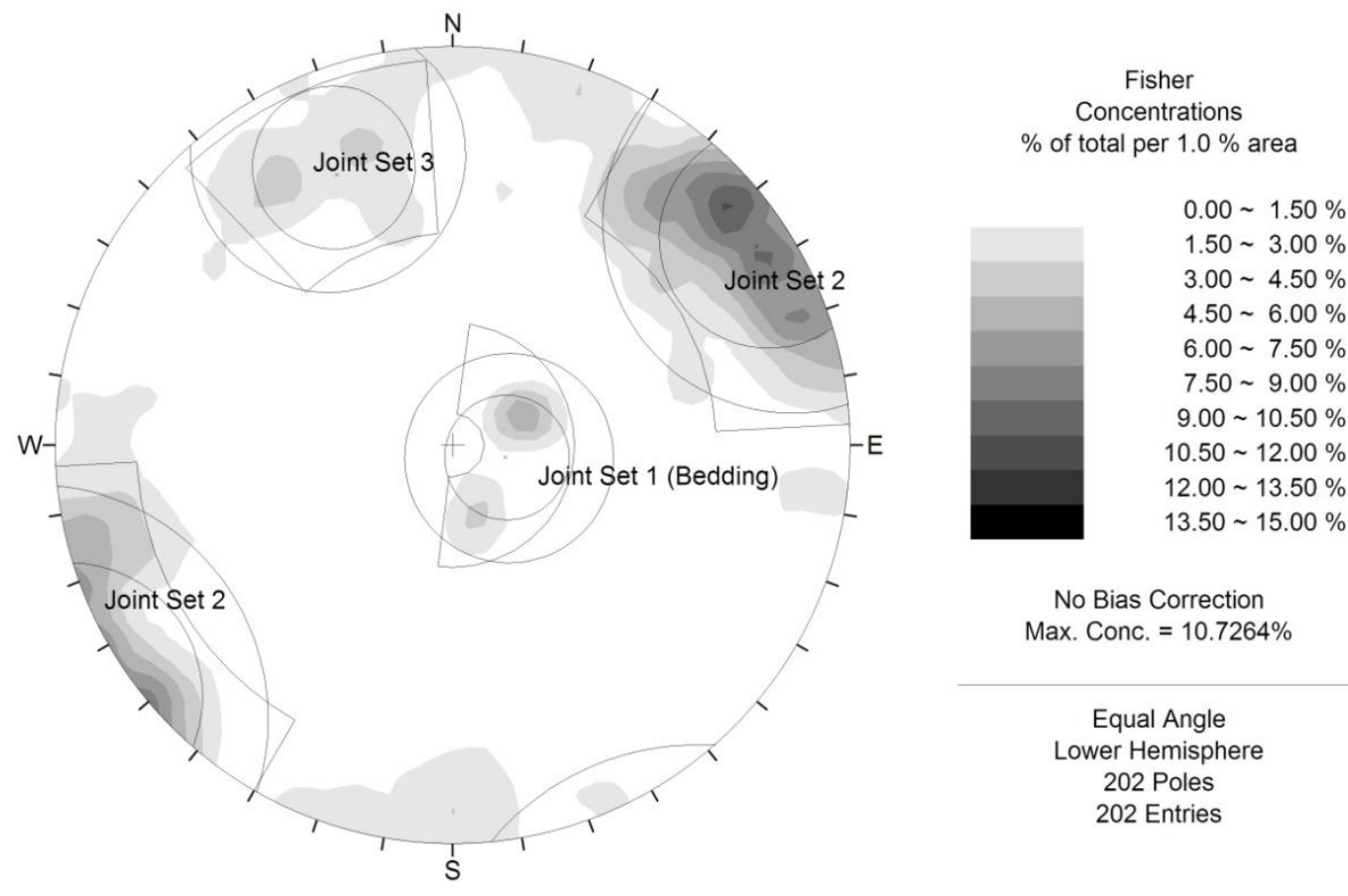

No Bias Correction Max. Conc. $=10.7264 \%$

Equal Angle Lower Hemisphere 202 Poles 202 Entries

Figure 6.2: Stereoplot showing the contoured plot of the poles and the three joint sets.

Table 6.1: Average discontinuity set data obtained from Dips.

\begin{tabular}{|c|c|c|c|}
\hline Joint set number & Dip $\left(^{\circ}\right)$ & Dip direction $\left(^{\circ}\right)$ & Roughness \\
\hline 1 Bedding $(\mathrm{J} 1)$ & 15 & 283 & Slightly rough \\
\hline 2 Joint $(\mathrm{J} 2)$ & 85 & 237 & Moderately rough \\
\hline 3 Joint $(\mathrm{J} 3)$ & 73 & 157 & Moderately rough \\
\hline
\end{tabular}

\subsubsection{Plane failure analysis}

The mechanism of failure was determined by analysing the relationship between the major joint sets and the slope face by the Markland (1972) tests as suggested by Hoek and Bray (1981). The dip and dip direction of the plane of failed slope was found to be $80^{\circ} / 040^{\circ}$.

As shown in Figure 6.3, to analyse plane failure the pole friction cone of plunge $90^{\circ}$ and $35^{\circ}$ dip was roughly estimated to represent friction angle of the quartzitic sandstone as prescribed by Hoek and Bray (1981). The daylight envelope is visible and marked with a green egg shaped circle. According to the Markland's test, any pole that falls outside the cone represents a plane 
that could slide if kinematically possible. Hence there was no chance for JS1 to slide because it falls within the friction cone area on the stereonet. Based on the analysis, there is an indication that (JS2) poles represent planes which would slide and were susceptible to plane failure.

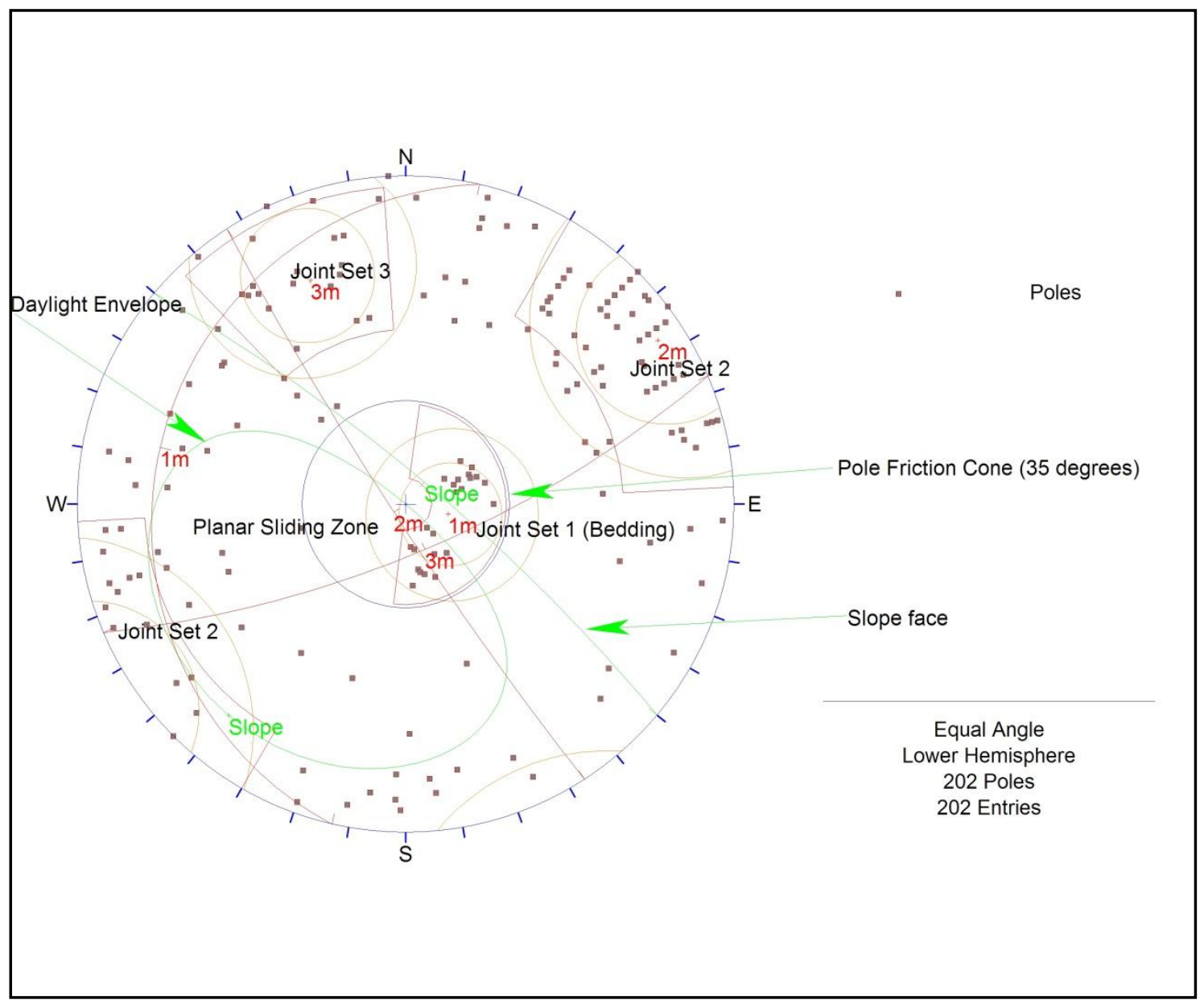

Figure 6.3: Stereonet plot showing analysis of plane failure using daylight envelope and friction cone.

A crescent shaped zone formed by the daylight envelope and the pole friction circle encloses the region of planar sliding. Estimating probability of failure based on poles of JS3 that fell within this zone was not relevant because the slope had already failed. Notably is that JS3 coincides with a fault that was mapped as an undifferentiated lineament which also coincides with the tension crack crest at the crest of the scarp (see Figure 2.4).

From the analysis, plane failure mode was determined based on the orientation of the slope, the orientation of rock discontinuities, and the internal angle of friction of the rock mass. This was found to be consistent with field observations (Chiliza and Hingston, 2014). These results support the use of suitable limit equilibrium method which is for structurally controlled planar 
failure (Hoek and Bray, 1981), for the back analysis in order to investigate the geotechnical conditions that may have led to failure.

\subsection{Geotechnical properties of the material}

This section presents the results of index properties of the rock material obtained from the laboratory tests. The results of the index tests conducted are summarized in Table 6.2 (a) and (b) and details of the calculation are presented in Appendix B.

Table 6.2a: Results of index and mechanical properties of the rock material obtained from laboratory testing.

\begin{tabular}{|c|c|c|c|c|c|}
\hline \multicolumn{4}{|c|}{ Schmidt hardness rebound test } & \multicolumn{2}{|c|}{ Point load test } \\
\hline \multicolumn{2}{|c|}{ Rebound values $(\mathbf{R})$} & \multicolumn{2}{|c|}{ UCS by Miller (1965), (MPa) } & \multirow{2}{*}{$\mathbf{I}_{\mathbf{s}(\mathbf{5 0})}$} & \multirow{2}{*}{$\begin{array}{l}\text { UCS given by } \\
\text { Broch and } \\
\text { Franklin } \\
\text { (1972), (MPa) }\end{array}$} \\
\hline Vertical & Horizontal & Vertical & Horizontal & & \\
\hline [28-50] & {$[28-48]$} & [50-135] & [50-130] & [1.37-12.28] & [31-282] \\
\hline (37) & (37) & (82) & (79) & $(5.51)$ & (126) \\
\hline$* 17$ & $* 23$ & $* 17$ & $* 23$ & $* 29$ & $* 29$ \\
\hline
\end{tabular}

Table 6.2b: Results of index and mechanical properties of the rock material obtained from laboratory testing.

\begin{tabular}{|c|c|c|c|}
\hline $\begin{array}{c}\text { Direct unconfined } \\
\text { compressive strength test } \\
\text { (UCS, MPa) }\end{array}$ & Unit weight $\left(\mathbf{k N} / \mathbf{m}^{\mathbf{3}}\right)$ & $\begin{array}{c}\text { Indirect tensile } \\
\text { (Brazilian) strength test } \\
(\mathbf{M P a})\end{array}$ & $\begin{array}{c}\text { Tilt angle test } \\
\mathbf{(}) \\
\left(\phi_{\mathbf{b}}-\text { basic }\right. \\
\text { friction } \\
\text { angle) }\end{array}$ \\
\hline$[145-250]$ & {$[28.54-28.64]$} & {$[4.1-7.8]$} & {$[25-31]$} \\
$(189)$ & $(28.59)$ & $(5.7)$ & $(26.5)$ \\
$* 5$ & $* 5$ & $* 6$ & $* 15$ \\
\hline
\end{tabular}

The results presented are discussed subsequently in succeeding sections. 


\subsubsection{Schmidt hardness rebound test}

The summary of the results as shown in Table 6.2a shows that the UCS values derived from Schmidt hammer tests ranged from $50 \mathrm{MPa}$ to $135 \mathrm{MPa}$ with a mean of 37 and $80 \mathrm{MPa}$ respectively. According to Duncan (1969) the intact rock strength of the quartzitic sandstone found at the project site classifies as a strong rock.

A table that shows separate values for the horizontal and vertical directions under which the Schmidt hardness rebound tests were conducted is included in Appendix B.

\subsubsection{Point load test}

The failure mode observed on the tested samples generally occurred parallel to the loading direction in a form of single extensional fracture planes. Isolated incidents of what was described as dihedral failure mode patterns were also observed whereby three extensional failure planes (i.e. triple junction) form $120^{\circ}$ angles.

The results from the point load test revealed that the corrected size index strength and UCS values range from 1.37 MPa to 12.28 $\mathrm{MPa}$ and $31 \mathrm{MPa}$ and $282 \mathrm{MPa}$ respectively with a mean of 5.51 and $126 \mathrm{MPa}$ respectively. According to ISRM (1979) strength classification for intact rock, the strength of the rock was classified as medium to very high.

\subsubsection{Unconfined compressive strength (UCS)}

The compressive strength for the quartzitic sandstone ranges from $145 \mathrm{MPa}$ to $250 \mathrm{MPa}$. Failure of the quartzitic sandstone occurred very violently and the two types of failure patterns that were evident were conical failure and axial splitting failure (fail into slabs parallel to the long axis of the core) (Figure 6.4). Sounds of 'the first stage in the failure process' could be heard as if micro-cracks were forming or tiny bits of rock were coming off the core surface under incremental load by the MTS UCS machine until pronounce failure occurred.

Based on the values obtained from the UCS tests, the strength of the quartzitic sandstone could be classified as high to very high based on the ISRM (1979) classification. This can be attributed to internal factors e.g. mineralogy, grain size and porosity. The tested rock contained about $90 \%$ of quartz mineral and the binding of grains was contact to contact which could have resulted in the high compressive strength. The grain sizes are small. According to Vutukuri et al. (1974), these factors are interrelated and they complement each other in determining the 
compressive strength of a rock. However, there can be cases where the compressive strength increases but not all of the above controls are present for example dolerite, which has less than $1 \%$ if none of quartz in it (Vutukuri et.al., 1974).

Based on the mean value results from Schmidt hammer, point load and direct UCS tests which were $80.15 \mathrm{MPa}, 126.71 \mathrm{MPa}$ and $189 \mathrm{MPa}$ respectively it can be concluded that the values obtained from the direct UCS test were higher than those obtained from Miller (1965) and Broch and Franklin (1972) equations. The values obtained from Schmidt hammer were even lower and this may be due to the strength in this test is not only a function of the degree of surface weathering, but also the sample size, base material and edge effect. The UCS test proved to be more reliable than the Schmidt hammer and point load tests.
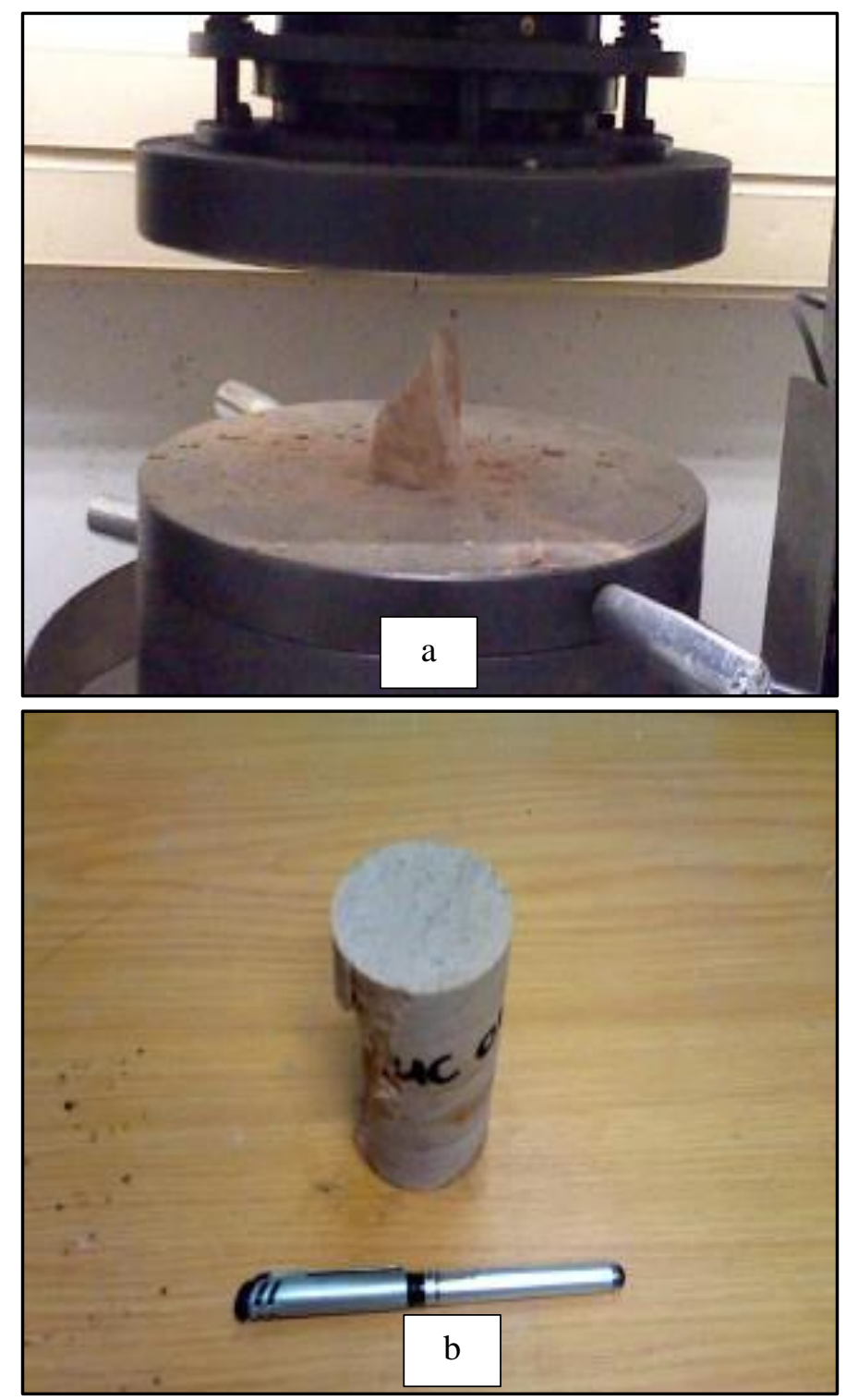

Figure 6.4: Conical and axial splitting failure patterns (a, and b respectively) from UCS testing. 


\subsubsection{Unit weight results}

It has been shown that the influence of the variability of the unit weight on the value of $\mathrm{F}$ is insignificant due to the fact that the variability in material density is small (Alonso, 1976). However, it is required in almost all rock engineering and mining practices because it is used to calculate the overburden stress and also in slope stability calculations (Goodman, 1980). The unit weight results showed minor variation of between $28.5 \mathrm{kN} / \mathrm{m}^{3}$ to $28.6 \mathrm{kN} / \mathrm{m}^{3}$, for the five core samples assessed (Table 6.2b). An average unit weight value of $28.5 \mathrm{kN} / \mathrm{m}^{3}$ was calculated for the quartzitic sandstone.

The unit weight results for quartzitic sandstone were in agreement with those published values of hard sandstone e.g. (Hoek and Bray, 1981) which range between 23 and $28 \mathrm{kN} / \mathrm{m}^{3}$. This could have been controlled by reduced porosity of quartzitic sandstone due to the recrystallization which in turn increased density.

\subsubsection{Indirect tensile strength results}

The failure mode observed on the tested samples was roughly parallel to the loading direction (or radial stress) and they are located in the central part of the sample between the two loading lines.

The results of the indirect tensile strength as shown in Table $6.2 \mathrm{~b}$ show that the tensile strength of quartzitic sandstone ranged from 4.1 MPa to 7.8 MPa with an average of 5.7 MPa.

The results for the tested rock generally fall within a range of values derived from previous studies of similar rock type. This is in comparison to values obtained by Bell (2007), where the Natal Group sandstone Brazilian strength ranges between 6-20 MPa with a mean of 14.9 MPa. But the values fall within the lower end of the spectrum of values derived by Bell (2007).

\subsubsection{Basic friction angle}

The results obtained for the basic friction angle, $\phi_{\mathrm{b}}$ are summarized in Table $6.2 \mathrm{~b}$. The values ranged between $25^{\circ}$ and $31^{\circ}$. An average basic friction angle $\left(\phi_{\mathrm{b}}\right)$ of $26.6^{\circ}$ was obtained which fell within the range of published values (Barton and Choubey, 1977) of sandstone which range from $25^{\circ}$ to $35^{\circ}$. 
Notably values in the first two tilt test are $5^{\circ}$ higher than the values obtained in the last two tilt tests of the same saw cut core sandstone sample. It is worth emphasising that the tilt angle test technique is based on a similar principle to that of Barton and Choubey (1976).

Hoek and Bray (1981) however stated that, tilt tests in which angle of inclination of the specimen required to cause sliding is measured, are not reliable for the determining of the basic friction angle because of the influence of very small scale surface roughness.

\subsection{Rock mass classification results}

The rock mass characterization was performed to obtain a preliminary evaluation of pre failure stability conditions and parameters of the rock slope mass of the study area. The rock mass was classified by making use of the Rock Mass Rating (RMR) by Bieniawski (1989), Geological Strength Index (GSI) by Hoek and Brown (1998) and then lastly the Slope Mass Rating (SMR) by Romana (1993) which is an adaptation of the RMR for slopes.

\subsubsection{Rock Mass Rating (RMR)}

The RMR incorporates six basic parameters (or 5 when excluding discontinuity orientation) in order to evaluate the strength of the rock mass (Bieniawski, 1989). The values of these parameters and their explanations as calculated in this study are shown in Table 6.3.

The rock mass class determined from the 5 basic parameters was 74, which according to Bieniawski (1989) falls in Class II for good rock masses (Bieniawski, 1989) before discontinuity orientation adjustment. 
Table 6.3: Determination of the RMR for the rock slope under consideration.

\begin{tabular}{|c|c|c|c|}
\hline \multicolumn{4}{|c|}{ RMR } \\
\hline Classification parameter & Condition description & Value & Rating \\
\hline $\begin{array}{l}\text { Uniaxial compressive } \\
\text { strength of rock material } \\
(\mathrm{MPa})\end{array}$ & $\begin{array}{l}\text { intact strength test } \\
\text { results }\end{array}$ & 189 & 12 \\
\hline $\begin{array}{c}\text { Rock Quality Designation } \\
\text { (RQD) (\%) }\end{array}$ & $\begin{array}{l}\text { based on a number of } \\
\text { fractures in a } 1 \mathrm{~m} \text { radius } \\
\text { area in an outcrop }\end{array}$ & 80 & 17 \\
\hline Spacing of discontinuities & $\begin{array}{c}\text { Generally uniform } \\
\text { spacing distance forming } \\
\text { a block rock mass } \\
\text { structure }\end{array}$ & $\begin{array}{l}300 \mathrm{~mm} \text { to over } \\
500 \mathrm{~mm}\end{array}$ & 10 \\
\hline Condition of discontinuities & $\begin{array}{l}\text { slightly rough undulating } \\
\text { surfaces }\end{array}$ & $\begin{array}{c}<1 \mathrm{~mm} \text {, slightly } \\
\text { weathered } \\
\text { surfaces }\end{array}$ & 20 \\
\hline Groundwater conditions & $\begin{array}{l}\text { Dry maybe slightly } \\
\text { damp in places }\end{array}$ & $0<0.1$ & 15 \\
\hline \multicolumn{3}{|c|}{ Total } & 74 \\
\hline
\end{tabular}

Rating adjustment for discontinuity orientation was set at $(-50)$ for the slope due to unfavourable JS3 described in section 6.2 which strikes almost parallel to the slope face and dips out of the slope. Hence the basic RMR after discontinuity orientation adjustment for application to the slope was $(74-50)=24$. The total rock mass classification determined from the 6 total ratings was Class IV for poor rock mass. Thus, according to Bieniawski (1989), the equivalent shear strength parameters of the failed natural slope at Lake Fundudzi were $100 \mathrm{kPa}$ to $200 \mathrm{kPa}$ and $15^{\circ}$ to $25^{\circ}$ for cohesion and friction angle respectively.

The results show the significance of unfavourable joint/discontinuity in the shear strength of rock mass. This could mean a reduction of an average stand-up time from 1 year of a $10 \mathrm{~m}$ span to 10 hours or $2.5 \mathrm{~m}$ span in tunnels and mines (Bieniawski, 1989).

\subsubsection{Geological Strength Index (GSI)}

The GSI is based upon an assessment of the lithology, structure and condition of discontinuity surfaces in the rock mass and it is estimated from visual examination of the rock mass exposed in outcrops (Hoek and Brown, 1998).

The surface conditions of the rock mass are generally good, characterised by rough, slightly weathered and altered surface with a block structure. The block structure is formed by three intersecting joint sets i.e. JS 1 (bedding) and JS 2 and JS 3 (discontinuities). The GSI "value" 
was decided upon to be 70 based on visual observation of a blocky rock mass structure and good surface conditions on RocLab program by Rocscience (Figure 6.5).

This number is then entered into a set of empirically developed equations by the program to estimate the rock-mass properties which can then be used as input into some form of numerical analysis.

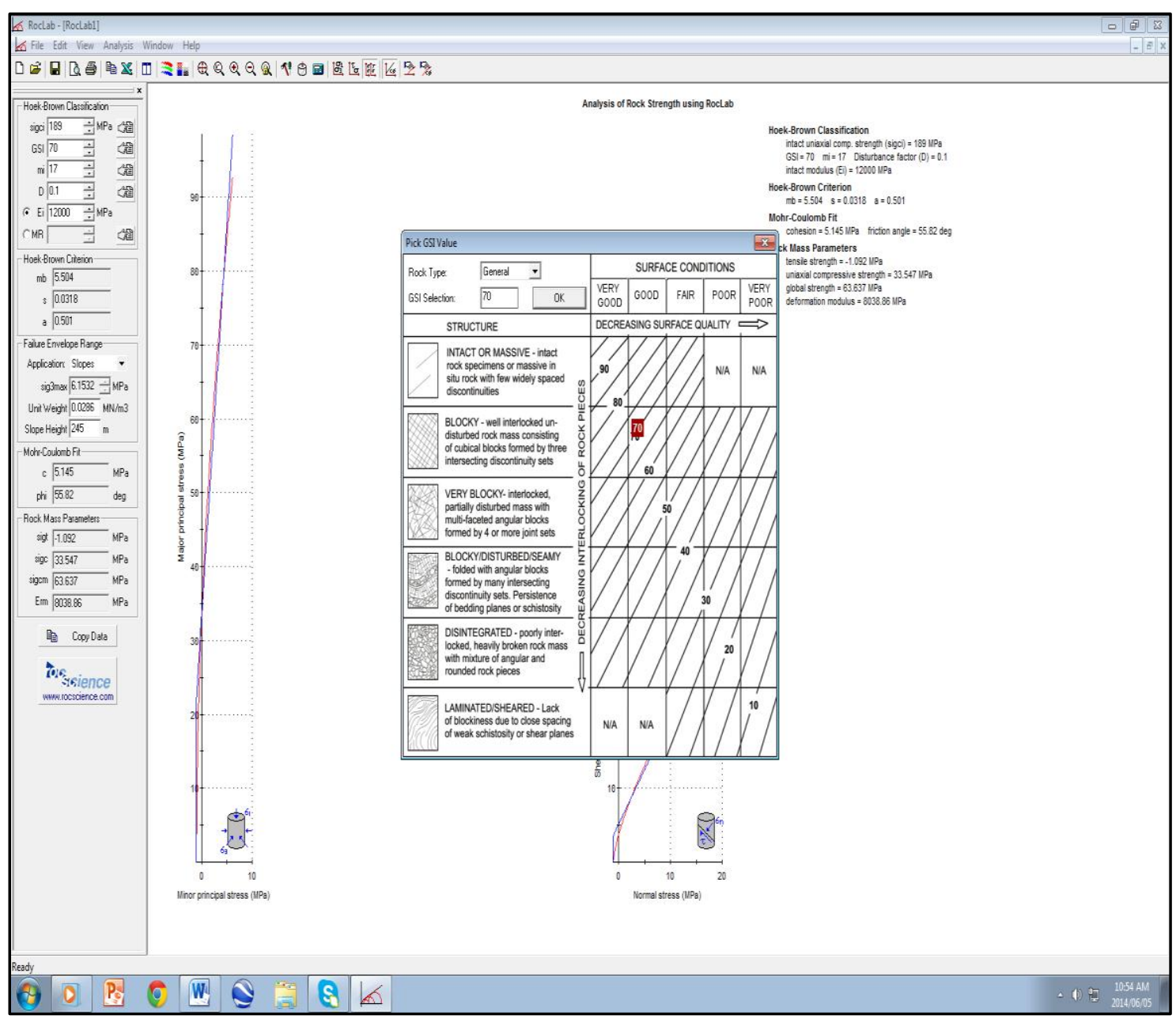

Figure 6.5: GSI values selection on RocLab program and resultant rock mass properties.

The rock mass parameter results computed from GSI were:

- $\quad$ Tensile strength $=-1.1 \mathrm{MPa}$

- Uniaxial compressive strength $=33.5 \mathrm{MPa}$

- Global strength $=63.6 \mathrm{MPa}$

- $\quad$ Deformation modulus $=8038.9 \mathrm{MPa}$

The Mohr-Coulomb fit results from GSI value for the rock mass are $5.1 \mathrm{MPa}$ and $55.8^{\circ}$ for cohesion and friction angle respectively. 
All these values which were computed from RocLab took consideration of slope height at project site, unit weight and UCS values calculated in the laboratory as part of this study.

\subsubsection{Slope Mass Rating (SMR)}

The Slope Mass Rating (SMR) is a modification from the basic RMR in order to adapt it for slope stability evaluation defined as (Romana, 1993):

$$
\text { SMR }=\text { RMR }+(\text { F1.F2.F3 })+\text { F4 }
$$

where,

F1 ranges from 1.00 to 0.15 depending on parallelism between joints and slope face strikes;

F2 ranges from 1.00 for joints dipping more than $45 \%$ to 0.15 for joints dipping less than $20^{\circ}$;

F3 reflects the relationship between the slope face and joint dip, and

F4 adjustment factor for the methods of excavation fixed empirically as +15 for natural slopes which is the same as rating adjustment for discontinuity orientations in Bieniawski (1989).

Therefore SMR $=74+(1.00 .1 .00 .-50)+15$

$$
=74+(-50)+15
$$

$$
\equiv \mathbf{3 9}
$$

Based on the SMR value obtained, the slope could be classified as Class IV, which the rock mass is described as 'bad'. Such a slope will have a probability of failure of 0.2 (Romana, 1993).

The final classes given by RMR and SMR systems which could be related and comparable were the same. Both gave class ratings of IV for 'poor' and 'bad' rock mass respectively. According to Romana (1993) these rating meant that the slope was unstable, where planar and big wedge failures can be anticipated.

Prior to inclusion of discontinuity orientation adjustment which reflects the relationship between the slope face and joint dip in both RMR and SMR systems the slope classified as Class II for 'good rock mass'. However, upon incorporating rating adjustment in RMR and SMR for discontinuity orientation, the rock mass quality of the slope dropped to 'poor' and 'bad' respectively. 
On the other hand, the GSI computed low shear strength values i.e. 5.1 $\mathrm{MPa}$ and $55.8^{\circ}$ for cohesion and friction angle respectively using RocLab.

\subsection{Golder shear box test results}

Direct shear tests were performed on natural discontinuities characterised by slightly rough planar surfaces samples which were tested in the laboratory using the Golder shear box apparatus as described in section 5.3.6.

The results of all the six Golder shear box tests conducted are presented in Appendix C.

The data obtained from each test was captured by an integrated Data Logger software program B.C. Catman Express. The software enables desired data e.g. horizontal displacement and shear load from each test to be imported to a specified file directory in Excel spreadsheet program.

The data had to be filtered in order to plot and analyse graphs accordingly for the purpose of determining peak shear stress and residual shear stress at a constant given normal strength of 0.5 MPa. According to recommendation by (Wyllie and Mah, 2005), the analysis of direct shear strength test results requires:

a) Plotting of shear stress against shear (horizontal) displacement with shear stress on the vertical axis; from the graph the peak and residual shear strengths of the surface are determined.

b) Plotting a graph of the shear (horizontal) displacement against vertical displacement with vertical displacement on the vertical axis; from the graph dilation-contraction behaviour of a joint can be assessed.

A graph depicting a typical plot of shear stress versus horizontal displacement graph plot Golder shear box tests conducted is presented in Figure 6.6. The other graphs are shown in Appendix C.

Shear displacement against shear stress curve in Figure 6.6 exhibit a moderately steep linear relationship, before reaching peak shear strength after $2.0 \mathrm{~mm}$ horizontal displacement. This is probably caused by asperities sliding into contact at the commencement of shearing, thereby causing a resistance to movement which leads to a build-up of shear stress. The curve generally maintains it linearity until it reaches a maximum value described as the peak shear strength 0.18 $\mathrm{MPa}$. This is followed by a drop to generally constant residual shear strength as shear or horizontal displacement is continued from $4 \mathrm{~mm}$ to $10 \mathrm{~mm}$ under $0.50 \mathrm{MPa}$ constant normal stress. 


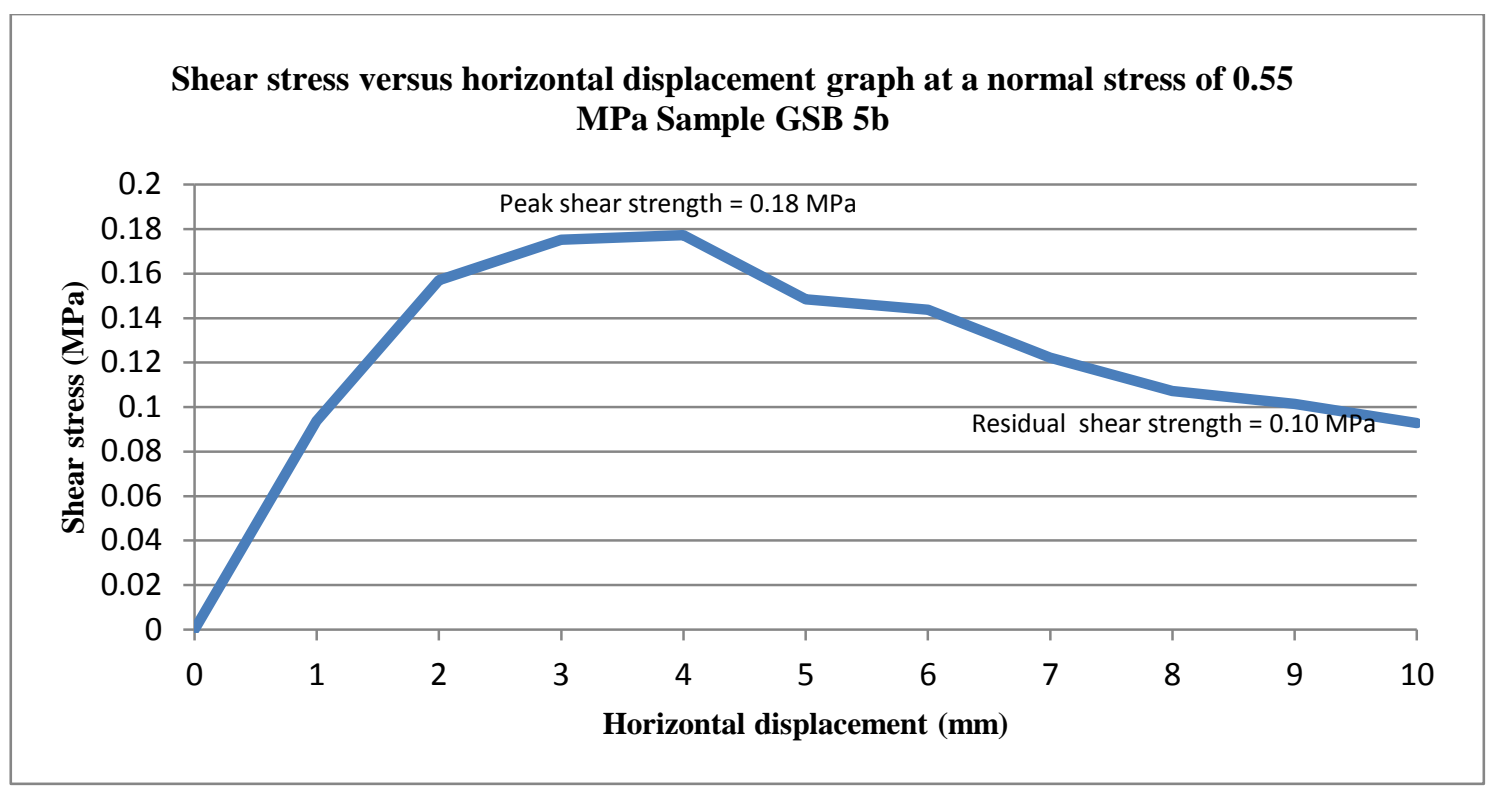

Figure 6.6: Shear displacement versus horizontal displacement graph for Golder shear box sample GSB-5b.

The samples tested showed similar plot to that of sample GSB 5b. However, peak shear strengths were attained at varied horizontal displacements which ranged from $3 \mathrm{~mm}$ to $8 \mathrm{~mm}$. This was followed by both sharp and steady decrease in shear strength for samples GSB (5a) and GSB B (1a,1b, 2, 3, 5a) respectively until residual shear strength of about $0.10 \mathrm{MPa}$ was reached. Secondary shear strength peaks were recorded in sample GSB 2 and that occurrence is often attributed to additional interlocking of asperities. In the case of sample GSB ( $1 \mathrm{a}$ and $5 \mathrm{~b}$ ) shear strength continued to decrease with continued horizontal displacement until the test was terminated.

Hingston (1997) found that, the Golder shear box was a more sensitive instrument in the testing of shear strength of discontinuities than the portable shear box.

The horizontal displacement versus vertical displacement plots for the tests conducted were varied which perhaps indicates differences in the joint profiles tested (Appendix C). In Figure 6.7 for Sample GSB 5b, initially a very minimal increase in vertical displacement was observed up about $2.00 \mathrm{~mm}$ of horizontal shearing. This was followed steady and persistent increase in vertical displacement (dilation) which was common in the joints tested, with continued horizontal displacement until the test was terminated. The increase in vertical displacement for Sample GSB 5b coincided with peak shear strength as the horizontal displacement progressed. The vertical displacement continued to steadily increase even post peak shear strength. Basically continued shearing resulted in a gradual dilation of the joint which could mean some of the asperities were essentially not sheared, possibly due to the low $0.55 \mathrm{MPa}$ normal stress 
under which the test was conducted. Better interlocking between discontinuity surfaces at higher normal stress levels would be expected as opposed to interlocking under low normal stresses.

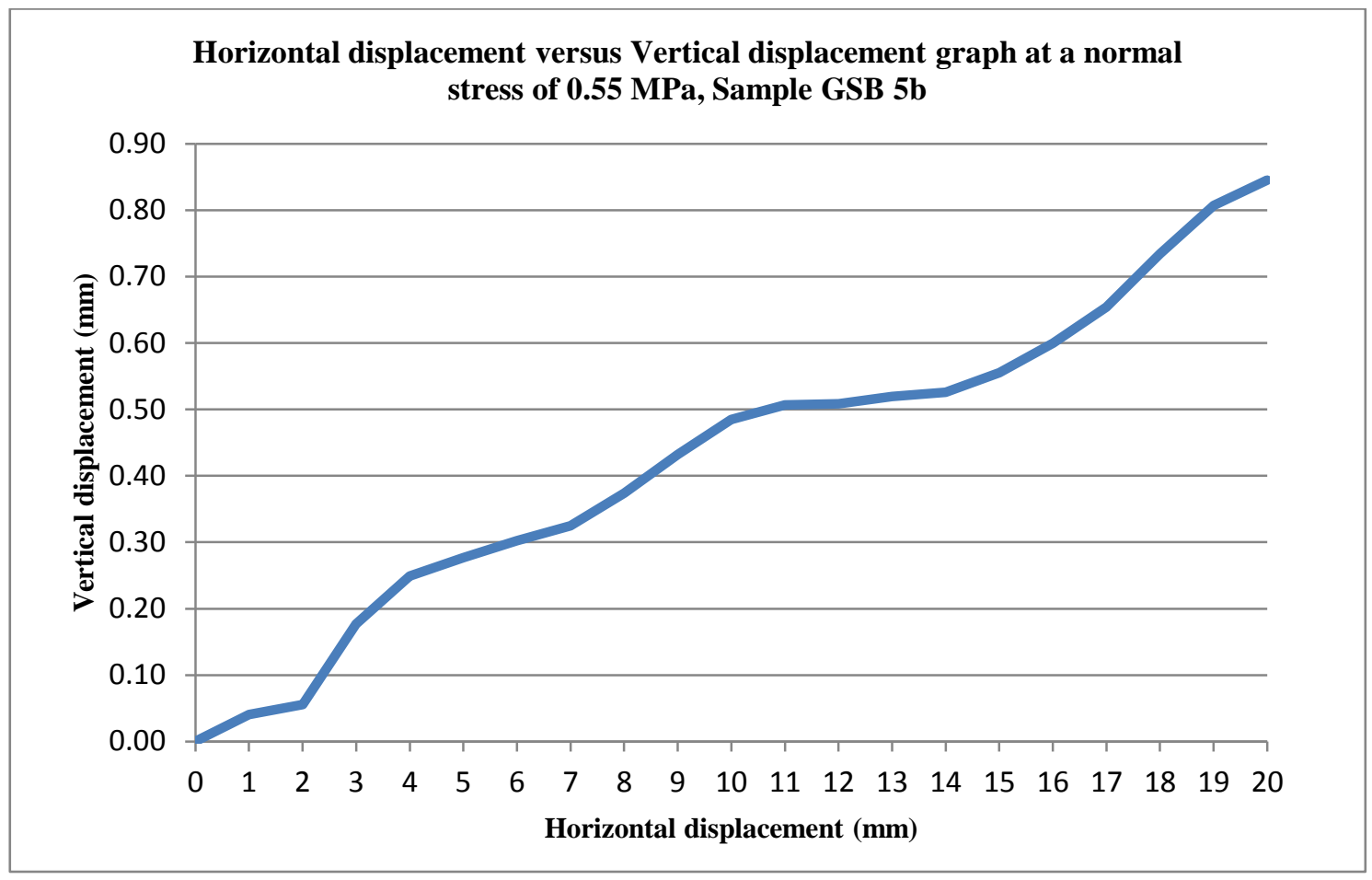

Figure 6.7: Shear displacement versus vertical displacement graph for Golder shear box sample GSB 5b.

Barton and Choubey (1977) stated that the magnitude of normal stress across the joint is the most important factor affecting shear strength. The most important external factor affecting shear strength is the magnitude of the effective normal stress $\left(\sigma_{n}\right)$ acting across the joint. In many rock engineering problems in civil engineering the maximum effective normal stress will lie in the range 0.1 to $2.0 \mathrm{MPa}$ for those joints considered critical for stability. However, in mining engineering this value can be much bigger (Barton, 1976). This effective normal stress is about three orders of magnitude lower than those used by tectonophysicists when studying the shear strength of faults under stress levels of for example 100 to $2000 \mathrm{MPa}$. In consequence, the literature contains shear strength data for rock joints spanning a stress range of at least four orders of magnitude. It is partly for this reason that opinions concerning shear strength vary so widely to the results of shear strength investigations on rock joints (Barton and Choubey, 1977).

Horizontal displacement versus vertical displacement plots for samples GSB ( 3 and 5a) showed similar behaviour trends to that observed in sample GSB 5b. However sample GSB (1a, 1b, 3) basically showed no change in vertical displacement until peak shear strength was reached where vertical displacement showed a sudden steady decrease. Hingston (1997) stated that this 
behaviour occurs at the commencement of shearing, where the asperities on either side of the joint will tend to slide into contact along their opposed sloping faces. This is marked by a negative or no vertical displacement in the horizontal versus vertical displacement.

The peak and residual shear strength values for each sample tested which were determined from the shear stress versus horizontal displacement graphs for the Golder shear box tests are shown in Table 6.4.

Table 6.4: Results of the direct shear strength tests on natural joints under constant normal stress.

\begin{tabular}{|c|c|c|c|c|}
\hline Sample Number & $\begin{array}{c}\text { Estimated } \\
\text { JRC }\end{array}$ & $\begin{array}{c}\text { Normal stress } \\
\text { (MPa) }\end{array}$ & $\begin{array}{c}\text { Peak shear } \\
\text { strength } \\
\text { (MPa) }\end{array}$ & $\begin{array}{c}\text { Residual shear } \\
\text { strength } \\
\text { (MPa) }\end{array}$ \\
\hline GSB 1a & 9 & 0.50 & 0.32 & 0.22 \\
\hline GSB 1b & 9 & 0.60 & 0.37 & 0.25 \\
\hline GSB 2 & 10 & 0.50 & 0.23 & 0.20 \\
\hline GSB 3 & 9 & 0.60 & 0.27 & 0.22 \\
\hline GSB 4 & 13 & 0.50 & - & - \\
\hline GSB 5a & 11 & 0.38 & 0.17 & 0.11 \\
\hline GSB 5b & 11 & 0.55 & 0.18 & 0.10 \\
\hline
\end{tabular}

In the case of sample GSB 4, no data was recorded during testing as there was a technical problem with the transducers and as such no data was logged.

After each testing, an inspection of the nature of the sheared surface of each sample tested was done. Figure 6.8 shows the sheared surface of sample GSB 4 after shearing at a normal stress of $0.50 \mathrm{MPa}$.

It is clearly visible that the actual contact area during shearing was extremely small in comparison to the overall total surface area of the joint. This situation was consistent in all tested samples and it is consistent with the findings of Jaeger (1971) and Barton (1971). In this case the joint aperture is a significant factor which ultimately determines the extent of contact between joint walls. A large joint aperture will result in lesser actual contact area during shearing. According to the damage visible at the end of a shear test, the real contact area may be anything from one tenth to one thousandth (or less) of the gross area (Barton and Choubey, 1977). 


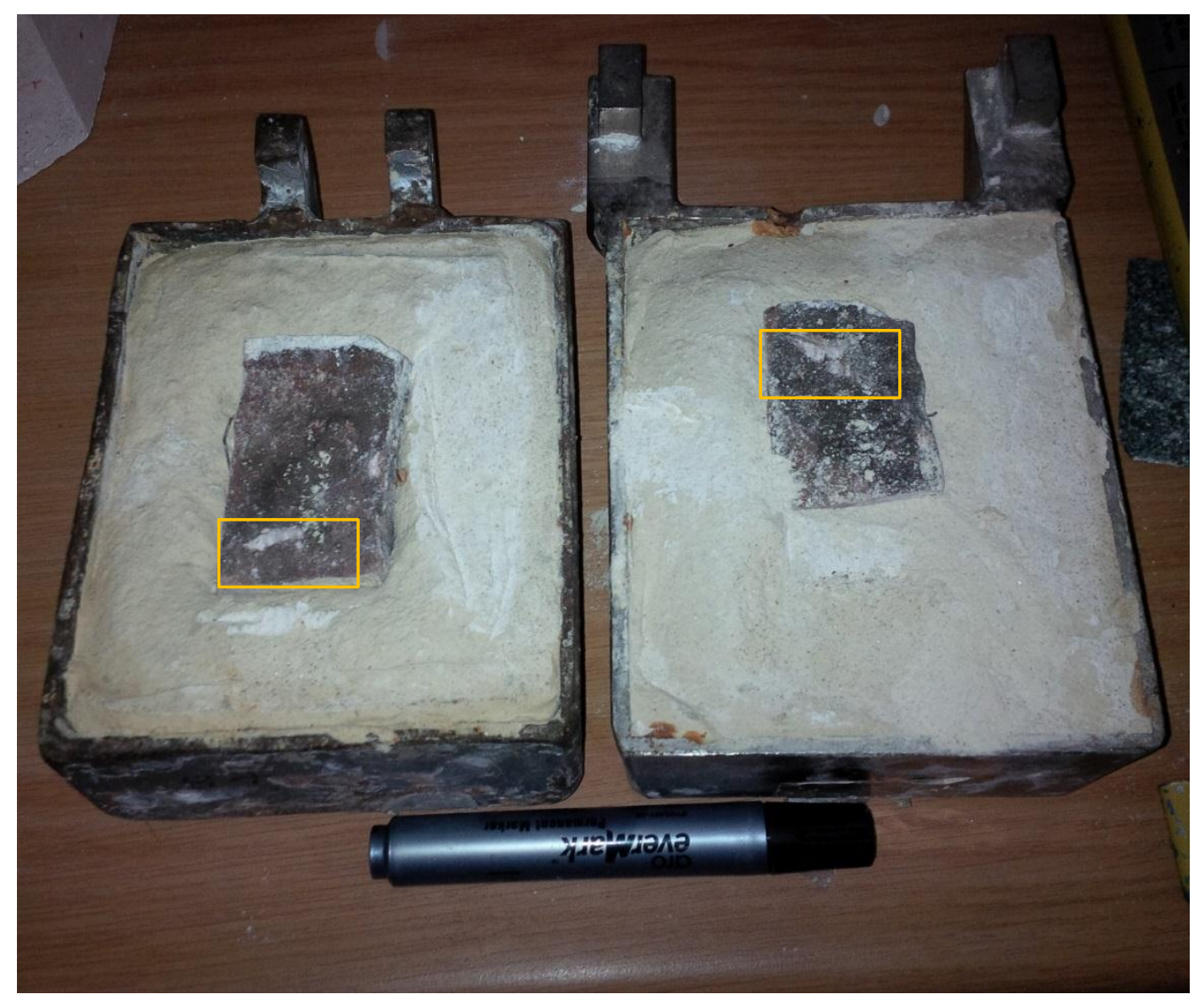

Figure 6.8: Shearing contact showing actual contact surface area for Sample GSB 4 .

\subsubsection{Back analysis calculation for JRC}

Back analysis was undertaken to determine the back calculated JRC values of the joints tested using the Barton and Choubey (1977) equation presented in section 5.5.3:

$$
\tau=\sigma_{\mathrm{n}} \tan \left[\phi_{\mathrm{b}}+\mathrm{JRC} \cdot \log 10\left(\mathrm{JCS} / \sigma_{\mathrm{n}}\right)\right]
$$

To back calculate the JRC values Equation (6.1) is re-arranged as follows

$$
J R C=\left[\left(\arctan \frac{\tau}{\sigma_{n}}\right) \div\left[\log \left(\frac{J C S}{\sigma_{n}}\right)\right]\right]
$$

Where $\tau$ is the peak shear strength determined from the shear tests, $\sigma_{\mathrm{n}}$ is the normal stress under which the shear tests were undertaken and JCS is the equivalent of the UCS.

Back calculated JRC values are shown in Table 6.5. The values of JCS and $\phi_{\mathrm{b}}$ used in the calculation were derived from average UCS and tilt angle tests results respectively presented earlier which are $189 \mathrm{MPa}$ and $26.5^{\circ} \sim 27^{\circ}$ respectively. The direct UCS test results were considered for JCS value as opposed to Schmidt hardness rebound results which gave an average of $80 \mathrm{MPa}$ because they were more reliable. 
The JRC values were earlier estimated using Barton and Choubey (1977) ten standard roughness profiles as shown in Figure 3.5 in Chapter 3. Miller et al. (1989) stated that estimates are very subjective and unreliable due to the small joint surface area of sample derived and used for the test.

Table 6.5: Back calculated JRC and peak shear strength results.

\begin{tabular}{|c|c|c|c|c|c|c|c|}
\hline $\begin{array}{c}\text { Sample } \\
\text { Number }\end{array}$ & $\begin{array}{c}\text { Normal } \\
\text { stress } \\
(\mathbf{M P a})\end{array}$ & $\begin{array}{c}\text { Estimated } \\
\text { JRC }\end{array}$ & $\begin{array}{c}\text { JCS } \\
(\mathbf{M P a})\end{array}$ & $\begin{array}{c}\text { Tilt test } \\
\phi_{\mathrm{b}}\left({ }^{\circ}\right)\end{array}$ & $\begin{array}{c}\text { Shear box } \\
\text { peak shear } \\
\text { strength } \\
\text { (MPa) }\end{array}$ & $\begin{array}{c}\text { Back } \\
\text { calculated } \\
\text { JRC }\end{array}$ & $\begin{array}{c}\text { Back calculated } \\
\text { peak shear } \\
\text { strength } \\
(\mathbf{M P a})\end{array}$ \\
\hline GSB1a & 0.5 & 9 & 189 & 27 & 0.32 & 10.1 & 0.32 \\
\hline GSB1b & 0.6 & 9 & 189 & 27 & 0.37 & 10.4 & 2.01 \\
\hline GSB2 & 0.5 & 10 & 189 & 27 & 0.23 & 10.1 & 1.07 \\
\hline GSB3 & 0.6 & 9 & 189 & 27 & 0.27 & 10.4 & 2.01 \\
\hline GSB4 & 0.5 & 13 & 189 & 27 & - & - & 0.16 \\
\hline GSB5a & 0.38 & 11 & 189 & 27 & 0.17 & 9.7 & 0.15 \\
\hline GSB5b & 0.55 & 11 & 189 & 27 & 0.18 & 10.3 & 0.84 \\
\hline
\end{tabular}

The results presented in Table 6.5 show that the back calculated JRC values were very close to the estimated JRC values. Estimated JRC values ranged between 9 and 13 and back calculation gave an average value of about 10 for JRC given all other known parameters shown in Table 6.5 for solving equation 6.2. The resultant back calculated average JRC of 10 falls between the estimated JRC range of 9 and 13. Back calculation of the JRC could be a better method of estimating the JRC of joints than by visual estimation which can be very subjective.

The laboratory testing program did achieve its objective of determining the strength parameters that define the Barton-Bandis (1990) criterion i.e. joint roughness coefficient (JRC), joint wall compressive strength (JCS) which was selected for use in the slope stability back analysis.

\subsection{Summary}

The chapter presented all the fieldwork and laboratory results with discussions.

The type of failure mechanisms was determined as planar failure from kinematic analysis which is based on Markland's test.

Rock mass classification results based on rock mass rating (RMR), geological strength index (GSI) and slope mass rating (SMR) were presented. The rock mass of the slope generally 
classified as poor and fair meaning that the slope was unstable or marginally stable due to unfavourably discontinuity orientation.

The laboratory results gave values of the relevant input parameters for the chosen BartonBandis (1990) shear strength criterion i.e. unit weight $(\gamma)$, joint wall compressive strength (JCS) and joint roughness coefficient (JRC) for slope stability analysis were also presented.

These were found to be (averages):

- unit weight $(\gamma)=28.59 \mathrm{kN} / \mathrm{m}^{3}$

- joint wall compressive strength (JCS) $=189 \mathrm{MPa}$

- $\quad$ back calculated joint roughness coefficient $(J R C)=10$

The next chapter presents slope stability back analyses of Lake Fundudzi planar rockslide. The chapter deals with determining the remaining shear strength parameter in Barton-Bandis (1990) equation i.e. residual friction angle using Slide and RocPlane limit equilibrium programs both made by Rocscience ${ }^{\circledR}$ where $\mathrm{F}=1.00$ is assumed as the point of imminent failure. The chapter also investigates the conditions that could have led to failure. 


\section{CHAPTER 7}

\section{SLOPE STABILITY ANALYSES OF THE PLANAR ROCKSLIDE}

\subsection{Introduction}

In order to conduct a successful back analysis, it is essential to understand the process and mechanisms driving instability. The kinematic analysis in the previous chapter has revealed that the stability of the slope at the project site was structurally controlled by main discontinuities which resulted in planar failure. The purpose of the back analyses presented herein was to determine the shear strength parameters along the sliding discontinuities or plane and the possible conditions that may have led to failure.

This chapter presents the procedure involved in the back analyses of the Lake Fundudzi landslide using Slide and RocPlane developed by Rocscience ${ }^{\circledR}$ Inc. which are both based on the limit equilibrium method of analysis.

The topography of the failed slope was reconstructed and the sliding block volume was also estimated.

Back analysis requires a known factory of safety which at failure is theoretically equal to unity (Sauer and Fredland, 1988). This eliminates one of the unknowns in the analysis. A "trial and error" procedure was used whereby the trial values of an unknown shear strength parameter which in this case was the residual friction angle $\left(\phi_{\mathrm{r}}\right)$ is matched (i.e. this is done by varying one variable at a time, while keeping all other variables constant), until the best fit of shear strength parameters is achieved for a value of $\mathrm{F}=1.00$.

Section 4.3.4 pointed out that there are some uncertainties that influence the back-calculated shear strength such as engineering properties of the other materials in the cross-section, slope geometry at the time of failure, phreatic surface, and pore water pressures present at the time of failure, effect of rainfall, location of failure surface and existence of tension cracks (Hussain et al., 2010).

Where uncertainty existed in determining possible triggering factors such as water pressure and seismic loading influence, a range of possible scenarios were considered in the analyses. 


\subsection{Selection of method of analyses}

The Lake Fundudzi landslide was analysed based on an observed planar failure mode which was confirmed by a kinematic analysis based on the procedures outlined by Markland (1972) and Hoek and Bray (1981). Sharifzadeh et al. (2009) and Stead et al. (2006) stated that, if the rock mass is competent with a good overall rock mass condition as in the case of the project site, its instability mechanism lies on a plane and can thus be analysed using the limit equilibrium methods, by making use of programs such as Slide and Slope $W$. Therefore, the use of Slide and RocPlane for back analysis was deemed suitable and sufficient for this study as failure was structurally controlled or occurred along a plane. The basic deterministic analysis approach which is used to calculate the stabilizing and driving forces and arrive at a factor of safety (F) was employed. In the deterministic analysis, representative strength parameter for the discontinuity is determined and this value is used to calculate $\mathrm{F}$. The result of the deterministic analysis for limit equilibrium is a single value of $\mathrm{F}$, based on the representative values of discontinuity parameters, which are typically taken as the mean values (Park and West, 2001).

In all of the analyses presented in the following sections, the Barton and Bandis (1990) criterion which establishes the shear strength of a failure plane was selected over the Mohr Coulomb popular failure criterion (i.e. cohesion and friction angle) which is satisfied by infinite set of answers which mean that many possible $(c, \phi)$ combinations will give $F=1.00$. The BartonBandis criterion results in a curvilinear failure envelope that more closely represents the actual physical characteristics of shear resistance. Another major advantage of the Barton-Bandis approach is the relative ease at which the shear strength parameters (i.e. JRC, JCS, $\sigma_{\mathrm{n}}$ and $\phi_{\mathrm{b}}$ ) can be established (Donnelly and Rigbey, 2003).

There are several slope stability analyses methods as explained in section 4.3.2. The general limit equilibrium method of slices (GLE) and Janbu are often used for noncircular or plane failure surfaces. The Janbu simplified limit equilibrium method was used for the slope stability analysis. The advantage of using the Janbu Simplified method is that it is less prone to convergence issues and tends to give a lower bound on the value of $\mathrm{F}$ (Fredlund et al., 1981). RocPlane does not use any method of slices as F is calculated for the entire block as a unit.

\subsubsection{Selection of cross section and geometry of slope}

In order to perform a back analysis of the failed slope, it was necessary to survey the dimensions and location of sections through the slide. Therefore, a simple slide-block 2-D slope geometry was re-constructed that satisfy planar geometrical conditions. The cross section was 
taken through the centre of the failure surface which represents the lowest sliding basal surface for landslide volume estimation. Oppikofer (2009) stated that, volume calculations of ancient rockslide may be feasible through aerial photographs, topographic maps by surface reconstruction based on contour lines patterns outside or within the scar area. No pre-landslide failure and aerial photographs could be obtained for the 20000 years old Lake Fundudzi landslide. This study made use of the slope height, failure plane, dip and slope angle data collected in the field, topographical maps and Google Earth ${ }^{\circledR}$ satellite imagery (Figure 7.1) to determine the pre and post failure geometry. The slope shape used for the pre-failure condition was obtained by contour-line smoothing of the topographical map with a 1:50 000 scale.

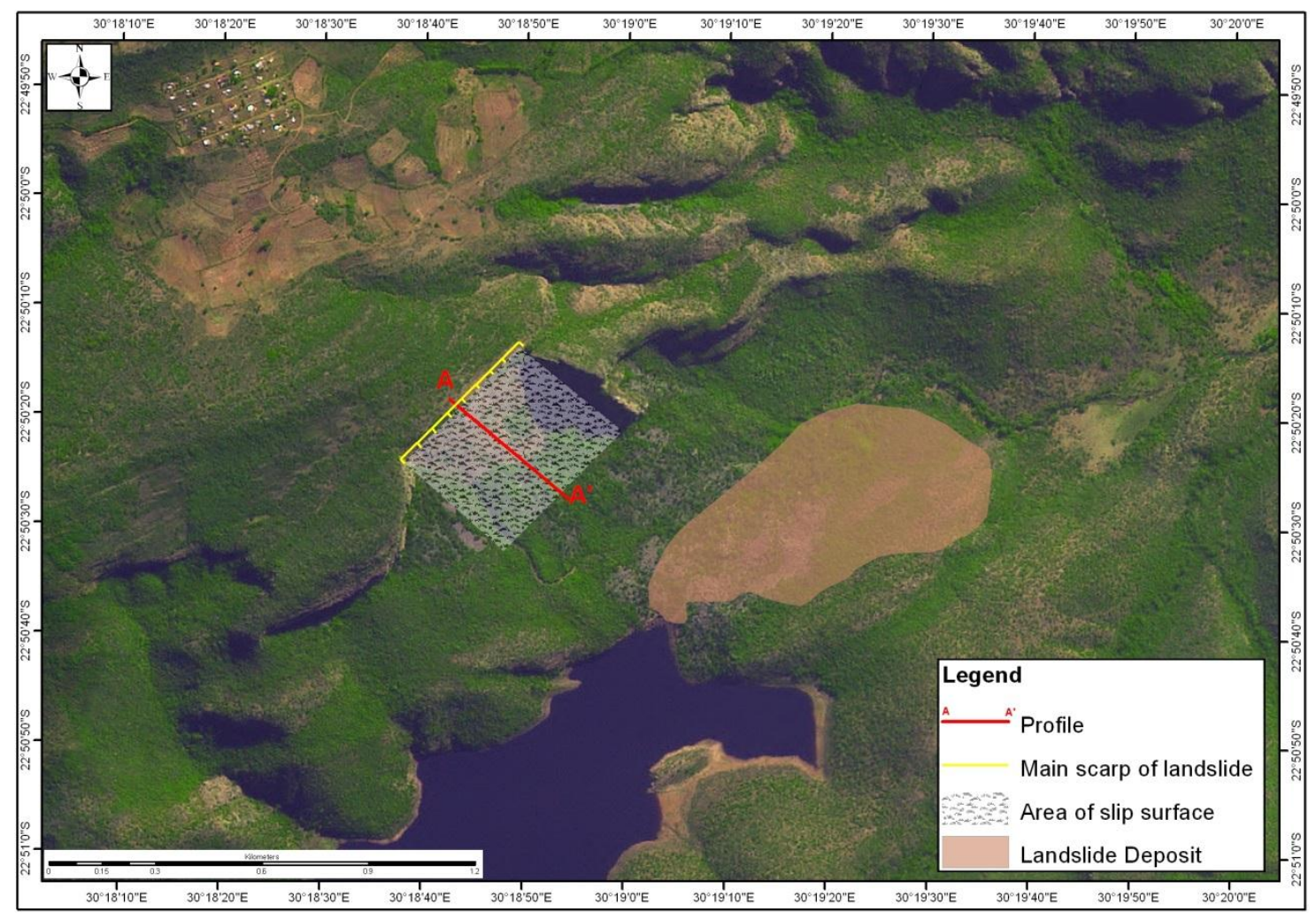

Figure 7.1: Line of cross section (A-A') for the analyses.

Undisturbed release surfaces of the slide which are about $500 \mathrm{~m}$ apart were also examined to estimate the pre-landslide slope geometry (reference can be made to Figure 1.2). The estimated volume of the landslide is between 7 and 9 million $\mathrm{m}^{3}$ and was estimated through field observations and use of triangular prism volume formula:

$$
\text { Volume }_{\text {triangular prism }}=[(\mathbf{h} * \mathbf{b} * \mathbf{l}) / 2]
$$

Where $\mathrm{h}$ is the height, $\mathrm{b}$ is the breath and $\mathrm{l}$ is the length. 
Table 7.1 shows the geometrical parameters of the slope that were essential for the analysis as defined in the equations for planar failure with a tension crack by Hoek and Bray (1981). The slope model re-constructed here is based on the parameters and dimensions listed in Table 7.1.

Table 7.1: Geometrical parameters of the reconstructed landslide features used in Slide and RocPlane limit equilibrium analyses.

\begin{tabular}{|c|c|c|}
\hline Parameter & Value & Unit \\
\hline Face height & 245 & $\mathrm{~m}$ \\
\hline Slope angle $(\beta)$ & 80 & ${ }^{\circ}$ \\
\hline Upper face angle $(\Psi)^{*}$ & $(-) 10$ & ${ }^{\circ}$ \\
\hline Tension crack distance & 115 & $\mathrm{~m}$ \\
\hline Inclination of failure plane & 60 & ${ }^{\circ}$ \\
\hline Tension crack angle & 90 & $\mathrm{o}$ \\
\hline Tension crack depth & 23 & $\mathrm{~m}$ \\
\hline
\end{tabular}

* The upper face is negative as it dips backwards in the opposite direction from the front slope face.

Assumptions are common and necessary practice in landslide back analysis such as failure conditions present along the slide mass/slope at the time of failure and assuming input parameters which yield $\mathrm{F}=1.00$ which may lead to uncertainties in the analysis (Hussain et al., 2010). Even though the factor of safety may be known (i.e. unity or $F=1.00$ ), back analysis can still involve some uncertainties, e.g. failure surface, slope geometry, pore-water pressures, tension cracks, shear strength and unit weight of other materials, and accuracy of the stability method (Hussain et al., 2010). The geometry parameters shown in Table 7.1 and other factors listed below are certain and thus reduce uncertainty in the analyses and these are:

- the failure surface is entirely barely exposed (or known) and the tension crack was easily located;

- type of failure has been shown to be planar;

- the failure surface cuts across one lithology which reduces the complexity of the analyses; and

- the remaining release surfaces or buttresses allowed for an acceptable slope geometry reconstruction.

Figure 7.2 shows an idealized re-constructed slope geometry at the time of failure in 2-D and the slope dimensions respectively. The analysed cross section is representative of profiles or cross sections along the landslide that cut through the plane failure. 


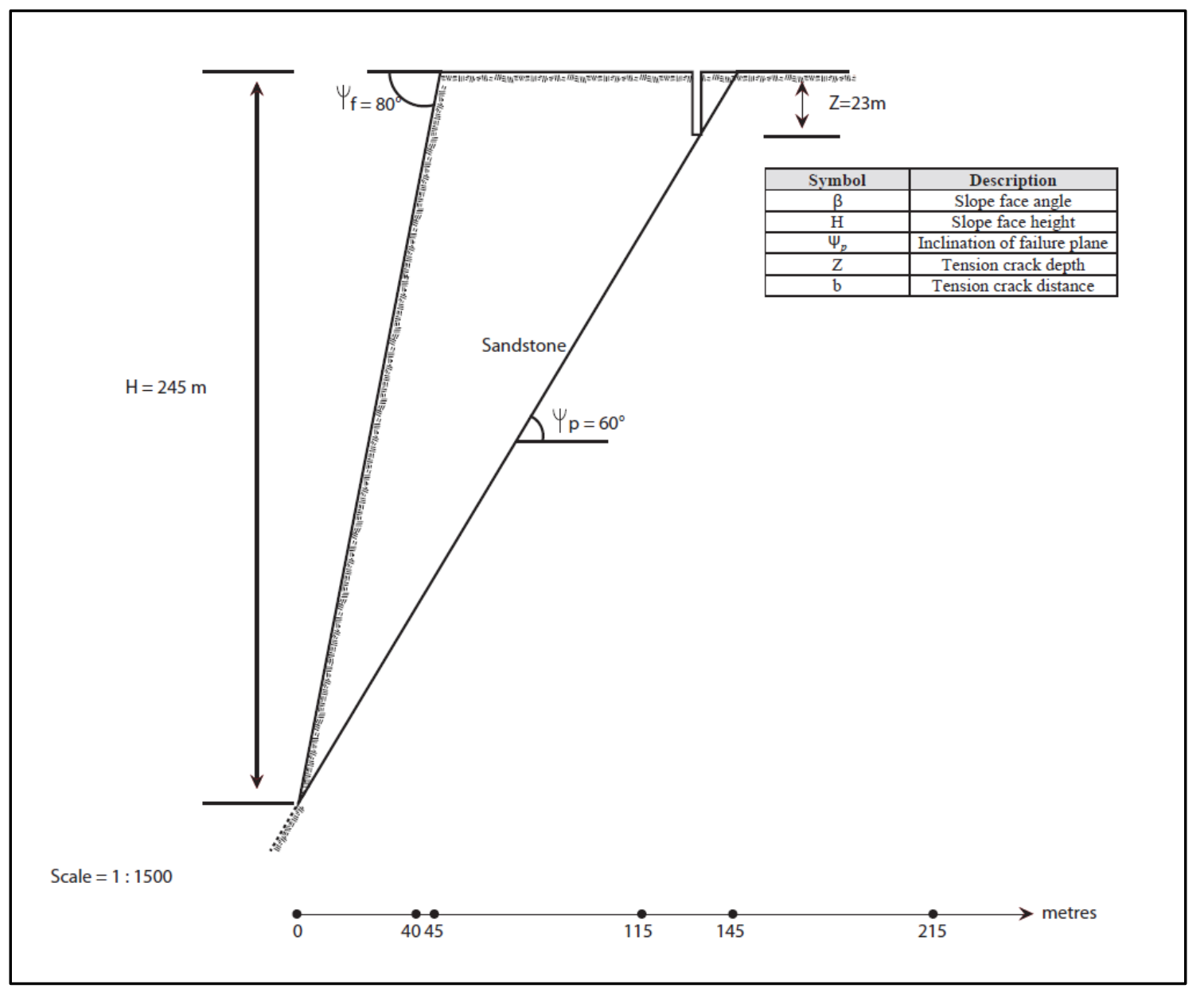

Figure 7.2: Re-constructed slope of the Lake Fundudzi rockslide cross section A-A' shown in Figure 7.1.

\subsubsection{Selection of geotechnical parameters for analyses}

Several shear strength failure criterion could have been employed as indicated in Chapter 4, depending on site conditions, type of failure and the relevant parameters that can be acquired from in situ and or laboratory testing. Barton and Choubey's (1977) method was used in the study because failure occurred along a persistent structural discontinuity. Accordingly, the laboratory testing programme achieved parameters that satisfy Barton and Choubey's (1977) estimate of shear strength, i.e.:

$$
\tau=\sigma_{\mathrm{n}} \tan \left[\phi_{\mathrm{b}}+\mathrm{JRC} \cdot \log 10\left(\mathrm{JCS} / \sigma_{\mathrm{n}}\right)\right]
$$

where, JRC $=$ joint roughness coefficient, JCS $=$ joint compressive strength, $\tau=$ shear strength along the rock joint, $\sigma_{\mathrm{n}}=$ normal stress acting on the surface of the rock joint, $\phi_{\mathrm{b}}=$ angle of frictional sliding of the planar surface (basic friction angle). 
The Barton and Choubey (1977) equation is part of the Barton-Bandis (1990) criterion for rock joint strength and deformability (Barton and Bandis, 1990). Table 7.2 shows the summary of shear strength parameters. El-Ramly et al. (2002) pointed out that the performance of a structure is often controlled by the average soil properties within a zone of influence, rather than soil properties at discrete locations. It is therefore logical to use average values for the geotechnical properties in a slope stability analysis as was the case in the results below.

Table 7.2: Summary of results for JRC values, average JRC and peak shear strength.

\begin{tabular}{|c|c|c|c|c|c|}
\hline $\begin{array}{c}\text { Number } \\
\text { of } \\
\text { samples }\end{array}$ & $\begin{array}{c}\text { JRC range } \\
\text { (visually } \\
\text { estimated) }\end{array}$ & $\begin{array}{c}\text { Average JCS: } \\
\text { from UCS (MPa) }\end{array}$ & $\begin{array}{c}\text { Back } \\
\text { calculated } \\
\text { JRC values: } \\
\text { Range }\end{array}$ & $\begin{array}{c}\text { Back } \\
\text { calculated } \\
\text { JRC: } \\
\text { Average }\end{array}$ & $\begin{array}{c}\text { Shear box peak } \\
\text { shear strength } \\
\text { (MPa): Average }\end{array}$ \\
\hline 6 & $9-13$ & 189 & $9.7-10.4$ & 10 & 0.26 \\
\hline
\end{tabular}

There are three strength parameters that define the Barton-Bandis criterion i.e. joint roughness coefficient (JRC), joint wall compressive strength (JCS) and residual friction angle $\left(\phi_{\mathrm{r}}\right)$. The JRC and JCS parameters have been successfully estimated and determined from the laboratory and subsequently back calculated. According to Bell (2007), the JCS is equivalent to the UCS of the rock if the joint is unweathered which was determined from laboratory testing. The JRC was determined by back calculation and peak shear strength as explained in Section 6.5. In addition to the shear strength parameters, the unit weight was also required for slope stability analyses. An average unit weight value of $28.5 \mathrm{kN} / \mathrm{m}^{3}$ was calculated for the quartzitic sandstone and was used in the analyses. However, Alonso (1976) pointed out that the influence of the variability of the unit weight on $\mathrm{F}$ is insignificant due to the fact that the variability in material density is small. Thus this value was kept constant throughout the analyses.

The residual friction angle $\left(\phi_{r}\right)$ was thus the outstanding parameter that needed to be determined by back analyses using Slide and RocPlane programs in Rocscience.

\subsubsection{Groundwater conditions for analyses}

Determination of the groundwater conditions at the time of the landslide is important because the pore water pressures affect the effective stress acting on the failure plane (Duncan and Stark, 1992). In this study, the determination of groundwater conditions presented a major uncertainty in the analyses as it was not certain what the groundwater conditions were at the time of failure. No water body or groundwater seepage was observed at the exposed sliding 
plane and across the landslide area which was hanging $350 \mathrm{~m}$ above the lake except for the Lake Fundudzi's vast water body at the bottom of the valley. The modelling of groundwater influence in the slope stability considered the presence of water in the tension crack. The SA Weather Services records revealed that the region experiences moderate average annual rainfall (1 $280 \mathrm{~mm}$ ). Due to the occurrence of a tension crack on the main scarp area of the rock slide, different groundwater scenarios in the tension crack which may have been open and filled with water were considered in the analyses.

The water level in a tension crack zone is very important to the stability analysis, because the additional hydrostatic force which can be exerted by water in a tension crack can significantly lower F of slip surfaces which intersect the tension crack zone (Slide V6.0, 2010).

There are several different options for defining the water level in a tension crack in Slide and RocPlane, such as:

- Dry: a completely dry tension crack zone. No additional hydrostatic forces will act on the slip surface.

- Filled: completely water-filled tension crack zone. This is the worst case scenario, and will exert the maximum hydrostatic force on the slip surface.

- Percentage filled: a percentage from $0 \%$ to $100 \%$ can be specified. This percentage defines the height of water in the tension crack, along any vertical line from the tension crack boundary to the ground surface.

Thus, three different scenarios of groundwater conditions in the tension crack were considered in the analyses. These were:

i. $\quad 0 \%$ for completely dry tension crack

ii. $\quad 50 \%$ for partially filled tension crack

iii. $\quad 100 \%$ for full tension crack

These three conditions were assumed constant for each of the set of analyses conducted. The water pressure distribution along the sliding surface has been assumed to decrease linearly from the base of the tension crack to the intersection of the failure surface and the slope surface. Hoek and Bray (1981) stated that, water in tension crack pressure build up is probably very much simpler than that which occurs in an actual slope but since the actual pressure distribution is unknown, this assumed distribution is as reasonable as any other which could be made. 


\subsubsection{Seismic ground acceleration condition for analyses}

Ground shaking can lead to ground acceleration and subsequently trigger landslides (Schuster and Kockelman, 1996). Available seismological data shows that the project site region has low seismic activity record and peak horizontal ground acceleration with a probability of $10 \%$ of being exceeded at least once in 50 years. However, it was still considered for the analysis in order to evaluate seismic influence on this slope stability given that the database from the Council for Geoscience shows two events of 5 Richter scale magnitudes to have occurred in 1940 and 1970 (data presented in section 3.7.1). The published seismic hazard map of Southern Africa (Fernandez and du Plessis, 1992) suggests that the study area is located in a region with a peak horizontal ground acceleration of between $0.5 \mathrm{~m} / \mathrm{s}^{2}$ and $1.0 \mathrm{~m} / \mathrm{s}^{2}$. Peak ground acceleration can be expressed in $g$ (the acceleration due to earth's gravity, equivalent to $g$-force) as either a decimal or percentage; in $\mathrm{m} / \mathrm{s}^{2}\left(1 \mathrm{~g}=9.81 \mathrm{~m} / \mathrm{s}^{2}\right)$ i.e. $0.05 \mathrm{~g}$ to $0.10 \mathrm{~g}$. Therefore, the seismic load was included to establish the effect of pseudo-static earthquake loading in the limit equilibrium analysis in both Slide and RocPlane.

The seismic coefficient $(\alpha)$ is a dimensionless number which represents the maximum earthquake acceleration as a fraction of the acceleration due to gravity. Typically, the seismic coefficient might be around 0.10 to 0.30 because seismic coefficients used in practice generally correspond to acceleration values well below the predicted peak accelerations (Kramer, 1996).

Approaches developed to assess the stability of slopes during earthquake fall into three general categories: (1) pseudo-static analysis, (2) stress-deformation analysis, and (3) permanent displacement analysis (Kramer, 1996). Selection of an appropriate seismic coefficient is the most important and difficult aspect of a pseudostatic stability analysis because the results of pseudostatic analyses are critically dependent on the value of the seismic coefficient (Kramer, 1996). As shown in Table 7.3, there are no specific rules for selection of an appropriate seismic coefficient for design. However, the different selection criterion suggests that the seismic coefficient should be based on the anticipated level of acceleration within the failure mass and should correspond to some fraction of the anticipated peak acceleration (Kramer, 1996). A pseudostatic stability approach which represents the most unfavourable condition for stability was used in this study in order to investigate whether seismic conditions could have triggered the landslide. 
Table 7.3: Recommended horizontal seismic coefficients for design (adapted after Melo and Sharma, 2004).

\begin{tabular}{|c|c|c|}
\hline $\begin{array}{l}\text { Horizontal Seismic } \\
\text { Coefficient, } \mathbf{k}_{\mathbf{h}}(\alpha)\end{array}$ & \multicolumn{2}{|c|}{ Description } \\
\hline $0.05-0.15$ & \multicolumn{2}{|c|}{ In the USA } \\
\hline $0.12-0.25$ & \multicolumn{2}{|c|}{ In Japan } \\
\hline 0.1 & 'severe" earthquake & \multirow{3}{*}{ Terzaghi (1950) } \\
\hline 0.2 & $\begin{array}{l}\text { "violent, destructive" } \\
\text { earthquakes }\end{array}$ & \\
\hline 0.5 & "catastrophic" earthquakes & \\
\hline $0.1-0.2$ & \multicolumn{2}{|c|}{ Seed (1979), F>1 } \\
\hline 0.1 & Major Earthquake, F>1 & \multirow[t]{2}{*}{ Corps of Engineers (1982) } \\
\hline 0.15 & Great Earthquake, $F>1$ & \\
\hline $1 / 2$ to $1 / 3$ of PHA & \multicolumn{2}{|c|}{ Marcuson and Franklin (1983), F > 1} \\
\hline $1 / 2$ of PHA & \multicolumn{2}{|c|}{ "Hynes-Griffin (1984), F > 1} \\
\hline $\mathrm{F}=$ Factor $\mathrm{c}$ & PHA $=$ Peak Horizontal A & leration, in g's \\
\hline
\end{tabular}

The Hynes-Griffin and Franklin (1984) method which recommended a seismic coefficient equal to 0.5 x PGA for pseudostatic analysis, was adopted for the pseudostatic analyses in Slide and RocPlane. Thus, the seismic coefficient values shown in Table 7.4 were used in the analyses.

Table 7.4: Seismic coefficient $(\alpha)$ values calculated from the available peak ground acceleration values.

\begin{tabular}{|c|c|c|}
\hline & $\begin{array}{c}\text { Published peak ground } \\
\text { acceleration values (adapted } \\
\text { from Fernandez and du } \\
\text { Plessis, 1992) } \\
\left(\mathbf{m} / \mathbf{s}^{2}\right)\end{array}$ & $\begin{array}{c}\text { Calculated Seismic }(\alpha) \\
\text { Coefficient based on } \\
\text { Hynes-Griffin and } \\
\text { Franklin, (1984): } \\
=\mathbf{0 . 5} \text { x PGA (peak ground } \\
\text { acceleration) }\end{array}$ \\
\hline Minimum & 0.05 & 0.025 \\
\hline Mean & 0.075 & 0.0375 \\
\hline Maximum & 0.10 & 0.05 \\
\hline
\end{tabular}

These calculated $\alpha$ values for horizontal direction were entered into the seismic load dialog which is found in both Slide and RocPlane for the evaluation of seismic load influence on stability. 


\subsection{Back analyses of the planar rockslide using Slide and RocPlane under dry and static conditions}

The analyses presented here look at various scenarios of geotechnical and triggering conditions which would result in $F=1.00$. Also important to mention is that the use of $\phi_{r}$ in the adopted Barton and Bandis (1990) shear strength criterion is based on weathering of joints. For fresh unweathered and slightly weathered joints $\phi_{r}=\phi_{b}$, where $\phi_{b}=$ basic friction angle. This recommendation occurred in 1977, and was unfortunately overlooked and/or not read by the chief supplier of the internet with his version of rock mechanics (Barton, 2013).

In back analysis, only one parameter can be determined at a time while assuming that all other slope parameters are known and keeping them constant. This is basically a trial and error procedure to determine a best fit of parameters to an existing slope failure for a value of $\mathrm{F}=$ 1.00 .

Sharifzadeh et al. (2009) stated that, in order to avoid the any adverse effects of back calculated parameters on further stability analysis, it is necessary to assess the influence of parameter variation on slope behaviour using a sensitivity analysis procedure.

\subsubsection{Sensitivity analysis using Slide}

Before presenting the back analysis results, sensitivity analysis was carried out to see the effect of JRC, $\phi_{\mathrm{r}}$ and JCS on F.

Figures 7.3 to 7.5 show sensitivity analyses curves for the significantly influential shear strength parameters i.e. JRC, $\phi_{\mathrm{r}}$ and JRC. Material unit weight was not considered for the sensitivity analysis because it does not have major influence in the analysis but it is required by the program for a complete definition of material properties (Alonso, 1976). 


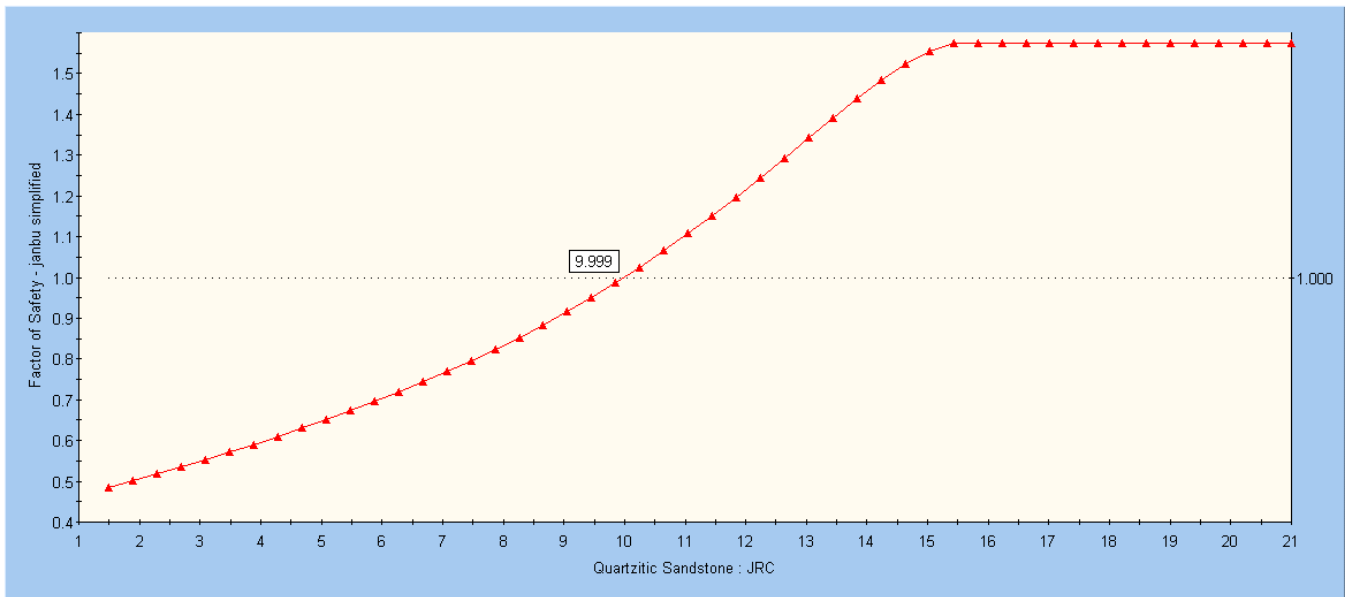

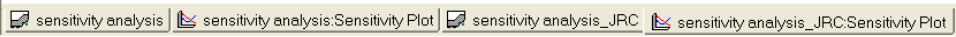

Figure 7.3: Sensitivity analysis plot for JRC (Slide).

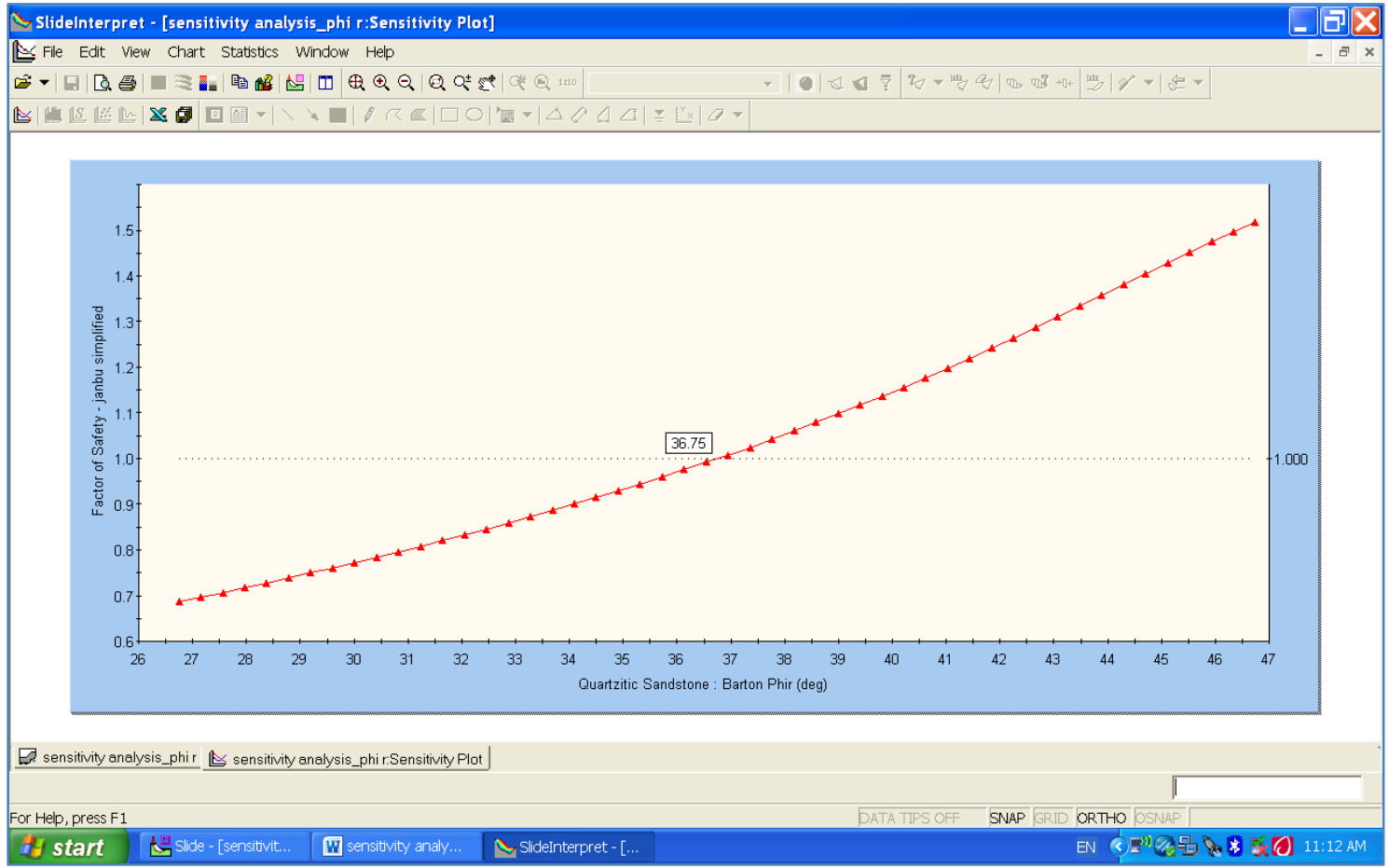

Figure 7.4: Sensitivity analysis plot for the residual friction angle (Slide). 


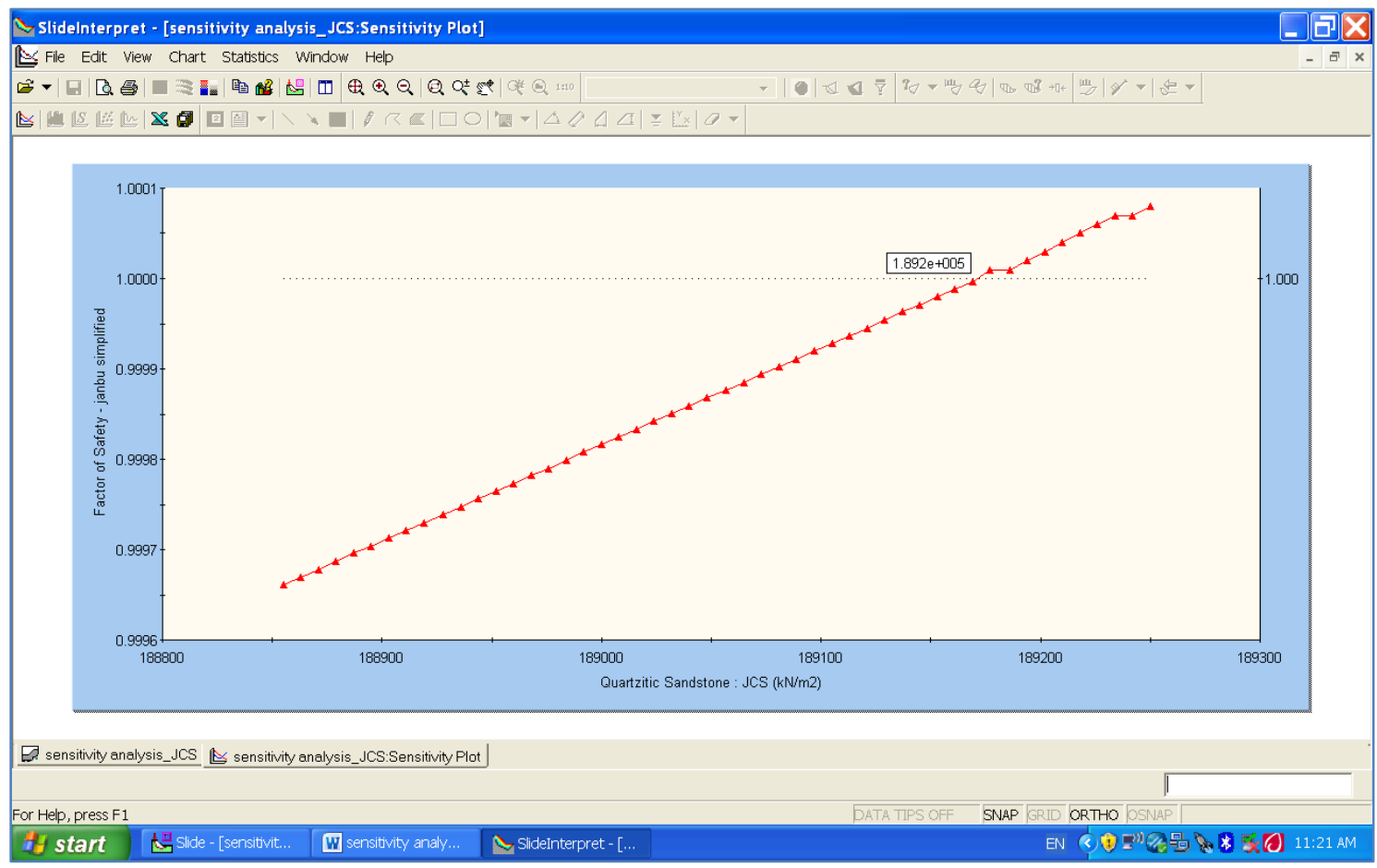

Figure 7.5: Sensitivity analysis plot for JCS (Slide).

The JRC range shown in Figure 7.3 from 7 to 15.5 obtained values of $F$ ranging from 0.7 to 1.5 . Beyond a JRC value of 15, there would be no impact of JRC on the factor of safety. This sensitivity analysis plot shows that JRC would have an impact $\mathrm{F}$ up to the value of 15 .

In considering a range of values for $\phi_{\mathrm{r}}$ from $26.5^{\circ}$ to $40^{\circ}$ (Figure 7.4) which falls within a typical sandstone range for $\phi_{\mathrm{r}}, \mathrm{F}$ similarly ranges from 0.7 to 1.1. This sensitivity analysis plot of $\phi_{\mathrm{r}}$ versus $\mathrm{F}$ shows that the residual friction angle also had a significant impact on $\mathrm{F}$.

The sensitivity analysis plot of JCS versus F shown in Figure 7.5 shows that from 188.9 MPa to 189.3 MPa JCS values, the corresponding difference in F was 0.0035 which is extremely negligible. This suggests that JCS has a very minimal impact on F.

Figure 7.6 shows a sensitivity plot of all shear strength parameters (i.e. $\phi_{\mathrm{r}}, \mathrm{RC}$ and JCS) above for Barton and Bandis (1990) criterion on Slide program. It is revealed from the plot that JCS has no effect on F. The steep curve of JRC suggests that, JRC could have been the most influential shear strength parameter on F. The basic friction angle curve shows a moderately steep trend which suggests that it also has a significant impact on F after JRC. 


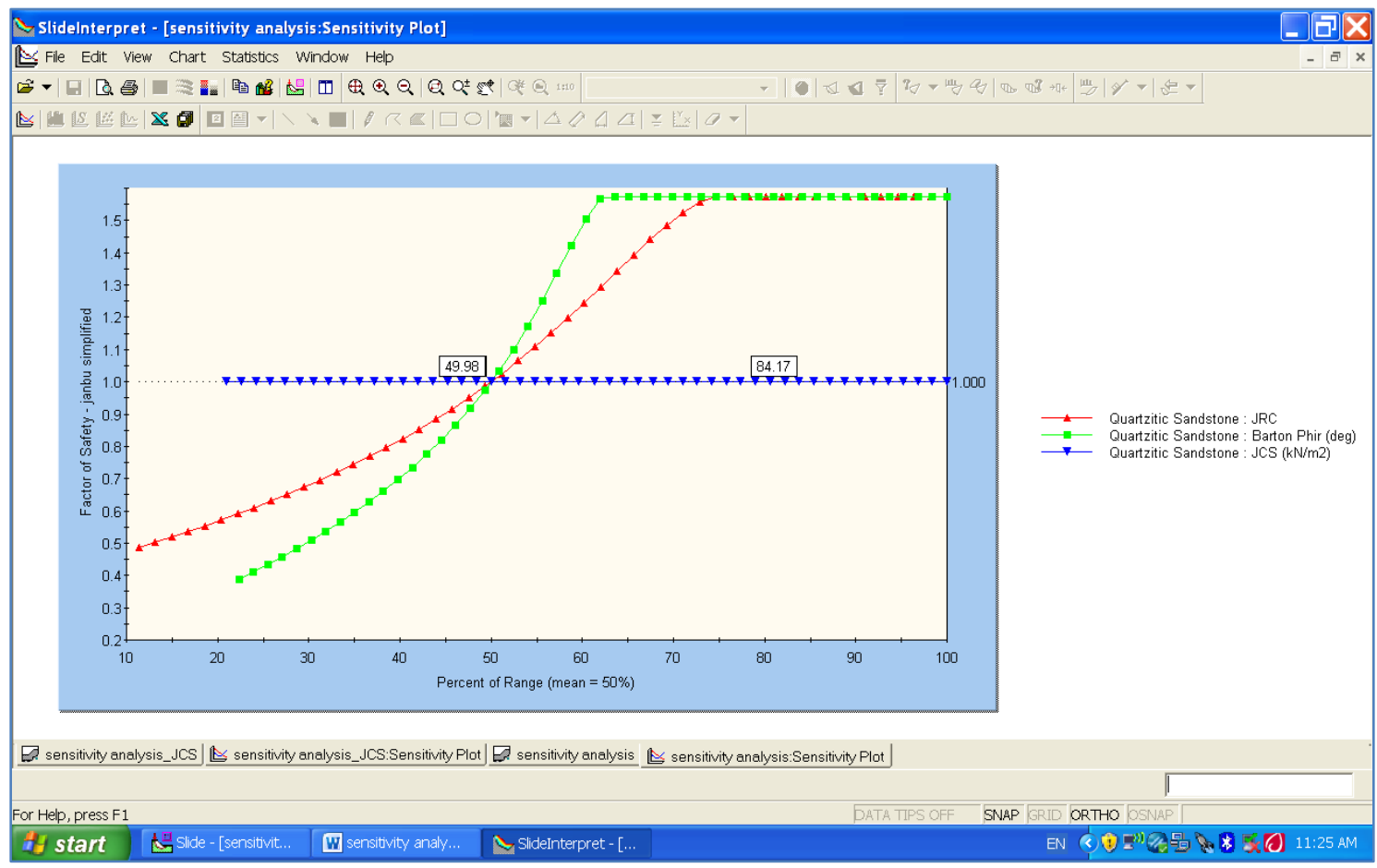

Figure 7.6: Sensitivity analysis of back calculated shear strength parameters (Slide).

The sensitivity analysis results shown in Figure 7.6 suggest that JRC and $\phi_{\mathrm{r}}$ are the main influential shear strength parameters on $\mathrm{F}$ as opposed to JCS. Hence the effect of the range in values of the back calculated JRC and $\phi_{\mathrm{r}}$ under various groundwater and seismic ground acceleration scenarios was evaluated in both Slide and RocPlane as presented in sections 7.4 to 7.7 .

\subsubsection{Back analysis using Slide}

The software Slide (version 6.0) in Rocscience does not have an explicit option for the back analysis of material properties. However, it is possible to carry out back analysis of material using sensitivity as outlined in Slide v.6.0 Tutorial Manual 23.

There are three shear strength parameters that define the Barton-Bandis (1990) criterion i.e. joint roughness coefficient (JRC), joint wall compressive strength (JCS) and residual friction angle $\left(\phi_{\mathrm{r}}\right)$. Two of these parameters, i.e. the JRC and JCS, have been successfully estimated from the laboratory followed by back calculations. The residual friction angle $\left(\phi_{r}\right)$ was the outstanding parameter that needed to be determined by back analysis using Slide software. The back analysis of shear strength parameters was first conducted assuming static and dry 
conditions because it was believed that the stage was set for a landslide to occur given the unfavourable joint orientation in relation to the slope.

Using sensitivity, and the fact that the failure surface was known (i.e. $\mathrm{F}=1.00$ ), the residual friction angle $\left(\phi_{\mathrm{r}}\right)$ at failure was determined. The back analysis was performed by using a trial and error procedure (Figure 7.7), which involves approximating a range of possible $\left(\phi_{\mathrm{r}}\right)$ values until a value of $\mathrm{F}=1.00$ was achieved.

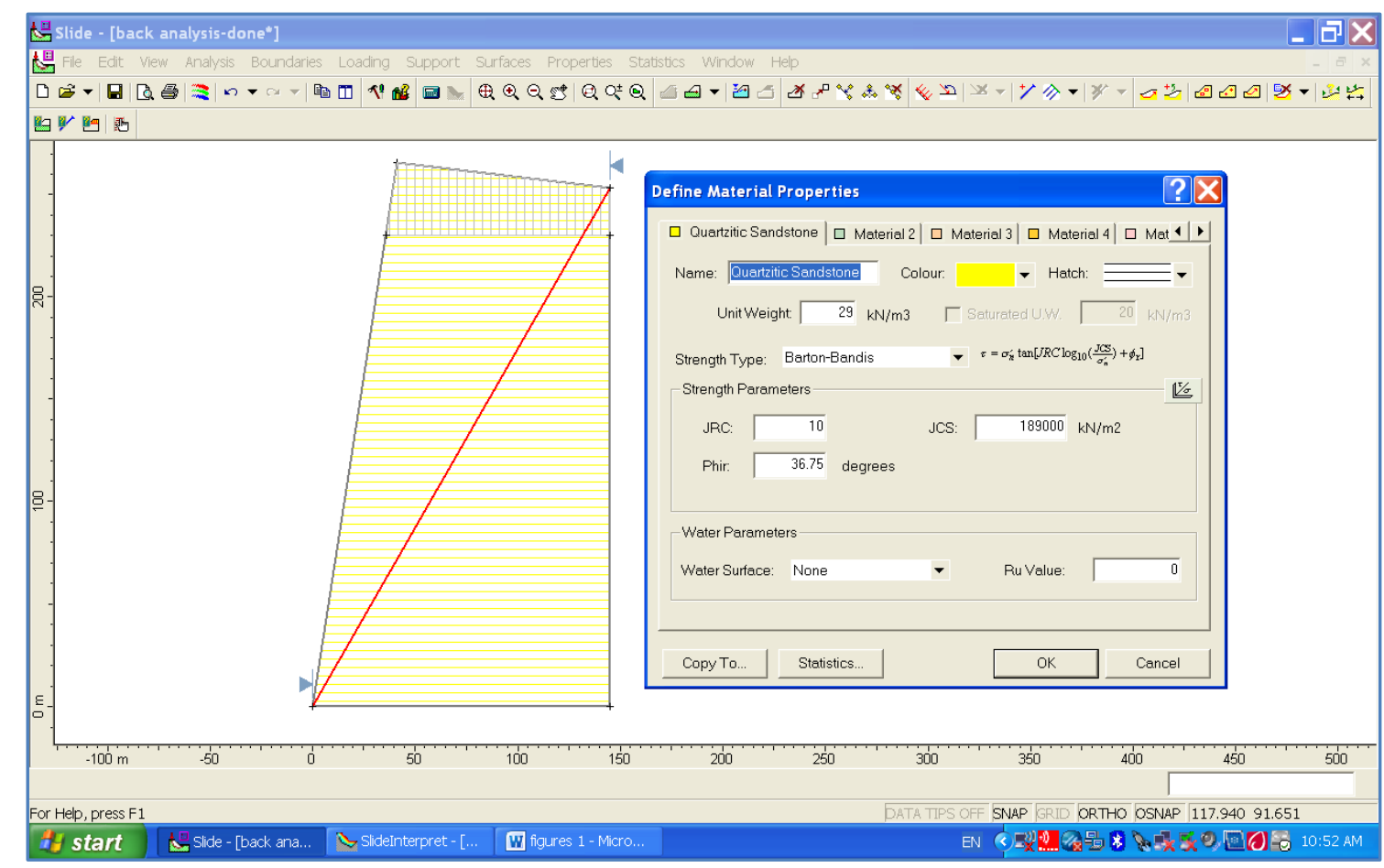

Figure 7.7: Input parameters for back analysis of residual friction angle along the failure surface.

Results from the analysis as shown in Figures 7.8 revealed that at $\mathrm{F}=1.00$, a residual friction angle $\left(\phi_{\mathrm{r}}\right)$ equal to $36.8^{\circ}$ will be required for a failure plane matching that of the Lake Fundudzi landslide, and given a rock mass unit weight of $29 \mathrm{kN} / \mathrm{m}^{3}$, with average JRC and JCS values of 10 and $189 \mathrm{MPa}$ respectively.

The deterministic analysis finally found that the best fit (i.e. $\mathrm{F}=1.00$ ) of parameters for the failure plane at Lake Fundudzi are an average value of 10 for JRC, $189 \mathrm{MPa}$ and $36.8^{\circ}$ for residual friction angle (Figure 7.7). Thus, based on a deterministic analysis done in Slide, the best fit of parameters for failure to have occurred (i.e. $F=1.00$ ) are an average value of 10 for JRC, $189 \mathrm{MPa}$ and $36.8^{\circ}$ for $\phi_{\mathrm{r}}$ (Figure 7.7). 


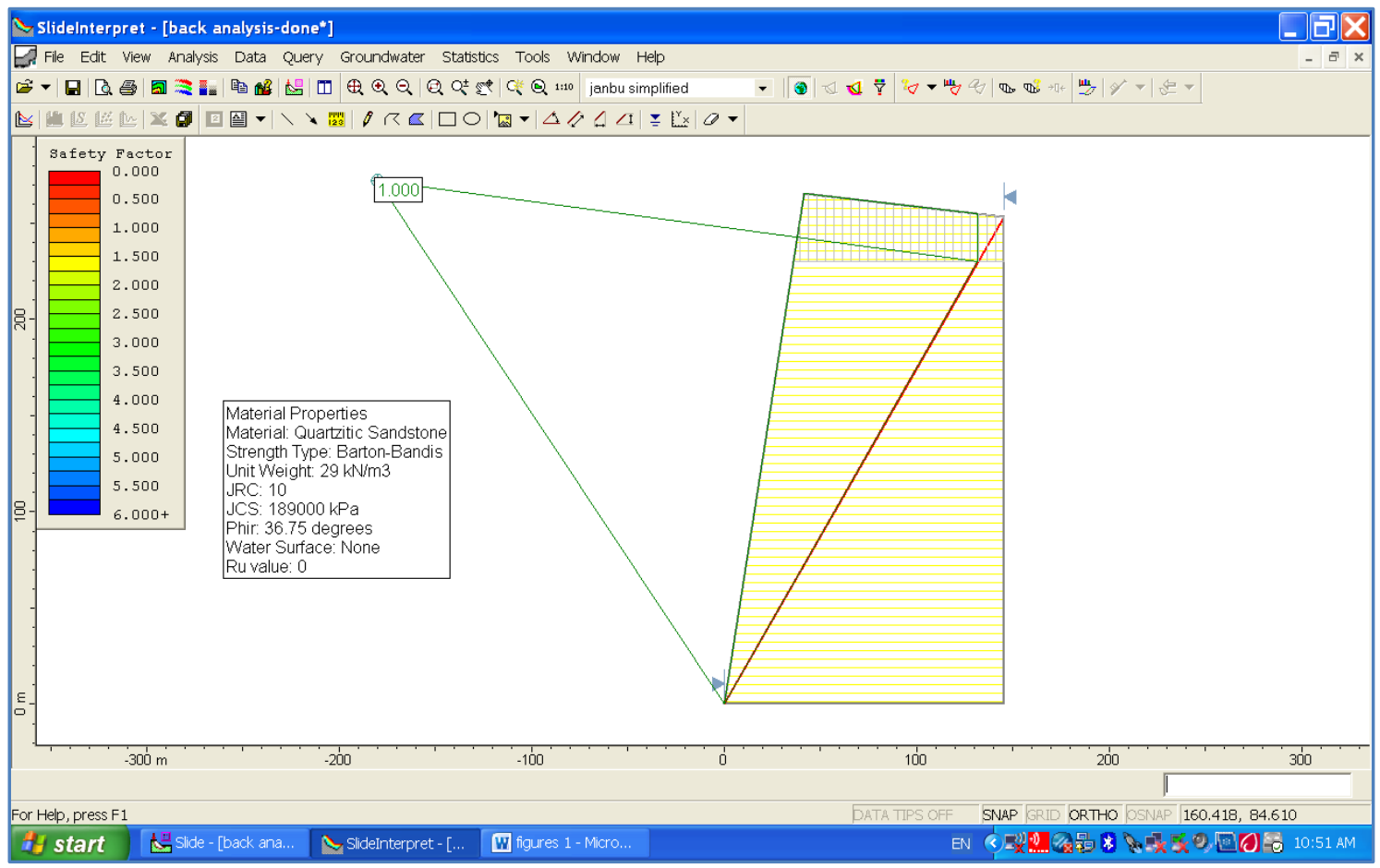

Figure 7.8: Back analysis of the shear strength parameters based on the Barton-Bandis shear strength criterion (Slide).

\subsubsection{Sensitivity analysis using RocPlane}

As in the case of the back analysis using Slide the sensitivity analysis was carried out to see the effect of JRC, $\phi_{\mathrm{r}}$ and JCS on F in RocPlane. Figure 7.9 shows the data for the geometrical features that characterise the slope which were inputted into RocPlane program. The pre-failure slope angle was $80^{\circ}$, the slope height is $245 \mathrm{~m}$ and the failure plane dips daylights on the slope face with a dip of $60^{\circ}$. The back analysis of shear strength parameters was firstly conducted assuming static and dry conditions.

Figure 7.10 shows a 3-D perspective of a modelled planar failure in RocPlane with similar features as those in the Slide analysis and shear strength parameters input data.

Figures 7.11, 7.12 and 7.13 show individual sensitivity analysis plots for the shear strength parameters i.e. JRC, $\phi_{\mathrm{r}}$ and JCS. 


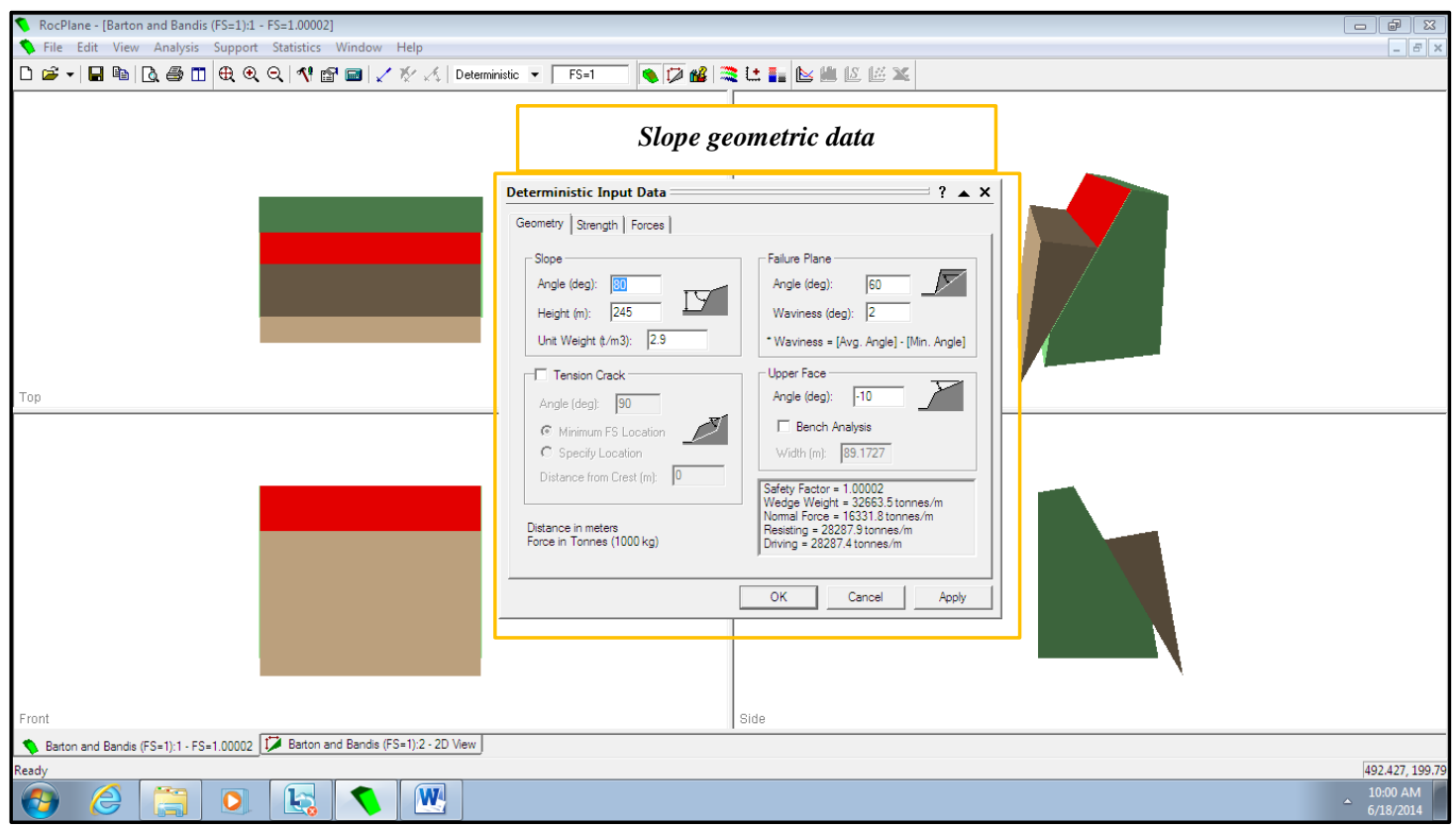

Figure 7.9: Geometric slope parameters captured on RocPlane.

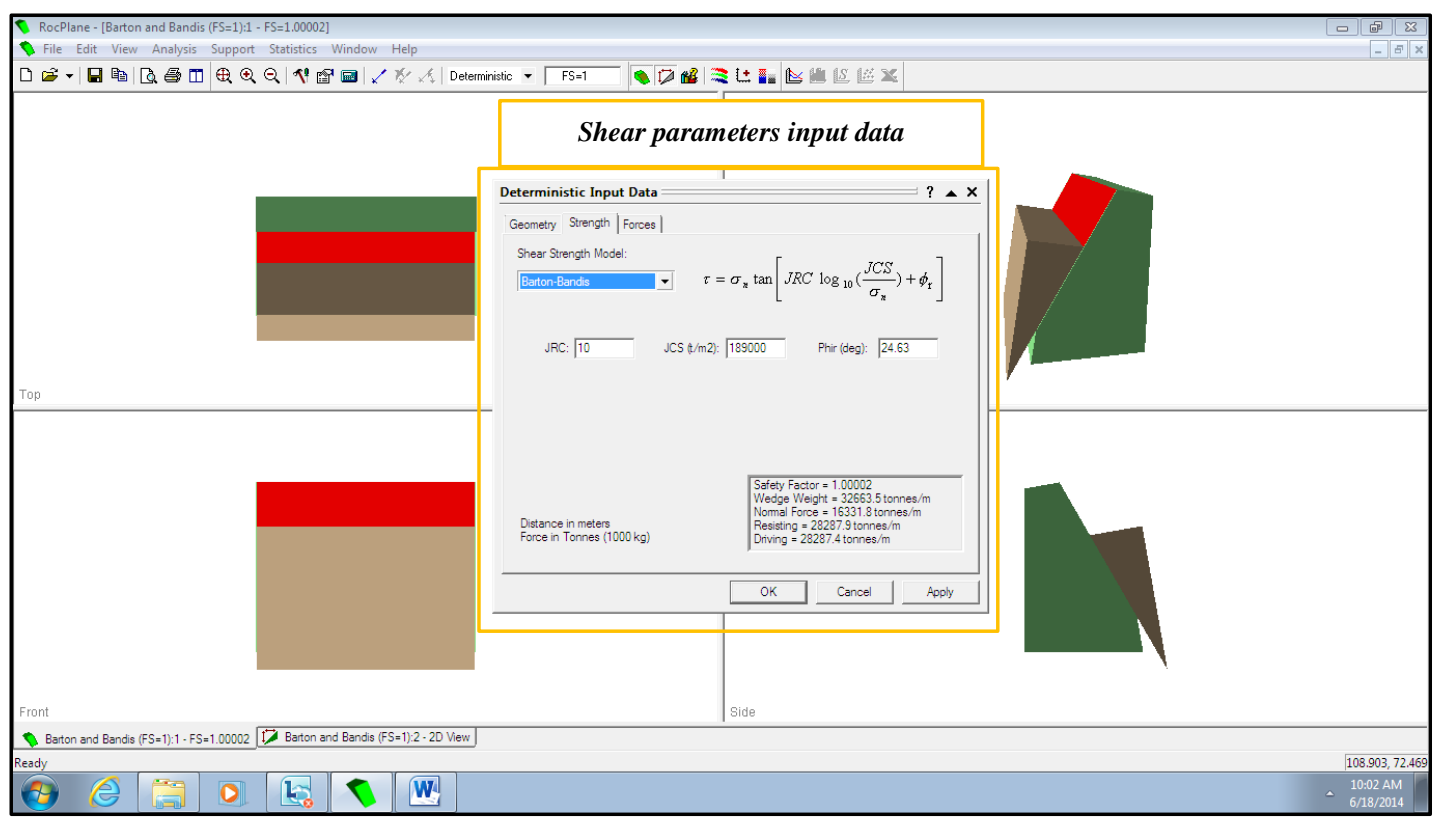

Figure 7.10: Shear strength input data used for back analysis in RocPlane and the slope's 3-D perspective view. 


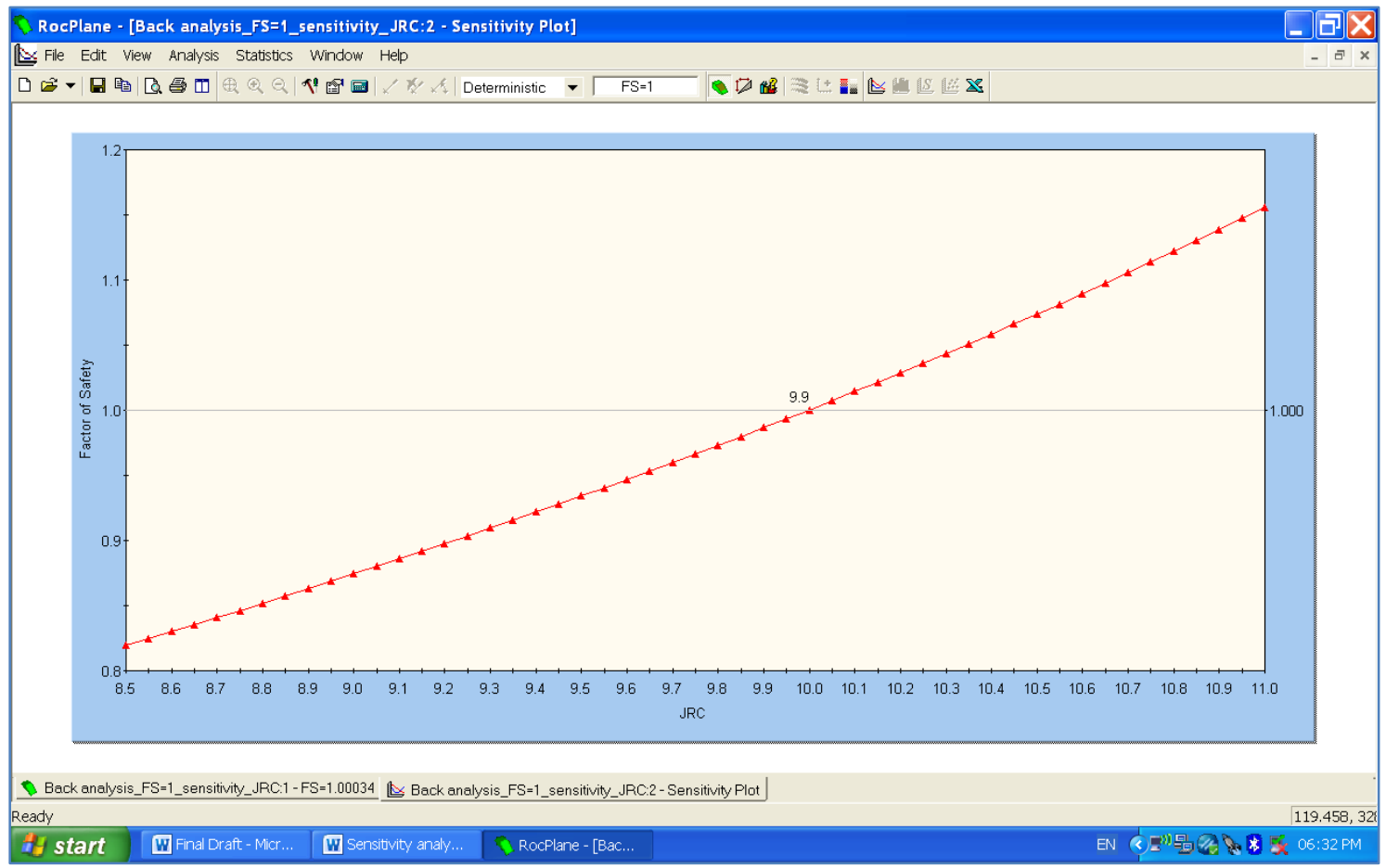

Figure 7.11: Sensitivity analysis plot for JRC (RocPlane).

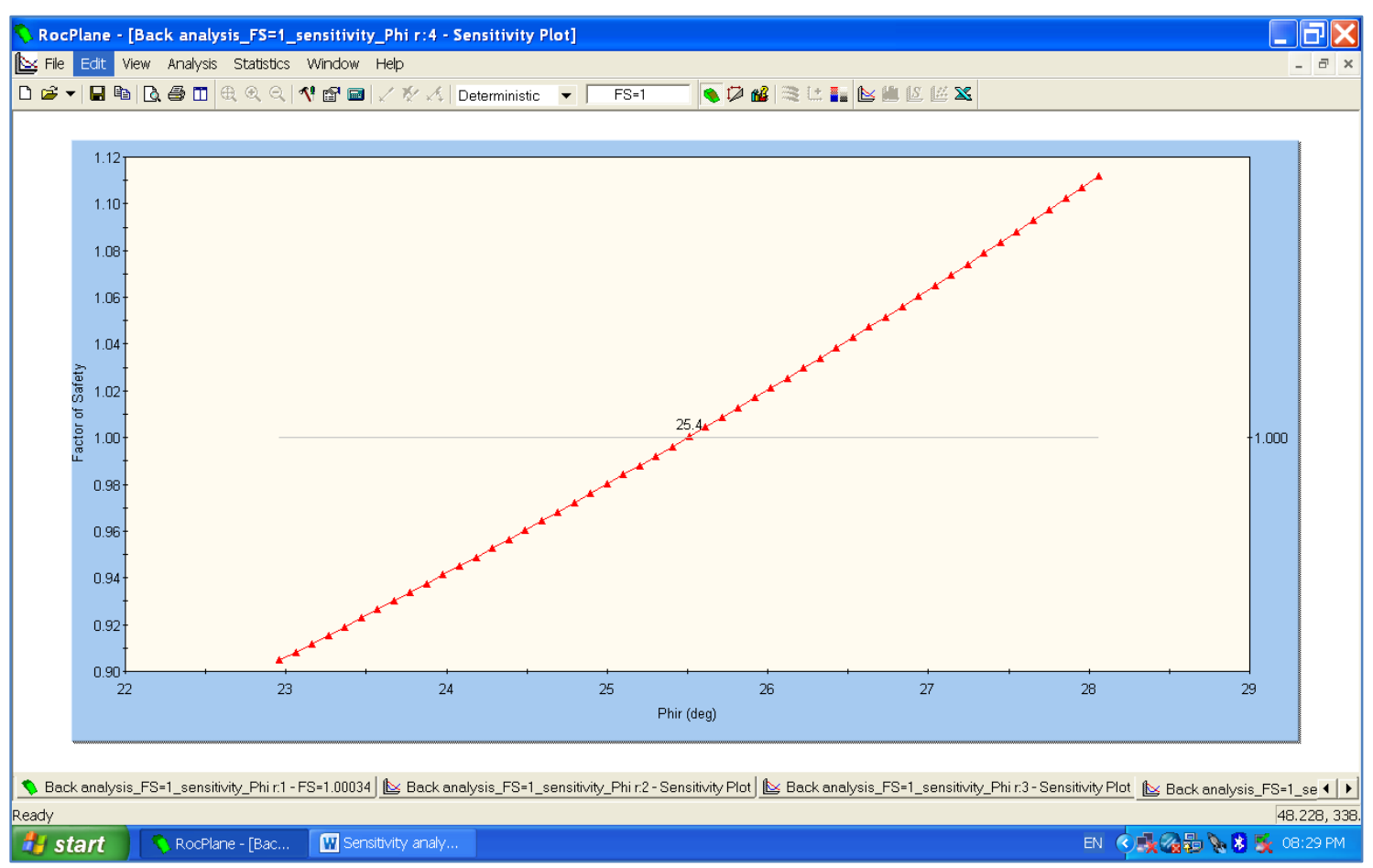

Figure 7.12: Sensitivity analysis plot for $\phi_{\mathrm{r}}($ RocPlane $)$. 


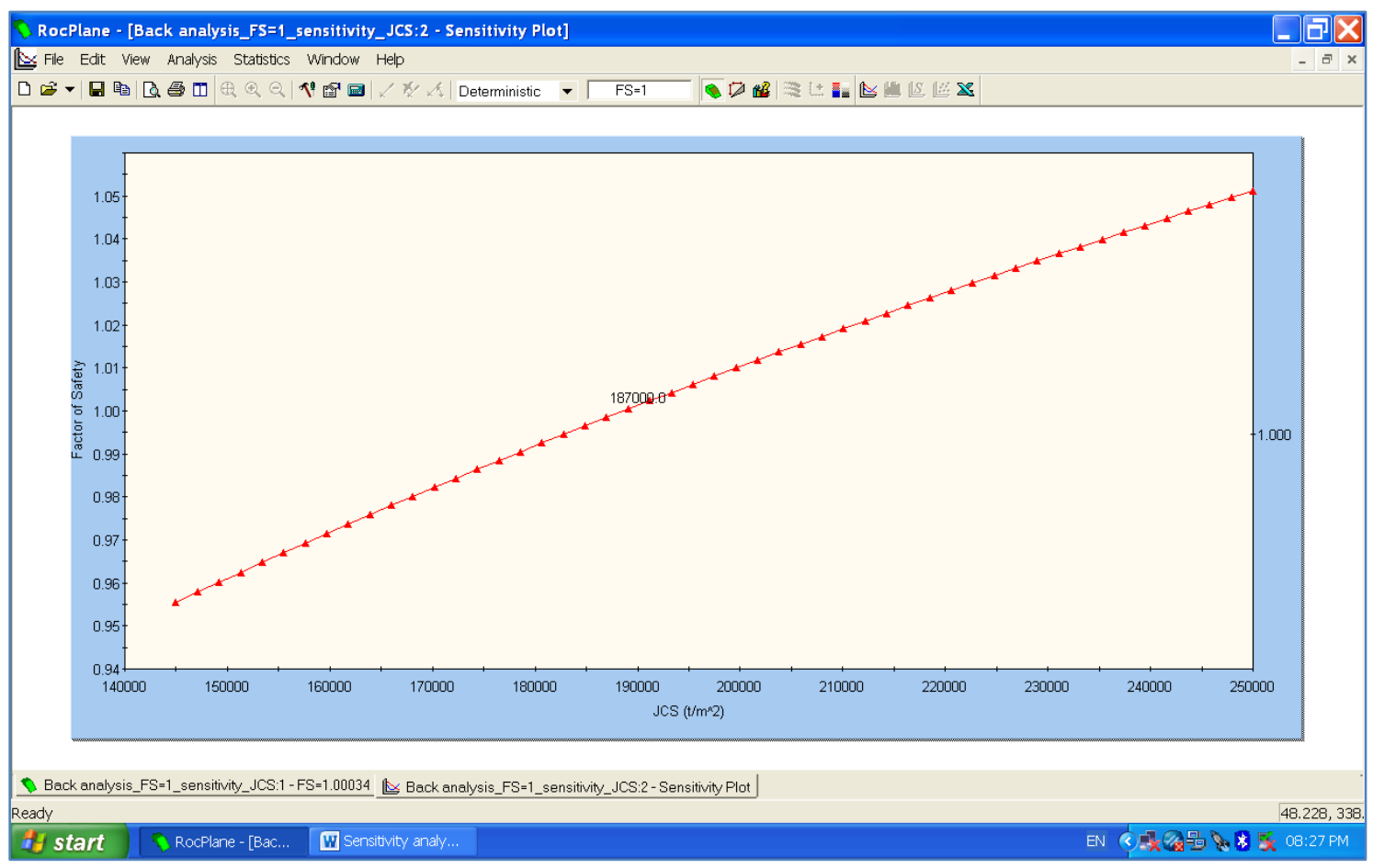

Figure 7.13: Sensitivity analysis plot for JCS (RocPlane).

The JRC values shown in Figure 7.11 range from 8.5 to 11 while the corresponding factor of safety ranged from 0.83 to 1.15 . This shows that for a difference of 2.5 in the JRC values, the factor of safety changed by 0.33 which is significant in slope stability analysis. This sensitivity analysis plot shows that JRC would have a significant impact on the slope stability (F).

When considering the residual friction angle range which was from $23^{\circ}$ to $29^{\circ}$ (Figure 7.12) based on values back analysed on RocPlane, $\mathrm{F}$ almost similarly range from 0.90 to 1.11 . This shows that over a $6^{\circ}$ change in the residual friction angle, the factor of safety changed by 0.21 which is significant in slope stability analysis. This sensitivity analysis plot of residual friction angle versus $\mathrm{F}$ shows that the residual friction angle also has a significant impact on $\mathrm{F}$.

The sensitivity analysis plot for JCS versus F shown in Figure 7.13 shows that from $145 \mathrm{MPa}$ to $250 \mathrm{MPa}$ the corresponding $\mathrm{F}$ increased from 0.95 to 1.05 which is about 0.1 change in $\mathrm{F}$. Hence given the $105 \mathrm{MPa}$ increase with only 0.1 increase in F, it suggests that the JCS had a very minimal impact on $\mathrm{F}$ for the range of values considered.

Figure 7.14 shows a sensitivity plot of all the shear strength parameters above for Barton and Bandis (1990) criterion on RocPlane program. It is revealed from the plot that the JCS has absolutely no effect on $\mathrm{F}$ for the range of values considered. The steep curve for JRC suggests that JRC is the most influential shear strength parameter on $\mathrm{F}$ of the three parameters 
considered, followed by $\phi_{\mathrm{r}}$ as was also observed analysed in the sensitivity analyses conducted in Slide.

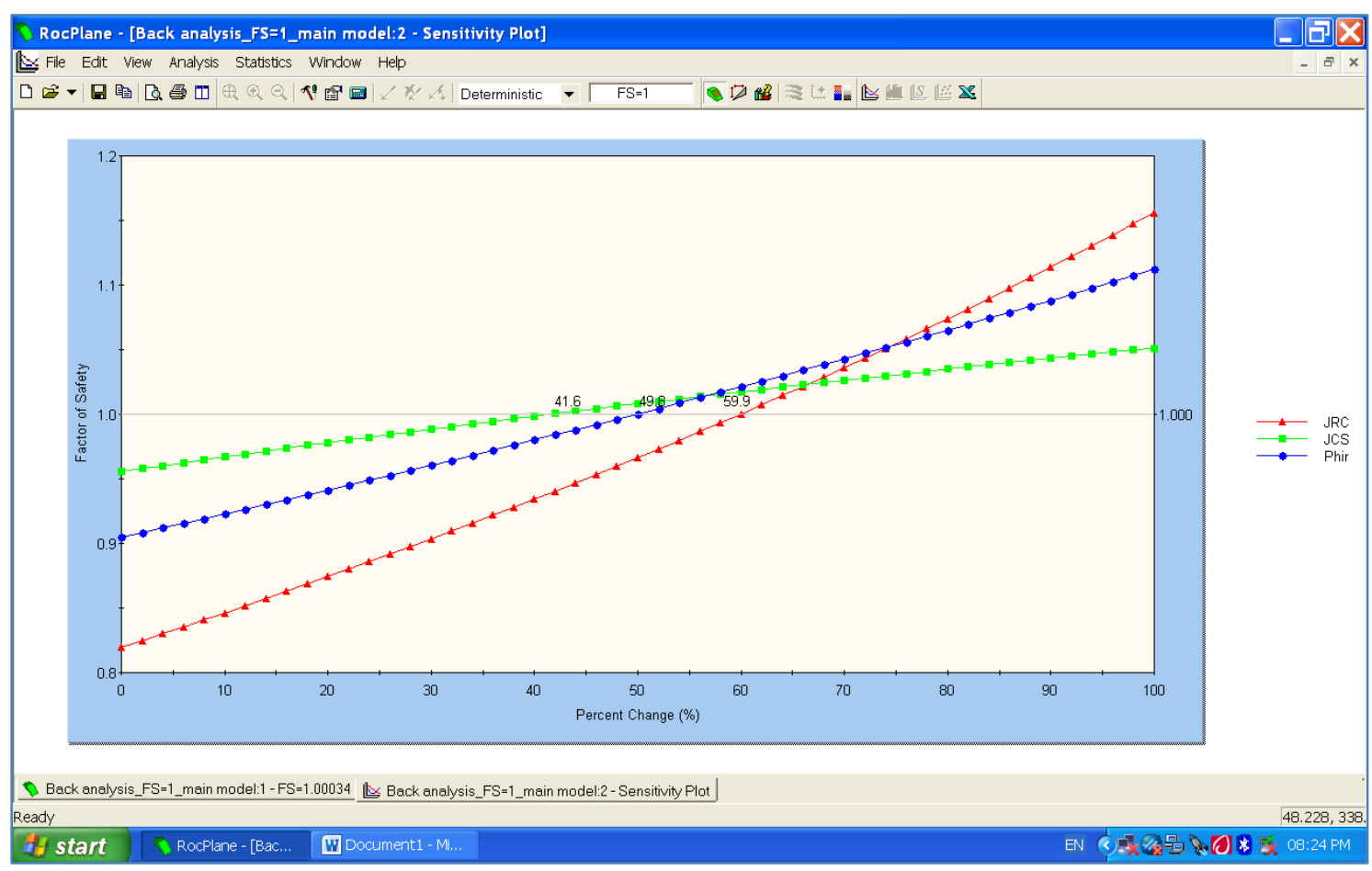

Figure 7.14: Sensitivity analysis of back calculated shear strength parameters (RocPlane).

\subsubsection{Back analysis using RocPlane}

The Barton-Bandis (1990) criterion for rock joint strength was also used for the back analysis in RocPlane. The unknown parameter was still $\phi_{r}$. The back analysis was performed using a trial and error procedure as explained in section 7.3. The two known parameters i.e. average JRC and JCS were set constant at 10 and $189 \mathrm{MPa}$ respectively and the unknown $\left(\phi_{r}\right)$ was varied until F $=1.00$ was obtained. The back analysis carried out on RocPlane showed that the best fit of $\phi_{r}$ based on the average values of JRC and JCS was found to be $25.4^{\circ}$.

The back analysis result obtained (Figure 7.15) from RocPlane is significantly different from the result obtained from the Slide analysis with respect to the back analysed residual friction angle, $\phi_{r}$. The results revealed that the residual friction angle of $25.4^{\circ}$ would be required to give $\mathrm{F}=1.00$, given the values 10 and $189 \mathrm{MPa}$ for average JRC and JCS respectively under similar conditions in contrast to $\phi_{\mathrm{r}}$ of $37.8^{\circ}$ computed using Slide program. This implies that the back calculated value of $\phi_{\mathrm{r}}$ from Slide is $34.5 \%$ higher than the back calculated value from RocPlane under dry static conditions. Slide and RocPlane use different methods of approach e.g. in 
RocPlane the block is treated as a single sliding mass, considering only force equilibrium whereas in Slide, the block is considered to be made up of individual slices.

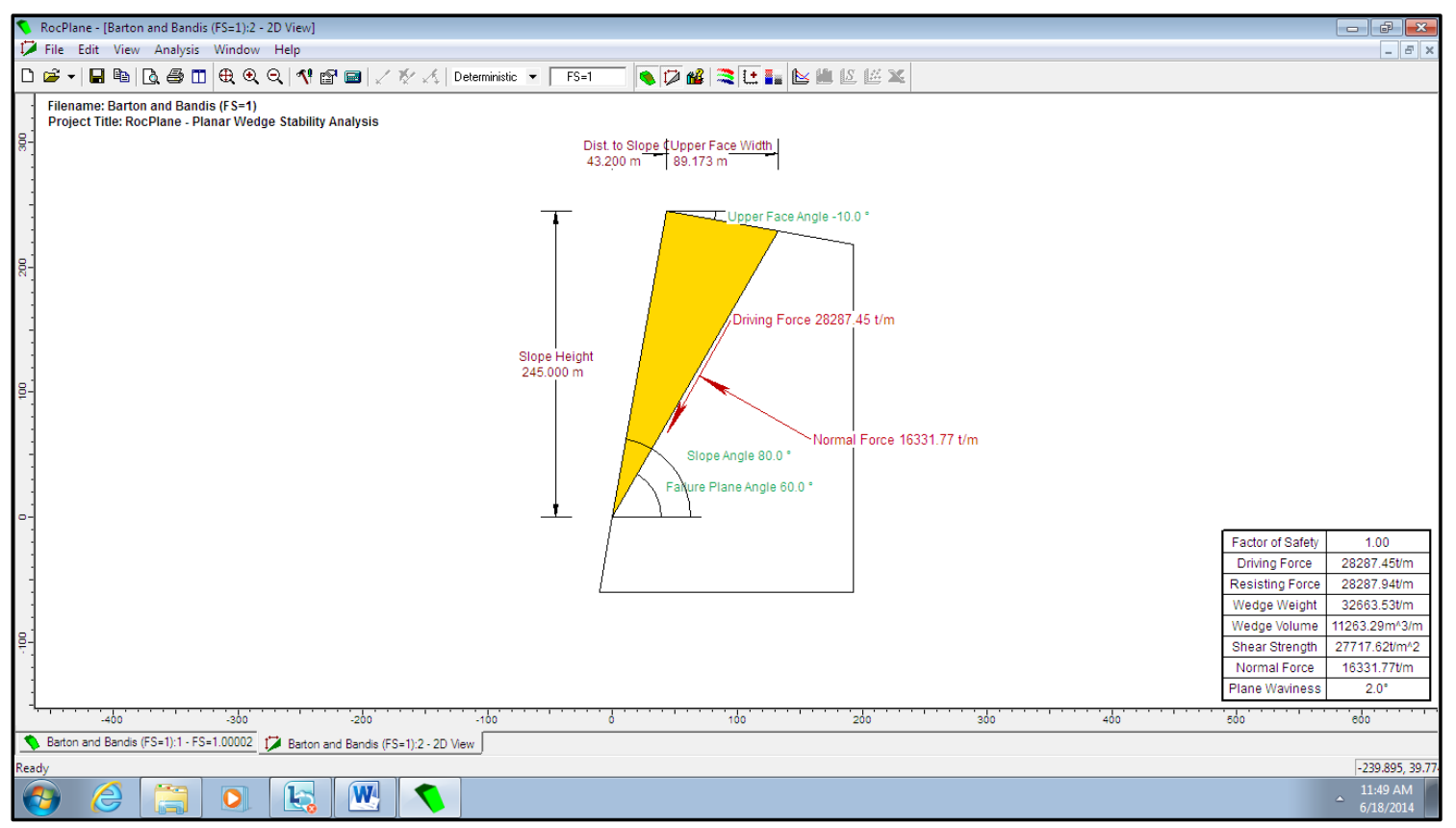

Figure 7.15: Planar failure stability back analysis using RocPlane.

\subsection{Back analyses of $\phi_{\mathrm{r}}$ under different JRC values and groundwater conditions using}

\section{Slide and RocPlane}

Back analyses of $\phi_{\mathrm{r}}$ under different JRC values and groundwater conditions using Slide and RocPlane was undertaken in order to investigate the groundwater conditions as a possible trigger for the landslide.

\subsubsection{Groundwater analysis in Slide}

The failure surface with a $60^{\circ}$ dip, did suggest that maybe the slope was bound to fail even with the slightest involvement of a triggering condition. Hence, the second phase of the analyses evaluated the influence of:

- $\quad$ back calculated JRC values range i.e. 8.5, 9.0, 9.5, 10, 10.5 and 11.0,

- under various groundwater conditions i.e. completely dry, partially (50\%) filled and filled $(100 \%)$ in the tension crack (Table 7.5), and

- ground acceleration scenarios of 0.025 minimum, 0.0375 average and 0.050 maximum, seismic coefficient values. 
Table 7.5: Back analysed $\phi_{\mathrm{r}}$ values under different groundwater levels in the tension crack (Slide).

\begin{tabular}{|c|c|c|c|}
\hline \multirow{2}{*}{$\begin{array}{c}\text { Assumed } \\
\text { JRC } \\
\text { values }\end{array}$} & \multicolumn{3}{|c|}{ Back calculated residual friction angle $\phi_{\mathbf{r}}\left({ }^{\circ}\right)$} \\
\cline { 2 - 4 } & $\begin{array}{c}\text { 0\% completely dry } \\
\text { tension crack }\end{array}$ & $\begin{array}{c}\mathbf{5 0 \%} \text { partially field } \\
\text { tension crack }\end{array}$ & $\begin{array}{c}\mathbf{1 0 0 \%} \text { filled tension } \\
\text { crack }\end{array}$ \\
\hline 8.5 & 40.3 & 40.4 & 40.7 \\
\hline 9 & 39.1 & 39.2 & 39.5 \\
\hline 9.5 & 37.9 & 38.0 & 38.3 \\
\hline 10 & 36.8 & 36.9 & 36.1 \\
\hline 10.5 & 35.6 & 35.7 & 36.0 \\
\hline 11 & 34.4 & 34.5 & 34.8 \\
\hline
\end{tabular}

Figure 7.16 shows the variability of back calculated residual friction angle under different water levels in the tension crack scenarios where $\mathrm{F}=1.00$.

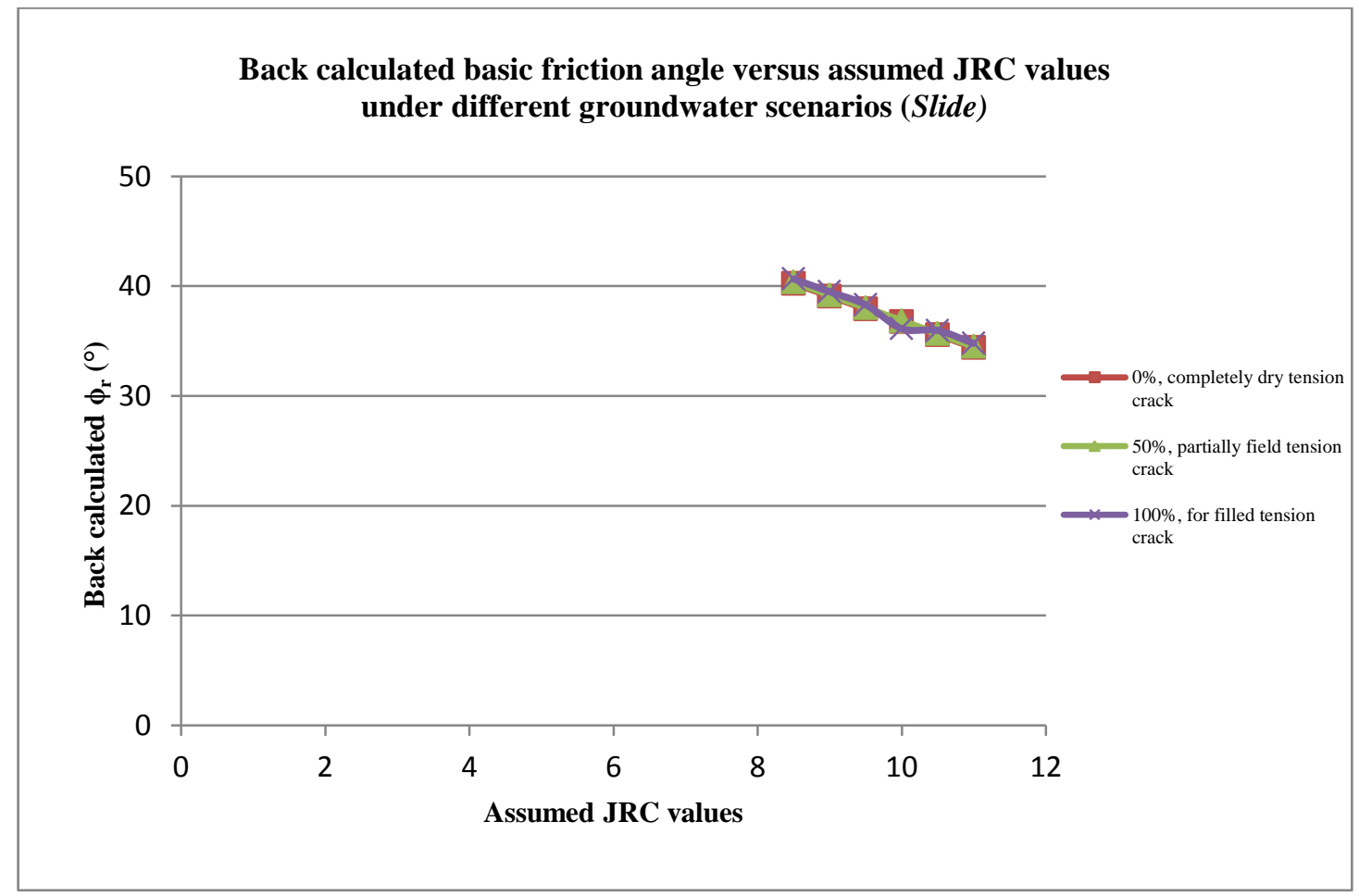

Figure 7.16: Graph of back calculated JRC values versus residual friction angle obtained from different groundwater conditions (Slide).

For each of the assumed JRC values the groundwater does not have much impact on $\phi_{\mathrm{r}}$. For example, at an assumed JRC value of 8.5 the obtained back calculated $\phi_{\mathrm{r}}$ was $40.3^{\circ}, 40.4^{\circ}$ and $40.7^{\circ}$ under completely dry, $50 \%$ and $100 \%$ filled tension crack groundwater conditions respectively. Figure 7.16 graphs show that the difference in obtained $\phi_{\mathrm{r}}$ is not large (i.e. $0.1^{\circ}$ and $\left.0.3^{\circ}\right)$. Within the range of 8.5 to 11 of the assumed JRC values, the required $\phi_{\mathrm{r}}$ for $\mathrm{F}=1.00$, ranges from $40.3^{\circ}$ to $34.4^{\circ}, 40.4^{\circ}$ to $34.5^{\circ}$ and 40.7 to $34.8^{\circ}$ under completely dry, $50 \%$ filled 
and $100 \%$ filled tension crack conditions respectively which translate to a difference of $5.9^{\circ}$ in the obtained $\phi_{\mathrm{r}}$.

However, the different graphs of back calculated JRC values versus $\phi_{\mathrm{r}}$ under dry, $50 \%$ filled and $100 \%$ filled tension crack groundwater conditions almost plot on top of each other. This suggests that the groundwater which was modelled by water level in the tension crack does not have much impact on the back analysed $\phi_{\mathrm{r}}$ according to Slide analysis.

The gentle sloping graphs (Figure 7.16) show an inverse relationship between JRC and $\phi_{\mathrm{r}}$.

\subsubsection{Groundwater analysis in RocPlane}

Table 7.6 shows the back analysed $\phi_{r}$ under different groundwater levels in the tension crack using (RocPlane). For each of the assumed JRC values the groundwater does seem to have impact on $\phi_{\mathrm{r}}$. For instance, at assumed JRC value of 8.5 the obtained $\phi_{r}$ is $30.7^{\circ}, 32.7^{\circ}$ and $34.9^{\circ}$ under completely dry, $50 \%$ filled and $100 \%$ tension crack groundwater conditions respectively. Three graphs (Figure 7.17) of assumed JRC values versus back analysed residual friction angle under dry, $50 \%$ filled and $100 \%$ filled tension cracks conditions plotted some distance apart and parallel to each other. This shows a difference in the obtained $\phi_{\mathrm{r}}$ which is $2.0^{\circ}$ and $2.2^{\circ}$ from complete dry tension crack to $50 \%$ filled tension crack and $50 \%$ filled tension crack to $100 \%$ filled tension crack respectively. The graphs also show a moderately steep inverse relationship between the back calculated $\phi_{\mathrm{r}}$ and assumed JRC values for $\mathrm{F}=1.00$ under various groundwater scenarios.

Table 7.6: Back analysed $\phi_{r}$ values under different groundwater levels in the tension crack (RocPlane).

\begin{tabular}{|c|c|c|c|}
\hline \multirow{2}{*}{$\begin{array}{c}\text { Assumed } \\
\text { JRC } \\
\text { value }\end{array}$} & \multicolumn{3}{|c|}{ Back calculated $\phi_{\mathrm{r}},\left(^{\circ}\right)$} \\
\hline & $\begin{array}{l}\text { 0\% completely dry tension } \\
\text { crack }\end{array}$ & $\begin{array}{l}50 \% \text { partially filled } \\
\text { tension crack }\end{array}$ & $\begin{array}{l}100 \% \text { filled } \\
\text { tension crack }\end{array}$ \\
\hline 8.5 & 30.7 & 32.7 & 34.9 \\
\hline 9 & 29.0 & 30.9 & 33.1 \\
\hline 9.5 & 27.2 & 29.2 & 31.4 \\
\hline 10 & 25.5 & 27.4 & 29.6 \\
\hline 10.5 & 23.8 & 25.7 & 27.8 \\
\hline 11 & 22.1 & 23.9 & 26.0 \\
\hline
\end{tabular}

Figure 7.17 shows the results of back analysed residual friction angle under different groundwater level scenarios in the tension crack where $\mathrm{F}=1.00$ (RocPlane). 


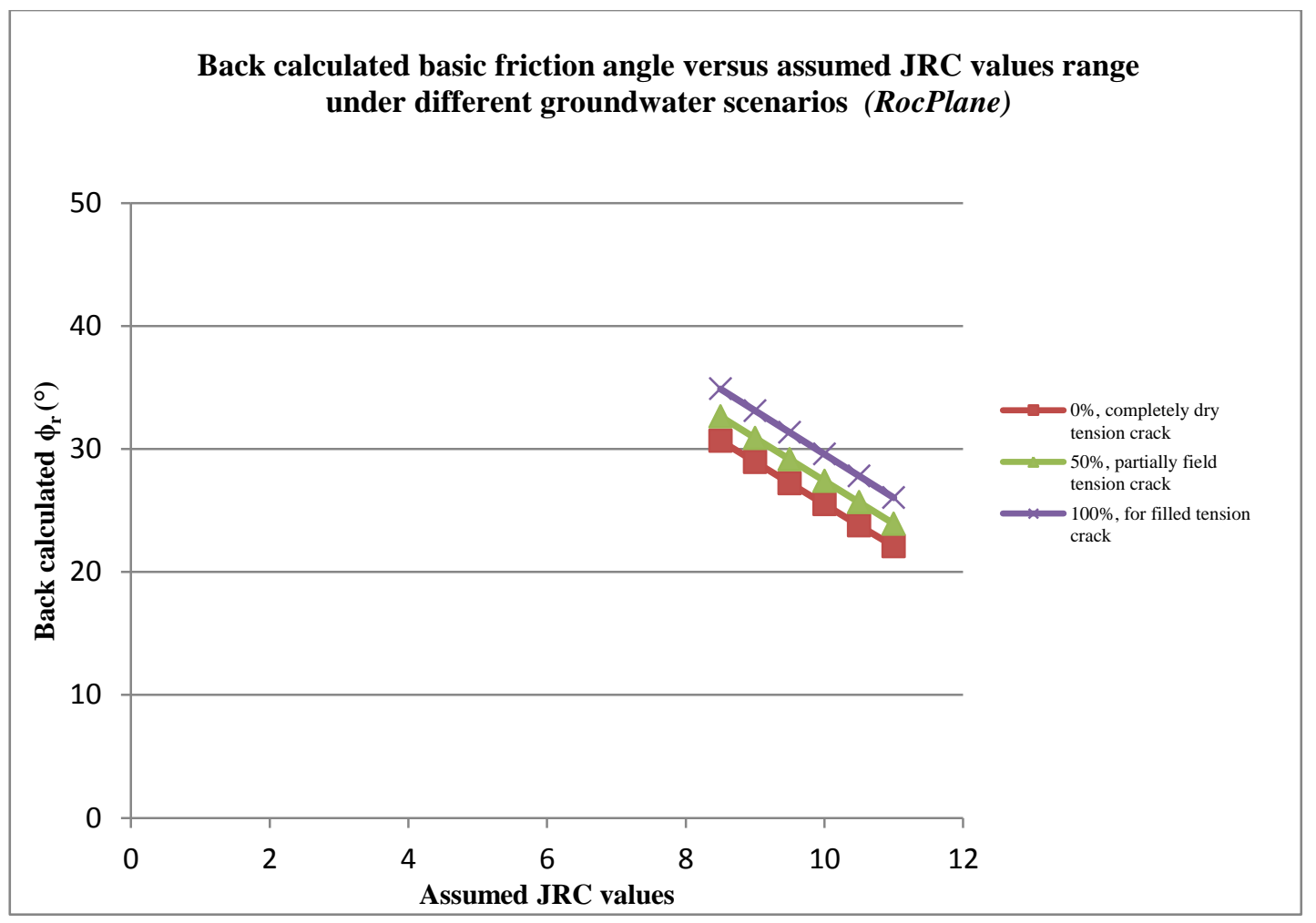

Figure 7.17: Graph of assumed JRC values versus residual friction angle obtained from different groundwater conditions (RocPlane).

On using RocPlane, within the range of 8.5 to 11 the required residual friction angle for $\mathrm{F}=$ 1.00 ranges from $30.7^{\circ}$ to $22.1,32.7^{\circ}$ to $23.9^{\circ}$ and 34.99 to $26.0^{\circ}$ under completely dry, $50 \%$ filled and $100 \%$ filled tension crack conditions respectively. This gives a difference of $8.1^{\circ}$, $8.8^{\circ}$ and $9.0^{\circ}$ respectively in the obtained $\phi_{\mathrm{r}}$ values. This combined with a difference in the values obtained for $\phi_{\mathrm{r}}$ suggests that the groundwater which was modelled by water level in the tension crack does not have much impact on the back analysed $\phi_{\mathrm{r}}$ value according to RocPlane analysis.

It is important to note that the impact of the groundwater conditions in RocPlane is greater than in Slide. Back analysed $\phi_{\mathrm{r}}$ values for $\mathrm{F}=1.00$ under various groundwater in the tension crack scenarios are lower in RocPlane than those obtained in Slide. A comparison of the results obtained in Slide and RocPlane is presented in section 7.9. 


\subsection{Back analyses of $\phi_{\mathrm{r}}$ under different JRC values and seismic coefficient scenarios using}

Slide and RocPlane

Back analyses of $\phi_{\mathrm{r}}$ under different assumed JRC values and seismic coefficient scenarios was undertaken using Slide and RocPlane in order to investigate seismic conditions as a possible trigger for the landslide.

\subsubsection{Pseudostatic analysis in Slide}

Table 7.7 presents back analysed $\phi_{\mathrm{r}}$ values obtained for the failed slope under different seismic coefficient value scenarios of 0.025 minimum, 0.0375 average and 0.05 maximum, seismic coefficient values using Slide.

Table 7.7: Back analysed $\phi_{\mathrm{r}}$ values under different seismic coefficient scenarios (Slide).

\begin{tabular}{|c|c|c|c|}
\hline \multirow{2}{*}{$\begin{array}{c}\text { Assumed } \\
\text { JRC } \\
\text { value }\end{array}$} & $\begin{array}{c}\text { Min. seismic coefficient } \\
(\boldsymbol{\alpha}) \text { condition }=\mathbf{0 . 0 2 5}\end{array}$ & $\begin{array}{c}\text { Back calculated } \boldsymbol{\phi}_{\mathbf{r}}\left(^{\circ}\right) \\
\text { coefficient conditions } \\
(\boldsymbol{\alpha})=\mathbf{0 . 0 3 7 5}\end{array}$ & $\begin{array}{c}\text { Max. seismic } \\
\text { coefficient conditions } \\
(\boldsymbol{\alpha})=\mathbf{0 . 0 5}\end{array}$ \\
\hline 8.5 & 42.8 & 44.1 & 45.3 \\
\hline 9 & 41.6 & 42.9 & 44.1 \\
\hline 9.5 & 40.4 & 41.7 & 42.9 \\
\hline 10 & 39.3 & 40.5 & 41.8 \\
\hline 10.5 & 38.1 & 39.3 & 40.6 \\
\hline 11 & 36.1 & 38.1 & 39.4 \\
\hline
\end{tabular}

For each of the assumed JRC values the seismic ground acceleration coefficient does have an impact on $\phi_{\mathrm{r}}$. For example, at an assumed JRC value of 8.5 the back analysed $\phi_{\mathrm{r}}$ value is $42.8^{\circ}$, $44.1^{\circ}$ and $45.3^{\circ}$ under under different scenarios of 0.025 (minimum), 0.0375 (average) and 0.05 (maximum) seismic ground acceleration coefficient values respectively. The difference in the value of $\phi_{\mathrm{r}}$ obtained from minimum to maximum seismic ground acceleration coefficient at an assumed JRC value of 8.5 is approximately $2.5^{\circ}$.

Back analysis of $\phi_{\mathbf{r}}$ under an assumed range of JRC values from 8.5 to 11 and seismic coefficient scenarios using Slide shows that, the required residual friction angle for $\mathrm{F}=1.00$ ranges from $42.8^{\circ}$ to $36.1^{\circ}$ for an assumed minimum value of $\alpha$ of $0.025,44.1^{\circ}$ to $38.1^{\circ}$ for a mean value of $\alpha$ of 0.0375 and $45.3^{\circ}$ to $39.4 .3^{\circ}$ for a maximum value of $\alpha$ of 0.05 .

The different plots shown in Figure 7.18 of assumed JRC values versus $\phi_{\mathrm{r}}$ under different seismic ground acceleration coefficient value scenarios of 0.025 minimum, 0.0375 average and 
0.05 maximum seismic coefficient values plotted parallel and some distance apart. This shows that a higher residual friction angle would be required to achieve $\mathrm{F}=1.00$ under maximum than minimum seismic ground acceleration coefficient value conditions. However, the graphs also show that there is an inverse relationship between the back analysed $\phi_{\mathrm{r}}$ and assumed JRC values for $\mathrm{F}=1.00$ under various seismic ground acceleration coefficient conditions when using Slide.

The significant difference in the values obtained for $\phi_{\mathrm{r}}$ suggests that the seismic ground acceleration condition which was modelled by seismic coefficient values of 0.025 (minimum), 0.0375 (average) and 0.05 (maximum) does have much impact on the back analysed $\phi_{\mathrm{r}}$ values according to pseudostatic analysis conducted in Slide.

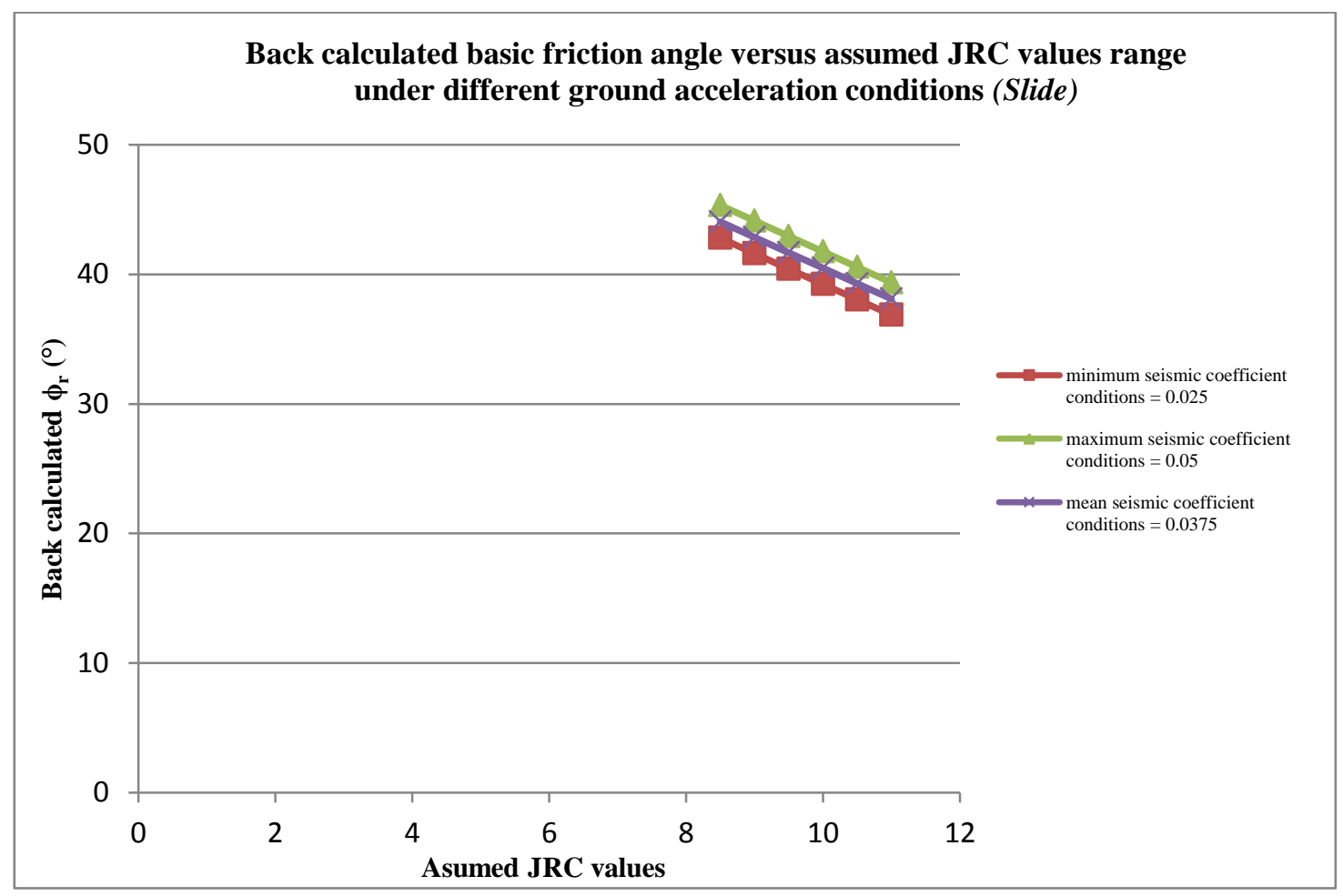

Figure 7.18: Graph of assumed JRC values versus residual friction angle obtained from different seismic ground acceleration scenarios (Slide).

\subsubsection{Pseudostatic analysis in RocPlane}

Table 7.8 presents back analysed residual friction angle under different seismic coefficient scenarios of 0.025 (minimum), 0.0375 (average) and 0.05 (maximum) using RocPlane. Similar procedure was followed as in Slide. For each of the assumed JRC values seismic ground acceleration does have an impact on $\phi_{\mathrm{r}}$. If considering an assumed JRC value of 8.5 the values obtained for $\phi_{\mathrm{r}}$ from back analysis are $33.3^{\circ}, 34.5^{\circ}$ and $35.7^{\circ}$ under 0.025 (minimum), 0.0375 (average) and 0.05 (maximum) seismic coefficient scenarios respectively. This reveals a 
difference of $2.5^{\circ}$ in the back analysed $\phi_{\mathrm{r}}$ from minimum to maximum seismic ground acceleration coefficient at an assumed JRC value of 8.5. Figure 7.19 shows the plots of the back calculated $\phi_{\mathrm{r}}$ values obtained for the range in JRC values under different seismic ground acceleration scenarios for $F=1.00$. Interesting to note that the same difference from minimum to maximum $\phi_{\mathrm{r}}$ obtained is the same as that obtained in Slide.

Table 7.8: Back analysed $\phi_{\mathrm{r}}$ values under different seismic coefficient scenarios (RocPlane).

\begin{tabular}{|c|c|c|c|}
\hline \multirow{2}{*}{$\begin{array}{c}\text { Assumed } \\
\text { JRC } \\
\text { values }\end{array}$} & \multicolumn{3}{|c|}{ Back calculated $\phi_{\mathrm{r}}\left(^{\circ}\right)$} \\
\hline & $\begin{array}{c}\text { minimum seismic } \\
\text { coefficient conditions }= \\
0.025\end{array}$ & $\begin{array}{c}\text { mean seismic } \\
\text { coefficient conditions }= \\
0.0375\end{array}$ & $\begin{array}{c}\text { maximum seismic } \\
\text { coefficient conditions }= \\
0.05\end{array}$ \\
\hline 8.5 & 33.2 & 34.5 & 35.7 \\
\hline 9 & 31.5 & 32.7 & 33.9 \\
\hline 9.5 & 29.7 & 31.0 & 32.2 \\
\hline 10 & 28.0 & 29.2 & 30.4 \\
\hline 10.5 & 26.2 & 27.4 & 28.6 \\
\hline 11 & 24.5 & 26.7 & 26.9 \\
\hline
\end{tabular}

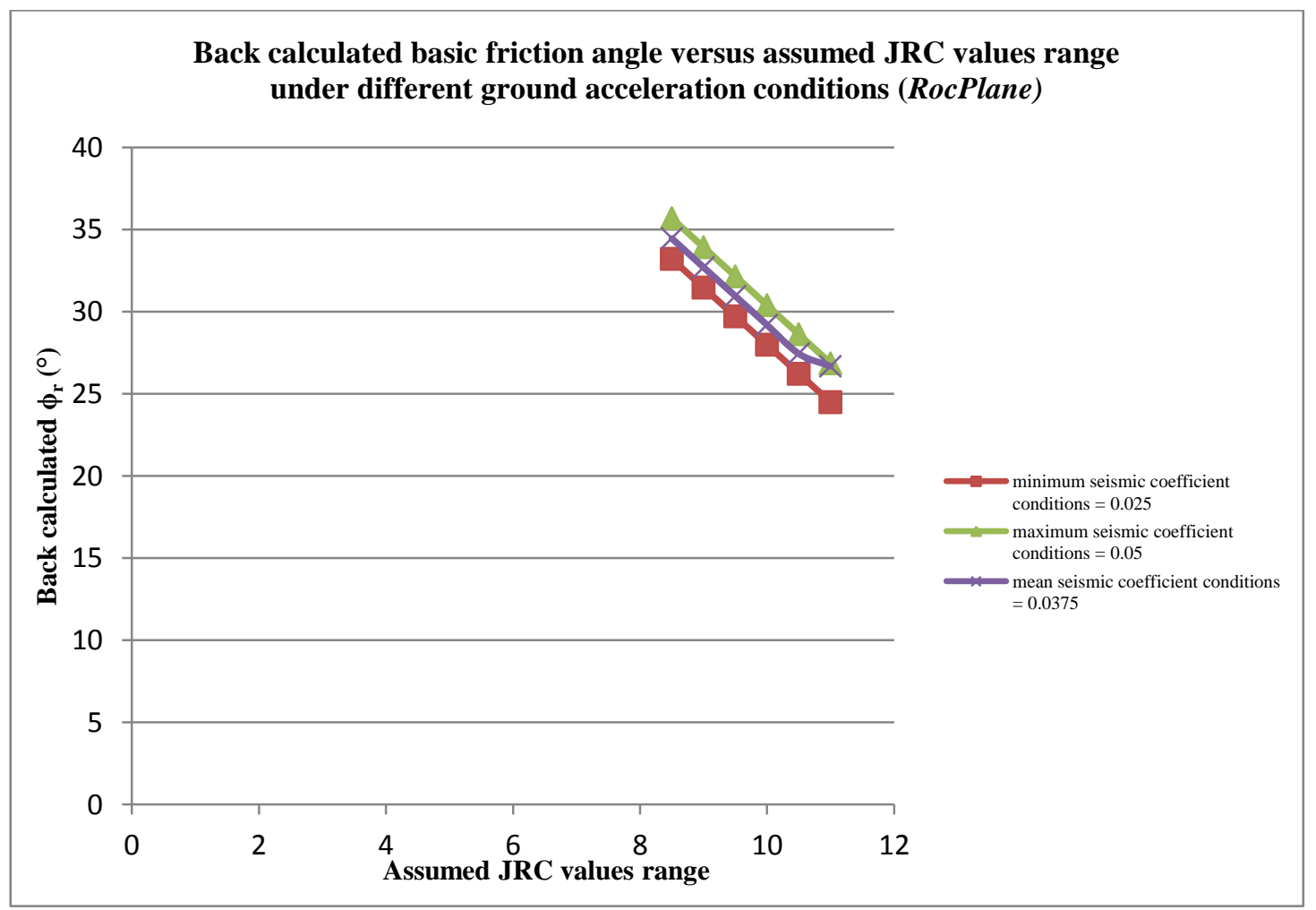

Figure 7.19: Graph of assumed JRC values versus residual friction angle obtained from different seismic ground acceleration scenarios (RocPlane). 
The back analysis of $\phi_{\mathrm{r}}$ under different JRC values and seismic coefficient scenarios using RocPlane showed that, the required residual friction angle for $\mathrm{F}=1.00$ ranges from $33.2^{\circ}$ to $24.5^{\circ}, 35.7$ to $26.9^{\circ}$ and 34.5 to $26.7^{\circ}$ under different seismic coefficient values of 0.025 (minimum), 0.0375 (average) and 0.05 (maximum) respectively within a range of 8.5 to 11 for assumed JRC values. This also shows an inverse relation relationship between the assumed JRC values and back analysed $\phi_{\mathrm{r}}$ for $\mathrm{F}=1.00$ under various seismic ground acceleration conditions when using RocPlane.

The difference in the obtained $\phi_{\mathrm{r}}$ values suggests that the seismic ground acceleration condition which was modelled by seismic coefficient values of 0.025 (minimum), 0.0375 (average) and 0.05 (maximum) have a slight impact on the back analysed $\phi_{\mathrm{r}}$ according to RocPlane pseudostatic analysis. However, the difference from the range in JRC values is almost $10^{\circ}$.

Back analysed $\phi_{\mathrm{r}}$ values for $\mathrm{F}=1.00$ under various seismic ground acceleration conditions are lower in RocPlane than those obtained in Slide. Comparison of Slide and RocPlane back analyses results is presented in section 7.9

\subsection{Back analysis of JRC under typical $\phi_{\mathrm{r}}$ values and groundwater conditions using Slide and RocPlane}

Typical friction angle values for sandstone ranging from $35^{\circ}$ to $40^{\circ}$ which are based on Hoek and Bray's (1981) rock properties suggestions for sedimentary rock were assumed to assess the required JRC for $\mathrm{F}=1.00$ under various groundwater conditions. In this phase of the analysis the purpose was to back analysed JRC values that would result in $\mathrm{F}=1.00$ based on the typical values of $\phi_{\mathrm{r}}$ for sandstone using Slide and RocPlane.

\subsubsection{Groundwater analysis in Slide}

The assumed $\phi_{\mathrm{r}}$ values for sandstone (i.e. $35^{\circ}-40^{\circ}$ ) were used to determine back analysed JRC values using the trial and error procedure in order to get $\mathrm{F}=1.00$ in Slide under different groundwater scenarios which considered dry, $50 \%$ filled and $100 \%$ filled water levels in the tension crack as shown in Table 7.9.

The results in Table 7.9 and Figure 7.20 reveal that that there is none or very minimal change in the back analysed JRC value for each of the assumed $\phi_{\mathrm{r}}$ value under all groundwater scenarios i.e. completely dry, partially filled and $100 \%$ filled tension crack. For example, at a $\phi_{\mathrm{r}}$ value of $35^{\circ}$, the same value was obtained for JRC for all three groundwater scenarios. While at $\phi_{\mathrm{r}}$ of 
$39.5^{\circ}$ the required JRC value only changed from 8.8 , to 8.9 and then 9.0 under dry, $50 \%$ filled and $100 \%$ filled water level scenarios in the tension crack respectively.

Table 7.9: Back analysed JRC values given assumed $\phi_{\mathrm{r}}$ values under different groundwater levels in the tension crack (Slide).

\begin{tabular}{|c|c|c|c|}
\hline \multirow{2}{*}{$\begin{array}{c}\text { Assumed typical } \phi_{\mathbf{r}} \\
\text { values for sandstone } \\
\left({ }^{\circ}\right)\end{array}$} & \multicolumn{3}{|c|}{ Back calculated JRC values } \\
\hline & $\begin{array}{l}0 \%, \text { completely dry } \\
\text { tension crack }\end{array}$ & $\begin{array}{l}50 \%, \text { partially field } \\
\text { tension crack }\end{array}$ & $\begin{array}{l}100 \% \text {, for filled } \\
\text { tension crack }\end{array}$ \\
\hline 35 & 10.8 & 10.8 & 10.8 \\
\hline 35.5 & 10.6 & 10.6 & 10.7 \\
\hline 36 & 10.4 & 10.4 & 10.5 \\
\hline 36.5 & 10.1 & 10.1 & 10.3 \\
\hline 37 & 9.9 & 9.9 & 10.1 \\
\hline 37.5 & 9.7 & 9.7 & 9.9 \\
\hline 38 & 9.5 & 9.5 & 9.6 \\
\hline 38.5 & 9.2 & 9.3 & 9.4 \\
\hline 39 & 9.1 & 9.1 & 9.2 \\
\hline 39.5 & 8.8 & 8.9 & 9.0 \\
\hline 40 & 8.6 & 8.6 & 8.8 \\
\hline
\end{tabular}

The results presented in Table 7.9 show that when using Slide there was no significant variation in the back analysed JRC values for each of the assumed $\phi_{\mathrm{r}}$ value with varying water levels scenarios in the tension crack. Within the assumed $\phi_{\mathrm{r}}$ values range i.e. from $35^{\circ}$ to $40^{\circ}$ the differences in the back analysed JRC values are 2.2, 2.2 and 2 under dry, 50\% filled and 100\% filled water level scenarios in the tension crack respectively.

Figure 7.20 and Table 7.9 shows back analysed JRC values given assumed $\phi_{\mathrm{r}}$ under different groundwater levels in the tension crack scenarios by Slide. The different graphs of back calculated JRC values versus $\phi_{\mathrm{r}}$ under these groundwater scenarios plot on top of each other. This suggests that various groundwater conditions have no impact of the back analysed JRC values and hence the stability of the slope. 


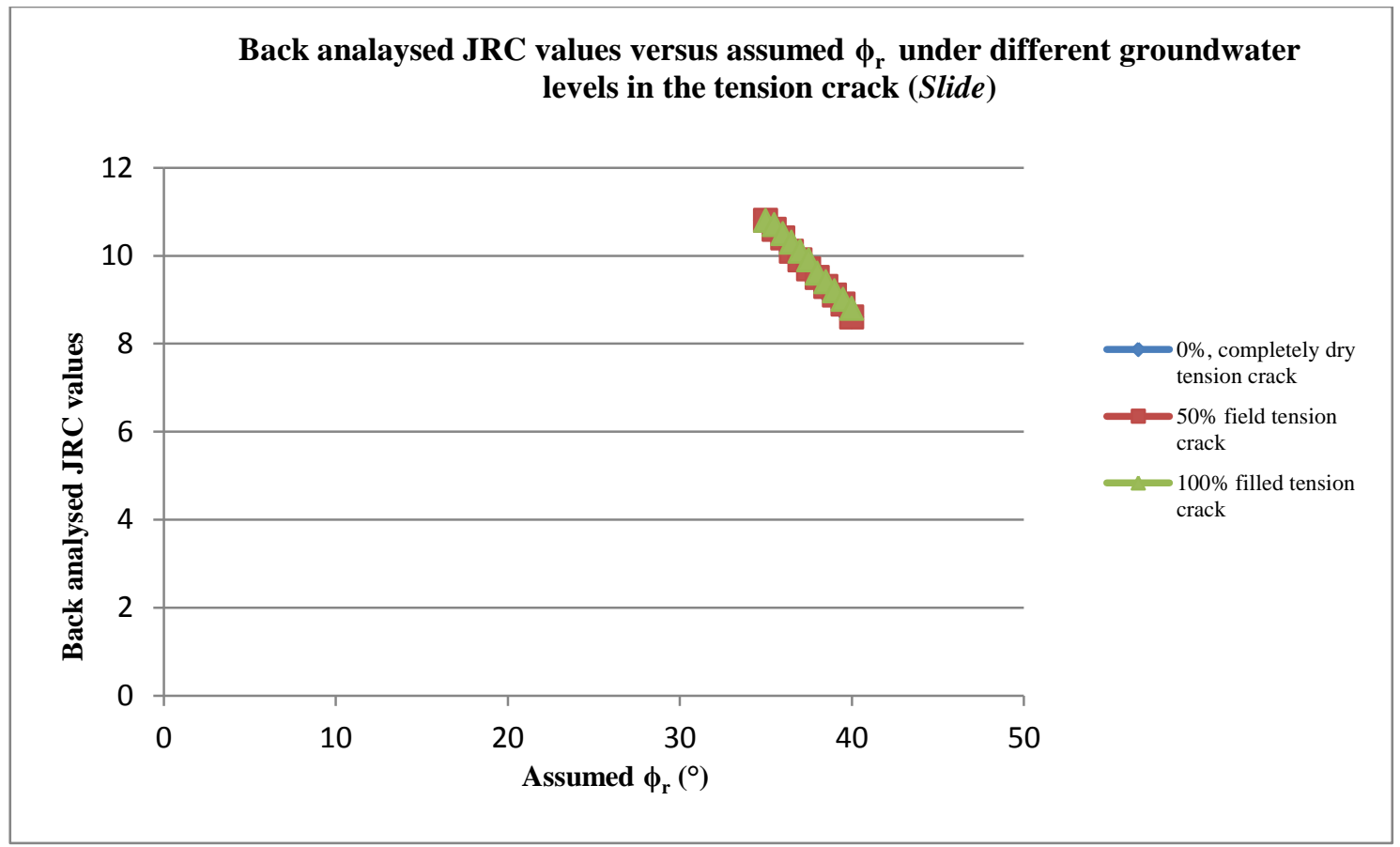

Figure 7.20: Back analysed JRC values for an assumed range of $\phi_{\mathrm{r}}$ values angle under different groundwater levels in the tension crack (Slide).

\subsubsection{Groundwater analysis in RocPlane}

An assumed range of values for $\phi_{\mathrm{r}}$ for sandstone (i.e. $35^{\circ}-40^{\circ}$ ) was again used to back analyse JRC using RocPlane under different groundwater scenarios which also considered dry, 50\% filled and $100 \%$ filled water levels in the tension crack as shown in Table 7.10.

It is evident from the results shown in Table 7.10 and Figure 7.21 that, for each of the assumed typical $\phi_{\mathrm{r}}$ values for sandstone that there is minimal change (i.e. less than 1.0) in back analysed JRC values across different groundwater scenarios. For example given the $35^{\circ}$ residual friction angle the required JRC only changed from 7.3 , to 7.8 and then 8.5 under dry, $50 \%$ filled and $100 \%$ filled water level scenarios in the tension crack respectively. 
Table 7.10: Back analysed JRC given $\phi_{\mathrm{r}}$ under different groundwater levels in the tension crack (RocPlane).

\begin{tabular}{|c|c|c|c|}
\hline \multirow{2}{*}{$\begin{array}{l}\text { Assumed typical } \phi_{\mathrm{r}} \\
\text { values for sandstone } \\
\left(^{\circ}\right)\end{array}$} & \multicolumn{3}{|c|}{ Back calculated JRC } \\
\hline & $\begin{array}{c}0 \%, \text { completely dry } \\
\text { tension crack }\end{array}$ & $\begin{array}{c}50 \%, \text { partially field } \\
\text { tension crack }\end{array}$ & $\begin{array}{c}100 \% \text {, for filled } \\
\text { tension crack }\end{array}$ \\
\hline 35 & 7.3 & 7.8 & 8.5 \\
\hline 35.5 & 7.1 & 7.7 & 8.3 \\
\hline 36 & 7.0 & 7.6 & 8.2 \\
\hline 36.5 & 6.8 & 7.4 & 8.0 \\
\hline 37 & 6.7 & 7.3 & 7.9 \\
\hline 37.5 & 6.5 & 7.1 & 7.8 \\
\hline 38 & 6.4 & 7.0 & 7.6 \\
\hline 38.5 & 6.2 & 6.8 & 7.5 \\
\hline 39 & 6.1 & 6.7 & 7.4 \\
\hline 39.5 & 6.0 & 6.6 & 7.2 \\
\hline 40 & 5.8 & 6.4 & 7.1 \\
\hline
\end{tabular}

The RocPlane analysis shows that for the assumed values of $\phi_{\mathrm{r}}$ ranging from $35^{\circ}$ to $40^{\circ}$ the difference in the back analysed JRC values are 1.5, 1.4 and 1.4 under dry, 50\% filled and 100\% filled water level scenarios in the tension crack respectively. For an assumed $\phi_{\mathrm{r}}$ value, the difference in JRC values obtained considering the three different groundwater conditions is very minimal as evident in the plots shown in Figure 7.21. Thus it can be deduced that the groundwater conditions have very little impact on the back analysed JRC values. This situation is similar to the results obtained using Slide as stated in the preceding sub-section 7.6.1.

The back analysed JRC values for $\mathrm{F}=1.00$ under various groundwater scenarios in the tension crack were found to be lower in RocPlane than the results obtained in Slide. A comparison between the results obtained in Slide and RocPlane back analyses is presented in section 7.9 


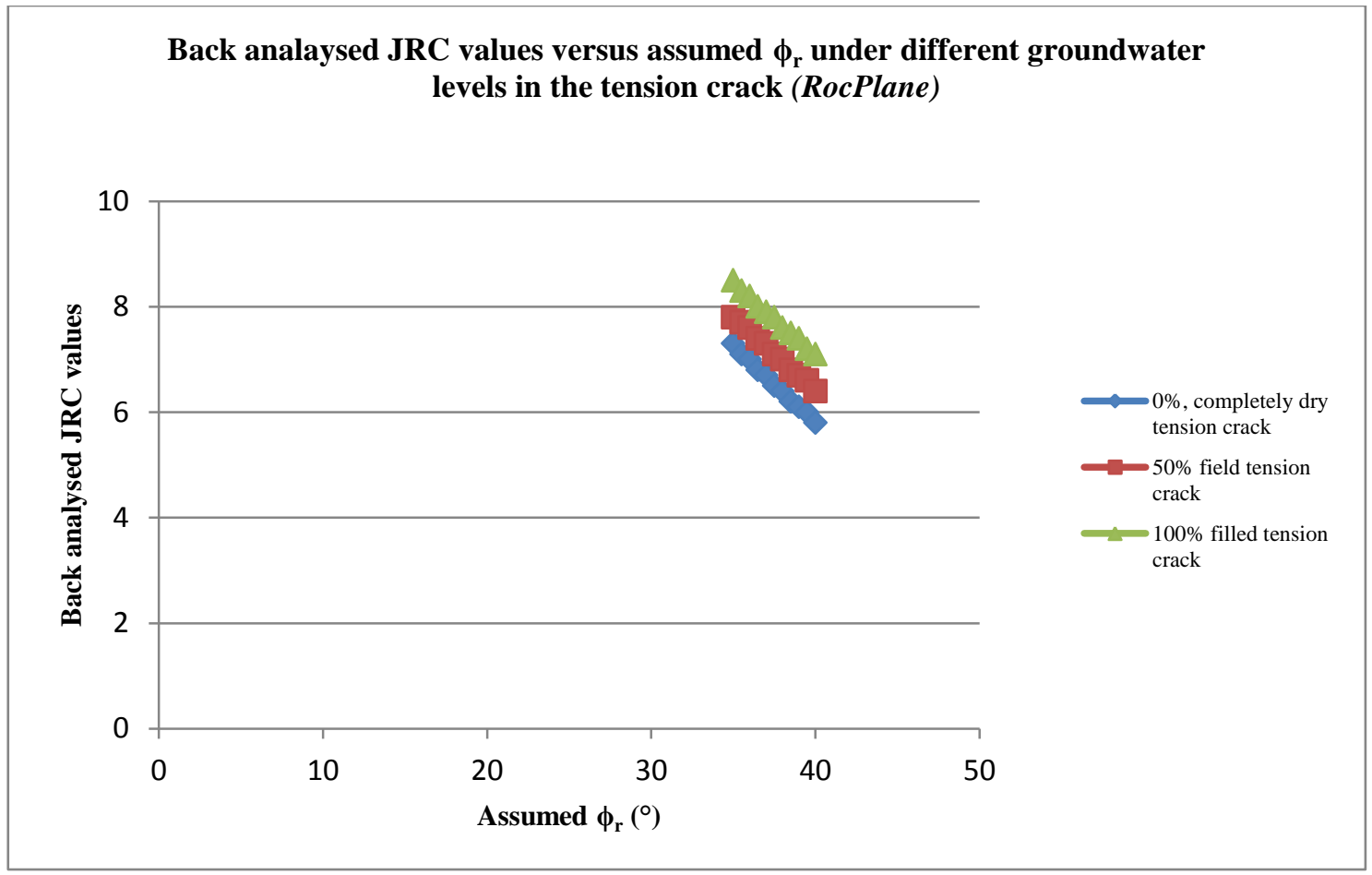

Figure 7.21: Back analysed JRC values for an assumed range of $\phi_{\mathrm{r}}$ values under different groundwater levels in the tension crack (RocPlane).

\subsection{Back analysis of JRC under typical assumed $\phi_{\mathrm{r}}$ values and seismic coefficient scenarios} using Slide and RocPlane

\subsubsection{Pseudostatic analysis in Slide}

Back analysis of JRC using (Slide) is presented for each of the assumed typical $\phi_{\mathbf{r}}$ values range for sandstone $\left(35^{\circ}-40^{\circ}\right)$ under minimum, mean and maximum seismic coefficients of 0.025 , 0.0375 and 0.05 respectively as shown in Table 7.11. This is done to assess the variation of JRC values obtained under different seismic ground acceleration conditions.

For each assumed $\phi_{\mathbf{r}}$ value, the seismic ground acceleration coefficient show little impact on back analysed JRC values (i.e. less than 1 unit difference) which is not significant. For example, at an assumed $\phi_{\mathbf{r}}$ value of $35^{\circ}$ the back analysed JRC values are $11.8^{\circ}, 12.3^{\circ}$ and $12.8^{\circ}$ under different ground acceleration scenarios of 0.025 (minimum), 0.0375 (average) and 0.05 (maximum) seismic coefficient values respectively. The difference in values obtained for JRC from minimum to maximum seismic ground acceleration coefficient at an assumed $\phi_{\mathrm{r}}$ value of $35^{\circ}$ is 1.0 . 
This and the plots which are very close to each other in Figure 7.22 show the difference in the JRC values obtained for an assumed $\phi_{\mathrm{r}}$ value is insignificant for the range in $\alpha$ values considered i.e. 0.025 to 0.05 seismic ground acceleration coefficient using Slide. The graphs also show a moderately steep inverse relationship between the back analysed JRC values and assumed $\phi_{\mathrm{r}}$ for $\mathrm{F}=1.00$.

Table 7.11: Back analysed JRC given assumed typical $\phi_{\mathrm{r}}$ values for sandstone under different seismic coefficient scenarios (Slide).

\begin{tabular}{|c|c|c|c|}
\hline $\begin{array}{c}\text { Assumed typical } \\
\boldsymbol{\phi}_{\mathbf{r}} \text { values for } \\
\text { sandstone } \\
\left({ }^{\circ}\right)\end{array}$ & $\begin{array}{c}\text { Min. seismic } \\
\text { coefficient }(\boldsymbol{\alpha}) \\
\text { condition } \mathbf{0 . 0 2 5}\end{array}$ & $\begin{array}{c}\text { Back calculated JRC } \\
\text { coefficient conditions } \\
(\boldsymbol{\alpha}) \mathbf{= 0 . 0 3 7 5}\end{array}$ & $\begin{array}{c}\text { Max. seismic } \\
\text { coefficient } \\
\text { conditions }(\boldsymbol{\alpha}) \\
\mathbf{0 . 0 5}\end{array}$ \\
\hline 35 & 11.8 & 12.3 & 12.8 \\
\hline 35.5 & 11.6 & 12.1 & 12.6 \\
\hline 36 & 11.4 & 11.9 & 12.4 \\
\hline 36.5 & 11.2 & 11.7 & 12.2 \\
\hline 37 & 10.9 & 11.5 & 12.0 \\
\hline 37.5 & 10.7 & 11.3 & 11.8 \\
\hline 38 & 10.5 & 11.0 & 11.6 \\
\hline 38.5 & 10.3 & 10.8 & 11.4 \\
\hline 39 & 10.1 & 10.6 & 11.2 \\
\hline 39.5 & 9.9 & 10.4 & 10.9 \\
\hline 40 & 9.7 & 10.2 & 10.7 \\
\hline
\end{tabular}

For the assumed range in $\phi_{\mathrm{r}}$ values from $35^{\circ}$ to $40^{\circ}$, the difference in the JRC values obtained was observed to be the same (i.e. 2.1) for each of the seismic coefficient scenario considered. Thus it can be deduced that seismic ground acceleration coefficient have very little impact on the back analysed JRC. 


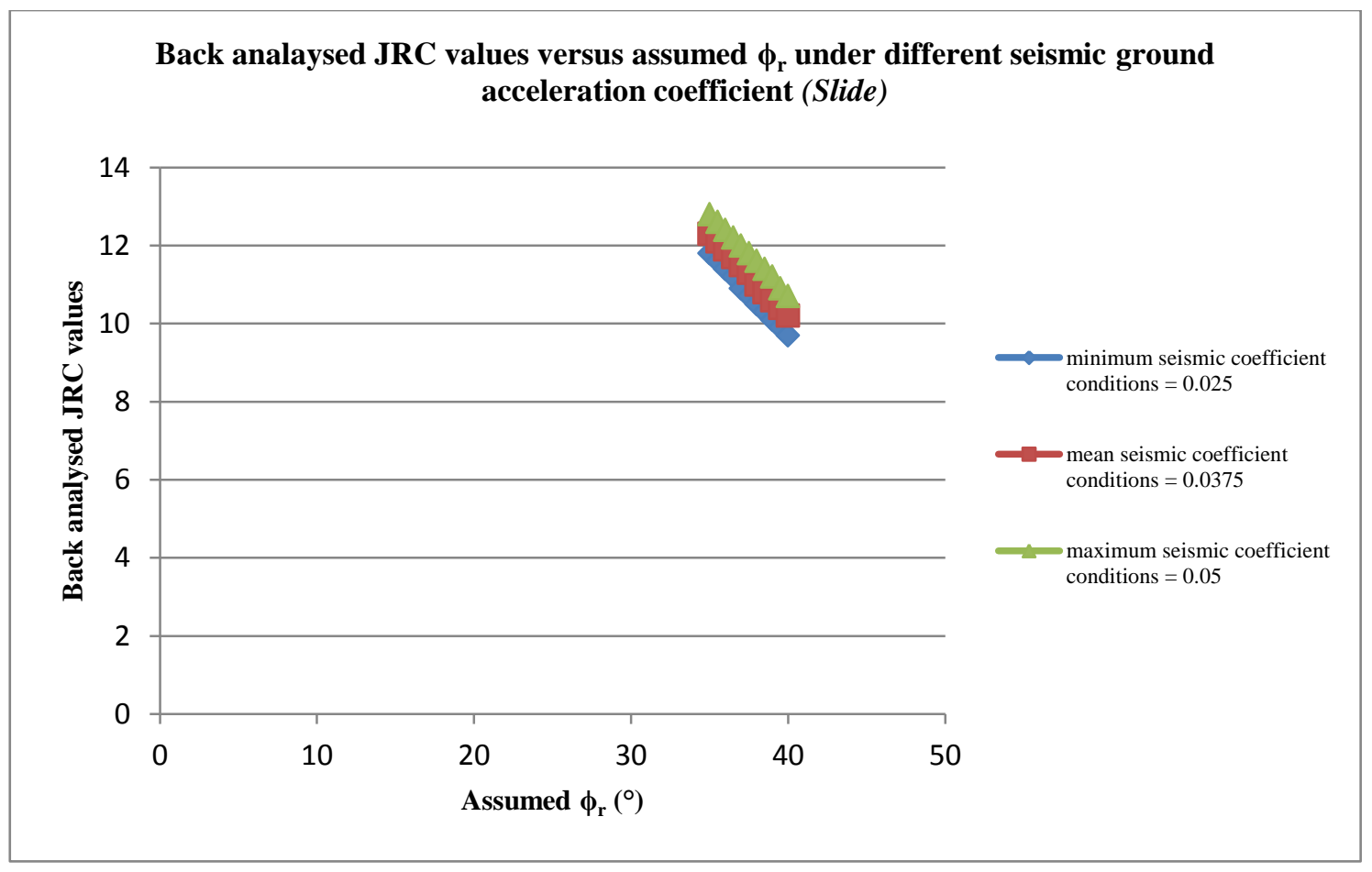

Figure 7.22: Back analysed JRC values versus assumed $\phi_{\mathrm{r}}$ under different seismic ground acceleration coefficient (Slide).

\subsubsection{Pseudostatic analysis in RocPlane}

Similarly to section 7.7.1, JRC back analysis was undertaken in RocPlane for a range in assumed typical $\phi_{\mathrm{r}}$ values for sandstone $\left(35^{\circ}-40^{\circ}\right)$ under minimum, mean and maximum seismic coefficients of $0.025,0.0375$ and 0.05 respectively. The results obtained are shown in Table 7.12, and the plots are shown in Figure 7.23.

For each assumed $\phi_{\mathrm{r}}$ value the seismic ground acceleration coefficient showed a minimal impact on back analysed JRC values. For each assumed $\phi_{\mathrm{r}}$ value, the difference in JRC values obtained for the three scenarios considered for $\alpha$ is minimal. For example at an assumed $\phi_{\mathrm{r}}$ value of $35^{\circ}$, the difference in JRC obtained between the minimum $\alpha$ value and maximum $\alpha$ value is 0.7 .

The results obtained also show that for the range in $\phi_{\mathrm{r}}$ values considered (i.e. $35^{\circ}-40^{\circ}$ ) the difference in JRC values obtained is approximately 1.4 in all three scenarios. This can be considered to be very minimal. This is evident in the plot shown in Figure 7.23 for the different scenarios. 
Table 7.12: Back analysed JRC values given $\phi_{\mathrm{r}}$ under different seismic coefficient scenarios (RocPlane).

\begin{tabular}{|c|c|c|c|}
\hline $\begin{array}{c}\text { Assumed typical } \\
\boldsymbol{\phi}_{\mathbf{r}} \text { values for } \\
\text { sandstone }\end{array}$ & \multicolumn{3}{|c|}{ Back calculated JRC } \\
\cline { 2 - 4 } & $\begin{array}{c}\text { Min. seismic } \\
\text { coefficient }(\boldsymbol{\alpha}) \\
\text { condition } \mathbf{0 . 0 2 5}\end{array}$ & $\begin{array}{c}\text { Mean seismic } \\
\text { coefficient conditions } \\
(\boldsymbol{\alpha}) \mathbf{( - 0 . 0 3 7 5}\end{array}$ & $\begin{array}{c}\text { Max. seismic } \\
\text { coefficient } \\
\text { conditions }(\boldsymbol{\alpha})= \\
\mathbf{0 . 0 5}\end{array}$ \\
\hline 35 & 8.0 & 8.4 & 8.7 \\
\hline 35.5 & 7.9 & 8.2 & 8.6 \\
\hline 36 & 7.7 & 8.1 & 8.4 \\
\hline 36.5 & 7.6 & 7.9 & 8.2 \\
\hline 37 & 7.4 & 7.8 & 8.1 \\
\hline 37.5 & 7.3 & 7.6 & 8.0 \\
\hline 38 & 7.1 & 7.5 & 7.9 \\
\hline 38.5 & 7.0 & 7.4 & 7.7 \\
\hline 39 & 6.9 & 7.2 & 7.4 \\
\hline 39.5 & 6.7 & 7.1 & 7.3 \\
\hline 40 & 6.6 & 6.9 & \\
\hline
\end{tabular}

It is evident from both the analyses in Slide and RocPlane that the difference in JRC values obtained for the range of assumed $\phi_{\mathrm{r}}$ values is minimal in all three scenarios. However, the back analysed JRC values obtained from RocPlane are lower than those obtained from Slide.

A comparison of the results obtained in Slide and RocPlane is presented in section 7.9. 


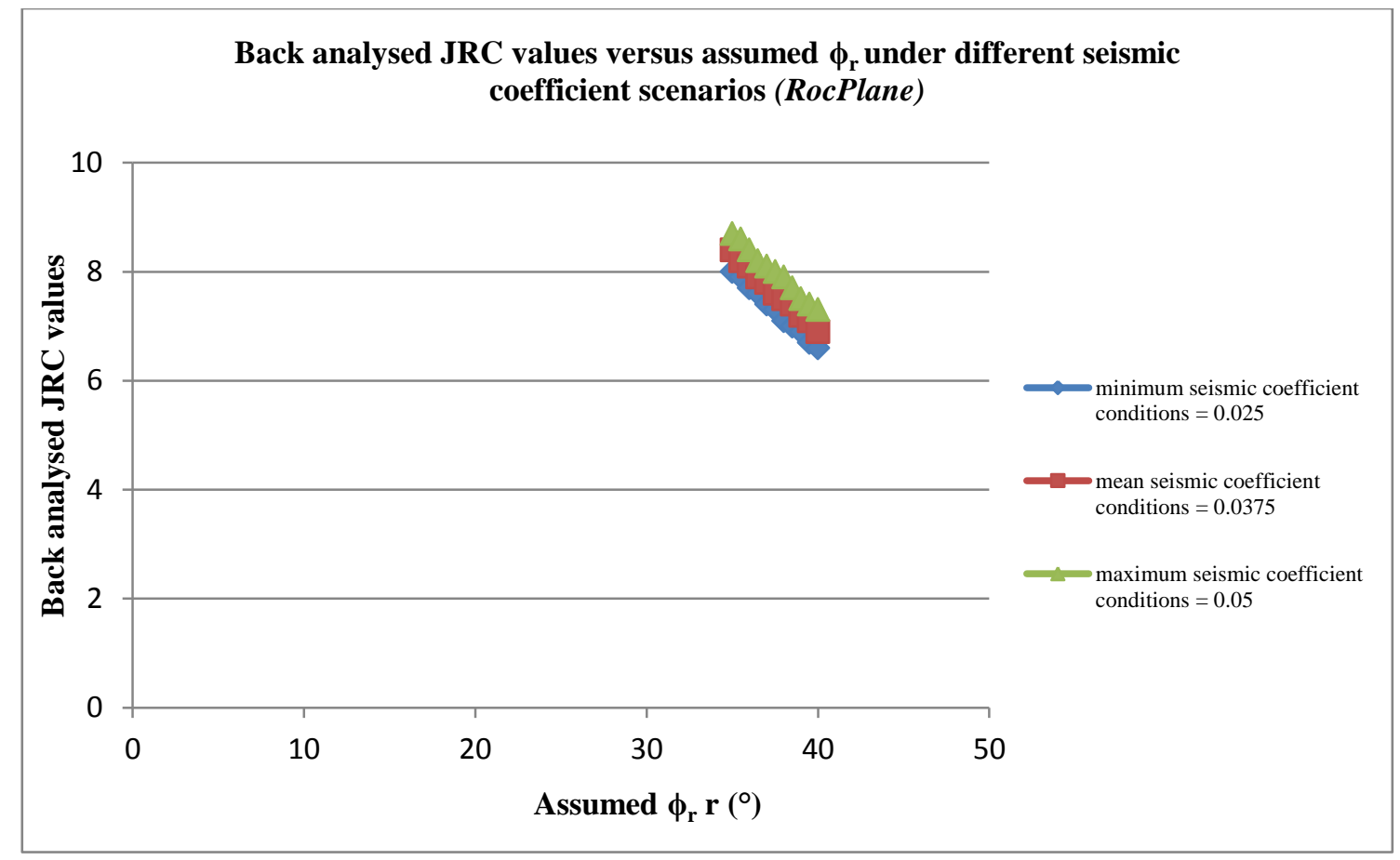

Figure 7.23: Back analysed JRC values versus assumed $\phi_{\mathrm{r}}$ under different seismic ground acceleration coefficient (RocPlane).

\subsection{Back analysis of the required seismic coefficient for $F=1.00$}

The determination of the required seismic loading coefficient to give a factor of safety of 1.00 based on the assumed average back analysed Barton-Bandis shear strength parameters was done using both Slide and RocPlane. This was done on the assumption that seismic activity could have triggered the rockslide.

\subsubsection{Back analysis of the required seismic coefficient in Slide}

Back calculation for the seismic coefficient based on assumed average values of JRC, JCS and $\phi_{\mathrm{r}}$ whereby $\mathrm{JRC}=10, \mathrm{JCS}=189 \mathrm{MPa}$ and $\phi_{\mathrm{r}}=36.8^{\circ}$ residual friction angle was undertaken considering dry conditions. Firstly, the calculated F using the Barton and Bandis (1990) criterion parameters average values was 1.02. Seismic loading coefficient which fall within the typical values shown in Table 7.4 for the study were inserted in order to get $F=1.00$. The analysis showed that a seismic coefficient of 0.01 magnitude could have triggered the failure of the rock slope. This suggests that the slope required the least minimal ground shaking for it to have failed or reach a point of imminent failure. 


\subsubsection{Back analysis of the required seismic coefficient in RocPlane}

Back calculation of seismic coefficient using average $\mathrm{JRC}=10, \mathrm{JCS}=189 \mathrm{MPa}$ and $\phi_{\mathrm{r}}=26.4^{\circ}$ was undertaken. These average values yielded a factor of safety of 1.04. Seismic loading coefficient which fall within the typical values shown in Table 7.4 were inserted in order to obtain a value of $F=1.00$. The analysis showed that the required seismic coefficient for $F=1$ would be 0.02 .

Hence the required seismic coefficient that might have triggered the rock slide could have ranged from 0.01 to 0.02 based on Slide and RocPlane analyses results. These required seismic coefficients obtained for $\mathrm{F}=1.00$ are lower than the published seismic coefficient equivalent peak horizontal ground acceleration. These results show that the landslide could have been triggered by much lower seismic ground acceleration magnitudes. This reveals that other causes of slope instability such as geometry, unfavourable joint orientations could have had adverse effect in the slope stability even prior to the introduction of a triggering mechanism. It can be deduced therefore; that the slope was marginally stable (i.e. the stage was always set for failure to occur).

\subsection{Comparison between Slide and RocPlane results}

\subsubsection{Back analysed $\phi_{\mathrm{r}}$}

The back analyses (i.e. required for $\mathrm{F}=1.00$ ) results show that shear strength (residual friction angle) results derived from using RocPlane were less than the results from Slide. The difference in back analysed residual friction angle ranged between $5.8^{\circ}$ and $12.3^{\circ}$ under $100 \%$ filled tension crack and dry tension crack groundwater conditions respectively as shown and highlighted in blue in Table 7.13. 
Table 7.13: Comparison between Slide and RocPlane back analysed $\phi_{\mathrm{r}}$ values under different groundwater scenarios.

\begin{tabular}{|c|c|c|c|c|c|c|c|c|c|}
\hline \multirow{2}{*}{$\begin{array}{c}\text { Assumed } \\
\text { JRC } \\
\text { values }\end{array}$} & \multicolumn{9}{|c|}{ Back calculated residual friction angle, $\phi_{\mathrm{r}}\left({ }^{\circ}\right)$} \\
\hline & Slide & RocPlane & Difference & Slide & RocPlane & Difference & Slide & RocPlane & Difference \\
\hline 8.5 & 40.3 & 30.7 & 9.6 & 40.4 & 32.7 & 7.7 & 40.7 & 34.9 & 5.8 \\
\hline 9 & 39.1 & 29.0 & 10.1 & 39.2 & 30.9 & 8.3 & 39.5 & 33.1 & 6.4 \\
\hline 10 & 36.8 & 25.5 & 11.2 & 36.9 & 27.4 & 9.4 & 36.1 & 29.6 & 6.6 \\
\hline 10.5 & 35.6 & 23.8 & 11.8 & 35.8 & 25.7 & 10 & 36.0 & 27.8 & 8.2 \\
\hline 11 & 34.4 & 22.1 & 12.3 & 34.5 & 23.9 & 10.6 & 34.8 & 26.0 & 8.8 \\
\hline
\end{tabular}

Table 7.14 shows that the difference in back analysed $\phi_{\mathrm{r}}$ values ranged from $9.6^{\circ}$ to $12.5^{\circ}$ under different seismic coefficient value scenarios of 0.025 (minimum), 0.0375 (average) and 0.05 (maximum) seismic coefficient values.

Table 7.14: Comparison between Slide and RocPlane back analysed $\phi_{\mathrm{r}}$ results under different seismic ground acceleration conditions.

\begin{tabular}{|c|c|c|c|c|c|c|c|c|c|}
\hline \multirow{2}{*}{$\begin{array}{c}\text { Assumed } \\
\text { JRC } \\
\text { values }\end{array}$} & \multicolumn{9}{|c|}{ Back calculated residual friction angle, $\phi_{\mathrm{r}}\left(^{\circ}\right)$} \\
\hline & \multicolumn{3}{|c|}{$\begin{array}{l}\text { Min. seismic coefficient }(\alpha) \\
\text { condition }=0.025\end{array}$} & \multicolumn{3}{|c|}{$\begin{array}{l}\text { Mean seismic coefficient } \\
\text { conditions }(\alpha)=0.0375\end{array}$} & \multicolumn{3}{|c|}{$\begin{array}{c}\text { Max. seismic coefficient conditions } \\
(\alpha)=0.05\end{array}$} \\
\hline 8.5 & 42.8 & 33.2 & 9.6 & 44.0 & 34.5 & 9.6 & 45.3 & 35.7 & 9.6 \\
\hline 9 & 41.6 & 31.5 & 10.1 & 42.9 & 32.7 & 10.2 & 44.1 & 33.9 & 10.2 \\
\hline 10 & 39.3 & 28.0 & 11.3 & 40.5 & 29.2 & 11.3 & 41.8 & 30.4 & 11.4 \\
\hline 10.5 & 38.0 & 26.2 & 11.8 & 39.3 & 27.4 & 11.8 & 40.6 & 28.6 & 11.9 \\
\hline 11 & 36.9 & 24.5 & 12.4 & 38.1 & 26.7 & 11.4 & 39.4 & 26.9 & 12.5 \\
\hline
\end{tabular}

The difference in the results given by Slide and RocPlane revealed that the $\phi_{\mathrm{r}}$ values obtained using Slide were higher than the values obtained using RocPlane in all the analyses conducted. 


\subsubsection{Back analysed JRC values}

Comparison of the results in both Slide and RocPlane shows that for an assumed $\phi_{\mathrm{r}}$ value, a higher JRC value would be required in Slide than in RocPlane to obtain a value of $F=1.00$.

The difference in the back analysed JRC ranged between 1.7 and 3.5 under $100 \%$ filled tension crack and dry tension crack groundwater conditions respectively as shown in Table 7.15. In looking at the results taking for example at $\phi_{\mathrm{r}}=35^{\circ}$, the difference in back analysed JRC is reduced from 3.5 to 2.3 under $0 \%$ completely dry to $100 \%$ filled water in the tension crack scenarios. This suggests that with increasing water level in the tension crack the difference (or gap) in back analysed JRC from both Slide and RocPlane is reduced. Again with increasing residual friction angle i.e. from $35^{\circ}$ to $40^{\circ}$ the required $\mathrm{JRC}$ for $\mathrm{F}=1$ is reduced from 10.8 to 8.6 and 8.5 to 5.8 when using Slide and RocPlane under $0 \%$ filled and $100 \%$ filled water level scenarios in the tension crack respectively.

Table 7.15: Comparison between Slide and RocPlane back analysed JRC results under different seismic ground acceleration conditions.

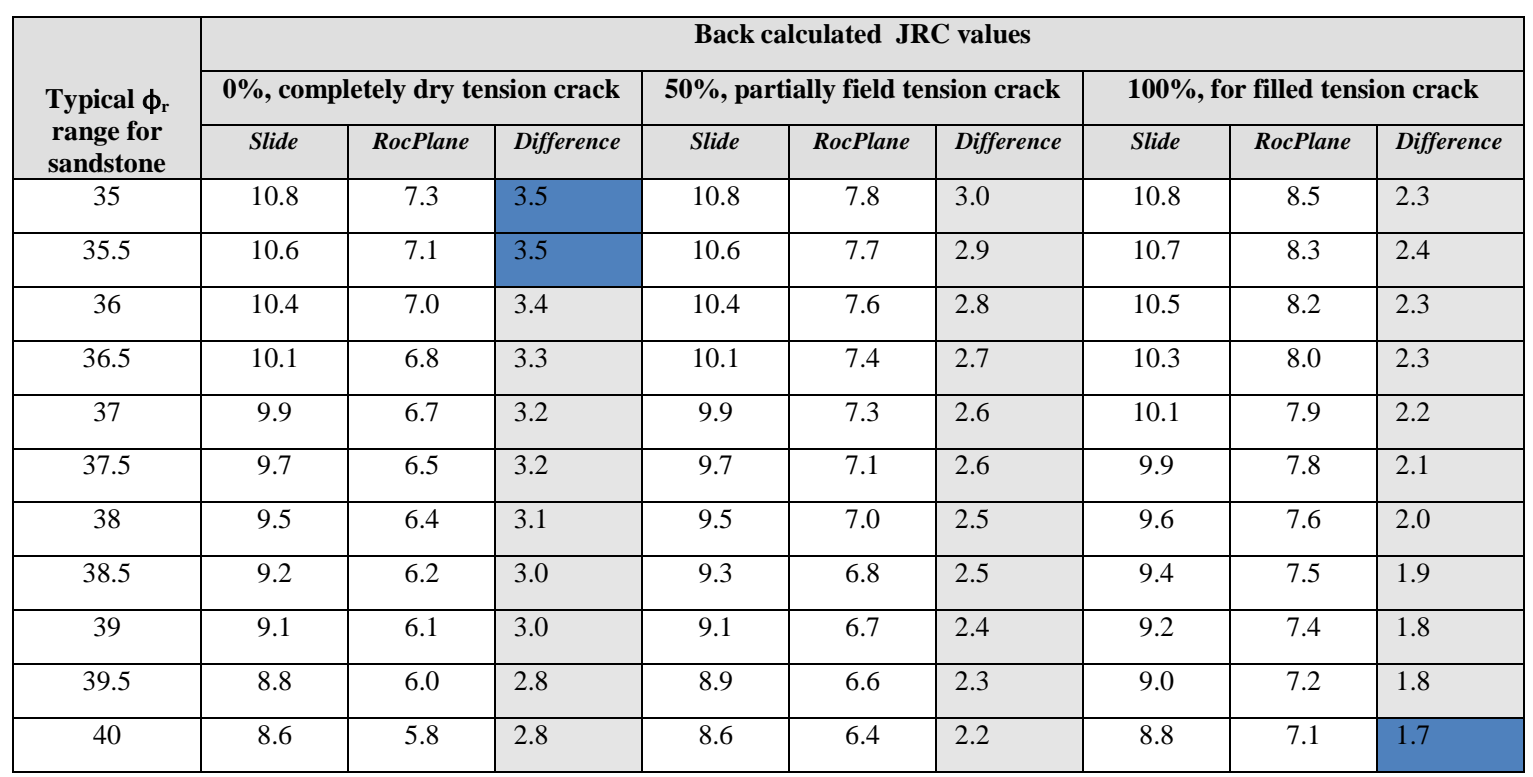

Table 7.16 shows that the comparison of the back analysed JRC values derived from Slide and RocPlane under different seismic coefficients of 0.025 minimum, 0.0375 average and 0.05 maximum scenarios. The comparison of back analysed JRC results shows that higher JRC values would be required in Slide than RocPlane analysis to get a values of F $=1.00$ for each assumed typical $\phi_{\mathrm{r}}$ values for sandstone. The difference in the back analysed JRC values ranged from 3.1 to 4.1 under 0.025 and 0.05 seismic coefficient scenarios respectively for the range in $\phi_{\mathrm{r}}$ values considered (i.e. $35^{\circ}-40^{\circ}$ ). Although very minimal for a particular value of $\phi_{\mathrm{r}}$, an 
inverse trend to that pointed out in sub-section 7.8.2 exists. For example at $\phi_{\mathrm{r}}=35^{\circ}$, the difference in back analysed JRC (i.e. required to give $\mathrm{F}=1.00$ ) increases from 3.8, 3.9 to 4.1 under different seismic coefficients of 0.025 minimum, 0.0375 average and 0.05 maximum, scenarios values. This suggests that with increasing seismic coefficient the difference (or gap) in back analysed JRC value from both Slide and RocPlane increases. The required JRC for $\mathrm{F}=1.00$ also increases with an increase in seismic coefficient. Also with increasing residual friction angle i.e. from $35^{\circ}$ to $40^{\circ}$ the required $\mathrm{JRC}$ for $\mathrm{F}=1.00$ is reduced from 11.8 to 9.7 and 8.0 to 6.6 from Slide and RocPlane respectively.

Table 7.16: Comparison between Slide and RocPlane back analysed JRC results under different seismic ground acceleration conditions.

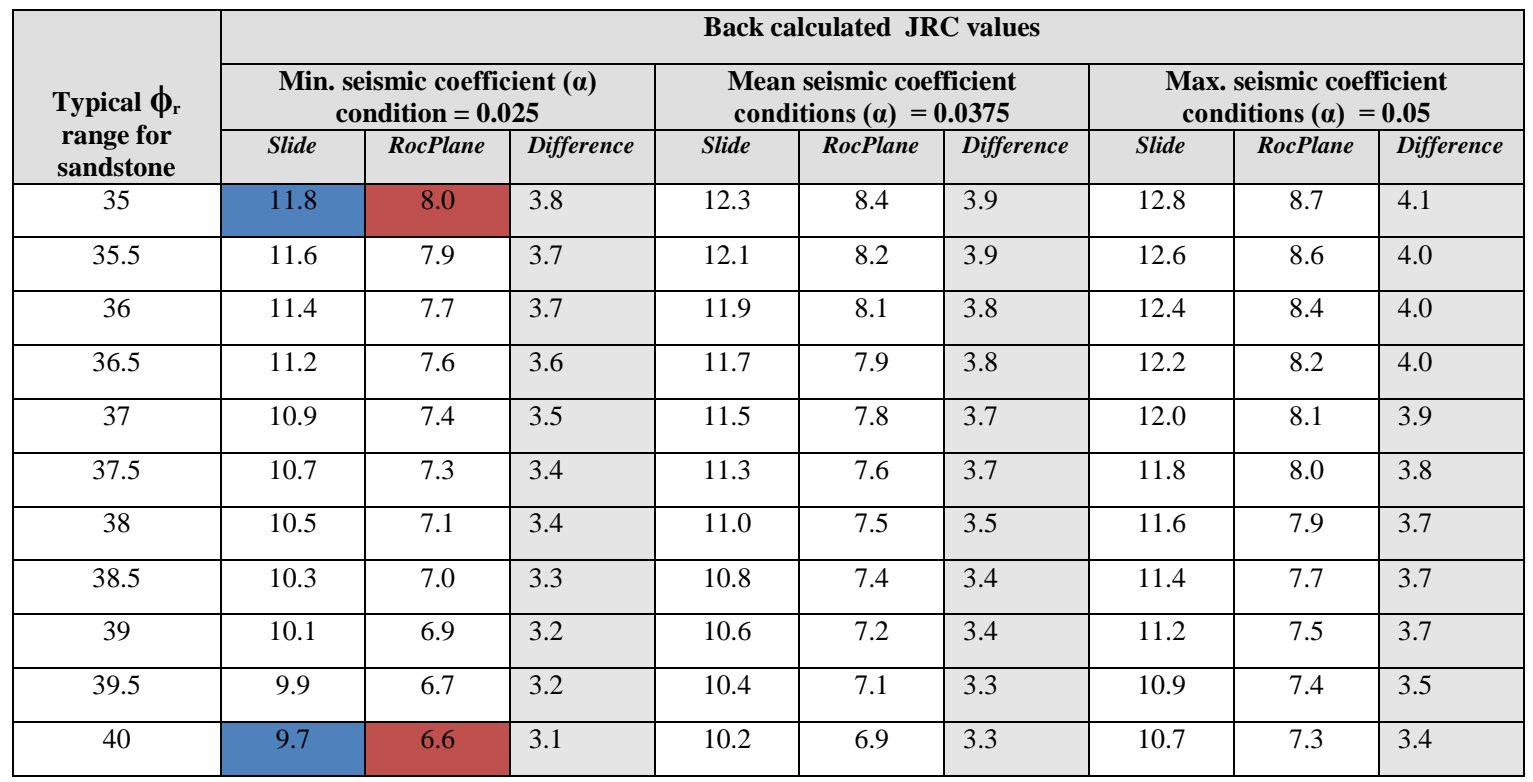

\subsection{Possible triggering factor based on results from back analysis}

Landslides can have several causes, which include geological morphological and human, but only one trigger (Cruden and Varnes, 1996). According to Wieczorek (1996), a trigger is an external stimulus such as intense rainfall, earthquake shaking, volcanic eruption, or storm waves that causes a near-immediate response in the form of a landslide by rapidly increasing shearing stresses or by reducing the strength of slope materials. The immediate cause or triggering mechanism is a local drop in the stability of a slope due to rainfall or ground shaking from earthquakes (Costa and Baker, 1981).

Duncan and Wright (2005) stated that when a slope fails, it is often not possible to determine a single cause that acted alone. For example, water influences the stability of slopes in so many ways that it is frequently impossible to isolate one effect of water and identify it as a single 
cause of failure (Duncan and Wright, 2005). In most cases, several causes exist simultaneously; therefore, attempting to decide which one finally triggered failure is not only difficult but also technically incorrect. Often the final factor is nothing more than a trigger that sets a body of earth in motion that was already on the verge of failure. The fact that it is so difficult to isolate a single cause of failure highlights the importance of considering and evaluating all potential causes of failure in order to develop an effective means of repairing and stabilizing slopes that have failed (Sowers, 1979).

The presence of either seismic ground acceleration or water pressure from water levels in the tension crack could have triggered the landslide. As sensitivity analysis had already shown that JRC followed by $\phi_{\mathrm{r}}$ had more impact on $\mathrm{F}$, the effect of possible triggering conditions was assessed on these parameters in both Slide and RocPlane using back analysis (i.e. F = 1.00). The planar failure surface is inclined at $60^{\circ}$ which is steeper than the back analysed residual friction angle which was found to be $36.8^{\circ}$ and $25.4^{\circ}$ under dry static conditions when using Slide and RocPlane respectively. Also, the critical slope height for a slope containing a planar discontinuity dipping at an angle of $60^{\circ}$ should be approximately $21 \mathrm{~m}$ (Hoek and Bray, 1981). Hence the failed rock slope which has a height of $245 \mathrm{~m}$ is about 12 times higher than the required threshold height for it to have remained stable.

Results obtained in Slide clearly showed that groundwater conditions had no impact on the back analysed $\phi_{\mathrm{r}}$ and JRC values in comparison to the analysis in RocPlane which showed very minimal impact. It also shows that seismic ground acceleration has more impact on the back analysed $\phi_{\mathrm{r}}$ and JRC values from the pseudostatic analysis in Slide and RocPlane. This suggests that the ground acceleration due to seismicity was the most likely trigger for the Lake Fundudzi rockslope failure. The rock avalanche or rock mass debris from this rockslide which was deposited across the valley floor is highly disrupted as shown in Figures 2.6, 2.8 and 3.11. According to Keefer (1984), seismic ground acceleration is probably required for very highly disrupted rock avalanche and soil avalanche. Thus, it can be deduced that a seismic event could have triggered the landslide whereby failure could have disrupted or broken down the competent sandstone rock mass to debris of large rock blocks deposited across the valley floor of Lake Fundudzi.

\subsection{Summary}

A range of scenarios were considered in the analyses in order to represent uncertainty and variability which are inherent in data collected on orientation and strength of discontinuities as stated by Park and West (2001). 
The two programs i.e. Slide and RocPlane yielded significantly different results. RocPlane predicted lower back analysed values of $\phi_{\mathrm{r}}$ and $\mathrm{JRC}$ that are required to give $\mathrm{F}=1.00$. A personal communication was made to Rocscience Inc. on the $22^{\text {nd }}$ August 2014 by the author to seek clarity about why the results were different for similar programs (i.e. both based on limit equilibrium approach with deterministic and probabilistic capabilities and can model noncircular failures) under which the analyses where conducted for same condition.

Mr. Heather Trommels who is an Engineering Communication Specialist at Rocscience Inc. pointed out that generally when analyzing planar failures the best results will be those derived from RocPlane. In RocPlane the planar block is treated as a single sliding mass, considering only force equilibrium. The stability of the block is calculated as a unit or single body. Whereas Slide uses methods of slices sliding mass above the surface of sliding is divided into a number of vertical parallel slices. The stability of each slice is calculated separately.

The back analysed JRC and $\phi_{\mathrm{r}}$ values are in close proximity with laboratory data obtained from joint testing and tilt angle tests.

Slide and RocPlane analysis shows that seismic ground acceleration was most likely trigger for the Lake Fundudzi ancient rockslide. 


\section{CHAPTER 8}

\section{DISCUSSION OF THE RESULTS}

\subsection{Introduction}

The chapter seeks to close the loop of the main research questions or aim which was to "investigate the geotechnical conditions that could have led to the landslide that formed Lake Fundudzi by back analyses techniques".

In order to achieve the main aim of this research, the following objectives had to be achieved:

1) to determine the type of failure mechanisms that may have led to the landslide.

2) to geotechnically characterize the site in order to obtain the relevant input parameters such as unit weight $(\gamma)$, joint wall compressive strength (JCS) and joint roughness coefficient (JRC) for slope stability analysis.

3) to undertake back analyses based on the limit equilibrium procedures using RocPlane and Slide in Rocscience ${ }^{\circledR} I n c$. software of the landslide that formed Lake Fundudzi in order to investigate the geotechnical conditions that may have led to failure.

4) to investigate the importance of back analysis techniques in landslide studies.

\subsection{Failure mode}

In order to conduct a successful back analysis, it is essential to understand the processes and mechanisms driving instability (Sharifzadeh et al., 2009). Methods vary with respect to the slope failure mechanism. Hence the first step in rock slope stability analysis is to determine if the orientation of the discontinuities could result in instability for a rock slope defined by those discontinuities and the possible failure mechanisms e.g. planar, topple or wedge failure (Park and West, 2001). If the kinematic analysis indicates that the structural condition is potentially unstable, the kinetic stability of the body is assessed using the limit equilibrium method; this provides the second step (Park and West, 2001).

The ancient rockslide which formed Lake Fundudzi was analysed on the basis of the Markland's (1972) test in conjunction with Rocscience ${ }^{\circledR}$ Inc. Dips software for kinematic analysis. Three major joints sets were discovered which included bedding. The maximum concentration or joint sets for bedding poles was approximated at $15^{\circ} / 283^{\circ}$. In the case of joint 
sets 2 and 3 , the maximum pole concentrations are approximated at $85^{\circ} / 237^{\circ}$ and $73^{\circ} / 157^{\circ}$. The results revealed that joint set 2 (JS 2) poles represent planes that were susceptible to plane failure. From the analysis, plane failure mode was determined based on the orientation of the slope, the orientation of rock discontinuities, and the internal angle of friction of the rock mass. This was found to be consistent with field observations. The determination of failure mechanism also gave credence to the use of limit equilibrium technique in the stability analysis given the relatively simple failure geometry.

\subsection{Geotechnical characteristics}

Determination of reliable shear strength parameters is a critical part of a slope stability analysis because relatively small changes in shear strength can result in significant changes in F (Bye and Bell, 2001). The most important factor in the lake Fundudzi rockslide slope stability analysis is the model (failure criterion) for estimating shear strength on the failure plane. The chosen Barton and Bandis (1990) criterion provides easy and practical procedures to predict the shear strength of rock joint from joint roughness (JRC) and joint wall strength (JCS).

Firstly, the physical and mechanical properties of rock material were determined using laboratory tests. Laboratory results revealed that the rock has a generally medium to high strength (ISRM, 1979) based on Schmidt hardness rebound, point load and unconfined compressive strength tests. What was evident from these results is that the rock mass had to be affected by other geological factors such as joints, discontinuities and faults for the slope to fail and not rock strength.

The rock mass was classified by rock mass rating (RMR), geological strength index (GSI) and slope mass rating (SMR). The results of these rock mass classifications allowed for a preliminary evaluation of pre-failure stability conditions. The final classes given by RMR and SMR systems which could be related and comparable, were the same. Both gave class ratings of IV for 'poor' and 'bad' rock mass respectively. According to Romana (1993), these ratings meant that the slope was unstable, where planar and wedge failures can be anticipated. Prior to inclusion of discontinuity orientation adjustment, which reflects the relationship between the slope face and joint dip in both RMR and SMR systems, the slope was classified as Class II for 'good rock mass'. However, upon incorporating rating adjustment in RMR and SMR for discontinuity orientation the rock mass quality of the slope dropped to 'poor' and 'bad' respectively. Clearly what was drawn from these two preliminary evaluations was that the presence of unfavourable major discontinuity orientations had an adverse effect on the stability of the slope and the rock mass strength. 
Laboratory direct shear tests were carried out on saw-cut and natural discontinuities sample for tilt angle test to measure the shear strength parameters. The basic friction angle values collected in this study and other previous studies at the University of KwaZulu-Natal i.e. Hannweg (1996) and Hingston (1997) were determined using a method similar to that described by Barton and Choubey (1976). The average basic friction angle obtained was $27^{\circ}$ which fell within the range for values for sandstone i.e. $\left(26^{\circ}-35^{\circ}\right)$ after Barton and Choubey (1977).

The results of Golder shear box testing presented in section 5.3.6 are not repeated here, but the main findings have been discussed here to highlight the behaviour of joints. The Golder shear box testing at normal stresses ranging from $0.38 \mathrm{MPa}$ to $0.60 \mathrm{MPa}$ and estimated JRC values ranging from 9 to 13 , revealed peak shear strengths which range from $0.17 \mathrm{MPa}$ and $0.37 \mathrm{MPa}$. The shear box test enables the determination of the peak and residual shear strength values and also aids in the back calculation of JRC. Based on the horizontal versus vertical displacement graphs, the dilatation behaviour of the joints can also be assessed.

The back calculation of JRC can be useful or better for determining joint profiles because of the subjectivity in visually matching joint surface profiles with the ten "standard" profiles whose JRC ranges from 0 to 20 (Miller et al. 1989). The back calculated JRC values using the Barton and Choubey (1977) empirical equation are in close proximity to the visually matched joint profile estimates for this study.

Based on the practical experience gained from conducting the shear box tests in this study it was observed that the operation procedure of the Golder shear box machine with two hands is very difficult. Another major design weakness in the machine is with the displacement transducers which kept losing position as shearing progressed particularly the vertical displacement transducer.

The physical and mechanical (geotechnical index) properties of rock material encountered at Lake Fundudzi were determined using laboratory tests such as UCS, indirect tensile strength and point load tests. The results revealed that the quartzitic sandstone classify as strong according to Duncan (1999). The strong rock material classification is one of the indicators that failure could have been mostly structurally controlled than rock material degradation.

An average value of $189 \mathrm{MPa}$ for JCS, 8.5 to 11 for JRC assumed values and residual friction angle values from $35^{\circ}$ to $40^{\circ}$ were selected for use in the stability analysis as input parameters. 


\subsection{Back analysis using Slide and RocPlane}

The limit equilibrium techniques are very simple and commonly adopted methods for carrying out stability analysis of structurally controlled slopes (Sharifzadeh et al., 2009). Thus, the slope failure has been studied by two separate analyses which are based on the limit equilibrium approach. Both Slide and RocPlane software codes by Rocscience ${ }^{\circledR}$ which are based on limit equilibrium approach were used for the stability analysis. Initially, the analysis started with sensitivity analysis to investigate the influence of parameter variation on $\mathrm{F}$ followed by back analysis of shear strength parameters under dry and static conditions. Both Slide and RocPlane revealed that JRC and $\phi_{\mathrm{r}}$ are the most influential shear strength parameters on F. Hence, JRC and $\phi_{\mathrm{r}}$ were back calculated further under various possible groundwater and seismic ground acceleration triggering conditions.

Both Slide and RocPlane analyses show that for each scenario, there exists a unique pair of JRC and $\phi_{\mathrm{r}}$ values for a value of $\mathrm{F}=1.00$.

Back analysis in Slide and RocPlane revealed different set of values for $\phi_{\mathrm{r}}$ for an assumed range of JRC values. For an assumed range of JRC values ranging from 8.5 to 11 , the values obtained for $\phi_{\mathrm{r}}$ ranged from $34.4^{\circ}$ to $40.7^{\circ}$ in Slide and 22.1 to $34.9^{\circ}$ in RocPlane under different groundwater scenarios. The difference in the range of $\phi_{\mathrm{r}}$ values obtained for the assumed JRC values in both Slide and RocPlane can be considered to be significant.

A similar situation was obtained in the back analysis of $\phi_{\mathrm{r}}$ and JRC under different seismic ground acceleration scenarios. For an assumed range of values of JRC ranging from 8.5 to 11 , the values obtained for $\phi_{\mathrm{r}}$ ranged from $36.9^{\circ}$ to $44.0^{\circ}$ in Slide and $24.5^{\circ}$ to $34.5^{\circ}$ in RocPlane under different seismic ground acceleration scenarios. For an assumed range of $\phi_{\mathrm{r}}$ values ranging from $35^{\circ}$ to $40^{\circ}$ under different groundwater scenarios, the values obtained for JRC ranged from 9.7 to 12.8 in Slide and 6.6 to 8.8 in RocPlane.

Based on the discussion in the above two paragraphs, it can be concluded that the range in the values of $\phi_{\mathrm{r}}$ obtained (back analysed) for the assumed JRC values, is wide and significant in contrast to the range of JRC values obtained (back analysed) for the assumed typical $\phi_{\mathrm{r}}$ values, which is small.

The results obtained from Slide showed that the back analysed $\phi_{\mathrm{r}}$ and JRC values were not affected by different groundwater scenarios whereas RocPlane results showed that different groundwater scenarios had minimal impact on back analysed $\phi_{\mathrm{r}}$ and JRC values. Results obtained from Slide clearly showed that the back analysed $\phi_{\mathrm{r}}$ and JRC values were affected by different seismic ground acceleration scenarios whereas RocPlane results showed that different 
seismic ground acceleration scenarios also had lesser impact on back analysed $\phi_{\mathrm{r}}$ and JRC respectively.

It was therefore concluded that the presence of either seismic groundwater acceleration or water pressure from water levels in the tension crack could have triggered the landslide. However the stability analysis results indicated that seismic ground acceleration would have had more influence on the shear strength parameters than groundwater conditions. As a result, the required seismic coefficient for $\mathrm{F}=1.00$ was determined using average shear strength values. The critical seismic coefficient (i.e. magnitude) which could have triggered this rock slope to fail was found to be 0.01 . This shows that a very minimum degree of seismic ground acceleration could have triggered this slope failure. The planar failure surface is inclined at $60^{\circ}$ which is steeper than the back analysed residual friction angle which was $36.8^{\circ}$ under dry static conditions. Also, the critical slope height for a slope containing a planar discontinuity dipping at an angle of $60^{\circ}$ is approximately $21 \mathrm{~m}$ which is about 12 times higher than the slope height at project site (Hoek and Bray, 1981). Hence, any triggering condition between the two could have been capable of triggering the rockslide as it is not known which of the two prevailed when the rockslide occurred about 20000 years ago. However, the sensitivity analysis of back calculated residual friction versus various parameters particularly JRC showed that JRC had the greatest impact on F as shown in both Slide and RocPlane slope stability back analyses results.

The debris of large rock blocks from this rockslide which was deposited across the valley floor is highly disrupted as shown in Figures 2.6, 2.8 and 3.11 gives a strong indication that the rockslide could have been triggered by a seismic event. According to Keefer (1984), seismic ground acceleration is probably required for very highly disrupted rock avalanche and soil avalanche. Thus, it can be deduced that a seismic event could have triggered the landslide whereby failure could have disrupted or broken down the competent sandstone rock mass to debris of large rock blocks deposited across the valley floor of Lake Fundudzi.

\subsubsection{Comparison between Slide and RocPlane results}

The shear strength parameters obtained from Slide were higher than the parameters obtained in RocPlane during back analysis. These results show that different methods of stability analysis can give different results. Therefore, the underestimation of strength parameters is highly possible if the methods of analysis are not selected carefully.

A personal communication was made to Rocscience Inc. on the 22nd August 2014 by the author to seek clarity about why the results were different for similar programs (i.e. both based on limit 
equilibrium approach with deterministic and probabilistic capabilities and can model noncircular failures) under which the analyses where conducted for same condition.

Mr Heather Trommels who is an Engineering Communication Specialist at Rocscience Inc. pointed out that generally when analyzing planar failures the best results will be those derived from RocPlane. In RocPlane the planar block is treated as a single sliding mass, considering only force equilibrium. The stability of the block is calculated as a unit or single body. On the other hand, Slide uses methods of slices where the sliding mass above the surface of sliding is divided into a number of vertical parallel slices. The stability of each slice is calculated separately.

This brings to a conclusion that selection of the method of analysis is very crucial in a slope stability analysis. This is also dependent on the type of failure. In this case, the analysis using RocPlane seems more plausible than Slide as the rockslide would have failed as a unit.

\subsubsection{Uncertainties in back analysis}

It is necessary to make emphasis on the limitations and basic assumptions that had to be made during this back analysis study. Several studies have dealt with the uncertainties that come with back analysis procedures e.g. Leroueil and Tavenas (1981) and more recently by Hussain (2010). The techniques of back analysis can however be used to reconstruct possible scenarios/ events that may have led to failure.

As pointed out earlier the, failure occurred about 20000 years ago, hence there was no factual record of events that prevailed or occurred during failure. In the case of the project site the general shape of sliding surface (failure plane) and the failure geometry are well known. Thus, it was possible to reconstruct the pre-landslide geometry. This brought about a reduction in the uncertainties in the analyses. However, the groundwater conditions presented the biggest uncertainty in the analysis. There was good certainty in the use of selected seismic condition coefficients which was determined on the basis of Hynes-Griffin (1984) and peak horizontal ground acceleration (PGA) record for the region of project site.

This fundamental uncertainty in some input data, does suggests that the back analysis approach must be applied with care and the results interpreted with caution. As a result, various possible scenarios from the most to the least favourable conditions were considered for the analysis to analyse all possibilities in order to come to a conclusion about possible conditions that may have led to failure. 
Although back analysis is a useful procedure for estimating material strengths, it is however also not possible to determine unique set of shear strength parameters for the material involved in a landslide that would have result in a value of $F=1.00$. Moreover, it cannot be used without assumption even under the simplest conditions (Duncan and Stark, 1992).

\subsection{The relevance or importance of back analysis in landslide studies.}

Determining shear strength parameters by back analysis avoids many of the problems associated with laboratory testing and in situ tests. This technique is an effective method of accounting for important factors that may not be well represented in laboratory tests (Duncan and Stark, 1992). The shear strength determined through back analysis provides a highly reliable basis for evaluating $\mathrm{F}$ of the slope after stabilization and repair (Duncan and Wright, 2005). According to Duncan and Stark (1992), the principle advantages of back analysis are:

- It avoids problems with disturbance, because back calculated strength are representative of the material in its natural state.

- It provides strength values that are representative of a failure plane having an area many orders of magnitude larger than the failure plane in any laboratory or in situ test.

- It gives a measure of the shear strength of the material mass that reflects the influences of soil fabric, fissures, and pre-existing shear planes.

- In most cases it involves a much longer time to failure than laboratory or in situ tests.

- Shear strengths determined by back analysis are in good agreement with values determined through very extensive laboratory test programs where conditions are simple and accurately known. 


\section{CHAPTER 9}

\section{CONCLUSIONS AND RECOMMENDATIONS}

\subsection{Conclusions}

This Chapter presents the main findings from this research and recommendations for future research. The main findings from this study are:

The lake, which is the only true inland lake in South Africa, was formed due to an ancient landslide event (20,000 year ago) that blocked the course of the eastward flowing Mutale River (Trevor 1926; Janisch 1931; van der Waal 1997). The lake itself is sacred to the Vendas (one of the ethnic groups in the province) and is shrouded by myths.

According to Costa and Schuster (1988), the lake has been classified as a Type II landslide dam in terms of the material deposits on the valley floor. Type II landslide dams span the entire valley floor, in some cases depositing material high on opposite valley sides.

The rockslide was detached from a near vertical, south facing $23 \mathrm{~m}$ deep scarp with an orientation that best coincides with one of the prominent joint sets. The crest of the landslide scarp is approximately $500 \mathrm{~m}$ in length, $300 \mathrm{~m}$ above the lake, and has a slope failure plane surface area of approximately 22 ha.

Undisturbed release surfaces of the slide were examined to estimate the pre-landslide slope geometry. The calculated volume of rock that slid down the failure surface was estimated at 7 9 million $\mathrm{m}^{3}$, while rock blocks travelled a distance of up to $700 \mathrm{~m}$ across the valley (Chiliza and Richardson 2008).

Literature review revealed that, the geology of the failed slope is characterised by sandstone of the Fundudzi Formation which Barker described as sandstone and quartzitic in places, locally gritty or conglomerate with interbedded basaltic lava, tuff, shale, agglomerate and siltstone. However, the field work undertaken during this study showed that, the failed slope was a homogenous sandstone rock slope which was quartzitic in places with joint sets and patterns that are consistent across the slope mass.

The available geological data also revealed that, the landslide boundaries corresponded with major discontinuities that occur in the site. Barker (1979) mapped two NW-NE and SW-NE intersecting faults which form the failure release surfaces (or buttresses). In addition, a 
lineament that was identified in this study from satellite imagery coincides with the tension crack at the crest of the scarp. This gave an indication that the occurrence of this large rockslide was perhaps controlled by these major discontinuities.

It was observed during field investigation, that the possible mode of failure (i.e. failure mechanism) of the landslide was planar. A kinematic analysis based on the Markland's (1972) test in conjunction with the Rocscience software Dips, was thus undertaken in order to confirm this. Kinematic analyses using Rocscience Inc. Dips revealed three major joint sets (JS 1, JS 2 and JS 3) in the rock mass which are oriented northeast-southwest, north west-south east, and north-south respectively (Chiliza and Hingston, 2014). The value obtained for $\phi_{\mathrm{r}}$ under dry static conditions (i.e. $36.8^{\circ}$ and $24.5^{\circ}$ ) via back analysis by Slide and RocPlane are within a very close range to the assumed pole friction cone of $35^{\circ}$ for the kinematic analysis. Also, all other poles are still much steeper than this range or (i.e. $36.8^{\circ}$ and $24.5^{\circ}$ ) including those which are kinematically possible (i.e. JS2) and thus make no change in the analysis results.

Kinematically controlled rock slope failures can be treated as a limit equilibrium problem (Eberhardt et al., 2004). In planar failure there is no internal deformation of the rock mass that is required because the kinematic release occur along one or more relatively dominant planar features. Failure was structurally controlled; as failure occurred along the persistent discontinuity sets JS2 which daylights out of the slope (dips towards the lake) thus enabling kinematic possibility.

Quantification of variable input parameters (groundwater pressures, active friction angle and seismic acceleration) is often a difficult task in slope stability analysis (Pathak and Nilsen, 2004). The study achieved to estimate the value of these variable parameters and study their sensitivity in rock slope stability analyses for the conditions that possibly prevailed at the project site.

Back analysis is an effective method of accounting for important factors that may not be well represented in laboratory tests (Duncan and Stark, 1992). Also, although back analysis may not give a definite set of parameters that would cause failure, but it can provide means of assessing past failures to mitigate against future failures. It also gives an insight into various scenarios that could lead to failure.

Different slope stability methods yield different results; hence the selection of the method of analysis is very crucial. The analysis conducted using Slide and RocPlane showed that both groundwater and seismic acceleration could have triggered the rockslide. However, RocPlane showed that seismic acceleration could have more likely adversely affect potential failure 
surfaces lowering the factor of safety of the slope and ultimately triggered failure than groundwater. RocPlane seems more credible for the analysis of a planar rockslide than Slide.

Today, the remaining rock slopes mass which are the buttresses or release surfaces adjacent to the rockslide scarp still shows signs of activity in the form of rock falls.

\subsection{Perspective}

The extent of the slope portion that failed is defined by the two NW-SE and SW-NE intersecting faults which form the failure release surfaces (or buttresses) and an undifferentiated lineament which coincides with the tension crack at the back scarp of the landslide.

It has been drawn from all approaches employed in this back analysis study of this rockslide that failure occurred predominantly due to the presence of the main discontinuities and joints, particularly JS 2 and their unfavourable orientation such as the very steep angle (i.e. $60^{\circ}$ ) of the failure plane which daylights to a very steep (i.e. $80^{\circ}$ ) slope face.

Extreme groundwater or water pressure increases and seismic ground acceleration conditions in the rock mass could have triggered the rockslide. However, it was evident though from Slide and RocPlane based analyses that the seismic ground acceleration had more adverse effect on $\mathrm{F}$ than the groundwater. Additionally, the fact that some of the highly disrupted failed rock mass blocks (debris) of diameters up to $7 \mathrm{~m}$ had travelled for distances up to $700 \mathrm{~m}$ across the opposite side of the valley floor does suggests that the rockslide was caused by a strong ground motion of an earthquake.

\subsection{Recommendations for future studies}

According to the author's knowledge, this was the first study of its kind (i.e. geotechnical slope stability analysis) for this large planar rockslide that formed Lake Fundudzi. Future work and improvements are recommended. These may include but not limited to:

i. The stability assessment of the remaining buttresses, which appear to be unstable particularly the Dongwe cliff. This question was also raised by one of the attendees of the 'Failure mechanisms of large rock slope", Session 2.10 of IAEG XII Torino 2014 in which the kinematic analysis results of this study were presented in the form of a paper and an oral presentation. Monitoring by means of borehole inclinometers and piezometers maybe necessary to assess the stability of the remaining buttresses and to 
aid in understanding the behaviour of the slope, and to help derive critical state of these slopes.

ii. Numerical discontinuum modelling to analyse the jointed rock mass strength degradation influence on rock slope deformation and its contribution to progressive failure by making use of the software e.g. Phase 2 or UDEC.

iii. Detailed displacement (acceleration) analysis studies as some rock blocks with up to 7 $\mathrm{m}$ diameter travelled up to $700 \mathrm{~m}$ to the opposite side across the valley floor.

iv. A probabilistic approach in back analysis to account for uncertainties in the analysis. 


\section{ACKNOWLEDGEMENTS}

Firstly, I would like to express my sincere gratitude to my Supervisor Dr E.D.C. Hingston for his motivation, guidance, encouragement and support throughout the study period. He has been a passionate advisor who always made time for discussion meetings. I thank him dearly for constantly pushing me to be productive and improve my work. It has been a pleasure working with him.

I am thankful also to Mr Mukesh Seyambu for assistance in sample preparations and equipment sets up in the rock engineering laboratory at the University.

Many thanks also go to Mrs Belinda Fourie, Mrs Lindy Heath and Ms Thabitha Sebeyi for their great assistance with Corel Draw and ArcGIS.

Thanks and gratefulness also goes to my kind, beautiful and lovely wife Thokozile and our children, Simphiwe and Angela for love and support. Keeping up with what was a hectically very busy schedule between work and studies for the past 3 years.

I thank my employer the Council for Geoscience for financial support and allowing me to take study leaves for field work in Limpopo and trips to Durban for meetings and laboratory testing work at the University of KwaZulu-Natal. 


\section{REFERENCES}

Abramson, L. W., Lee, T. S., Sharma, S., and Boyce, G. M. (2002). Slope Stability Concepts. Slope Stabilisation and Stabilisation Methods, Second edition, published by John Willey \& Sons, Inc., pp. 329-461.

Alexander, D. (1995). Natural Disasters. New York: Chapman and Hall.

Alonso, E.E. (1976). Risk analysis of slopes and its application to slopes in Canadian sensitive clays. Géotechnique, 26: 453-472.

Aryal, K.P. (2008). "Differences between LE and FE Methods used in Slope Stability Evaluations", The 12th International Conference of International Association for Computer Methods and Advances in Geomechanics (IACMAG), Goa, India, pp. 45094516.

ASTM (1988). "Standard Guide for using the Rock Mass Rating (RMR) System (Geomechanics Classification) in Engineering Practices." American Society for Testing and Materials, Book of Standards D5878-08, v.04.09, Philadelphia, PA.

ASTM (2005). Standard test method for determination of rock hardness by Rebound Hammer Method, 2005.D 873-05.

ASTM D2938. Standard test methods for unconfined compressive strength of intact rock core specimens. In Annual Book of ASTM Standards (Vol. 04.08). Philadelphia: American Society for Testing and Materials.

ASTM D5607. Standard test methods for performing laboratory direct shear strength tests of rock specimens. In Annual Book of ASTM Standards (Vol. 04.08). Philadelphia: American Society for Testing and Materials.

ASTM D5731. Standard Test Method for Determination of the Point Load Strength Index of Rock and Application to Rock Strength Classifications. ASTM International, West Conshohocken, PA, 1995, DOI: 10.1520/C0033-03, www.astm.org.

Atkinson, R.H. (1978). Suggested methods for determining hardness and abrasiveness of rocks. Int. J. Rock Mech. Min. Sci. \& Geomech. Abstr., Vol. 15, No.3, pp. 89-97.

Aydin, A. (2008). ISRM Suggested method for determination of the Schmidt hammer rebound hardness: $\quad$ Revised $\quad$ version. Int.J.RockMech.Mining.Sci. doi:10.1016/j.ijrmms.2008.01.020. 
Baeza, N., Corominas, B., De Paz, J., A. and Marturiá, J. (2003). A GIS-Based Multivariate Statistical Analysis for Shallow Landslide Susceptibility Mapping in La Pobla de Lillet Area (Eastern Pyrenees, Spain). Natural Hazards, 30:3, pp. 281-295.

Barker, O.B. (1976). Discussion of paper by H. Jansen "The Soutpansberg trough (northel Transvaal) - a aulacogen". Trans. Geol. Soc. S. Afri., 79, 146 - 148.

Barker O.B. (1979). A contribution to the geology of the Soutpansberg Group, Waterberg Group, Northern Transvaal. M.Sc. thesis. (Unpubl), University of the Witwatersrand, Johannesburg.

Barker, O.B. (1983). A proposed geotectonic model for the Soutpansberg Group within the Limpopo Mobile Belt, South Africa. In: Van Biljon, W.J. and Legg, J.H. (Eds.), The Limpopo Belt. Spec. Publ. Geol. So. S. Africa., 8, $181-190$.

Barker, O.B., Brandl, G., Callaghan, C.C., Eriksson, P.G., van der Neut, M. (2006). The Soutpansberg and Waterberg Groups and the Blouberg Formation. In: Johnson M.R., Anhaeusser C.R., Thomas R.J (Eds.).The Geology of South Africa. Geological Society of South Africa, Johannesburg/Council for Geosciences, Pretoria, 301- 319.

Barton, N. (1971). A relationship between joint roughness and joint shear strength. Proc. of Symp. of Int. Soc. Rock Mech. Rock Fracture. Nancy, paper I - 8, 20 p.

Barton, N.R. (1973). Review of a new shear strength criterion for rock joints. Eng. Geol. 7, $287-$ 332.

Barton, N.R. (1974). A review of the shear strength of filled discontinuities in rock. Norwegian Geotech. Inst. Publ. No. 105. Oslo: Norwegian Geotech. Inst.

Barton, N.R. (1976). The shear strength of rock and rock joints. Int. J. Mech. Min. Sci. \& Geomech. Abstr. 13(10), 1-24.

Barton, N.R. and Bandis, S.C. (1982). Effects of block size on the shear behaviour of jointed rock. 23rd U.S. symp. on rock mechanics, Berkeley, 739-760.

Barton, N.R. and Bandis, S.C. (1990). Review of predictive capabilities of JRC-JCS model in engineering practice. In Rock joints, proc. int. symp. on rock joints, Loen, Norway, (eds N. Barton and O. Stephansson), 603-610. Rotterdam: Balkema.

Barton, N.R. and Choubey, V. (1977). The shear strength of rock joints in theory and practice. Rock Mech. 10(1-2), 1-54. 
Barton, N., (2013). Shear strength criteria for rock, rock joints, rockfill and rock masses: Problems and some solutions. Journal of Rock Mechanics and Geotechnical Engineering Vol; 5 pp. 249-261.

Bell F.G. (1992). Engineering Geology ( $\left.1^{s t} e d.\right)$. Oxford: Blackwells Scientific Publications. $368 \mathrm{pp}$.

Bell, F.G. (1994). Influence of weathering and discontinuities on the behaviour of rock masses, In: Bell, F.G. Engineering in rock masses. Butterworth-Heinemann Ltd. Ch 2, pp. $27-$ 53.

Bell, F.G., (2007). Engineering Geology, (2 $\left.2^{\text {nd }} e d.\right)$. Butterworth-Heinemann (Elsevier) Burlington, MA. $581 \mathrm{p}$.

Bell, F.G., and Maud, R.R. (1996). Examples of landslides associated with the Natal Group and Pietermaritzburg Formation in the Greater Durban area of Natal, South Africa. Bull Int Assoc Eng Geol 53:11-20.

Bieniawski, Z.T. (1988). The rock mass rating (RMR) system (geomechanics classification) in engineering practice. In: Kirkaldie L (ed) Rock classification system for engineering purposes. (Special technical publication-papers from Symp) pp. $17-31$.

Bieniawski, Z.T. (1989). Engineering rock mass classifications. New York: Wiley. Brabb and Pampeyan, 1972

Bieniawski, Z.T., and Orr, C.M. (1976) Rapid site appraisal for dam foundations by the geomechanics classification, Proc. 12th Int. Cong. on Large Dams, Mexico, pp. 483501.

Bishop, A.W. (1995). "The use of slip circles in the stability analysis of earth slopes." Geotechnique 5, no. 1:pp 7-17.

Blight, G.E., (1981). The landslide at Amsterdamhoek. In: Symposium on the Engineering Geology of cities in South Africa, pp. 231-235.

Boelhouwers, J., Duiker, J.M.C., van Duffelen, E.A. (1998). Spatial, morphological and sedimentological aspects of recent debris flows in Du Toits Kloof, Western Cape. S Afr J Geol 101(1):73-89

Brady, B.H.G., and Brown, E.T. (2006). Rock mechanics for underground mining, $3^{\text {rd }}$ Edition, Springer, The Netherlands. 
Brabb, E.E., Pampeyan, E.H. (1972). Landslide susceptibility in San Mateo County, California: U.S. Geological Survey Miscellaneous Field Studies Map MF-360, scale 1:62.500.

Brandl, G. (1981). The geology of the Messina area. Explain. Sheet 2230 (Messina), Geol. Surv. S. Afri., 35 pp.

Brandl, G., (1999). Soutpansberg Group. In: Johnson, M.R. (Ed.), Catalogue of South African Lithostratigraphic Units, SA Committee for Stratigraphy, Council for Geoscience, pp.6-39-6-41.

Broch, E., and Franklin, J.A., (1972). The Point load strength test, Int. J. Rock Mech, and Mining Sci., Vol. 9, No 6, pp. $669-697$

Brown, E.T., (1981). Rock characterization testing and monitoring: ISRM suggested methods. Pergamon Press, Oxford, 211 pages.

Bye, A.R., and Bell, F.G. (2001). Stability assessment and slope design at Sandsloot open pit, South Africa. International Journal of Rock Mechanics \& Mining Sciences 38, 449466

Cheney, E.S., Barton, J.M. and Brandl, G. (1990). Extent and age of the Soutpansberg sequences of Southern Africa. S. Afr. J. Geol. Soc. S. Afr., 80, 145-156.

Chiliza and Hingston (2014). A kinematic analysis of an ancient rockslide at Lake Fundudzi, South Africa. In: G. Lollino et al. (eds.), Proceedings of the XII International IAEG Congress, Engineering Geology for Society and Territory - Volume 2, Torino, Italy. Springer International Publishing Switzerland pp. 783 - 786

Chiliza, S.G. and Richardson, S., (2008). Landslide incidence in the Limpopo Province, South Africa. In: Proceedings of the First World Landslide Forum, United Nations University, Tokyo, Japan, pp. 100-103

Christian, J. (2004). "Geotechnical Engineering Reliability: How Well Do We Know What We Are Doing?.” J. Geotech. Geoenviron. Eng., 130(10), 985-1003.

Chung C., J. F., Fabbri, A.G., and van Westen, C.J. (1995). Multivariate regression analysis for landslide hazard zonation. In: Carrara, A. and Guzzetti, F. (eds.) Geographical Information Systems in Assessing Natural Hazards, Kluwer Academic Publisher, Dordrecht, The Netherlands, pp107-142.

Cliché, C.A., (1999). Rock Slope Stability. Society for Mining Metallurgy \& Exploration. 272pages. 
Coggan, J.S., Stead, D., Eyre, J. (1998). Evaluation of techniques for quarry slope stability assessment. Trans. Inst. Min. Metall., Sect. B: Appl. Earth Sci. 107, B 139- B147

Cornforth, D. H. (2005). Landslides in Practice, John Wiley and Sons, Hoboken, NJ, 596 pages.

Corps of Engineers, (1982). "Slope Stability Manual EM-1110-2-1902." Washington, D. C.: Department of the Army, Office of the Chief of Engineers.

Costa, J.E., and Baker, V.R. (1981). Surficial geology-Building with the Earth: New York, John Wiley and Sons, 498 pages.

Costa, J.E. and Schuster, R.L. (1988). The formation and failure of natural dams. Geological Society of America Bulletin. Vol 100. pp. 1054-1068.

Crosta, G.B., and Frattini, P. (2008). Rainfall-induced landslides and debris flows. Hydrol Process 22(4), pp. 473-477.

Crozier, M.J. (1986). Landslides: causes, consequences \& environment. Croom Helm Pub., London.

Cruden, D.M. (1991). A simple definition of a landslide. Bulletin International Association of Engineering Geology, 43: 27-29.

Cruden, D.M., and Varnes, DJ. (1996). Landslide types and processes. In Special Report 247: Landslides: Investigation and Mitigation, Transportation Research Board, Washington D.C..

Dai, F.C., Lee, C.F., and Ngai, Y.Y. (2002). Landslide risk assessment and management: an overview. Engineering Geology, 64(1), 65-87.

Deere, D. U., (1963). Technical description of rock cores for engineering purposes, Felsmechanik und Ingenieugeologie, 1(1). 16-22.

Deere, D.U., and Miller, R.P. (1966). Engineering classification and index properties for intact rocks. Tech Rep Air Force Weapons Lab, New Mexico, no AFNL-TR, 65-116.

Department of Water Affairs (2002). Hydrogeological 1: 500000 map Messina 2127.

Dingle, R.V. (1977). The anatomy of a large submarine slump on a sheared continental margin (southeast Africa). Journal of the Geological Society of London, 134, 293-310. 
Diop. S., Forbes, C., and Chiliza, S.G. (2010). Landslide inventorization and susceptibility mapping in South Africa. Landslides 7 (2), pp. 207-210, published online: 3 November 2009.

Donnely, C.R., and Rigbey, S.J. (2005). The Assessment of Sliding Resistance Beneath Concrete Structures. WaterPower XIII.

Duncan, J.M., and Stark, T.D. (1992). "Soil Strengths from Back-Analysis of Slope Failures," Proc. Stability and Performance of Slopes and Embankments II, ASCE, GSP 31, pp. 890-904, Berkeley.

Duncan, J. M. (1996). "State of the Art: Limit equilibrium and finite-element analysis of slopes." Journal of Geotechnical and Geoenvironmental Engineering, ASCE, 763-786.

Duncan, J. M., and Wright, S. G. (2005). Soil Strength and Slope Stability. Canada: John Wiley \& Sons Inc.

Duncan, J.M. (1996). Soil slope stability analysis. In Turner and Schuster (eds.), Landslides: Investigation and Mitigation (Special Report 247). National Academy Press Washington, D.C., pp. $337-371$.

Eberhardt, E., Stead, D., and Coggag, J.S. (2004). Numerical analysis of initiation and progressive failure in natural rock slopes - the 1991 Randa rockslide. International Journal of Rock Mechanics and Mining Sciences 41, pp. 69-87

Eberhardt, E. (2003). Rock Slope Stability Analysis - Utilization of Advanced Numerical Techniques, Vancouver, Canada: Earth and Ocean Sciences, University of British Columbia.

El-Ramly, H., Morgenstern, N.R., and Cruden, Cruden, D.M. (2002). Probabilistic slope stability analysis for practice. Canadian Geotechnical Journal, 39, pp. 665-683.

Erzin, Y., and, Cetin, T. (2012). The prediction of the critical factor of safety of homogeneous finite slopes using neural networks and multiple regressions. Comput Geosci.

Fernández, L.M. and du Plessis, A. 1992. Seismic hazard maps for Southern Africa, Council for Geoscience, Geological Survey of South Africa, Pretoria

Filz, G.M., Brandon, T.L, and Duncan, J.M. (1992). "Back Analysis of the Olmstead Landslide Using Anisotropic Strengths" Transportation Research Board, $71^{\text {st }}$ Annual Meeting, Washington, DC, January, pp. $12-16$. 
Fredlund, D. G. and Krahn, J. (1997). "Comparison of slope stability methods of analysis." Canadian Geotechnical Journal, pp. 429-439.

Fredlund, D.G., Krahn, J., and Pufahl, D.E. (1981). The relation- ship between limit equilibrium slope stability methods. 111 Proceedings, $10^{\text {th }}$ International Conference on Soil Mechanics and Foundation Engineering, Stockholm, Sweden, Balkema, Rotterdam, vol. 3, pp. 409-416.

Gadney, D.S., and Weber, W.G., Jr. (1978). Design and construction of soil slopes. In: R.L. Schuster and R.J. Krizek (Editor), Landslides - Analysis and Control: Transportation Research Board, National Academy of Sciences, Washington, DC, Special Report 176, pp. 172-191.

Garland, G., and Olivier, M.J. (1993). Predicting landslides from rainfall in a humid, subtropical region. Geomorphology 8:165-173.

Geli, L., Bard, P.Y., and Jullien, B. (1988). The effects of topography on earthquake ground motion. A review and new results. Bulletin of the Seismological Society of America 78 (1), pp. $42-63$.

Giani, G.P. (1992), Rock slope stability analysis. Balkema, Rotterdam, 362 pages.

Glade, T. and Crozier, M.J., (2005a). The nature of landslide hazard impact. In: Glade, T., Anderson, M.G. and Crozier, M.J. (eds.) Landslide Hazard and Risk. John Wiley, pp. 43-74.

Glade, T., and Crozier, M.J., (2005b). A review of scale dependency in landslide hazard and risk analysis. In: Glade, T., Anderson, M.G. and Crozier, M.J. (eds.) Landslide Hazard and Risk. John Wiley, pp. 75-138.

Goodman, R.E.,Taylor, R.L., and Brekke,T.L. (1968). A model for the mechanics of jointed rock. Journal of the Soil Mechanics and Foundations Division, ASCE, pp. 637-659.

Goodman, R.E. (1980). Introduction to Rock Mechanics, $1^{\text {st }}$.Ed. Wiley, New York.

Griffiths, J.S., Mather A E, and Hart, A. B. (2002). Landslide susceptibility in the Rio Aguas catchment, SE Spain. Q J Eng Geol Hydrogeol, 35(1): 9-17.

Gupta, V., (2001). Geomorphological controls on landslide activity in the du Toits Kloof, Western Cape Mountains, South Africa. S Afr Geogr J 83(3):258-263. 
Guzzetti, F., Carrara A., Cardinali, M. and Reichenbach, P. (1999). Landslide hazard evaluation: a review of current techniques and their application in a multi-scale study, Central Italy. Geomorphology 31:181-216.

Hammah, R.E., Yacoub, T.E., Corkum, B., and, Curran, J.H. (2008). The Practical Modelling of Discontinuous Rock Masses with Finite Element Analysis. In Proceedings of the 42nd U.S. Rock Mechanics Symposium -2nd U.S.-Canada Rock Mechanics Symposium, San Francisco, US.

Hammah, R.E. and Yacoub, T.E. (2009). Probabilistic Slope Analysis with the Finite Element Method, 43rd US Rock Mechanics Symposium and 4th U.S.-Canada Rock Mechanics Symposium, Asheville, ARMA 09-149.

Hannweg, L.A. (1996). A practical analysis of standard joint roughness profiles. Hons. thesis. Univ. of Natal (Durban), 50 pages.

Hencher, S. R., and Richards, L. R. (1989). "Laboratory direct shear testing of rock discontinuities". Ground Engineering 22 (2): pp. 24-31.

Hencher, S.R. and Richards, L.R. (1982). The basic frictional resistance of sheeting joints in Hong Kong granite Hong Kong Engineer, pp. 21-25.

Hervás, J., Barredo, J.I., Rosin, P.L., Pasuto, A., Mantovani, F., and Silvano, S. (2003). Monitoring landslides from optical remotely sensed imagery: the case history of Tessina landslide, Italy. Geomorphology, 54: 63-75.

Hingston, E.D.C., (1997). Shear Testing and analysis of Rock Models made from the Standard Roughness Profiles. Unpubl. MSc. Univ. of Natal (Durban), pp. 1-70.

Hoek, E., and Bray, J.W. (1991). Rock slope engineering, 3rd edn. Institute of Mineralogy and Metallurgy, London, 358 pages.

Hoek, E. (2000), 'Rock Engineering. Course Notes by Evert Hoek'. Available for downloading at 'Hoek's Corner', www.rocscience.com

Hoek, E. (1998) Rock Engineering. Chapter 8 - factor of safety and probability of failure. Course notes, Internet edition, http://www.rockeng.utoronto.ca/hoekcorner.htm, pp. $105-114$.

Hoek, E., and Brown, E.T. (1998). Practical estimates of rock mass strength. Int j Rock Mech Min Sci 34: pp. 1165 - 1186. 
Hoek, E. (1994). Strength of rock and rock masses, ISRM News J, 2(2), 4-16.

Hoek, E. (2007). Practical Rock Engineering. Toronto: Rocscience, e-book.

Hoek, E., and Bray, J. W. (1981) Rock Slope Engineering, Institution of Mining and Metallurgy, London., 359 pages.

Hoek, E., Carranza-Torres, C., and Corkum, B. (2002). Hoek-Brown failure criterion - 2002 Edition. Proc. 5th North American Rock Mechanics Symposium, Toronto, July 2002, pp. 267-273.

Hoek, E., Kaiser, P.K. and Bawden. W.F. (1995). Support of underground excavations in hard rock. Rotterdam: Balkema.

Hudson, J.A., and Harrison, J.P. (1997). Engineering Rock Mechanics: an Introduction to the Principles. Elsevier Science: Oxford, 444 pp.

Hussain, M., Start, T. D., and Akhtar, K. (2010). "Back-Analysis Procedure for Landslides," Proceedings of the International Conference on Geotechnical Engineering, Lahore, Pakistan, Pakistan Geotechnical Engineering Society, pp. 159-166.

Hutchinson, J. N., (1968). Mass Movement. In: The Encyclopedia of Geomorphology (Fairbridge, R.W., ed.), Reinhold Book Corp., New York, pp. 688-696.

Hynes-Griffin, M. E., and Franklin, A. G. (1984). "Rationalizing the Seismic Coefficient Method. ' U.S. Army Engineer Waterways Experiment Station, Vicksburg, Mississippi, Misc. Paper GL-84-13

ISRM (1974). Suggested methods for determining shear strength. Committee on Field Tests. Document No. 1, Final draft, February 1974.

ISRM (1978). Suggested methods for the determining the uniaxial compressive strength and deformability of rock material. Committee on laboratory tests, September 1978.

ISRM (1978). Suggested methods for the quantitative description of discontinuities in rock masses. Int. J. Rock Mech. Min. Sci. \& Geomech. Abstr.15, 319-368.

ISRM (1979): Suggested methods for determining in situ deformability of rock. Int. J. Rock Mech. Min. Sci. \& Geomech. Abstr., Vol. 16, No. 3, pp. 195-214.

ISRM (1985). International Society of Rock Mechanics Commission on Testing Methods, Suggested Method for Determining Point Load Strength, Int. J. Rock Mech. Min. Sci. and Geomech. Abstr. 22, pp.51-60. 
ISRM (1981). Suggested methods for determining hardness and abrasiveness of rocks. In: Brown ET editor. Rock characterization, testing and monitoring: ISRM suggested Methods. Oxford: Pergamon; 1981. p. 95-6.

Iverson. (2000). Landslide triggering by rain infiltration. Water Resources Research 367, pp.1897-1910.

Jaeger, J. C. (1971). Friction of rocks and stability of rock slopes. Geotechnique. 21(2), pp. 97143.

Janbu, N. (1973). Slope Stability Computations. Embankment Dam Engineering, Casagrande Volume, pp. 47-86.

Janisch, E.P. (1931). Notes on the central part of the Soutpansberg and on the origin of Lake Fundudzi. Transactions of the Geological survey of South Africa, 54. pp. 152-162.

Jensen, H. (1975). Precambrian basins on the Transvaal craton and their sedimentological and structural features. Trans. Geol. Soc S. Afri., 78, 2533.

Keefer, D.K., (1984). Landslides caused by earthquakes. Geological Society of American Bulletin 95, 406-421.

Khorombi, M. (2000). Towards a sustainable land-use plan for the Lake Fundudzi catchment area. M.Inst.Agr. thesis. (Unpubl), University of Pretoria, South Africa.

Kliche, C.A. (1999). Rock Slope Stability, SME, Littleton, CO, 253 pages

Knight, K., Everitt, P.R., and Sugden, M.B. (1977). Stability of shale slopes in the Natal Coastal belt. In: Proceedings of the Fifth Southeast Asian Conference on Soil Engineering, Bangkok, pp. 201-212

Krahn, J. (2003). The limits of limit equilibrium analysis. Canadian Geotechnical Journal, Vol. 40, pp. 643-60.

Kramer, S.L. (1996). “Geotechnical Earthquake Engineering.” Prentice-Hall, Inc., Upper Saddle River, New Jersey 07458, pp. 434-437.

Ladanyi, B., and Archambault, G. (1970). Simulation of the shear behaviour of a jointed rock mass, Proc. 11th. U.S. Symp. on Rock Mechanics, pp. 105 - 125.

Lama, R.D., and Vutukuri V.S. (1978): Handbook on mechanical properties of rocks. Trans Tech Publications, Clausthal, Germany, 4 Volumes. 
Lane, K. S. (1967). Stability of reservoir slopes, in: Failure and breakage of rock, Charles Fairhurst, ed. Proceedings of the Eighth Symposium on Rock Mechanics, Sept. 15-17, 1966, University of Minnesota, Minneapolis, Minnesota, pp. 321-336.

Leroueil, S., and Tavenas, F. (1981). "Pitfalls of Back-Analysis," X Int. Conf. Of Soil Mech. And Foundation Engineering, Vol 1, Stockholm pp. 185-190.

Limpopo Provincial Disaster Management Unit, (2000). Status Quo report on the flood-related disaster in the Northern Province (unpubl.) Vol 3.

Lin, H.M., Chang, S.K., Wu, J.H., and Juang, C.H. (2009). Neural network-based model for assessing failure potential of highway slopes in the Alishan, Taiwan Area: Pre- and post-earthquake investigation. Engineering Geology, 104(3-4), 280-289.

Lia, A.J., Merifielda, R.S., and, Lyaminb, A.V. (2008). Stability charts for rock slopes based on the Hoek-Brown failure criterion. International Journal of Rock Mechanics \& Mining Sciences, 45 (2008), pp. 689-700.

Marcuson, W.F., and Franklin, A.G. (1983). "Seismic Design, Analysis, and Remedial Measures to Improve the Stability of Existing Earth Dams - Corps of Engineers Approach", in: Seismic Design of Embankments and Caverns, T.R. Howard, Ed., New York, ASCE.

Marinos. P., and Hoek, E. (2001). Estimating the geotechnical properties of heterogeneous rock masses such as flysch. Bull Eng Geol Env, 60, pp. 82-92

Markland, J.T. (1972). A Useful Technique for Estimating the Stability of Rock Slope when the Rigid Wedge Slide Type of Failure is Expected. Imperial College Rock Mechanics Research Reprint, No. 19.

Mathis, J. I. (1987). Discontinuity mapping- A comparison between line and area mapping, Proc. 6th Int. Cong. Int. Soc. Rock Mech., Balkema. 2, pp. 1111-1114.

Maurenbrecher, P.M., and Booth, A.R. (1975). Some slope stability problems in soils derived from the Ecca shales of Natal, South Africa. Engineering Geology 9, pp. 99-121.

Melo, C., and Sharma, S. (2004). Seismic coefficients for pseudostatic slope analysis. 13th World Conference on Earthquake Engineering, Vancouver, B.C., Canada, August 1-6, Paper No. 369.

Miller, R.P. (1965). Engineering classification and index properties for intact rock. $\mathrm{PhD}$ thesis, University of Illinois. 
Miller, S.M., McWilliams, P.C., and Kerkering, J.C. (1989). Evaluation of stereo digitizing for measuring rock fracture. In: Rock mechanics as a guide for efficient utilization of natural resources. Proceedings of $30^{\text {th }}$ US symposium on rock mechanics, West Virginia. Balkema, Rotterdam, pp. 201-208.

Morgenstern, N. R. (1977). "Slopes and Excavations." State of Art Report, 9th Intl. Conf. on Soil Mechanics and Foundation Engineering. pp. 567-581.

Morgenstern, N. R., and Price, V. E. (1965). "The analysis of the stability of general slip surfaces." Geotechnique, pp. 79-93.

Mohr, O. (1900). Welche Umstande bedingen die Elastizitatsgrenzeund den Bruch eines Materials? Z. Ver.dt. Ing., 44, pp. 1524-30; pp. 1572-77.

Nash, D. T. F. (1987). "A comprehensive review of limit equilibrium methods of slope stability analysis." Slope stability, M. G. Anderson and K. S. Richards, ed., John Wiley, New York, N.Y., pp. 11-75.

Newmark, N., (1965). Effects of earthquakes on dams and embankments. Geotechnique 15 (2), pp. 139- 160 .

Nilsen, B. (2000). New trends in rock slope stability analysis. Bull Eng Geol Env, 58, pp. 173178.

Oppikofer, T., (2009). Detection, analysis and monitoring of slope movements by highresolution digital elevation models, Faculty of Geosciences and Environment Université de Lausanne (UNIL), Lausanne, 183 pages.

Paige-Green, P. (1985). The development of a landslide susceptibility map for Southern Africa. In: Proceedings Annual Transportation Convention, Pretoria vol. FB.

Paige-Green, P., and Croukamp. L. (2004). A revised landslide susceptibility map of Southern Africa. Geoscience Africa, 508 pages.

Paige-Green, P. (1989). Landslides: extent and economic significance in southern Africa, in Brabb and Harrad (eds). Landslides, pp. 261-269.

Park, H., and West, T.R. (2001). Development of a probabilistic approach for rock wedge failure. Engineering Geology 59, pp. 233 - 251.

Pathak, S., and Nilsen, B. (2004). Probabilistic rock slope stability analysis for Himalayan condition. Bull Eng Geol Env (2004) 63, pp. 25-32. 
Patton, F.D. (1966). Multiple modes of shear failure in rock. Proc. 1st congr. Int. Soc. Rock Mech., Lisbon 1, 509-513.ISRM (1974 and 2006)

Piteau, D. R., and Peckover, F. L. (1978). Engineering of Rock Slope, in: Landslides, Analysis and Control, Transportation Research Board, Special Report 176, edited by: Schuster, R. L. and Krizek, R. J., Washington, DC, 192-228, 1978.

Planstrom, A. (1975). “Karakterisering av Oppsprekningsgrad og Fjellmassers Kvalild” Internal Report, Ing. A. B. Berdal A/S, Oslo, Norway. 1-26.

Rocscience Inc. (2001). RocPlane Version 2.0 - Planar Sliding Stability Analysis for Rock Slopes. www.rocscience.com, Toronto, Ontario, Canada.

Rocscience Inc. (2002), RocLab Version 1.0 - Rock Mass Strength Analysis using the Generalized Hoek-Brown failure criterion. www.rocscience.com, Toronto, Ontario, Canada.

Rocscience Inc. (2010), Slide Version 6.0 - 2D Limit Equilibrium Slope Stability Analysis. www.rocscience.com, Toronto, Ontario, Canada.

Rocscience Inc. (2012), Dips Version 6.0 - Graphical and Statistical Analysis of Orientation Data. www.rocscience.com, Toronto, Ontario, Canada.

Romana, M. (1993). A geomechanical classification for slopes: slope mass rating. In: Hudson, J.A. (Ed.), Comprehesive Rock Engineering. Pergamon Press, Oxford, pp. 575-599.

Saaty, T.L. (1980). The Analytical Hierarchy Process. McGraw Hill, New York.

SACS: South Africa Committee for Stratigraphy of South Africa (1980). Part1 (Comp. L.E. Kent). Lithostratigraphy of the Republic of South Africa, South West Africa/ Namibia, and the Republics of Bophuthatswana, Transkei and Venda. Handb. Geol. Surv. S. Afri., 8, 690 pages.

Sancio, R.T. (1981). The use of back-calculations to obtain shear and tensile strength of weathered rocks. In: Proceedings of the international symposium on weak rock, Tokyo, Japan, September, pp. 647-652.

Santacana, N., Baeza, B., Corominas, J., De Paz, A., and Marturia, J. (2003). A GIS-based multivariate statistical analysis for shallow landslide susceptibility mapping in La Pobla de Lillet Area (Eastern Pyrenees, Spain). Nat Hazards 30, pp. 281-295. 
Sakellariou, M.G. and Ferentinou, M. (2005). A study of slope stability prediction using neural networks. Geotechnical and Geological Engineering, Vol. 23, Issue 4, Kluwer Academic Publishers, pp. 419-445.

Sauer, E.K., and Fredlund, D.G. (1988). Effective Stress, Limit Equilibrium back-analysis of Failed Slopes: Guidelines, Landslides-Glissements de terrain, Christophe Bonnard ed., Proceedings of the 5th Int. Symp. On Landslides, Balkema, Rotterdam.

Schmidt, E. (1951), A non-destructive concrete tester. Concrete, 59 (8), pp. 34-35.

Schuster, R. L., and Kockelman, W. J. (1996). Principles of landslide hazard reduction, in Landslides, Investigation and mitigation, Transportation Research Board Special Report 247, edited by A. K. Turner and R. L. Schuster, National Academy Press, Washington, D.C., pp. 91-105.

Schuster, R.L. and Highland, L.M. (2001), Socioeconomic and Environmental Impacts of Landslides in the Western Hemisphere, US Geological Survey. Open File Report 010276, http://pubs.usgs.gov/of/2001/ofr-01-0276/.

Schuster, R.L. (1996). Socioeconomic significance of landslides, in Turner, A.K., and Schuster, R.L. (eds), Landslides: Investigation and Mitigation, Transportation Research Board, National Research Council, Special Report 247 (Washington, DC: National Academy Press), pp. 12-35.

Seed, H.B. (1979). "Considerations in the earthquake-resistant design of earth and rockfill dams." Géotechnique, Vol. 29, No. 3, pp. 215-263.

Selby, M. J. (1982). Hillslope materials and processes. Oxford: Oxford Univ. Press.

Sepúlveda, S.A., Murphy, W., and Petley, D.N. (2002). Rock slope failure during the 1999 ChiChi Earthquake, Taiwan: an example of topographic amplification effects? Poster presented at the Geological Society of America Annual Meeting, Denver, October.

Shahin, M.A., Jaksa, M.B. and Maier, H.R. (2008). State of the Art of Artificial Neural Networks in Geotechnical Engineering. Electronic Journal of Geotechnical Engineering, www.ejge.com, ISSN: 1089-3032.

Sharifzadeh, M., Sharifi, M., and Delbari S.M. (2009). Back analysis of an excavated slope failure in highly fractured rock mass: the case study of Kargar slope failure (Iran). Environ Earth Sci 60, pp.183-192. 
Singh, R.G. (2009). Landslide Classification, Characterization and Susceptibility Modelling in KwaZulu-Natal. MSc. Thesis, University of Witwatersrand, 156 pages. (Unpublished).

Singh, R.G., Botha, G.A., Richards, N.P., McCarthy, T.S. (2008). Holocene landslides in KwaZulu-Natal, South Africa. S Afr J Geol 111, pp. 39-52.

Singhroy, V. (2004). Landslide Hazard and Risk, edited by Thomas Glade, Malcom Anderson and Michea . Crozier. John Wiley \& Sons, Ltd. pp. $469-492$.

Skempton, A. W. (1985). "Residual strength of clays in landslides, folded strata and the laboratory." Geotechnique, pp. 3-18.

Soeters, R., and van Western, C.J. (1996). Slope instability recognition, analysis, and zonation. In Landslides investigation and Mitigation. Transportation Research Board, US National Research Council, Turner, A.K. And Schuster, R.L. (Eds). Special Report, 247, pp. 129-177.

Sonmez, H., Ulusay, R., and Gokceoglu, C. (1998). A practical procedure for the back analysis of slope failures in closely jointed rock masses. Int J Rock Mech Min Sci 35(2), pp. 219-233.

Sonmez. H., and Ulusay, R. (1999). Modifications to the geological strength index (GSI) and their applicability to the stability of slopes. Int J Rock Mech Min Sci, 36, pp.743-760.

Sowers, G.F. (1979). Introductory Soil Mechanics and Foundations: Geotechnical Engineering, $4^{\text {th }}$ ed.,, Macmillan, New York.

Spencer, E. (1976). "A method of analysis of the stability of embankments assuming parallel inter-slice forces." Geotechnique, pp. 11-26.

Stayt, H.A. (1968). The Bavenda. (Facsimile of 1931 edition). Frank Css, London.

Stead, D., Eberhardt, E., and Coggan, J.S. (2006). Developments in the characterization of complex rock slope deformation and failure using numerical modelling techniques, Engineering Geology, 83, pp.217-235.

Stimpson, B. (1981). A suggested technique for determining the basic friction angle of rock surfaces using core: International Journal of Rock Mechanics and Mining Sciences and Geomechanics Abstracts, Vol. 18, pp. 63-65.

Styles, T.D., Coggan, J.S., and Pine, R.J. (2011). Back analysis of the Joss Bay Chalk Cliff Failure using numerical modelling. Engineering Geology 120, pp. 81-90. 
Terzaghi. K. (1950). Mechanisms of landslides. In: Paige S (ed) Application of geology to engineering practice. Geological Society of America, Berkley, pp. 83-123

Terzaghi, K. (1962). Stability of steep slope on hard unweathered rock. Geotechnique 12, pp. 251-270.

Terzaghi, K. (1943). Theoretical soil mechanics, Wiley, New York.

Terzaghi, K., and Peck, R.B. (1948). Soil mechanics in engineering practice. 1st ed. John Wiley and Sons, Inc., New York.

Terzaghi, R.D., (1965). Source of error in joint surveys. Geotechnique 15, pp. 287-304.

Thiebes, B., (2012). Landslide Analysis and Early Warning Systems: Local and Regional Case Study in the Swabian Alb, Germany. Springer, Nature - 282 pages.

Trevor, T.G. (1926). Some notes on a visit to Lake Fundudzi in the Soutpansberg district of the Transvaal, paid in August 1917. In Transactions of the Royal Society of South Africa. 8 , pp. 87-89.

UNESCO/IAEG. (1976). Engineering Geological maps: A guide to their preparation. The Unesco Press. Paris, 79 pages.

Van der Waal, B.C.W. (1997). Fundudzi, a unique, sacred and unknown South African lake. South African Journal of Aquatic Science, 1997. Vol 23(1), pp. 42-55.

Van Eeden, O.R., Visser, H.N., Van Zyl, J.S., Coertze, F.J. and Wessels, J.T. (1955). The geology of the eastern Soutpansberg and the Lowveld to the north. Explain. Sheet 42 (Soutpansberg), Geol. Surv. S. Afr., 117 pages.

Van Westen, C.J., Rengers, N., Terlien, M.T.J., and Soeters, R. (1997). Prediction of the occurrence of slope instability phenomena through GIS-based hazard zonation. Geol Rundsch 86: Elsevier, landslide, quartzitic sandstone, Venda, pp. 404-414.

Varnes, D.J. (1958). Landslide types and processes. Highway Research Board Special Report 29, Washington, DC, pp. 20-47.

Varnes, D.J. (1978). Slope movement types and processes. In Special report 176: Landslides: Analysis and Control, Transportation Research Board, Washington, D.C.

Visser D.J.L. (1984). Geological Map of the Republic of South Africa and the Kingdoms of Lesotho and Swaziland: 1:1000 00 scale Geological Series, Department of Mineral and Energy Affairs. 
Visser, J.N.J. (1998). The Geotectonic Evolution of South Africa and Offshore Areas. Explanation of Structure Map Scale 1: 1000 000. Council for Geoscience, Geological survey of South Africa, 219 pages.

Vutukuri, V.S., Lama, R.D., and Saluda, S.S. (1974). Mechanical Properties of Rocks, Volume1. Trans Tech Publications, Switzerland, 280 pages.

Wieczorek, G.F., Gori, P.L. and Highland, L.M. (2005). Reducing landslide hazards and risk in the United States: the role of the U.S. Geological Survey. In: Glade, T., Anderson, M.G. and Crozier, M.J. (eds.) Landslide risk assessment. John Wiley, pp. 351-375.

Wieczorek, G. F. (1996). Landslide triggering mechanisms Landslides: Investigation and Mitigation. Special Report 247. A. K. Turner and R. L. Schuster. Washington D.C.: Transportation Research Board, National Research Council.

Wieczorek, G.F., Gori, P.L., Jager, S., Kappel, W.M. and Negussey, D. (1996) Assessment and Management of Landslide Hazards near Tully Valley Landslide, Syracuse, New York, USA. In: Proceedings 7th International Symposium on Landslides, Trondheim. A.A. Balkema Publishers, Rotterdam, pp. 411- 416.

Wilson, R.C., and Keefer, D.K. (1983). Dynamic analysis of a slope failure from the 6 August, 1979 Coyote Lake, California, earthquake: Seismological Society of America Bulletin, v. 73 , no. 3, pp. 863-877.

Wittke, W. (1990). Rock Mechanics theory and applications with case histories. SpringerVerlag Berlin Heidelberg., Germany, 1057 pages.

WP/WLI. (1990). A suggested method for reporting a landslide. Bulletin of the International Association of Engineering Geology, No. 41.

WP/WLI. 1993. A suggested method for describing the activity of a landslide. Bulletin of the International Association of Engineering Geology, No. 47.

Wright, S. (1969), “A Study of Slope Stability and the undrained Shear Strength of Clay Shales", Ph.D. Thesis, University of California, Berkeley, California.

www.weathersa.co.za

Wyllie, D.C. and C. W. Mah. (2005). Rock Slope Engineering, Civil and Mining, 4th ed., Spoon Press, 431 pages. 
Yu, L., Liu, J., Kong, X.J., and Hu, Y. (2008). "Three-dimensional RITSS large displacement finite element method for penetration of foundations into soil." Comput. Geotech., 35(3), 372-382.

Zhu, D. Y., Lee C. F. \& Jiang H. D. (2003). Generalized Framework of Limit Equilibrium Methods for the Stability Analysis, Géotechnique 53, N.4, 2003, pp. 377-395. 
12. APPENDICES 
1. Earthquake Richter scale magnitude data within $150 \mathrm{~km}$ of Lake Fundudzi rockslide.

\begin{tabular}{|c|c|c|c|c|c|c|c|c|}
\hline Year & Month & Day & Hour & Minute & Second & Latitude & Longitude & $\begin{array}{c}\text { Earthquake } \\
\text { Richter scale } \\
\text { magnitude } \\
\text { (MI) }\end{array}$ \\
\hline 1908 & 2 & 20 & 2 & 45 & 0.00 & -23.800 & 30.100 & 3.7 \\
\hline 1908 & 9 & 24 & 18 & 50 & 0.00 & -24.000 & 30.500 & 4 \\
\hline 1909 & 8 & 17 & 12 & 20 & 0.00 & -24.000 & 30.500 & 3.7 \\
\hline 1913 & 6 & 13 & 5 & 0 & 0.00 & -24.000 & 30.300 & 3.7 \\
\hline 1914 & 8 & 21 & 6 & 59 & 0.00 & -23.600 & 30.200 & 3 \\
\hline 1917 & 12 & 17 & 9 & 20 & 0.00 & -24.000 & 30.300 & 3.7 \\
\hline 1918 & 3 & 9 & 3 & 26 & 0.00 & -23.700 & 30.200 & 3.7 \\
\hline 1919 & 12 & 6 & 21 & 0 & 0.00 & -23.900 & 30.100 & 3 \\
\hline 1921 & 9 & 24 & 2 & 20 & 0.00 & -23.700 & 30.200 & 3.7 \\
\hline 1924 & 4 & 9 & 14 & 55 & 0.00 & -23.900 & 30.100 & 4 \\
\hline 1925 & 1 & 26 & 8 & 27 & 0.00 & -24.000 & 30.300 & 3 \\
\hline 1930 & 5 & 27 & 6 & 0 & 0.00 & -23.600 & 30.200 & 3.7 \\
\hline 1933 & 12 & 8 & 8 & 0 & 0.00 & -23.900 & 30.100 & 3.7 \\
\hline 1940 & 11 & 10 & 21 & 0 & 0.00 & -24.000 & 30.200 & 5 \\
\hline 1957 & 8 & 2 & 1 & 0 & 0.00 & -22.500 & 31.300 & 3.7 \\
\hline 1966 & 10 & 13 & 11 & 7 & 7.00 & -23.300 & 30.800 & 3.2 \\
\hline 1967 & 3 & 11 & 13 & 32 & 36.00 & -23.800 & 31.200 & 2.4 \\
\hline 1967 & 7 & 7 & 13 & 6 & 5.00 & -23.900 & 31.000 & 2.7 \\
\hline 1969 & 1 & 15 & 14 & 16 & 24.00 & -23.900 & 31.100 & 2.7 \\
\hline 1970 & 11 & 19 & 5 & 30 & 20.00 & -22.300 & 31.000 & 5 \\
\hline 1972 & 1 & 9 & 23 & 24 & 19.60 & -22.100 & 31.000 & 3.4 \\
\hline 1973 & 2 & 5 & 18 & 12 & 35.40 & -23.700 & 30.500 & 4.4 \\
\hline 1975 & 8 & 3 & 16 & 49 & 38.00 & -22.100 & 30.900 & 3.3 \\
\hline 1976 & 7 & 6 & 9 & 21 & 13.00 & -22.200 & 31.100 & 4 \\
\hline 1981 & 12 & 3 & 21 & 11 & 15.76 & -23.790 & 29.770 & 3 \\
\hline 1988 & 8 & 11 & 2 & 8 & 11.40 & -22.230 & 30.170 & 4.3 \\
\hline 1988 & 8 & 31 & 2 & 8 & 7.90 & -22.000 & 30.600 & 4.4 \\
\hline 1992 & 11 & 24 & 11 & 6 & 55.00 & -21.700 & 30.000 & 4.1 \\
\hline 1995 & 6 & 8 & 7 & 21 & 3.00 & -22.300 & 29.690 & 4.5 \\
\hline 1999 & 9 & 8 & 21 & 18 & 16.90 & -21.980 & 31.190 & 4.6 \\
\hline 2000 & 11 & 22 & 1 & 14 & 39.60 & -23.170 & 30.790 & 3.7 \\
\hline 2003 & 9 & 25 & 3 & 28 & 30.00 & -23.991 & 30.536 & 3.3 \\
\hline 2004 & 3 & 9 & 21 & 8 & 26.10 & -23.941 & 30.365 & 2.6 \\
\hline 2004 & 4 & 15 & 9 & 53 & 53.10 & -23.891 & 31.117 & 2.8 \\
\hline 2007 & 3 & 2 & 5 & 9 & 53.50 & -22.236 & 29.681 & 3.8 \\
\hline 2007 & 5 & 31 & 4 & 56 & 22.50 & -23.760 & 29.702 & 2.1 \\
\hline 2007 & 6 & 24 & 10 & 51 & 48.60 & -22.572 & 29.572 & 2.1 \\
\hline 2007 & 6 & 30 & 13 & 3 & 57.80 & -21.863 & 29.541 & 2.8 \\
\hline 2007 & 7 & 19 & 11 & 10 & 57.80 & -22.441 & 29.244 & 2.6 \\
\hline 2007 & 9 & 13 & 5 & 22 & 11.50 & -22.672 & 29.574 & 2.6 \\
\hline
\end{tabular}




\begin{tabular}{|c|c|c|c|c|c|c|c|c|}
\hline Year & Month & Day & Hour & Minute & Second & Latitude & Longitude & $\begin{array}{c}\text { Earthquake } \\
\text { Richter scale } \\
\text { magnitude } \\
\text { (MI) }\end{array}$ \\
\hline 2007 & 10 & 27 & 12 & 26 & 48.00 & -22.682 & 29.468 & 2.1 \\
\hline 2007 & 10 & 31 & 14 & 35 & 3.70 & -22.517 & 29.363 & 2.6 \\
\hline 2007 & 11 & 30 & 1 & 38 & 40.50 & -22.512 & 29.433 & 2.4 \\
\hline
\end{tabular}


Appendix A:

Discontinuity survey log sheets 


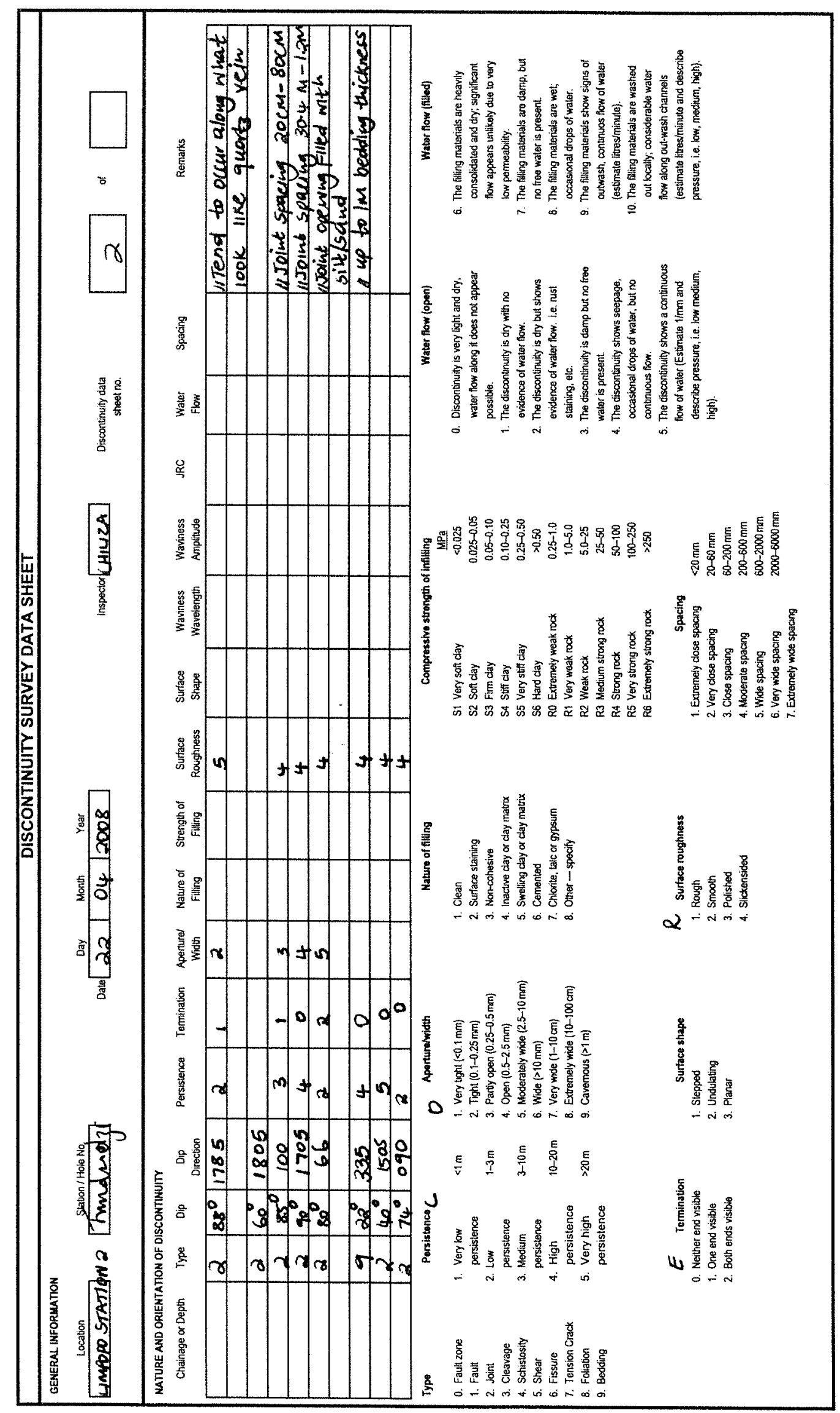




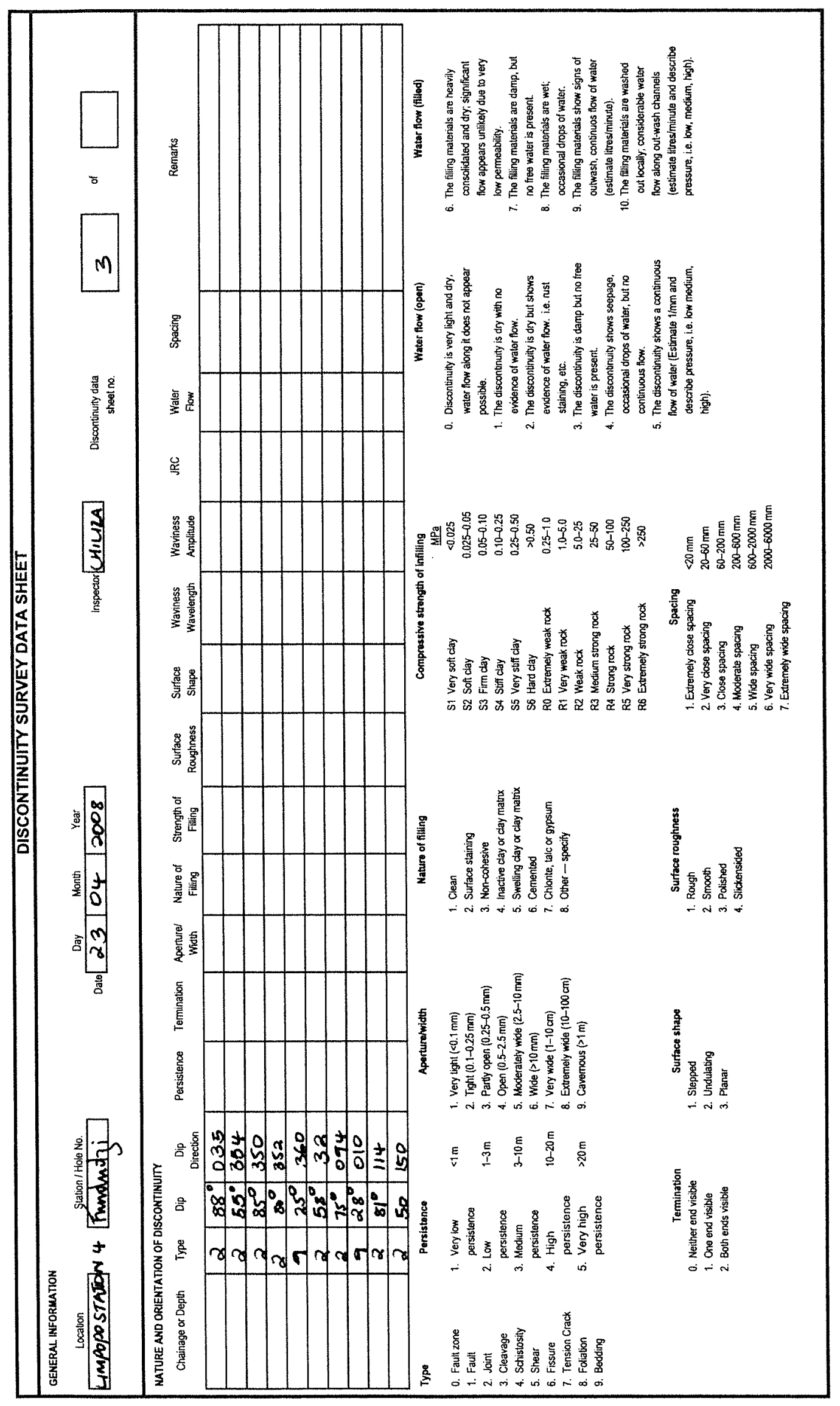




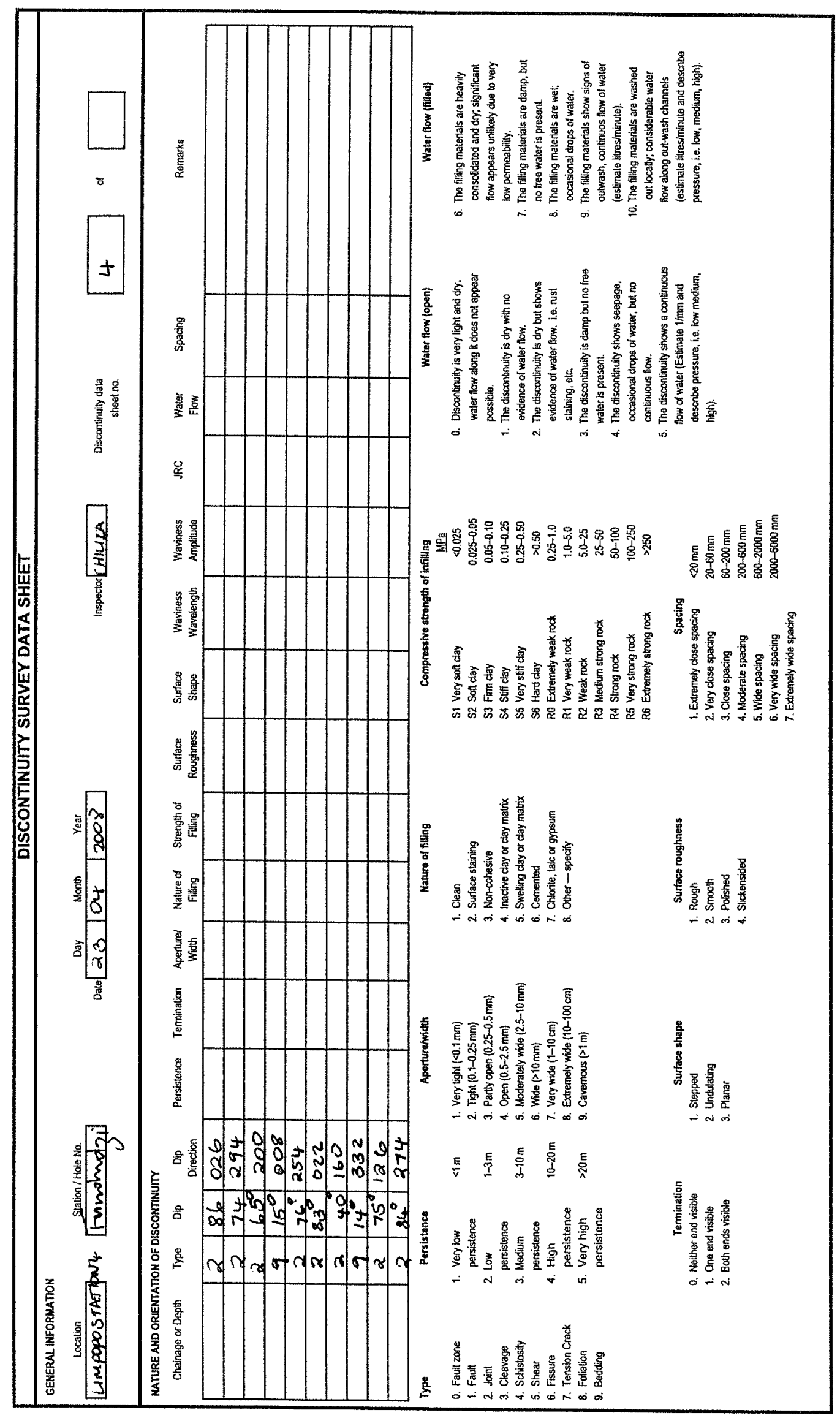




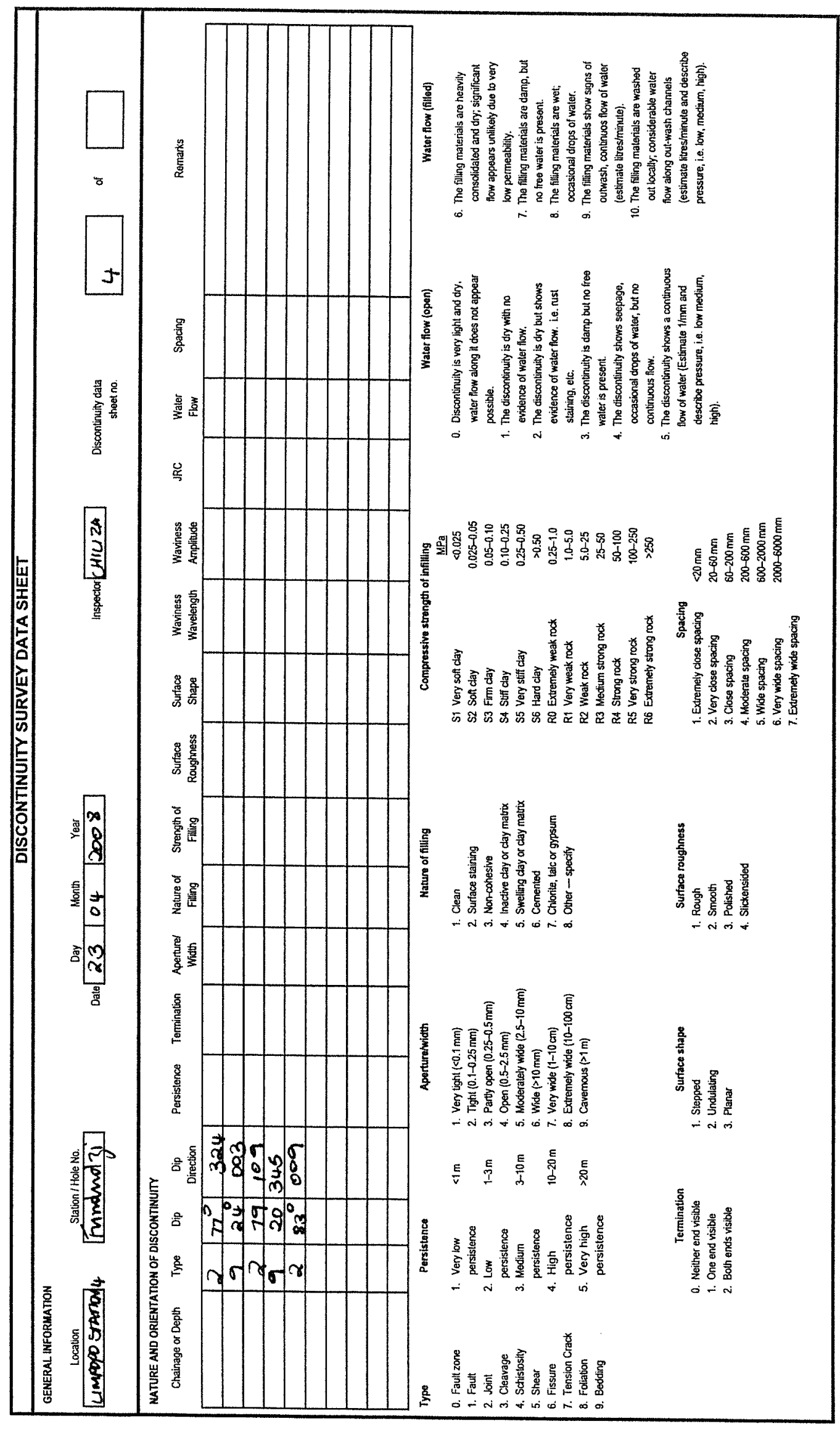




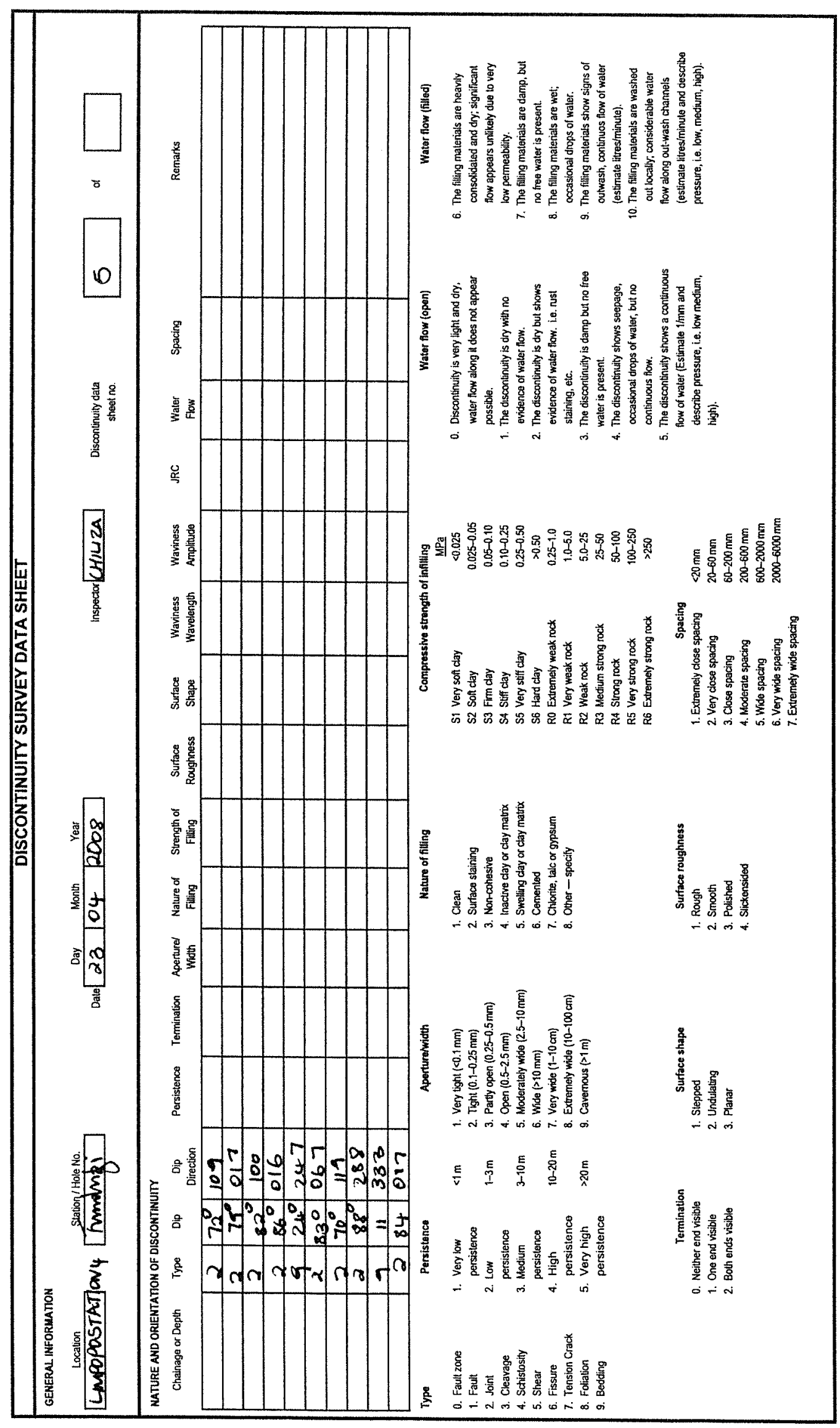




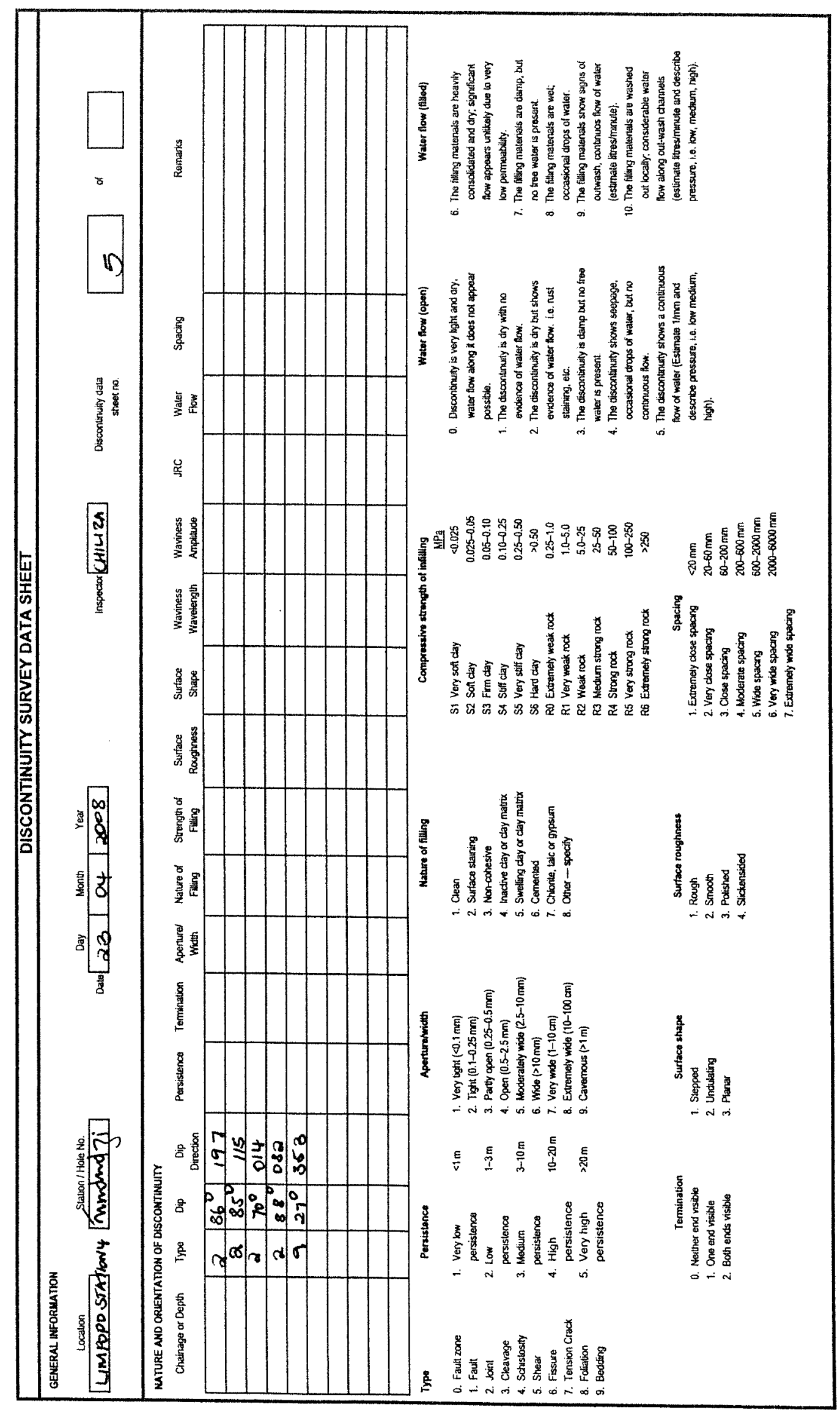




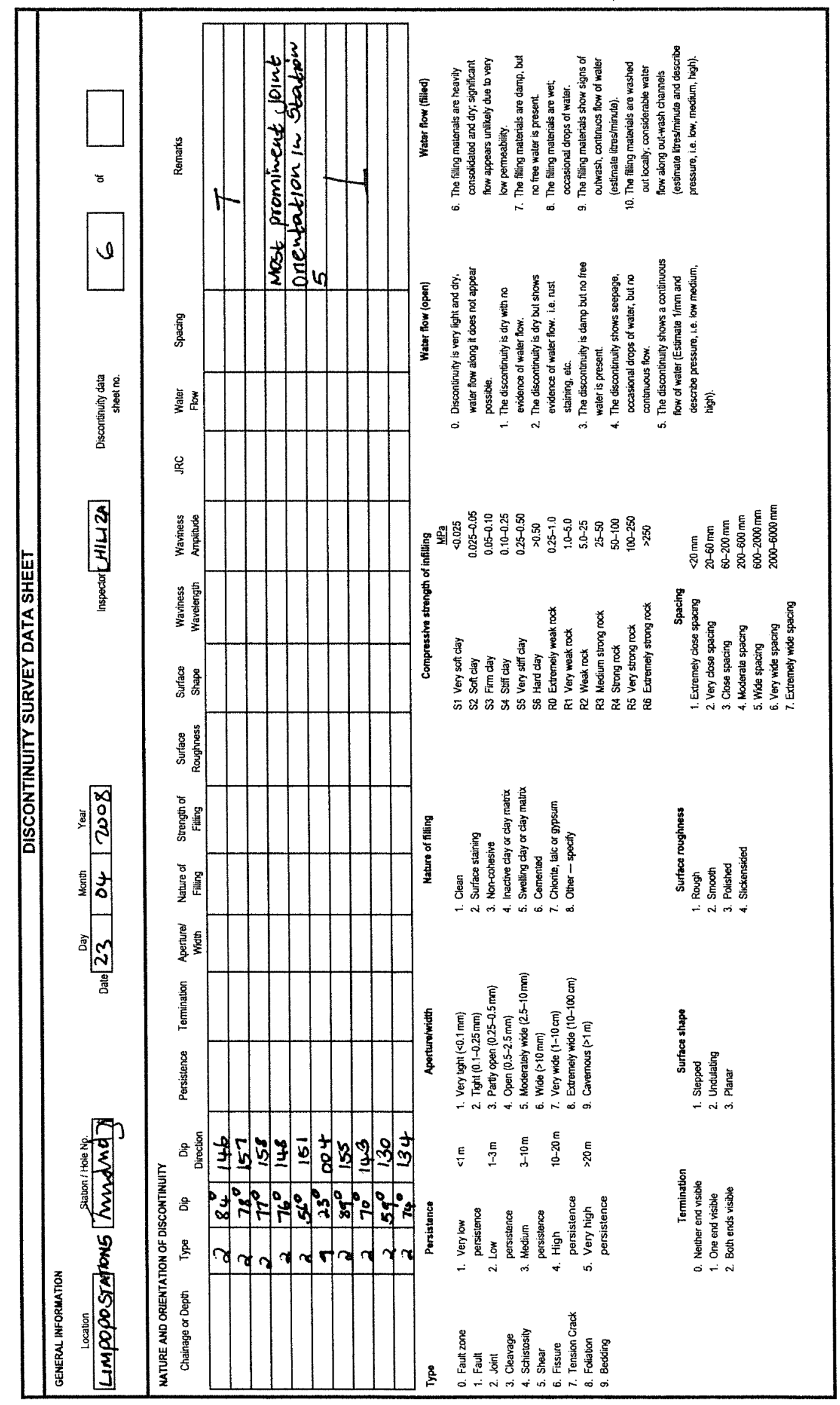




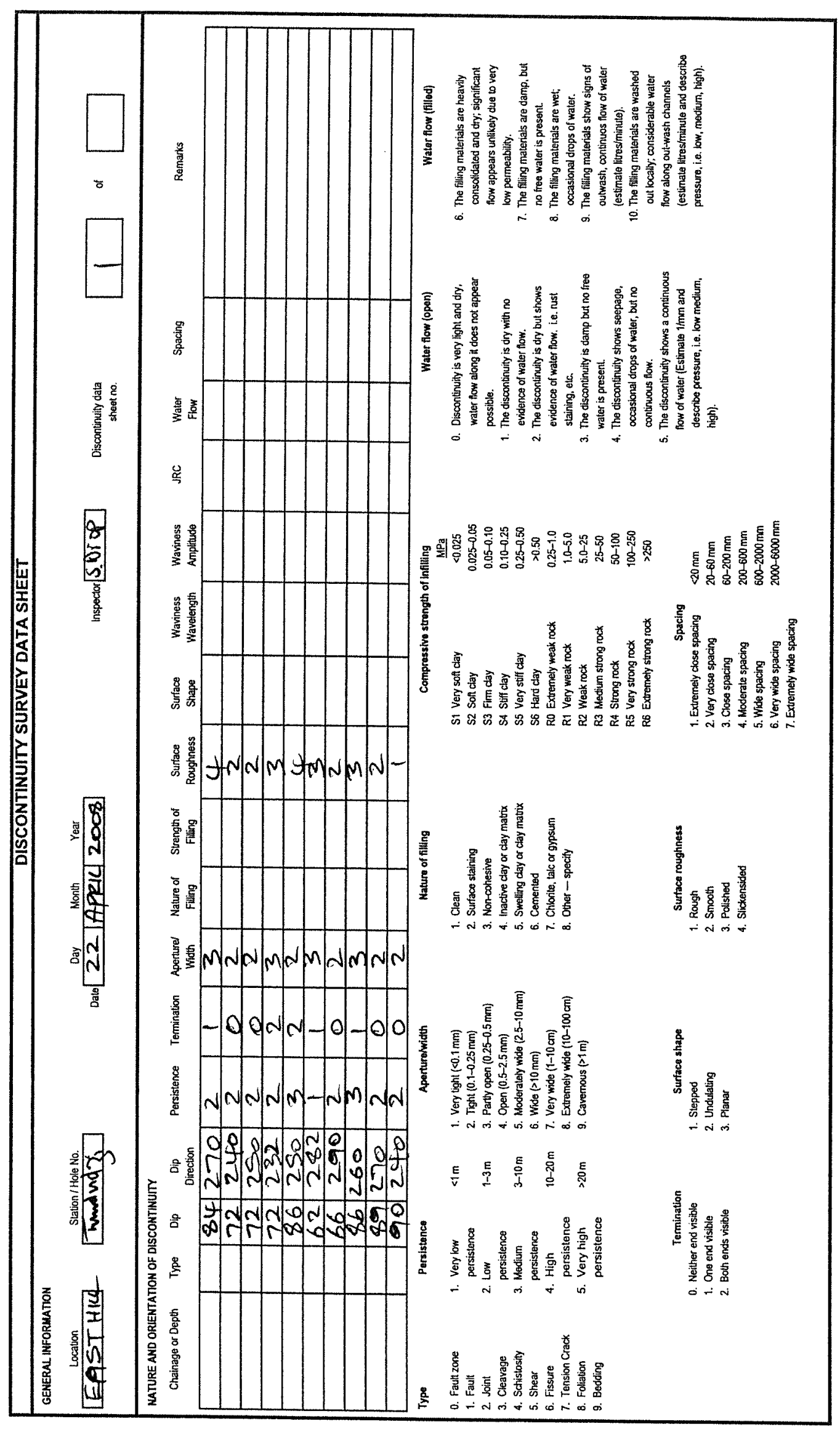




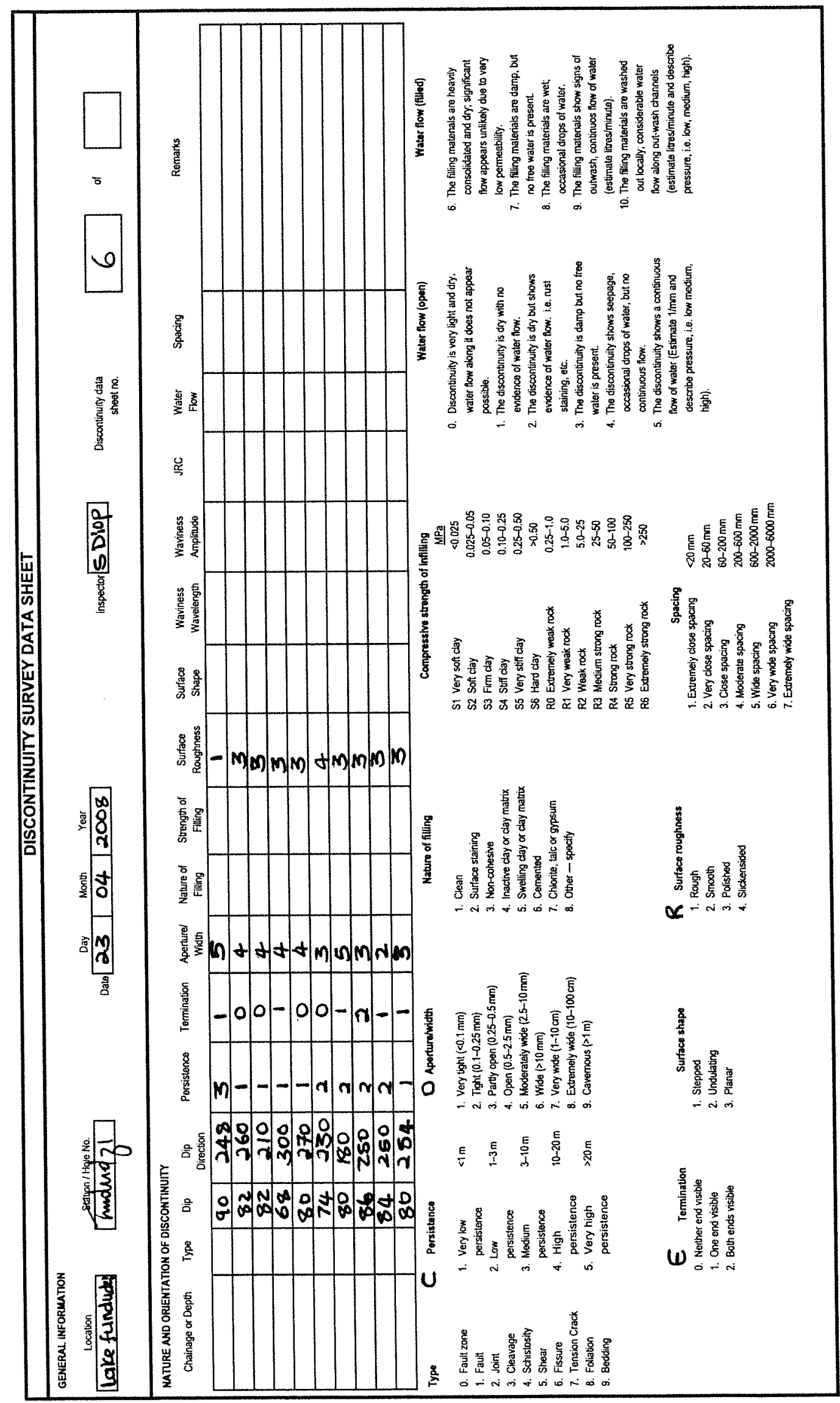




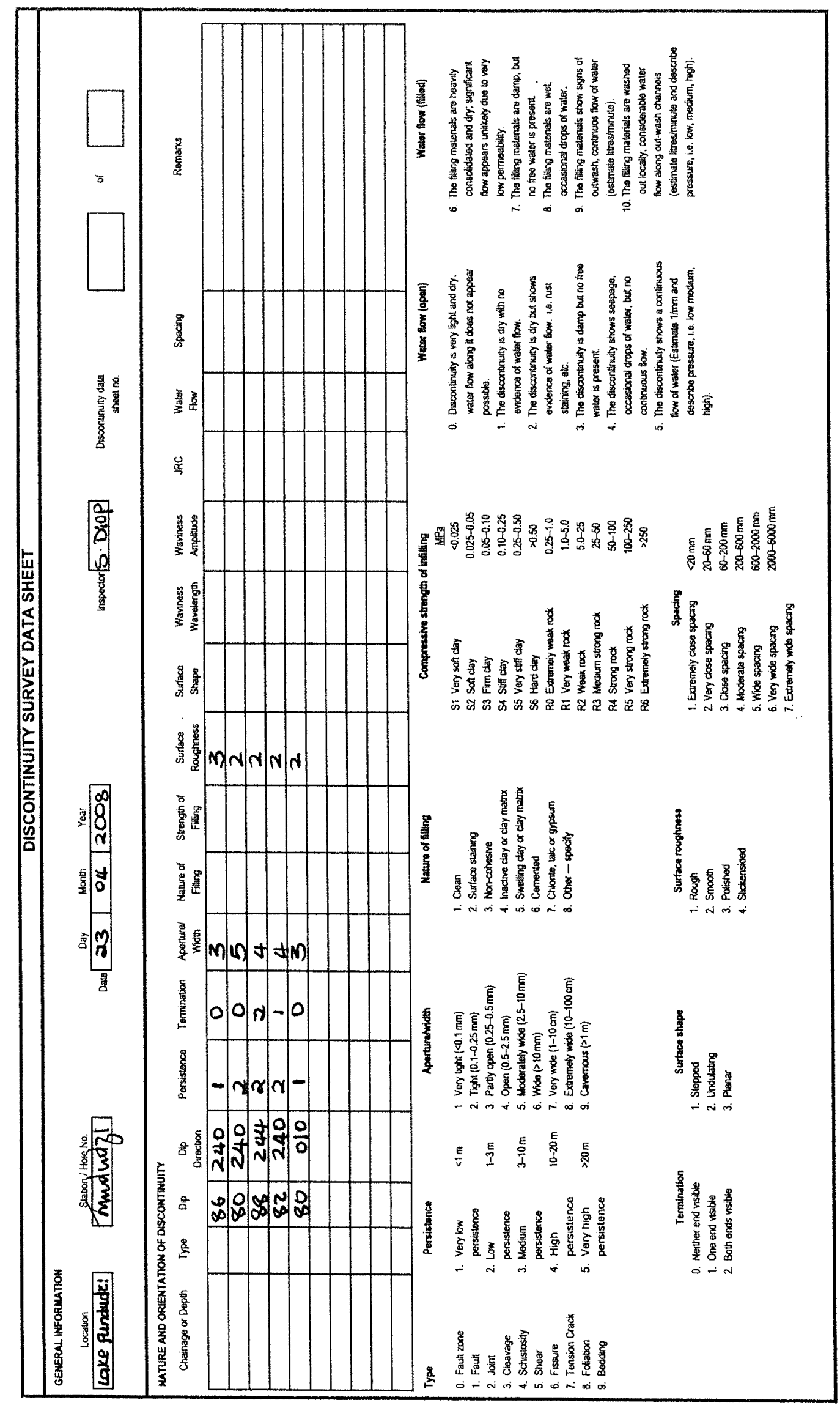




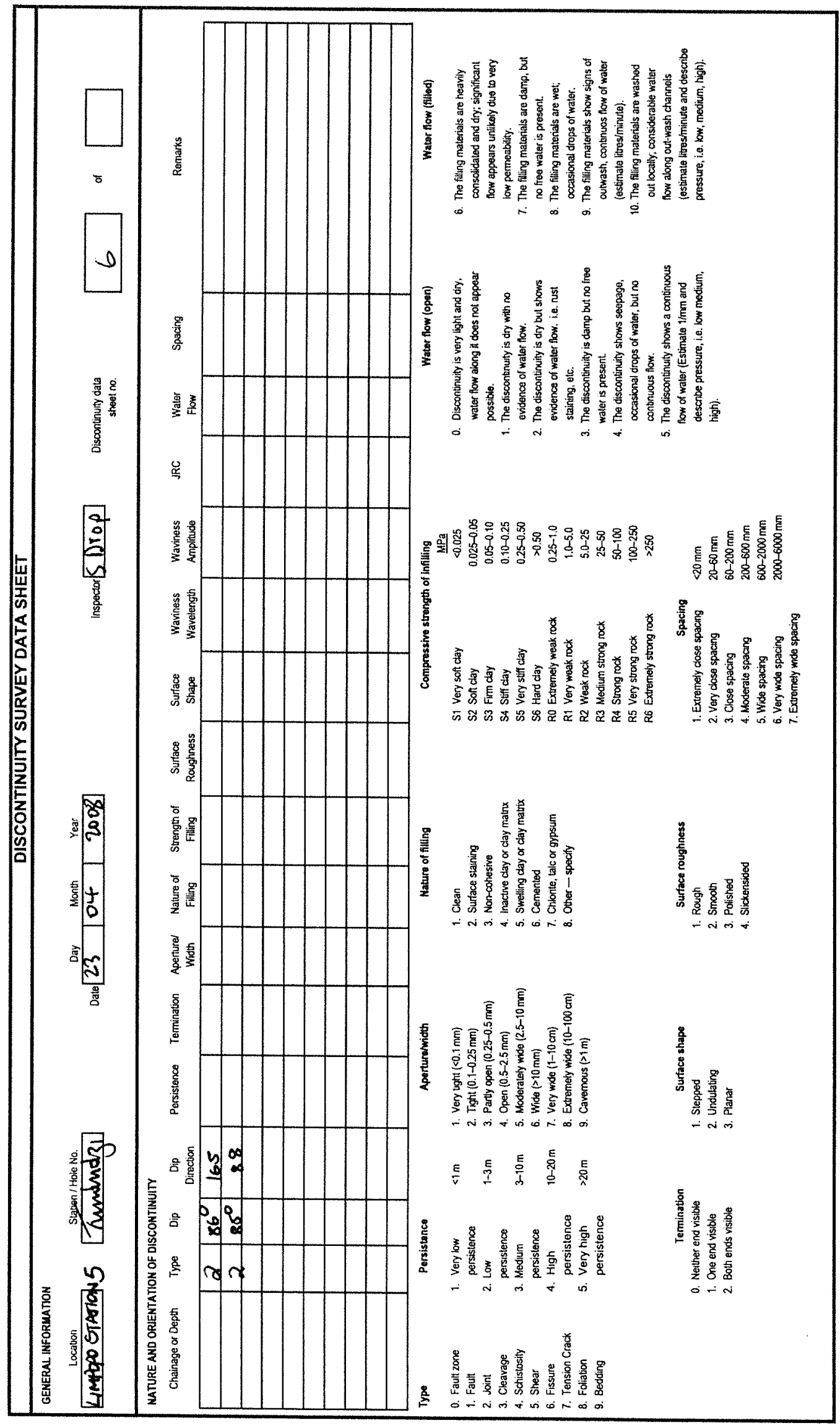




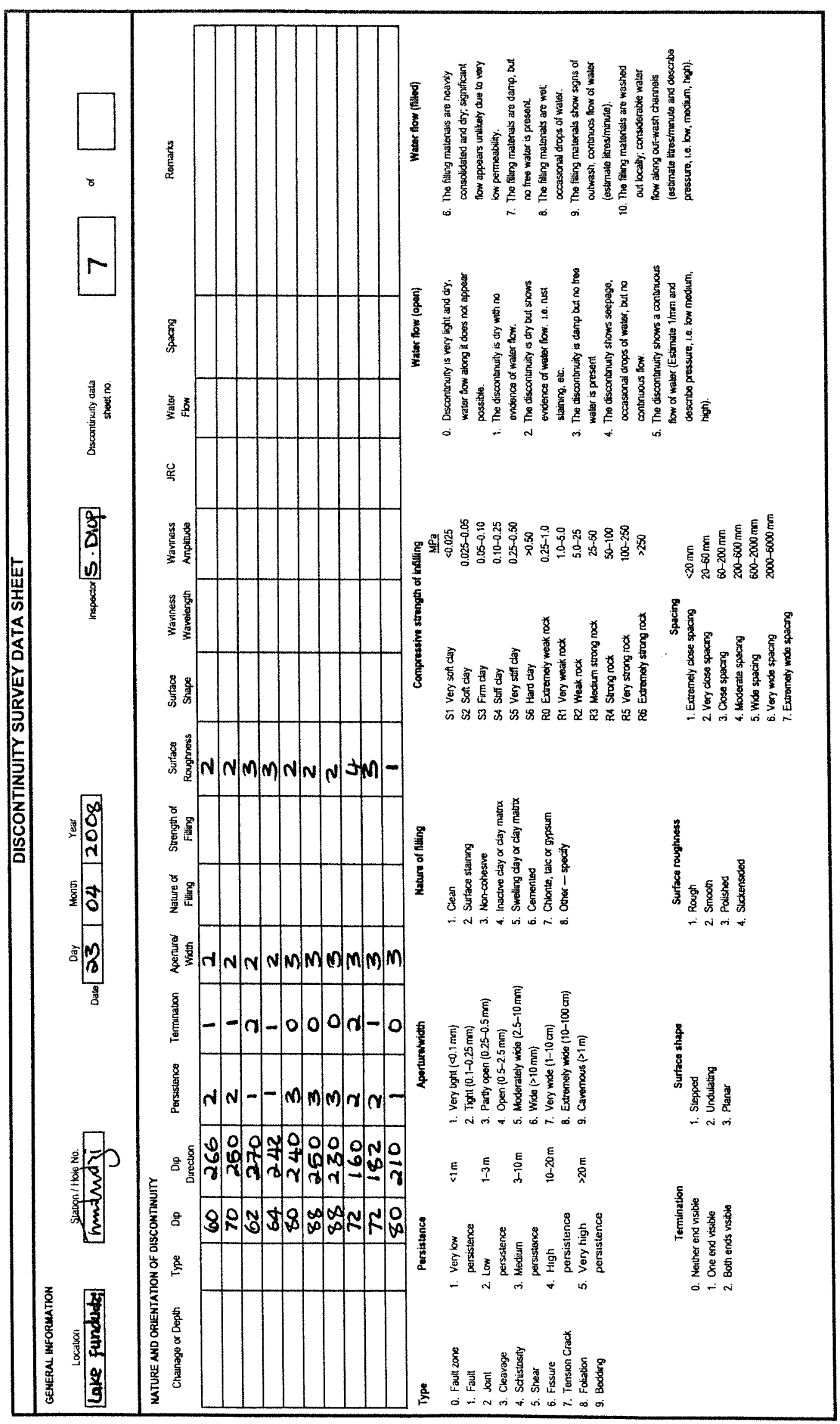




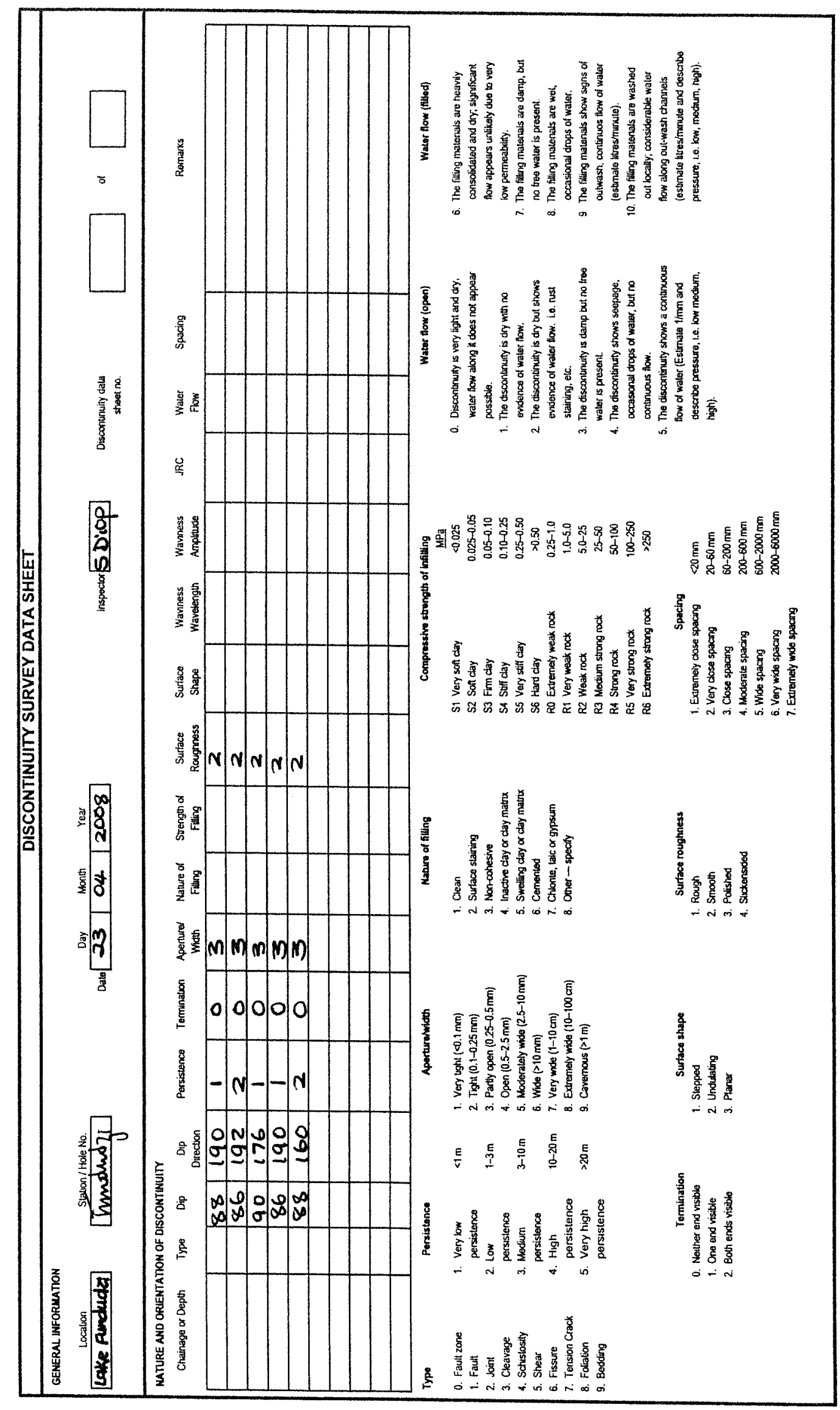




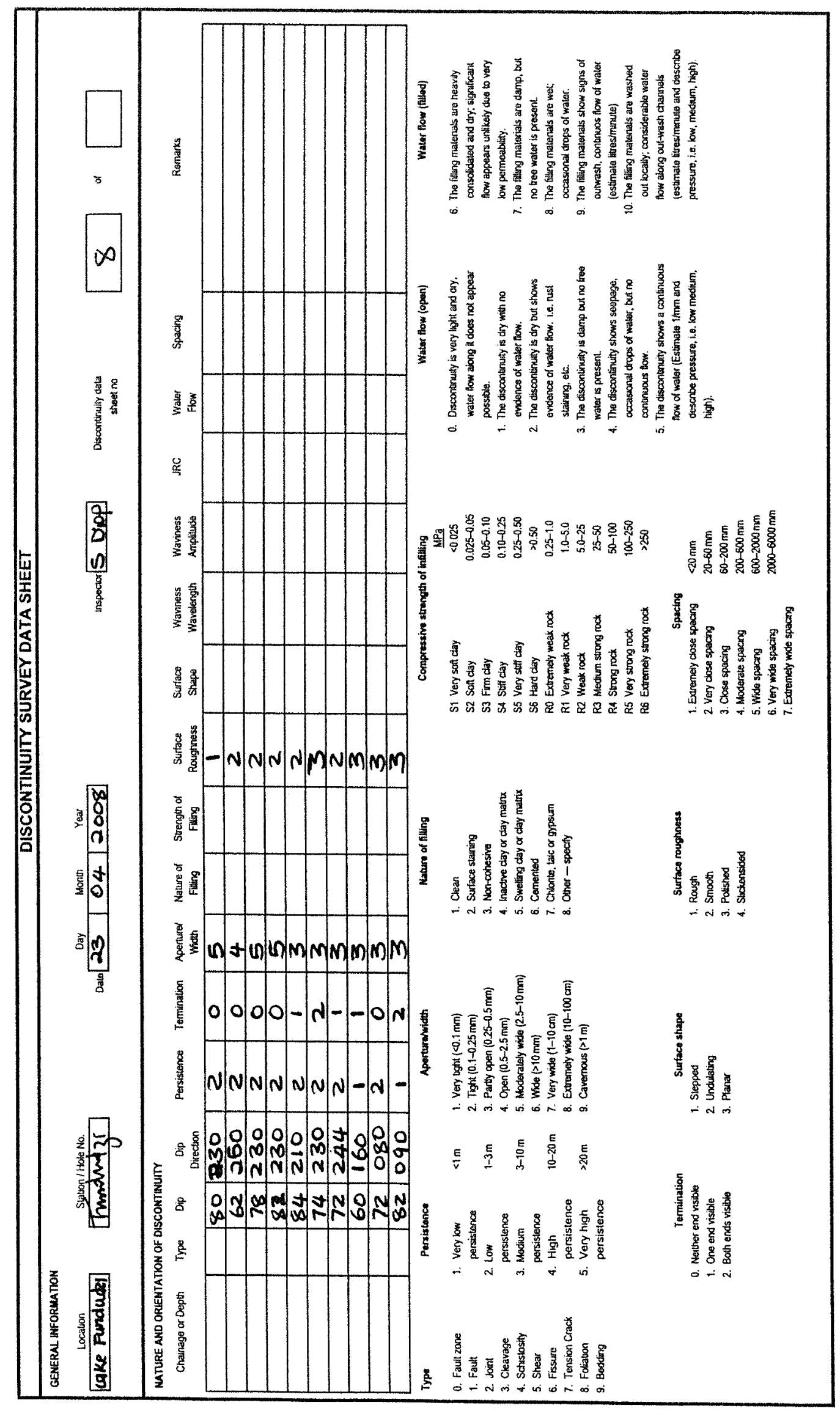




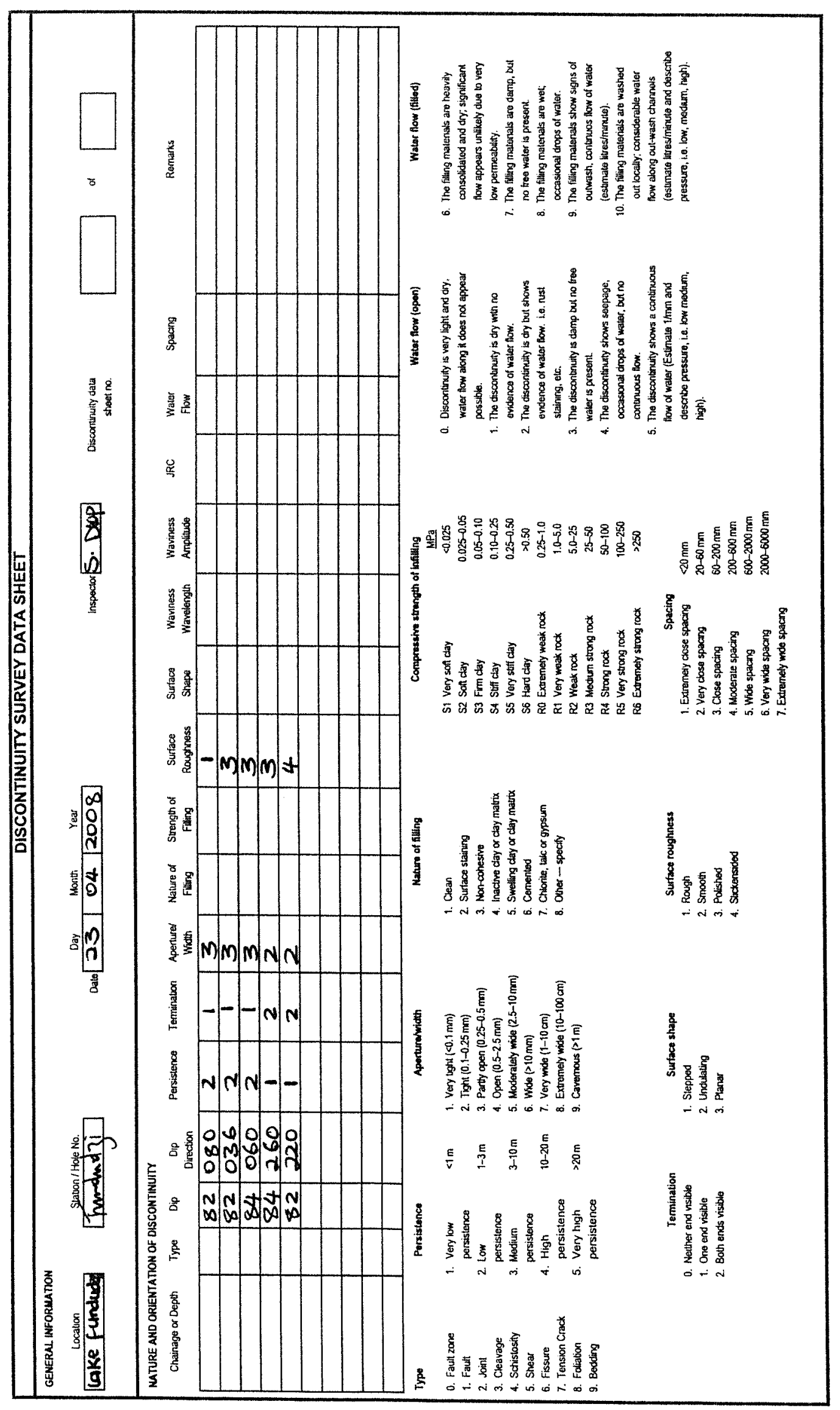




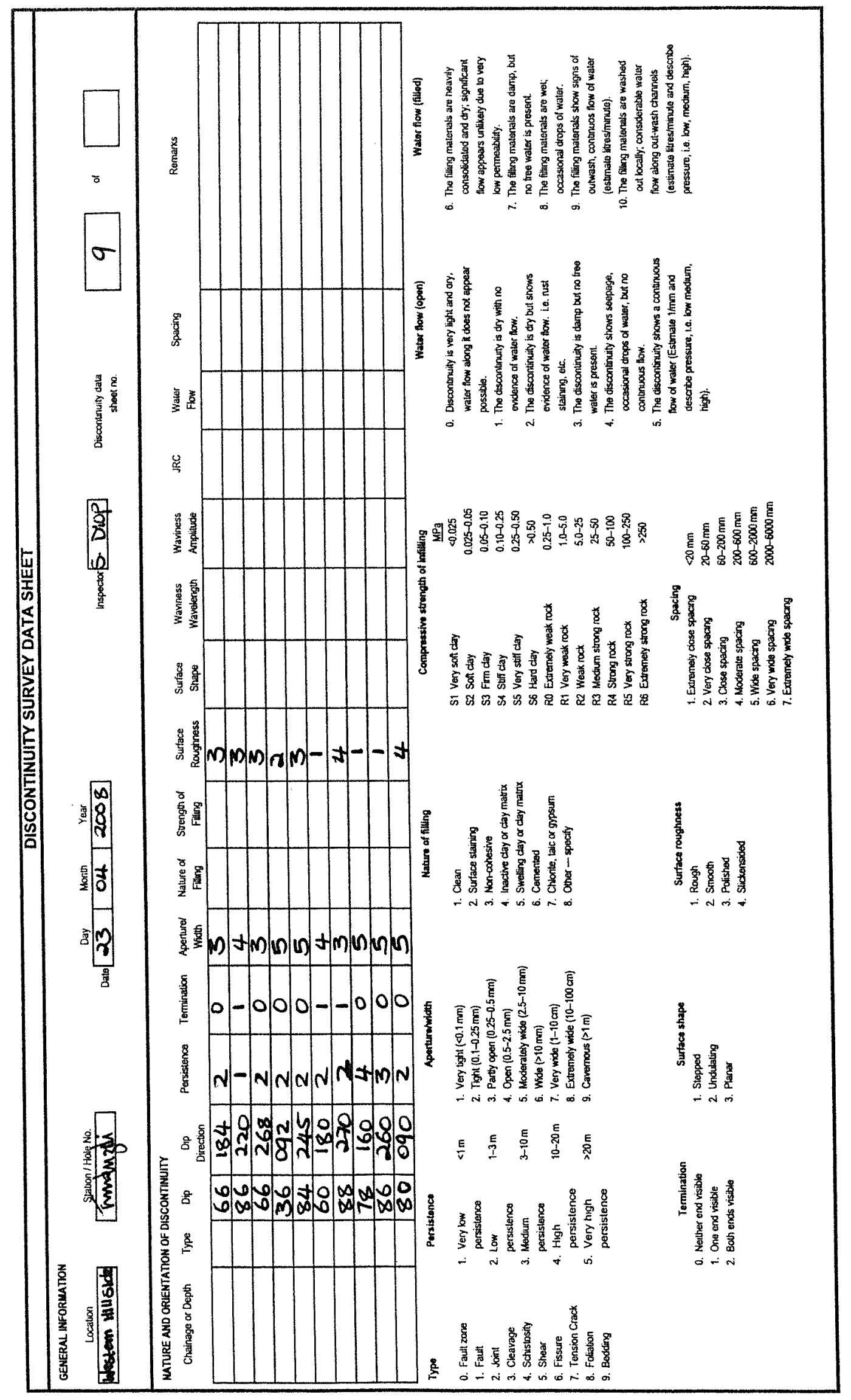









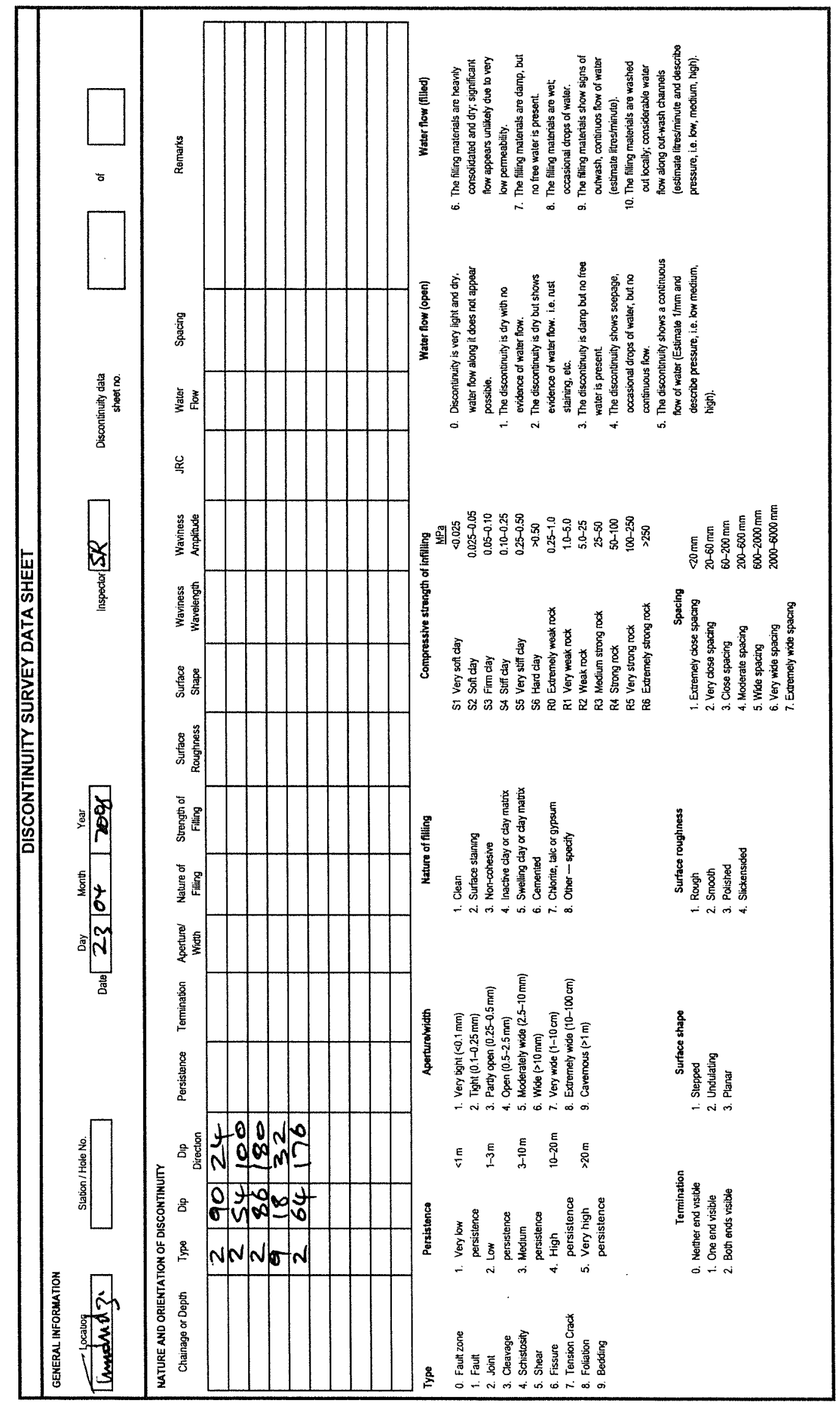




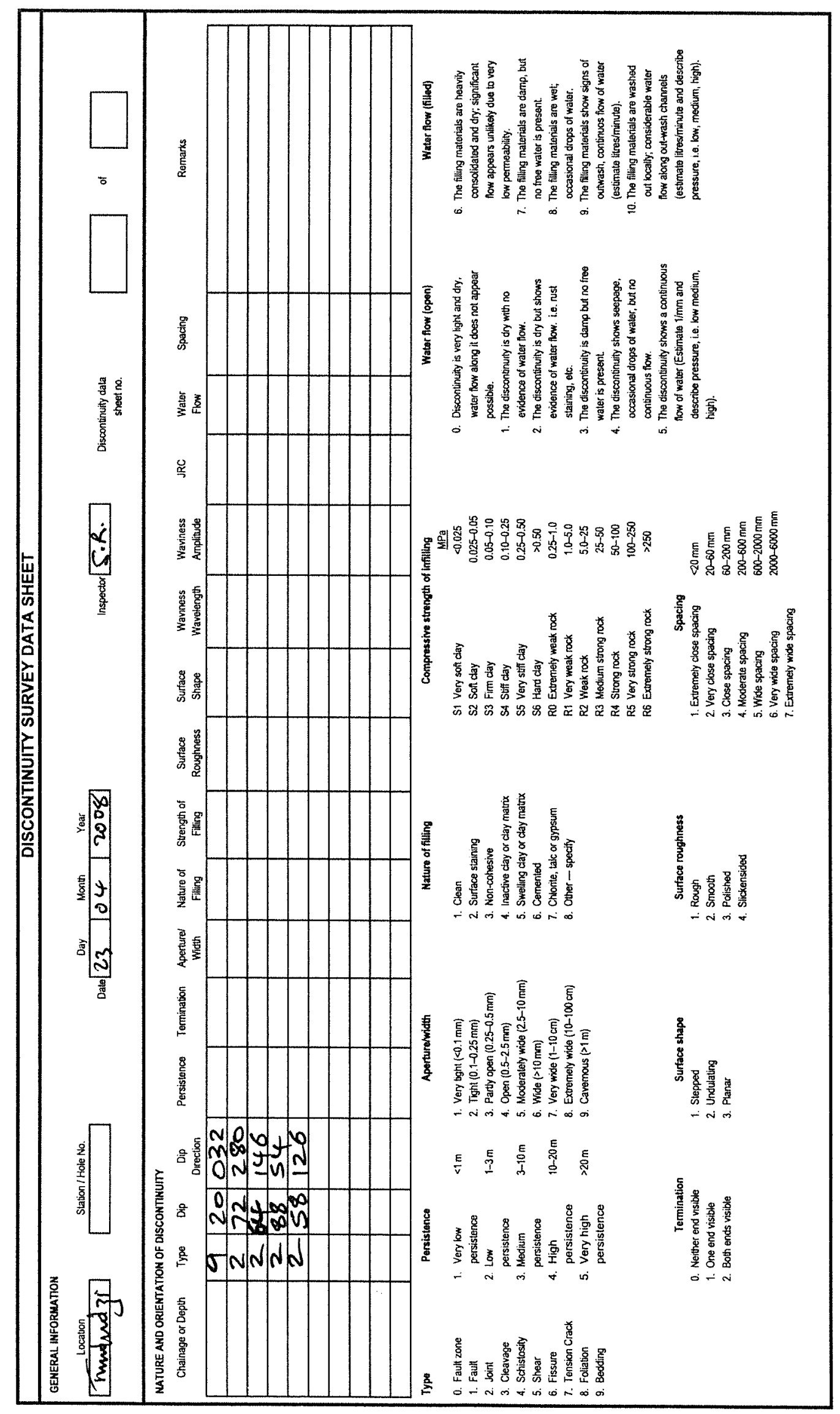




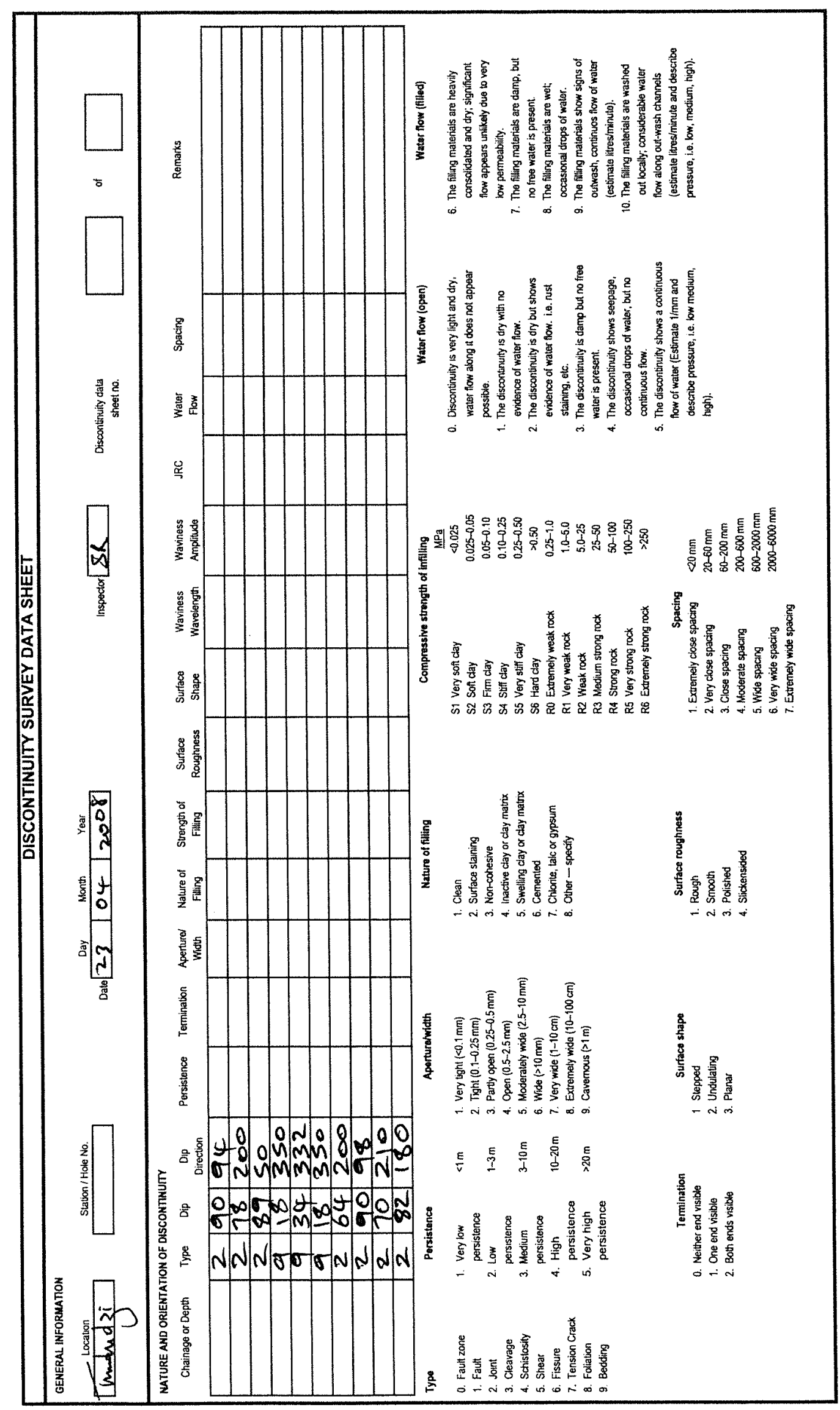




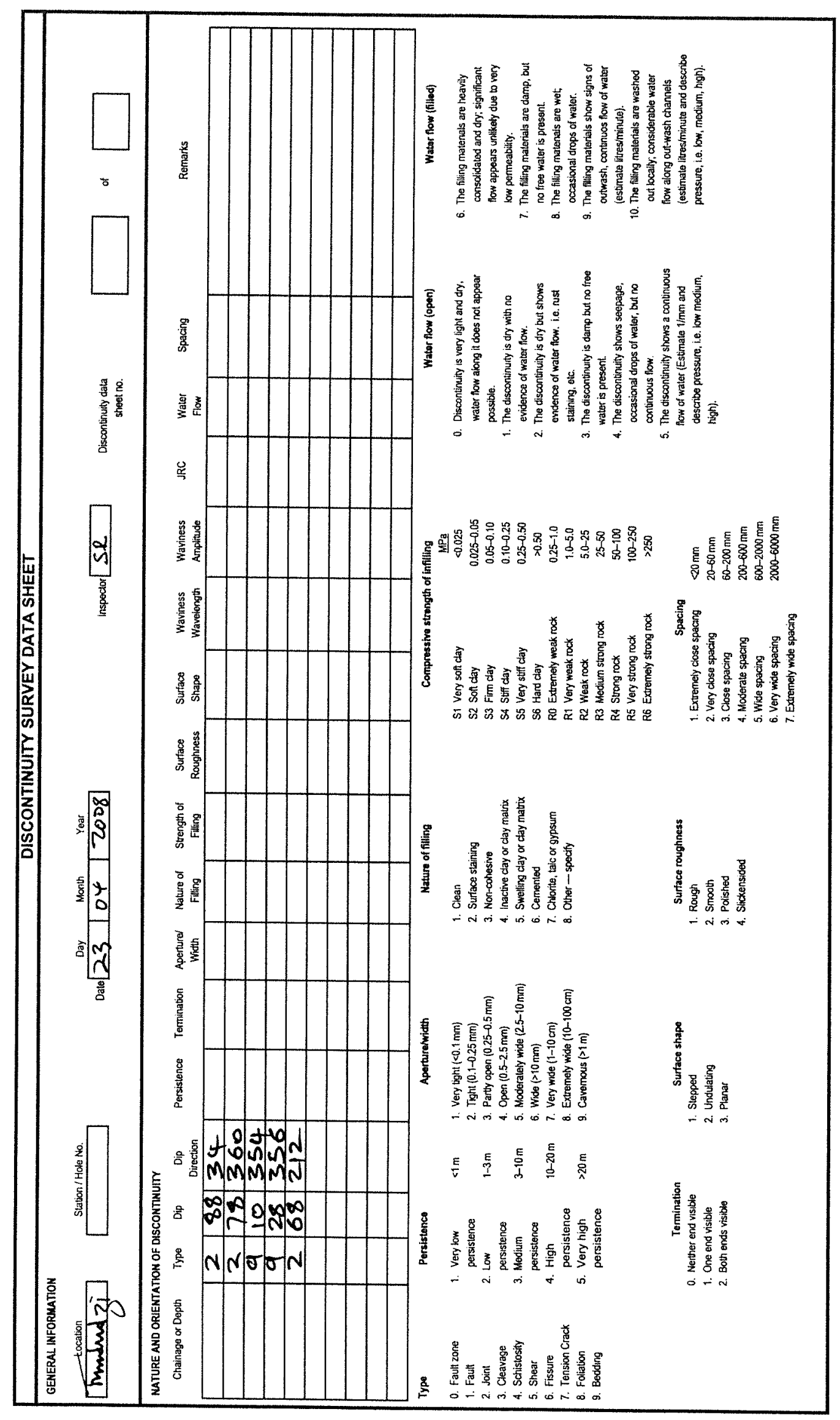




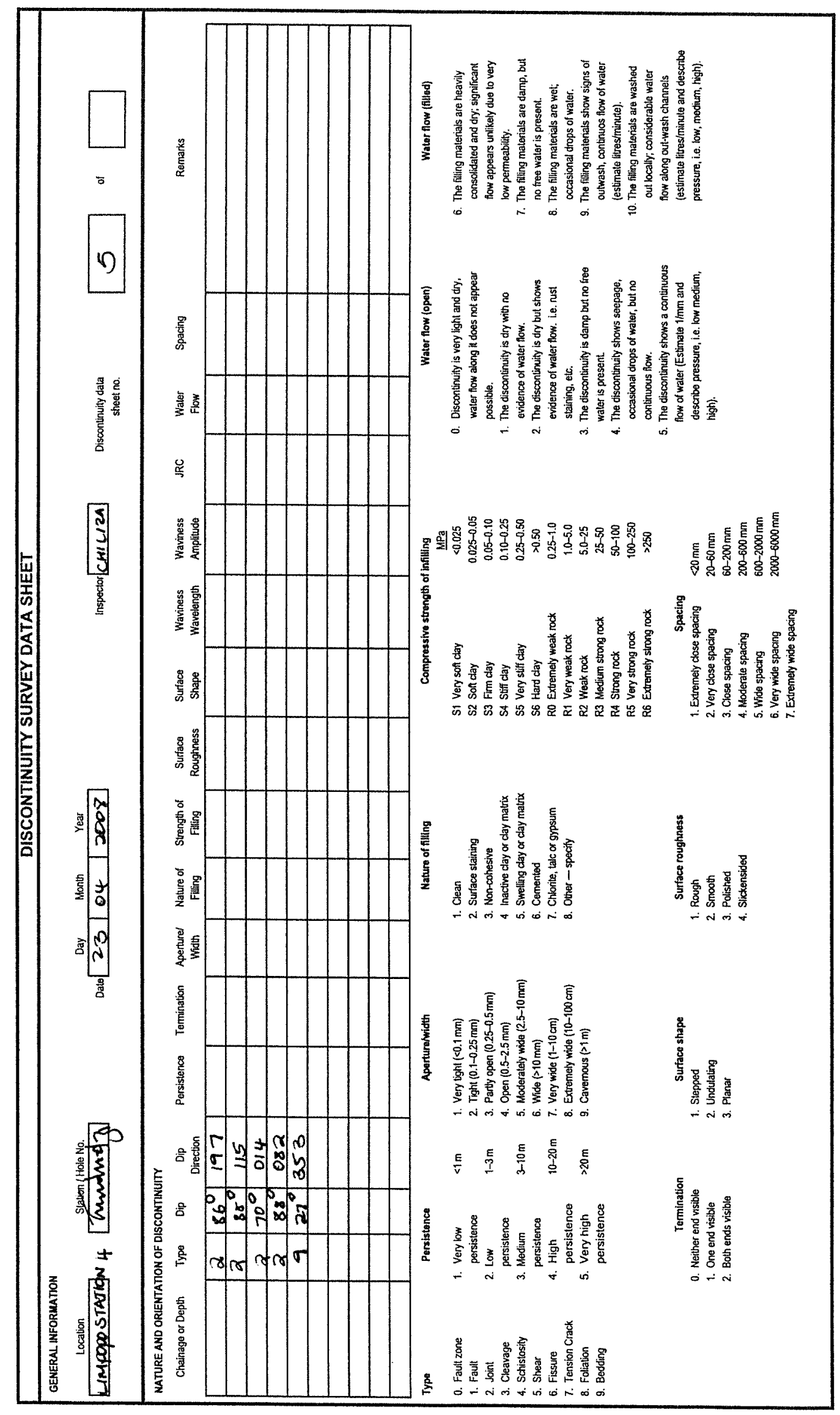




\section{Appendix B:}

Core sample list

\section{Unit weight measurements}

UCS tests

Schmidt hardness rebound tests

Point load tests

Tilt angle tests

Indirect tensile strength (Brazilian) tests 
1. Core samples list

\begin{tabular}{|c|c|c|c|}
\hline Sample number & Mass $\mathbf{( g )}$ & Length $(\mathbf{m m})$ & Diameter $(\mathbf{m m})$ \\
\hline UC01 & 705.7 & 107.6 & 53.5 \\
\hline UC02 & 727.3 & 110.8 & 53.5 \\
\hline UC03 & 705.8 & 107.8 & 53.5 \\
\hline UC04 & 706.4 & 108.0 & 53.5 \\
\hline UC05 & 720.3 & 110.0 & 53.5 \\
\hline
\end{tabular}

2. Unit weight measurements and results

\begin{tabular}{|c|c|c|c|c|}
\hline $\begin{array}{l}\text { Sample } \\
\text { number }\end{array}$ & Mass (g) & $\begin{array}{c}\text { Volume } \\
\left(\pi r^{2} h\right)\end{array}$ & Unit Weight $\mathrm{g} / \mathrm{cm}^{3}$ & Unit Weight $\left(\mathrm{kN} / \mathrm{m}^{3}\right)$ \\
\hline UC01 & 705.7 & 241.76 & 2.92 & 28.62 \\
\hline $\mathrm{UC02}$ & 727.3 & 248.95 & 2.92 & 28.64 \\
\hline UC03 & 705.8 & 242.21 & 2.91 & 28.57 \\
\hline UC04 & 706.4 & 242.66 & 2.91 & 28.54 \\
\hline UC05 & 720.3 & 247.16 & 2.91 & 28.57 \\
\hline
\end{tabular}

\section{UCS test results}

\begin{tabular}{|c|c|c|c|}
\hline Sample number & $\begin{array}{c}\text { Maximum load } \\
\mathbf{( k N}\end{array}$ & $\begin{array}{c}\text { Cross sectional area } \\
\left(\mathbf{m m}^{\mathbf{2}}\right)\end{array}$ & $\begin{array}{c}\text { Unconfined Compressive } \\
\text { Strength (UCS) } \\
\mathbf{M P a}\end{array}$ \\
\hline UC01 & 384157 & 2248 & 170 \\
\hline UC02 & 522010 & 2248 & 232 \\
\hline UC03 & 325635 & 2248 & 145 \\
\hline UC04 & 332220 & 2248 & 250 \\
\hline UC05 & 562034 & 2248 & 148 \\
\hline
\end{tabular}




\section{Schmidt hardness rebound tests}

\begin{tabular}{|c|c|c|c|c|}
\hline \multirow{2}{*}{$\begin{array}{l}\text { Estimates of joint } \\
\text { wall compressive } \\
\text { strength (JCS) } \\
\text { from Schmidt } \\
\text { hammer - Type L } \\
\text { (Orientation) }\end{array}$} & \multicolumn{2}{|c|}{ Schimdt Rebound Values (R) } & \multicolumn{2}{|c|}{ UCS } \\
\hline & Horizontal & Vertical down & Horizontal & Vertical down \\
\hline$\rightarrow$ & 44 & 38 & 110 & 100 \\
\hline$\rightarrow$ & 42 & 38 & 85 & 100 \\
\hline$\rightarrow$ & 30 & 34 & 50 & 85 \\
\hline$\rightarrow$ & 46 & 28 & 110 & 60 \\
\hline$\downarrow$ & 32 & 32 & 50 & 64 \\
\hline$\downarrow$ & 40 & 48 & 83 & 130 \\
\hline$\rightarrow$ & 42 & 50 & 86 & 135 \\
\hline$\rightarrow$ & 32 & 32 & 52 & 52 \\
\hline$\rightarrow$ & 32 & 32 & 64 & 58 \\
\hline$\rightarrow$ & 36 & 32 & 64 & 58 \\
\hline$\downarrow$ & 48 & 44 & 130 & 106 \\
\hline$\downarrow$ & 46 & 32 & 125 & 50 \\
\hline$\downarrow$ & 40 & 32 & 85 & 50 \\
\hline$\rightarrow$ & 32 & 42 & 52 & 85 \\
\hline$\rightarrow$ & 28 & 36 & 52 & 64 \\
\hline$\rightarrow$ & 32 & 38 & 50 & 100 \\
\hline$\rightarrow$ & 36 & 38 & 64 & 100 \\
\hline$\downarrow$ & 38 & 37 & 95 & 82 \\
\hline$\downarrow$ & 38 & & 95 & \\
\hline$\downarrow$ & 28 & & 62 & \\
\hline$\rightarrow$ & 36 & & 85 & \\
\hline$\rightarrow$ & 42 & & 95 & \\
\hline$\rightarrow$ & 32 & & 65 & \\
\hline$\downarrow$ & 37 & & 79 & \\
\hline
\end{tabular}




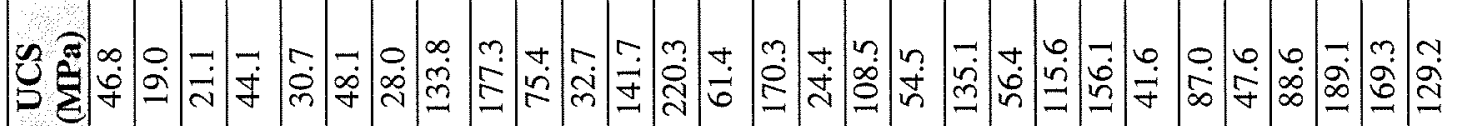

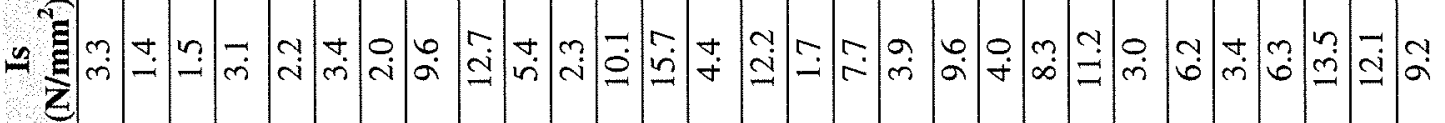

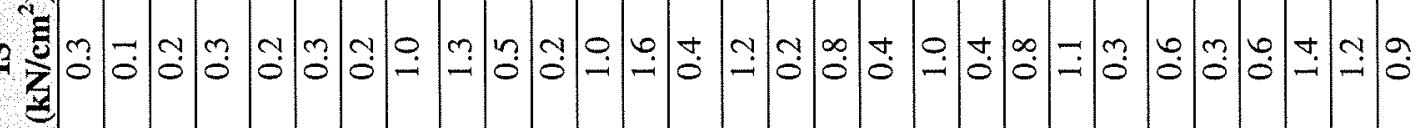

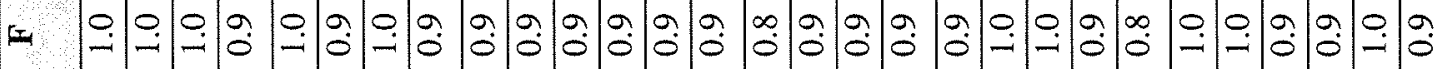

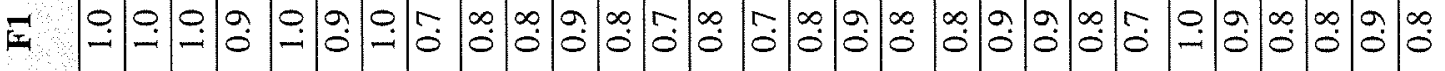

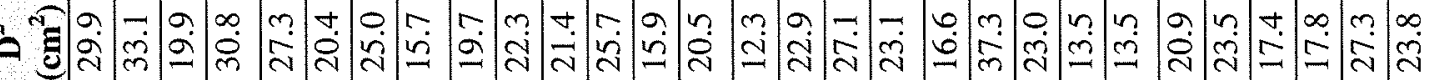

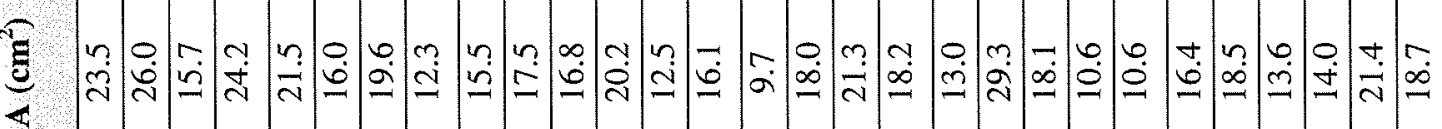

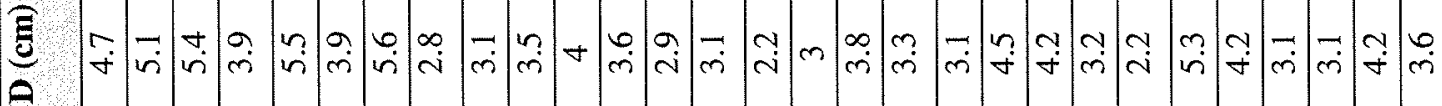

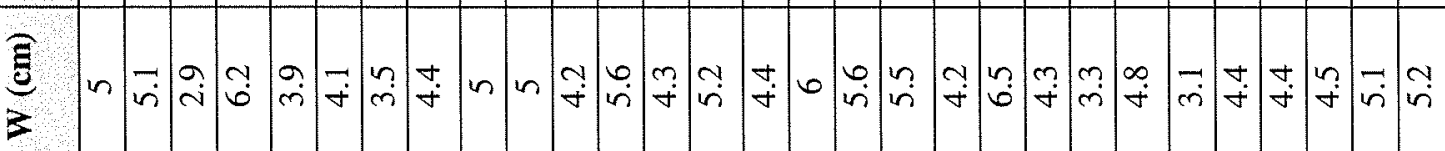

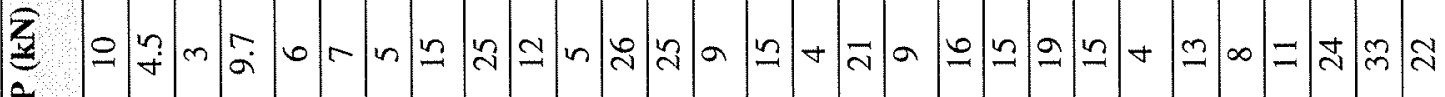

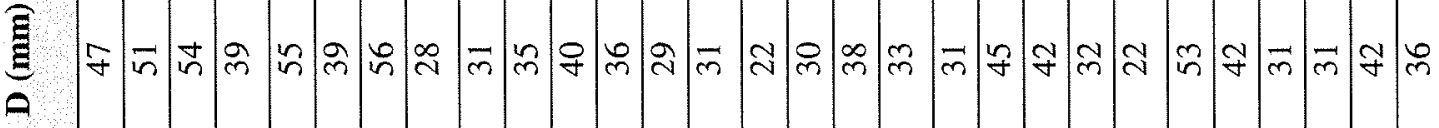

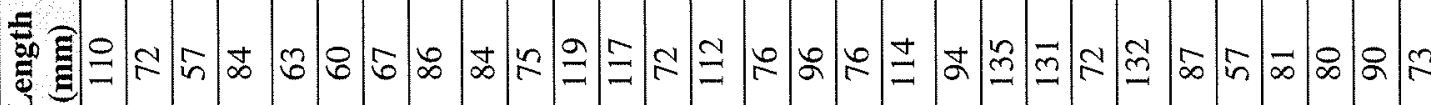

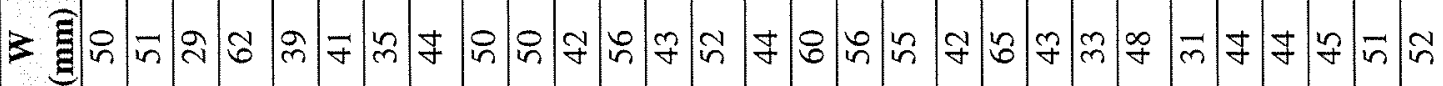

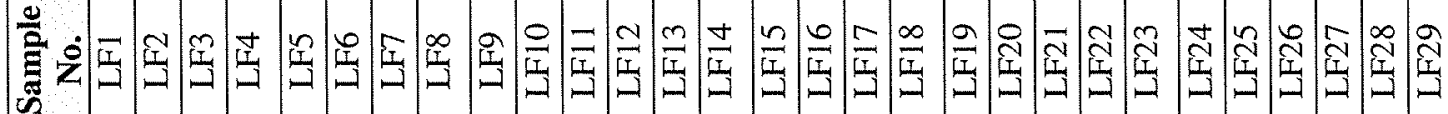


6. Basic friction angle results obtained from tilt angle test

\begin{tabular}{|c|c|c|c|}
\hline Reading & $\begin{array}{l}\Phi_{b} \\
\left({ }^{\circ}\right)\end{array}$ & $\begin{array}{c}\text { Average } \Phi_{b} \\
\left({ }^{\circ}\right)\end{array}$ & $\begin{array}{c}\text { Average sandstone } \phi_{\mathrm{b}} \text { value } \\
\left({ }^{\circ}\right) \\
\text { (after Barton and Choubey, } \\
1977)\end{array}$ \\
\hline 1 & 31 & \multirow{15}{*}{26.5} & \multirow{15}{*}{$26-35$} \\
\hline 2 & 30 & & \\
\hline 3 & 26 & & \\
\hline 4 & 27 & & \\
\hline 5 & 29 & & \\
\hline 6 & 26 & & \\
\hline 7 & 25 & & \\
\hline 8 & 26 & & \\
\hline 9 & 25 & & \\
\hline 10 & 26 & & \\
\hline 11 & 26 & & \\
\hline 12 & 25 & & \\
\hline 13 & 25 & & \\
\hline 14 & 25 & & \\
\hline 15 & 26 & & \\
\hline
\end{tabular}

7. Indirect tensile (Brazilian) strength results

\begin{tabular}{|c|c|c|c|c|c|c|}
\hline $\begin{array}{l}\text { Sample } \\
\text { number }\end{array}$ & $\begin{array}{c}\text { Diameter } \\
(\mathbf{m})\end{array}$ & $\begin{array}{c}\text { Length } \\
(\mathrm{mm})\end{array}$ & $\begin{array}{c}\begin{array}{c}\text { Pressure at } \\
\text { failure } \\
\text { (MPa) }\end{array} \\
\end{array}$ & $\begin{array}{c}\operatorname{Ram} \\
\operatorname{area}\left(\mathbf{m}^{2}\right)\end{array}$ & $\begin{array}{l}\text { Load at } \\
\text { failure }\end{array}$ & $\begin{array}{c}\text { Brazilian disk } \\
\text { strength } \\
\text { (MPa) }\end{array}$ \\
\hline BD01 & 0.0535 & 0.024 & 3.12 & 0.005027 & 0.0156842 & 7.8 \\
\hline $\mathrm{BD} 02$ & 0.0535 & 0.0255 & 2.5 & 0.005027 & 0.0125675 & 5.9 \\
\hline $\mathrm{BD} 03$ & 0.0535 & 0.0245 & 2.65 & 0.005027 & 0.0133216 & 6.5 \\
\hline BD04 & 0.0535 & 0.02 & 1.81 & 0.005027 & 0.0090989 & 5.4 \\
\hline BD05 & 0.0535 & 0.0295 & 2.01 & 0.005027 & 0.0101043 & 4.1 \\
\hline BD06 & 0.0535 & 0.025 & 1.93 & 0.005027 & 0.0097021 & 4.6 \\
\hline
\end{tabular}


Appendix C:

Golder shear box tests 


\begin{tabular}{|c|c|c|}
\hline \multicolumn{2}{|c|}{ Golder shear box tests sample list and hanger loading weights } \\
\hline Sample Number & Area $\mathbf{~ ( m}^{\mathbf{2}}$ ) & Visually estimated JRC \\
\hline GSB 1a & 0.00368 & 9 \\
\hline GSB 1b & 0.00386 & 9 \\
\hline GSB 2 & 0.00304 & 10 \\
\hline GSB 3 & 0.00159 & 9 \\
\hline GSB 4 & 0.00242 & 13 \\
\hline GSB 5a & 0.00337 & 11 \\
\hline GSB 5b & 0.00337 & 11 \\
\hline
\end{tabular}

Determination of Hanger Loading weight for testing at $0.5 \mathrm{MPa}$ for each joint.

Load versus weight on hanger regression analysis equation

$\mathrm{Y}=\mathbf{0 . 1 1 2 2 0 7 x}+$

0.156859

Where,

$\mathrm{x}=$ weight in Hanger

$(\mathrm{kg})$

$\mathrm{Y}=\operatorname{Load}(\mathrm{MPa})$

$x$ for (GSB 1a)

Weight on Hanger (kg)

$x$ for (GSB 1b)

15.0

$x$ for (GSB 2)

15.8

$x$ for (GSB 3)

12.1

$x$ for (GSB 4)

5.7

$x$ for (GSB 5)

9.4

$x$ for (GSB 5)

13.6

13.6 
GSB 1a

\begin{tabular}{|c|c|c|}
\hline Horizontal displacement & Vertical displacement & Shear Stress (MPa) \\
\hline 0 & 0 & 0 \\
\hline 1 & 0.04 & 0.17 \\
\hline 2 & 0.03 & 0.22 \\
\hline 3 & 0.03 & 0.29 \\
\hline 4 & -0.09 & 0.31 \\
\hline 5 & -0.32 & 0.31 \\
\hline 6 & -0.52 & 0.32 \\
\hline 7 & -0.80 & 0.29 \\
\hline 8 & -0.80 & 0.26 \\
\hline 9 & & 0.24 \\
\hline 10 & & 0.22 \\
\hline 11 & & 0.22 \\
\hline 12 & & 0.21 \\
\hline
\end{tabular}




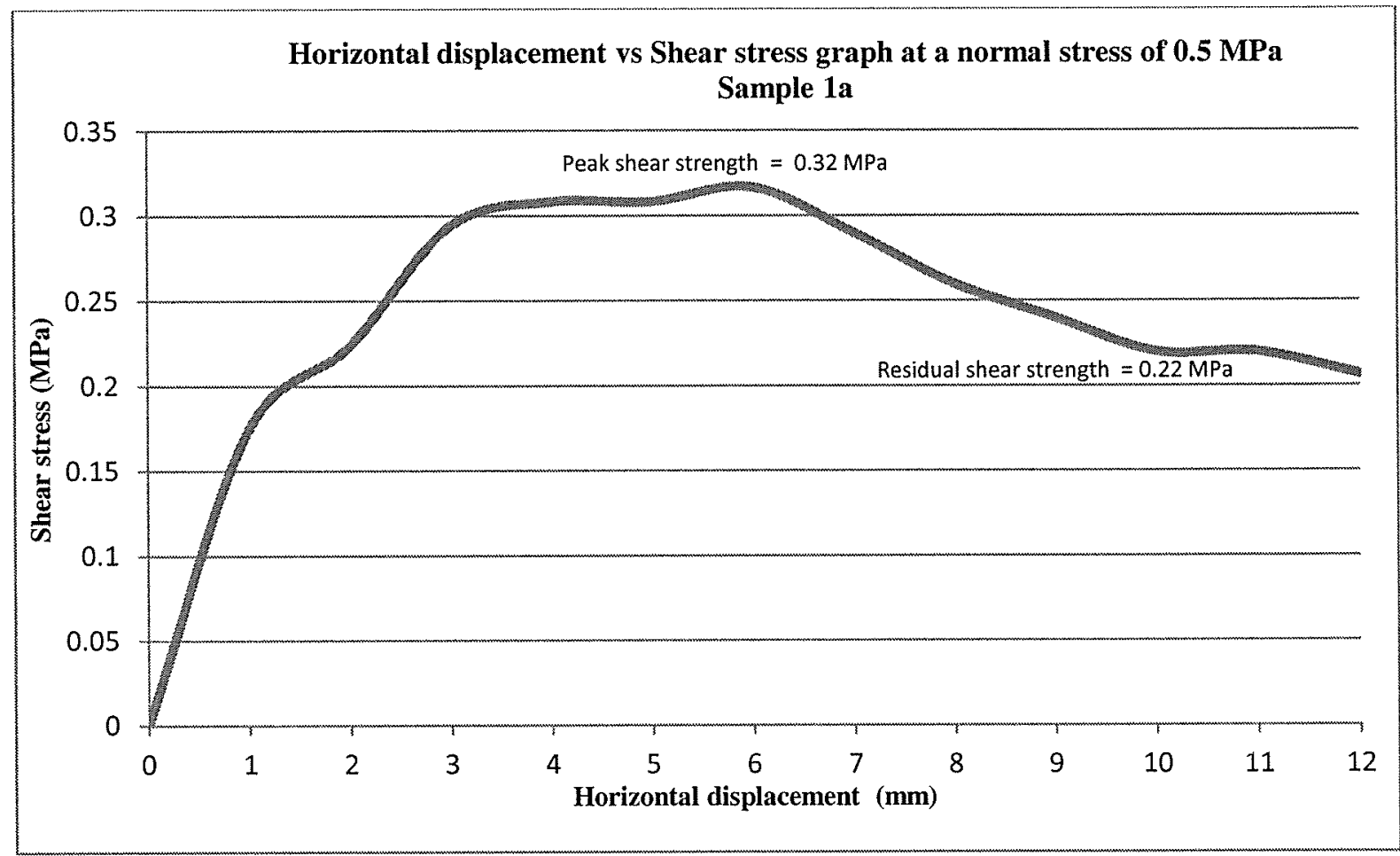

Horizontal displacement versus Vertical displacement graph at a normal stress of 0.5 MPa Sample GSB 1a

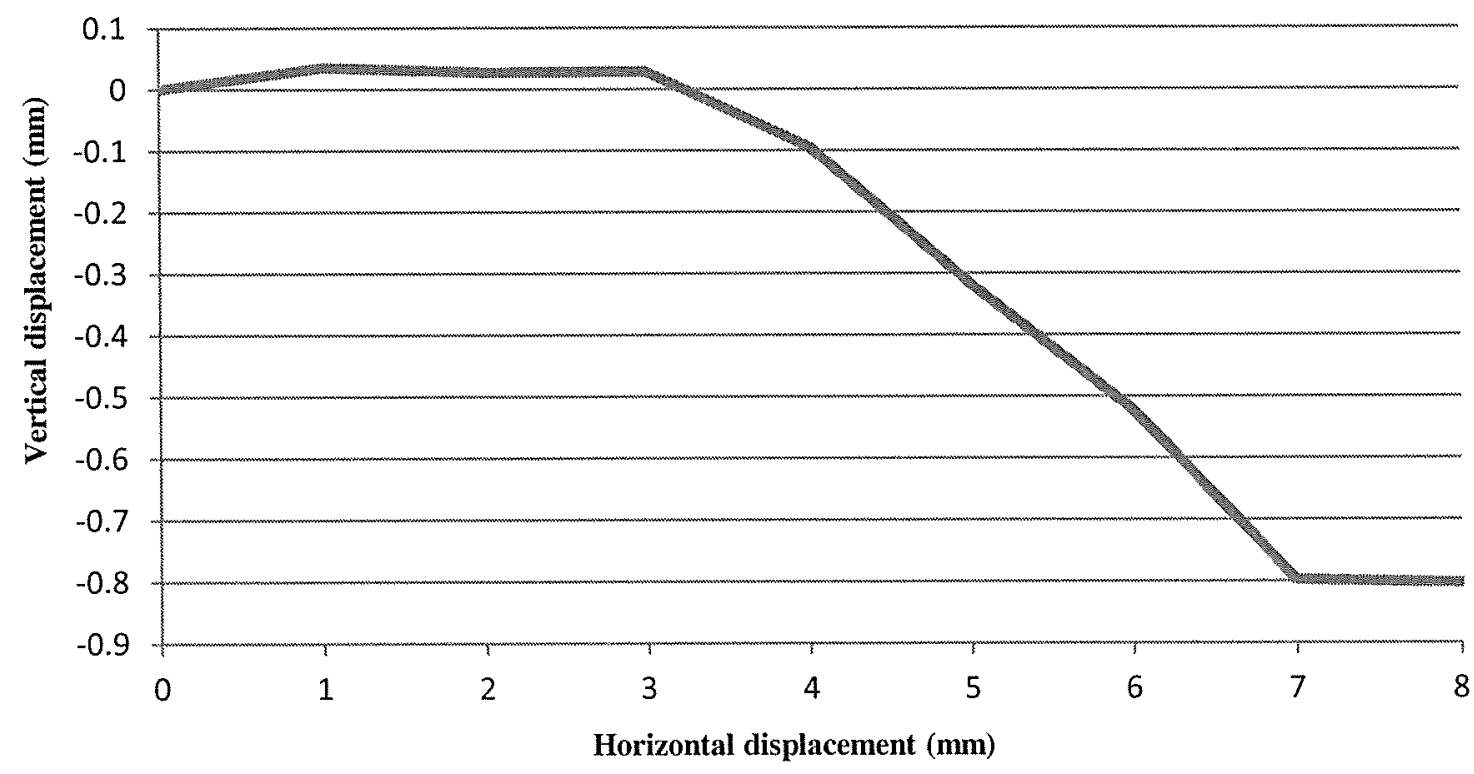


GSB 1b

\begin{tabular}{|c|c|c|}
\hline Horizontal displacement & Vertical displacement & Shear Stress (MPa) \\
\hline 0 & 0 & 0 \\
\hline 1 & 0 & 0.11 \\
\hline 2 & 0 & 0.14 \\
\hline 3 & -0.09 & 0.26 \\
\hline 4 & -0.19 & 0.27 \\
\hline 5 & -0.26 & 0.36 \\
\hline 6 & -0.32 & 0.37 \\
\hline 7 & -0.32 & 0.33 \\
\hline 9 & -0.36 & 0.32 \\
\hline 10 & -0.36 & 0.28 \\
\hline 11 & -0.44 & 0.27 \\
\hline 12 & -0.44 & 0.26 \\
\hline 13 & -0.46 & 0.26 \\
\hline 14 & -0.47 & 0.26 \\
\hline 15 & -0.49 & 0.25 \\
\hline
\end{tabular}



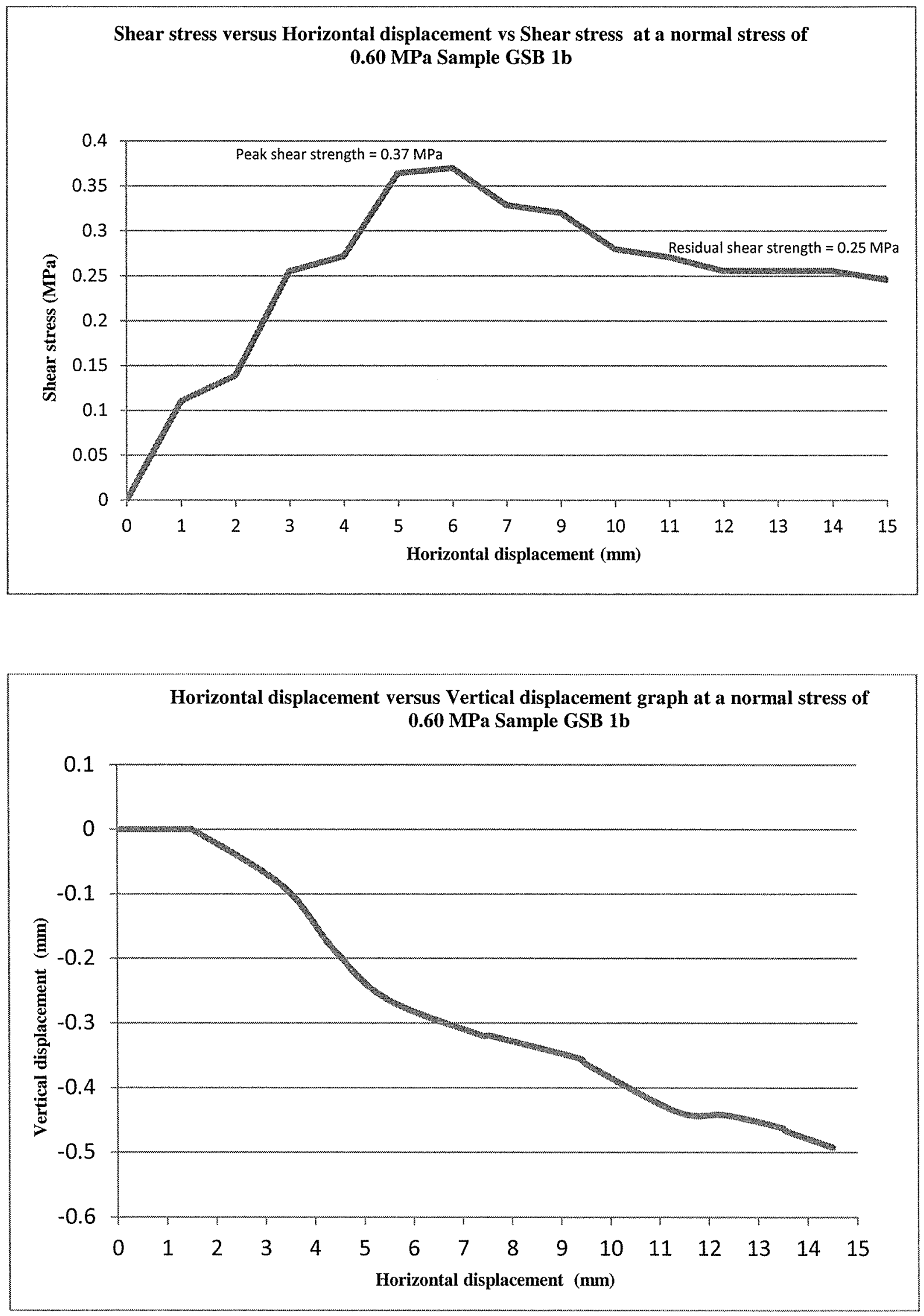


\section{GSB 2}

\begin{tabular}{|c|c|c|}
\hline Horizontal displacement & Vertical displacement & Shear Stress (MPa) \\
\hline 0 & 0.00 & 0.00 \\
\hline 1 & 0.02 & 0.07 \\
\hline 2 & 0.04 & 0.15 \\
\hline 3 & 0.04 & 0.17 \\
\hline 4 & 0.01 & 0.20 \\
\hline 5 & -0.04 & 0.22 \\
\hline 6 & -0.11 & 0.23 \\
\hline 7 & -0.16 & 0.23 \\
\hline 8 & -0.25 & 0.23 \\
\hline 9 & -0.29 & 0.22 \\
\hline 10 & -0.32 & 0.22 \\
\hline 11 & -0.35 & 0.22 \\
\hline 12 & -0.37 & 0.22 \\
\hline 13 & -0.40 & 0.21 \\
\hline 14 & -0.43 & 0.20 \\
\hline 15 & -0.48 & 0.20 \\
\hline 16 & -0.51 & 0.20 \\
\hline 17 & -0.54 & 0.20 \\
\hline
\end{tabular}



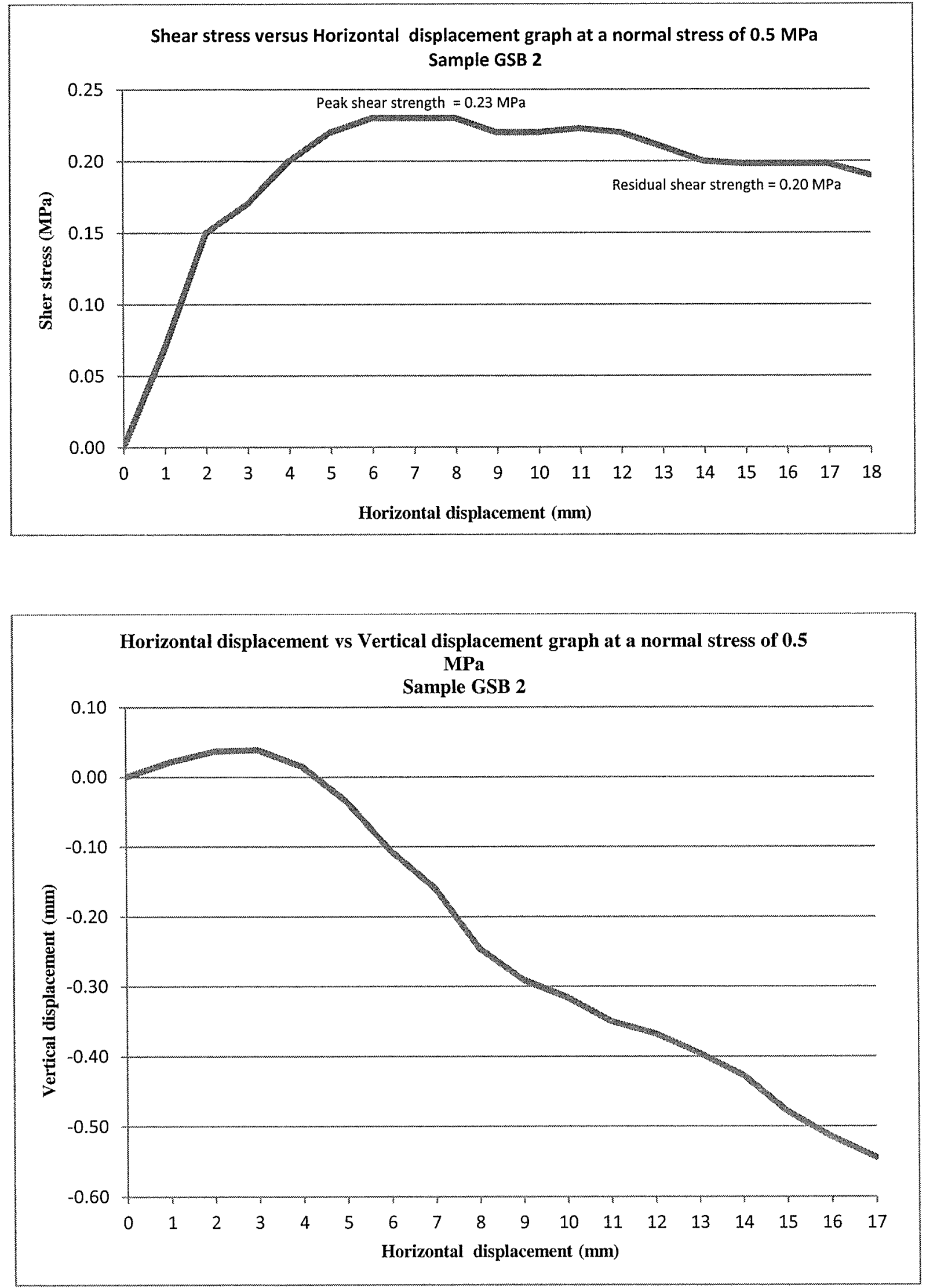
GSB 3

\begin{tabular}{|c|c|c|}
\hline Horizontal displacement & Vertical displacement & Shear Stress (MPa) \\
\hline 0 & 0.0 & 0 \\
\hline 1 & 0.0 & 0.01 \\
\hline 2 & 0.0 & 0.04 \\
\hline 3 & 0.0 & 0.06 \\
\hline 4 & 0.0 & 0.07 \\
\hline 5 & 0.0 & 0.11 \\
\hline 6 & 0.0 & 0.19 \\
\hline 7 & 0.0 & 0.22 \\
\hline 8 & 0.1 & 0.27 \\
\hline 9 & 0.1 & 0.27 \\
\hline 10 & 0.1 & 0.25 \\
\hline 11 & 0.1 & 0.24 \\
\hline 12 & 0.2 & 0.23 \\
\hline 13 & 0.3 & 0.23 \\
\hline 14 & 0.4 & 0.23 \\
\hline 15 & 0.5 & 0.23 \\
\hline 16 & 0.5 & 0.23 \\
\hline 17 & 0.6 & 0.23 \\
\hline 18 & 0.6 & 0.23 \\
\hline
\end{tabular}



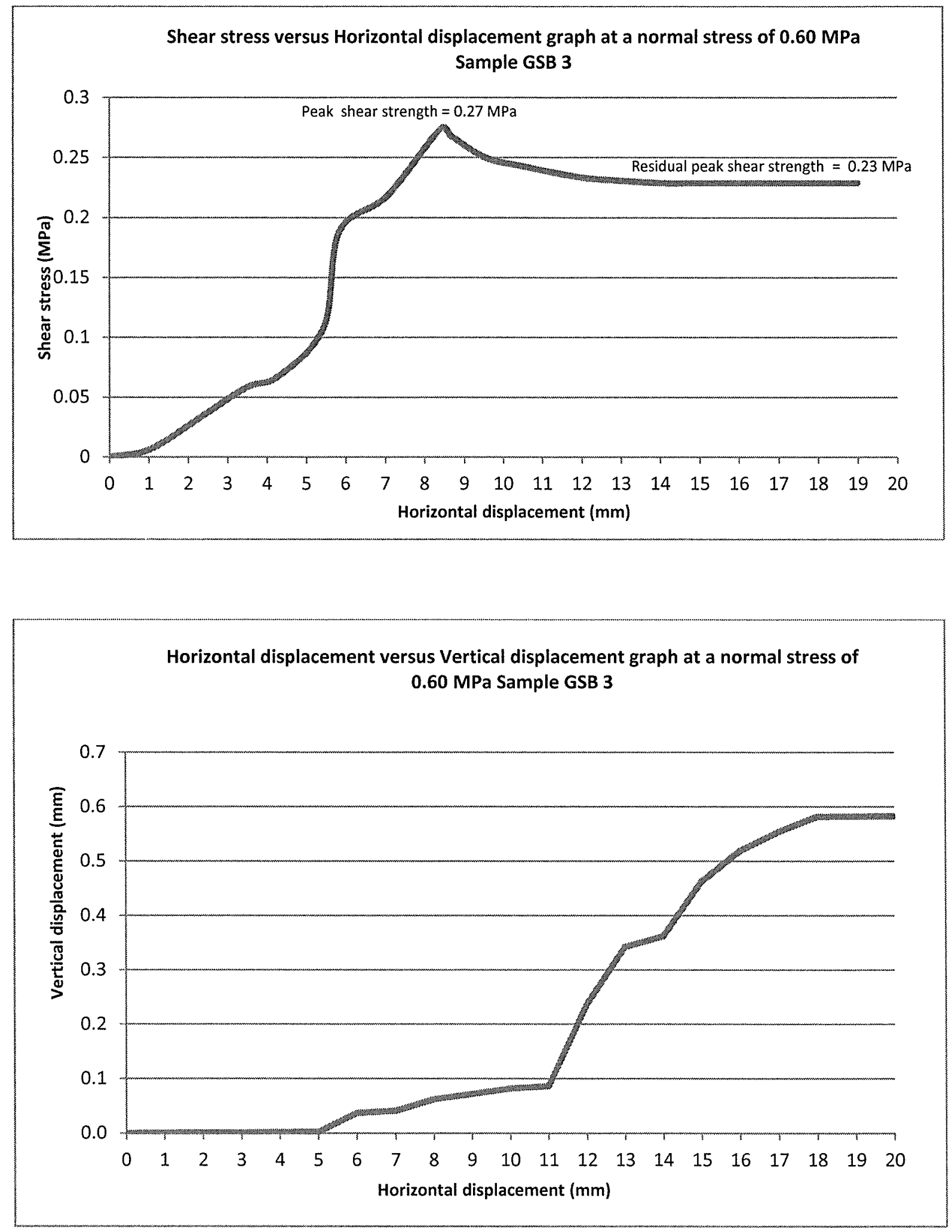
GSB 5a

\begin{tabular}{|c|c|c|}
\hline $\begin{array}{c}\text { Horizontal (shear) } \\
\text { displacement }\end{array}$ & Vertical displacement & Shear Stress (MPa) \\
\hline 0 & 0 & 0 \\
\hline 1 & 0.05 & 0.05 \\
\hline 2 & 0.12 & 0.06 \\
\hline 3 & 0.16 & 0.07 \\
\hline 4 & 0.18 & 0.09 \\
\hline 5 & 0.19 & 0.12 \\
\hline 6 & 0.19 & 0.14 \\
\hline 7 & 0.19 & 0.17 \\
\hline 8 & 0.20 & 0.18 \\
\hline 9 & 0.20 & 0.17 \\
\hline 10 & 0.20 & 0.12 \\
\hline 11 & 0.20 & 0.11 \\
\hline 12 & 0.20 & 0.11 \\
\hline 13 & 0.20 & 0.11 \\
\hline 14 & 0.20 & 0.11 \\
\hline 15 & 0.20 & 0.11 \\
\hline 16 & 0.20 & 0.10 \\
\hline
\end{tabular}



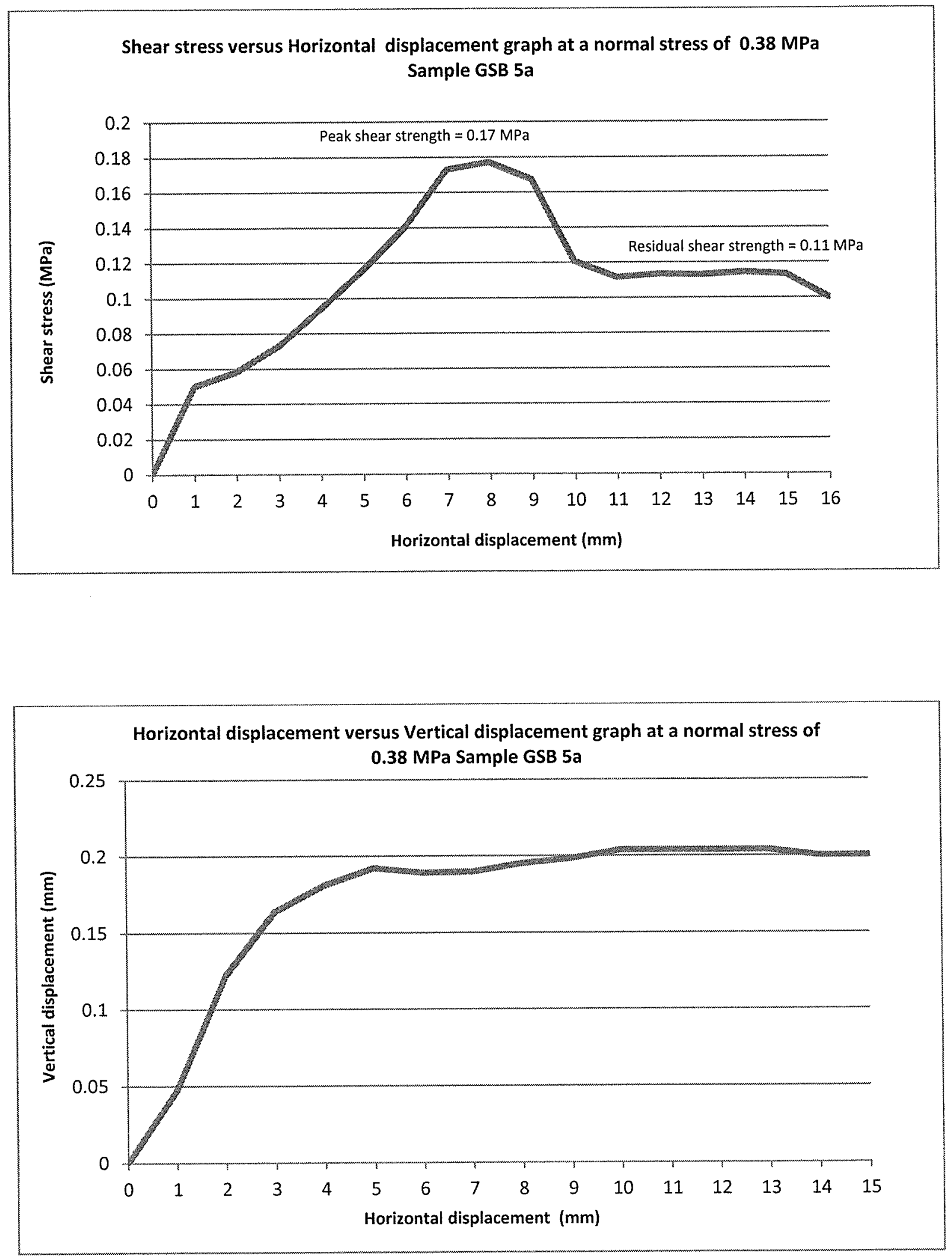
GSB 5b

\begin{tabular}{|c|c|c|}
\hline $\begin{array}{c}\text { Horizontal (shear) } \\
\text { displacement }\end{array}$ & Vertical displacement & Shear Stress (MPa) \\
\hline 0 & 0.00 & 0 \\
\hline 1 & 0.04 & 0.09 \\
\hline 2 & 0.06 & 0.16 \\
\hline 3 & 0.18 & 0.18 \\
\hline 4 & 0.25 & 0.18 \\
\hline 5 & 0.28 & 0.15 \\
\hline 6 & 0.30 & 0.14 \\
\hline 7 & 0.32 & 0.12 \\
\hline 8 & 0.37 & 0.11 \\
\hline 9 & 0.43 & 0.10 \\
\hline 10 & 0.48 & 0.09 \\
\hline 11 & 0.51 & \\
\hline 12 & 0.51 & \\
\hline 13 & 0.52 & \\
\hline 14 & 0.53 & \\
\hline 15 & 0.56 & \\
\hline 16 & 0.60 & \\
\hline 17 & 0.65 & \\
\hline 18 & 0.73 & \\
\hline 19 & 0.81 & \\
\hline 20 & 0.85 & \\
\hline & & \\
\hline
\end{tabular}



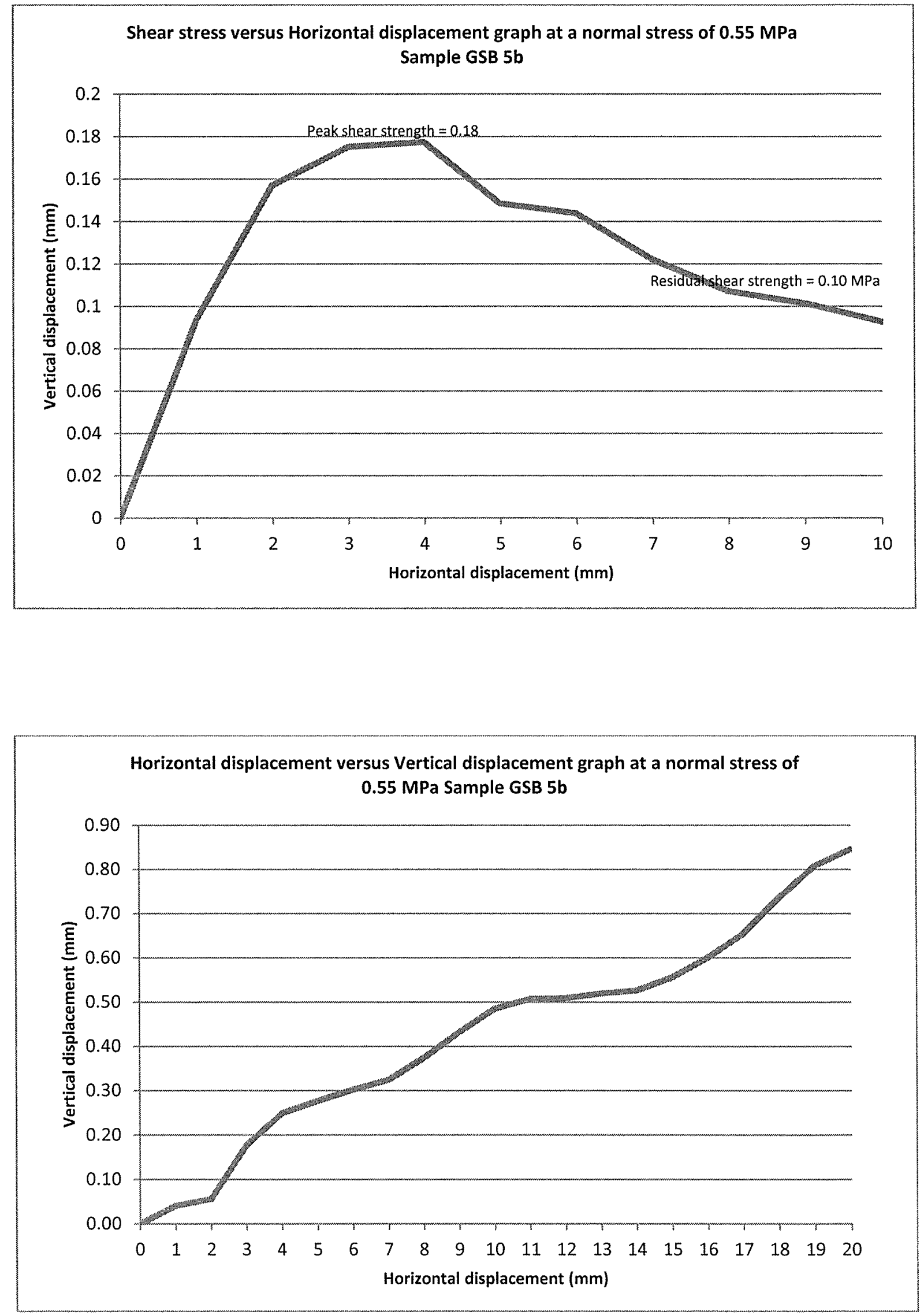